\title{
CONCRETO DE ALTO DESEMPENHO: ESTUDO DA ADERÊNCIA COM A ARMADURA SOB AÇÕES REPETIDAS
}

\section{Clayton Moreira de Castro}

Dissertação apresentada à Escola de Engenharia de São Carlos da Universidade de São Paulo como parte dos requisitos para obtenção do Título de Mestre em Engenharia de Estruturas.

Orientadora:

Prof. ${ }^{\text {a }}$. . a Ana Lúcia Homce de Cresce El Debs 


\section{Castro, Clayton Moreira de}

C355c Concreto de alto desempenho : estudo da aderência com a armadura sob ações repetidas / Clayton Moreira de Castro. -- São Carlos, 2002.

Dissertação (Mestrado) -- Escola de Engenharia de São Carlos-Universidade de São Paulo, 2002.

Área: Engenharia de Estruturas.

Orientador: Profa. Dra . Ana Lúcia Homce de Cresce El Debs.

1. Concreto armado. 2. Concreto de alto desempenho. 3. Aderência. 4. Ação repetida. I. Título. 
FOLHA DE JULGAMENTO

Candidato: Engenheiro CLAYTON MOREIRA DE CASTRO

Dissertação defendida e julgada em $16-07-2002$ perante a Comissão Julgadora:

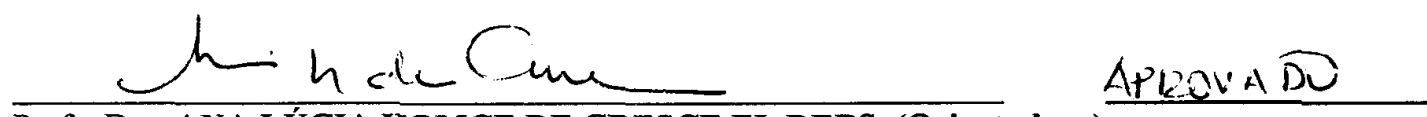

Profa. Dra. ANA LÚCIA HOMCE DE CRESCE EL DEBS (Orientadora)

(Escola de Engenharia de São Carlos/USP)

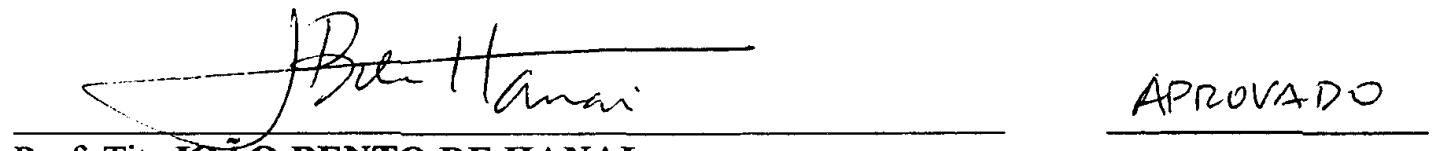

Prof. Tit. JOÃO BENTO DE HANAI

(Escola de Engenharia de São Carlos/USP)
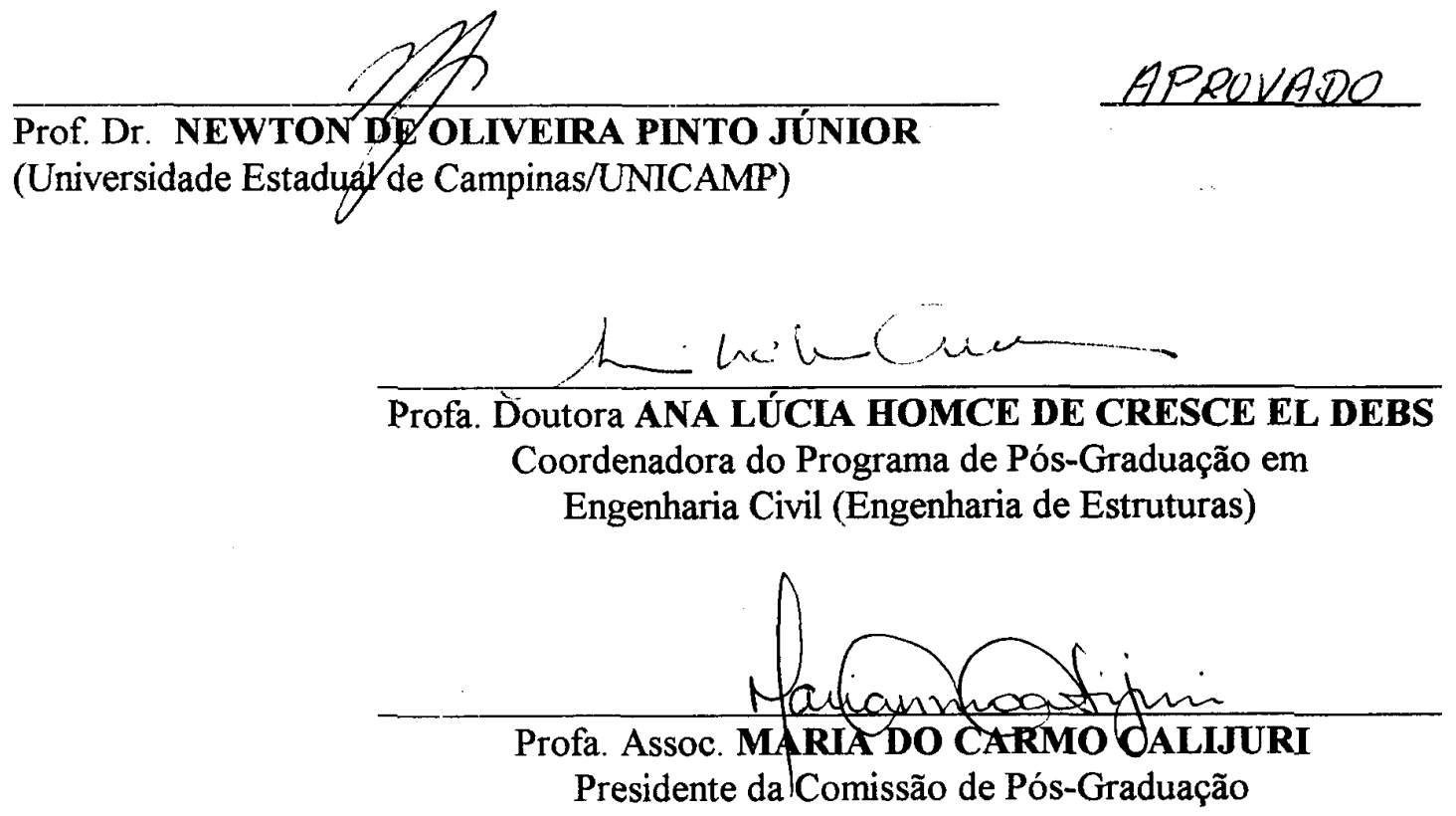
Aos meus pais,

José Carlos e Rosângela. 


\section{AGRADECIMENTOS}

Primeiramente a Deus.

À professora Ana Lúcia Homce de Cresce El Debs, pelo apoio e orientação.

Aos professores João Bento de Hanai, Newton de Oliveira Pinto Júnior e Sergio Persival Baroncini Proença, pelas sugestões.

Aos técnicos do Laboratório de Estruturas, pelo empenho na execução dos ensaios.

A todos funcionários, professores e colegas do Departamento de Engenharia de Estruturas que colaboraram para o desenvolvimento deste trabalho.

À Coordenação de Aperfeiçoamento de Pessoal de Nível Superior - CAPES, pela bolsa de estudo. 


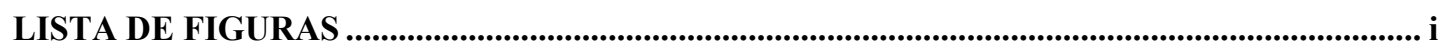

LISTA DE TABELAS.............................................................................................................. viii

LISTA DE ABREVIATURAS E SIGLAS ……………...................................................................... $\mathrm{x}$

LISTA DE SÍMBOLOS ...................................................................................................................... $\mathrm{xi}$

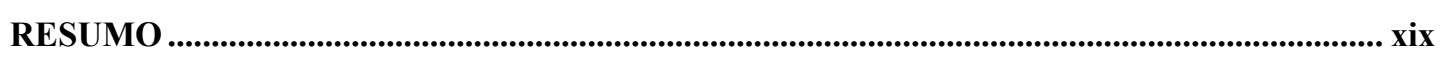

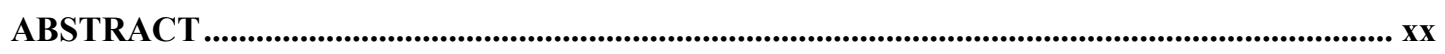

CAPÍTULO 1 - INTRODUÇÃO.................................................................................................... 1

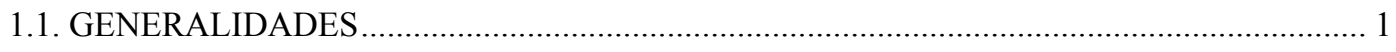

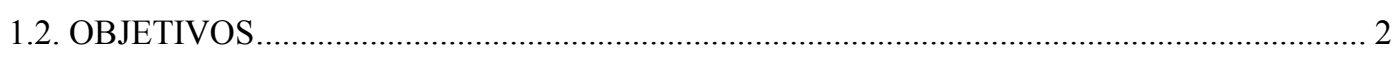

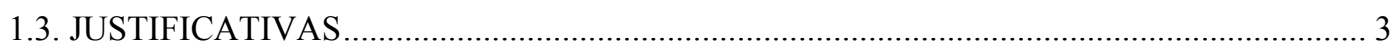

CAPÍTULO 2 - ADERÊNCIA ENTRE CONCRETO E ARMADURA......................................... 4

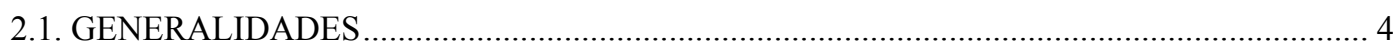

2.2. CAUSAS DAS TENSÕES DE ADERÊNCIA EM ESTRUTURAS ……………................... 5

2.3. FISSURAÇÃO E ESFORÇOS MOBILIZADOS PELA ADERÊNCIA ……….......................... 6

2.4. DISTRIBUIÇÃO DAS TENSÕES DE ADERÊNCIA AO LONGO DA ANCORAGEM ..... 13

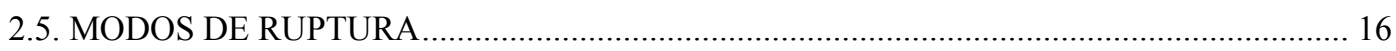

2.6. COMPORTAMENTO DA ADERÊNCIA ………................................................................. 19

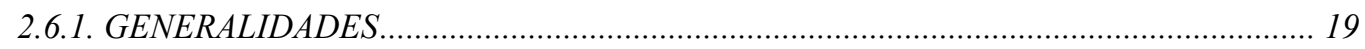

2.6.2. MECANISMOS DE RESISTÊNCIA DA ADERÊNCIA ……............................................. 20 
2.6.2.1. ADERÊNCIA POR ADESÃO

2.6.2.2. ADERENCIA POR ATRITO

2.6.2.3. ADERÊNCIA MECÂNICA

2.6.3. MODELOS TEÓRICOS.

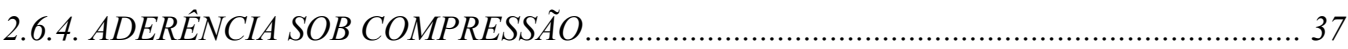

2.7. FATORES QUE INFLUENCIAM O COMPORTAMENTO DA ADERÊNCIA ................... 38

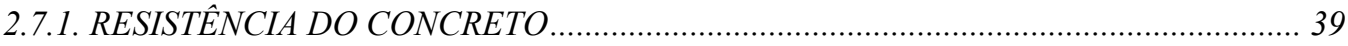

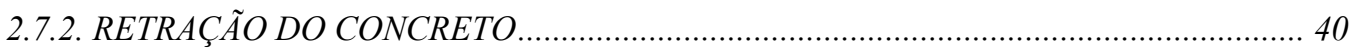

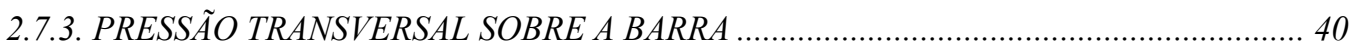

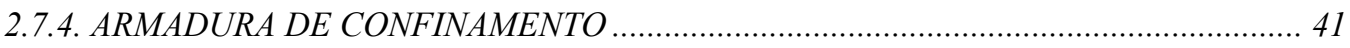

2.7.5. COBRIMENTO E ESPAÇAMENTO DAS BARRAS DA ARMADURA ........................... 41

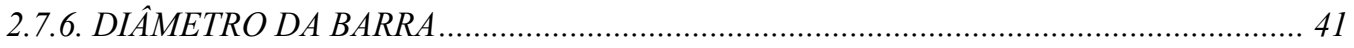

2.7.7. POSIÇÃO E INCLINAÇÃO DAS BARRAS DURANTE A CONCRETAGEM ................. 42

2.7.8. TIPO E GEOMETRIA DAS NERVURAS .................................................................. 44

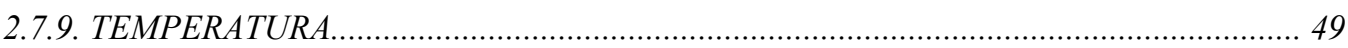

2.8. ENSAIOS PARA DETERMINAÇÃO DA RESISTÊNCIA DE ADERÊNCIA ..................... 49

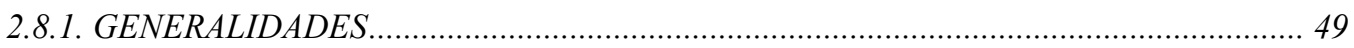

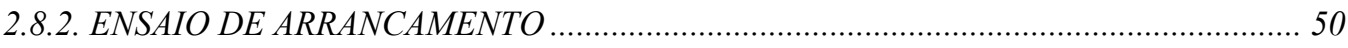

2.8.2.1. ENSAIO DE ARRANCAMENTO RILEM-FIP-CEB (1973) ................................................... 55

2.8.2.2. ENSAIO DE ARRANCAMENTO ASTM C-234 .................................................................. 56

2.8.2.3. ENSAIO DE ARRANCAMENTO SEGUNDO REHM ........................................................... 58

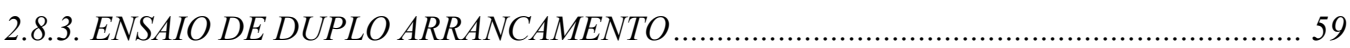

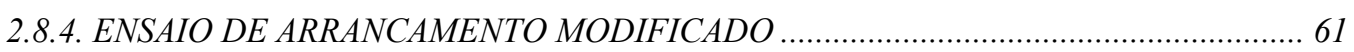

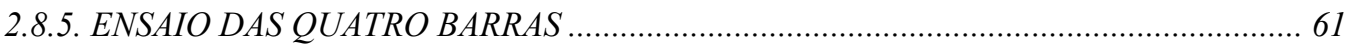

2.8.6. ENSAIO DE TRAÇÃO EM VIGAS …............................................................................. 62

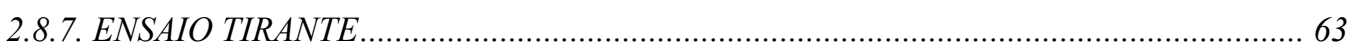

2.8.8. ANÁLISE DO COMPORTAMENTO DOS DIVERSOS TIPOS DE ENSAIO................... 65

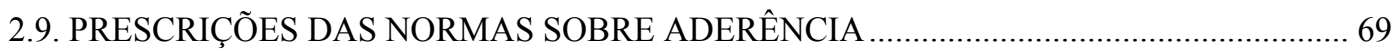

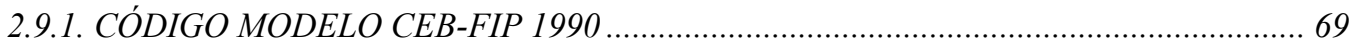

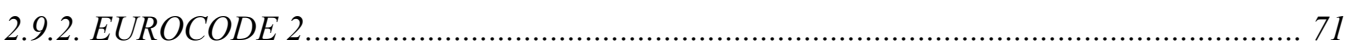

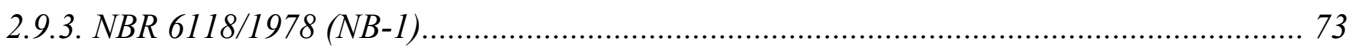

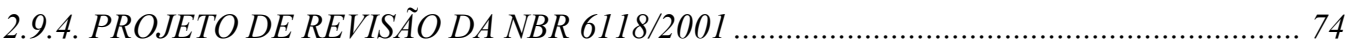

CAPÍTULO 3 - ADERÊNCIA EM CONCRETO DE ALTO DESEMPENHO ........................... 75

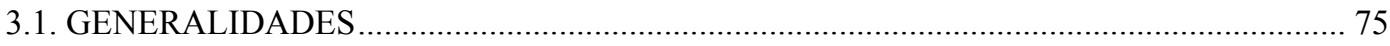

3.2. COMPORTAMENTO LOCAL DA ADERÊNCIA ............................................................. 76

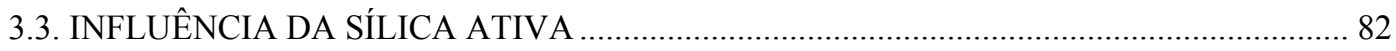

3.4. INFLUÊNCIA DA POSIÇÃO DA BARRA ……............................................................ 85

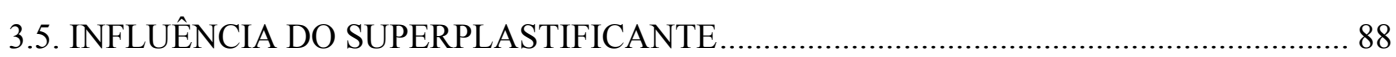


CAPÍTULO 4 - ADERÊNCIA SOB AÇÕES CÍCLICAS............................................................ 90

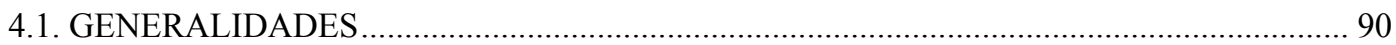

4.2. AÇÕES REPETIDAS COM AMPLITUDE CONSTANTE ........................................................ 91

4.3. AÇÕES REPETIDAS COM AMPLITUDE VARIÁVEL ………….................................... 98

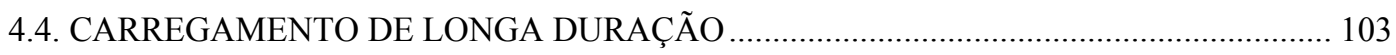

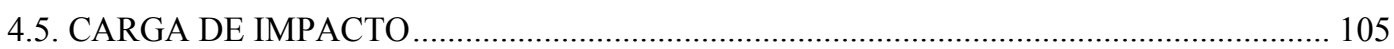

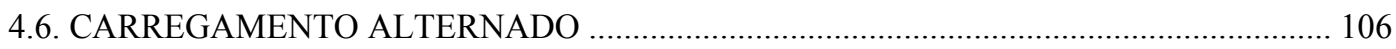

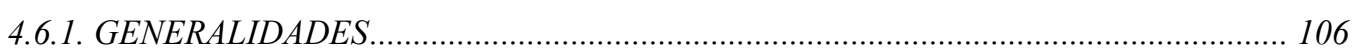

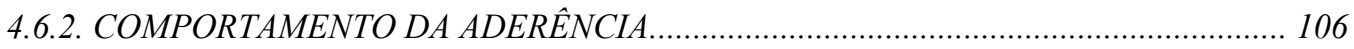

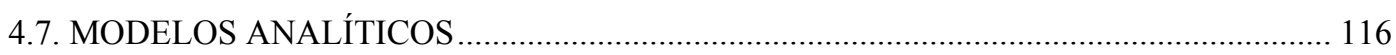

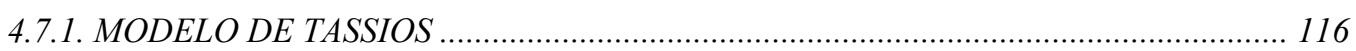

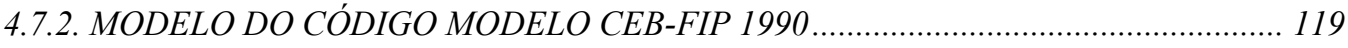

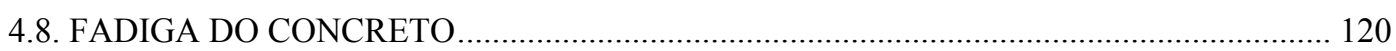

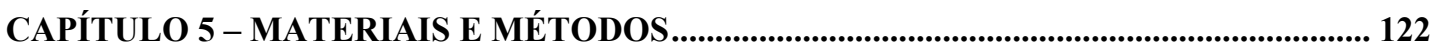

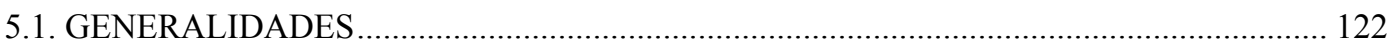

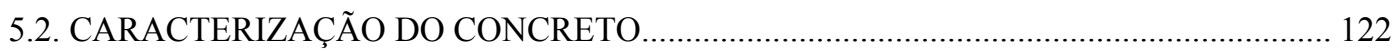

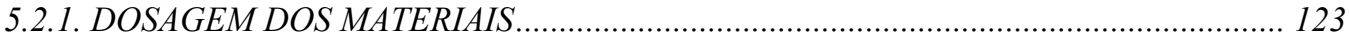

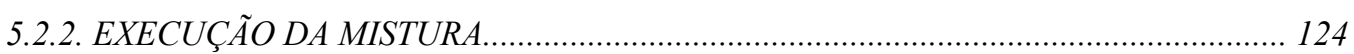

5.2.3. RESISTÊNCIAS À COMPRESSÃO E ̀̀ TRAÇÃO DO CONCRETO ………................. 124

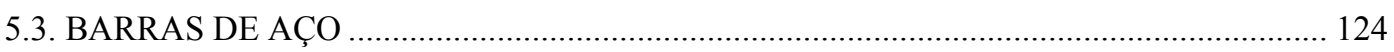

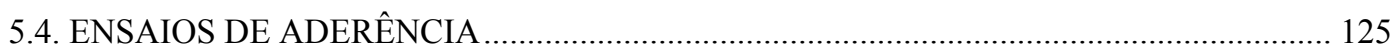

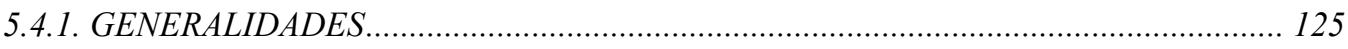

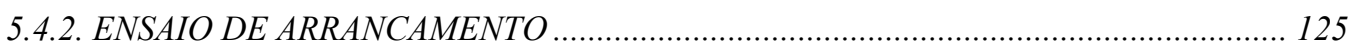

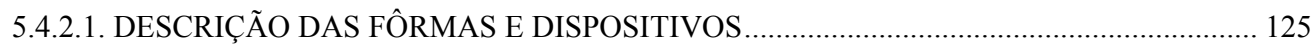

5.4.2.2. MOLDAGEM E CURA DOS CORPOS-DE-PROVA ………………………………………... 127

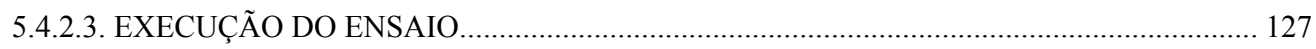

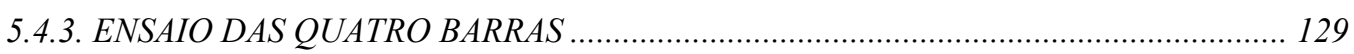

5.4.3.1. DESCRIÇÃO DAS FÔRMAS E DISPOSITIVOS............................................................... 129

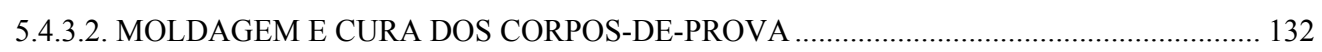

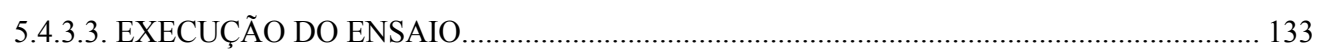

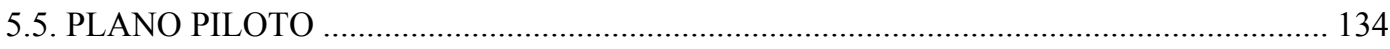

5.5.1. CORPO-DE-PROVA DO ENSAIO DE ARRANCAMENTO ……………………......... 134

5.5.2. CORPOS-DE-PROVA DO ENSAIO DAS QUATRO BARRAS …………………......... 136

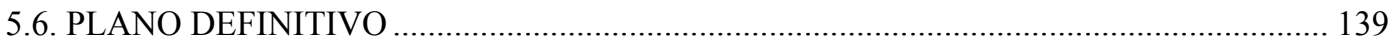

5.7. INSTRUMENTAÇÃO INTERNA DE BARRAS DE AÇO..................................................... 145

5.8. INSTRUMENTOS E EQUIPAMENTOS UTILIZADOS ….................................................. 147

CAPÍTULO 6 - RESULTADOS E DISCUSSÃO DOS ENSAIOS.............................................. 149

6.1. CARACTERIZAÇÃO DO CONCRETO E DO AÇO ............................................................ 149 


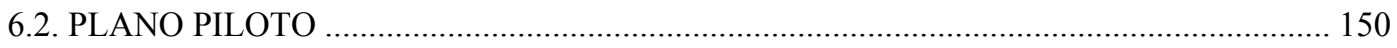

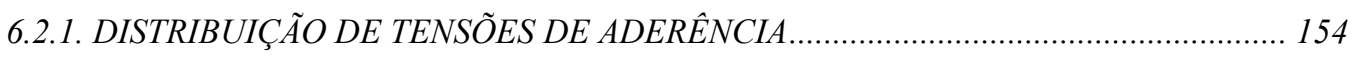

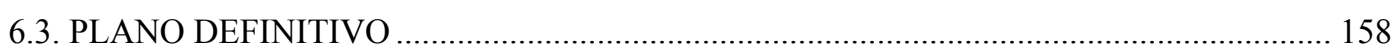

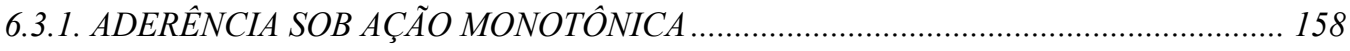

6.3.2. COMPARAÇÃO DA ADERÊNCIA MONOTÔNICA COM OS VALORES

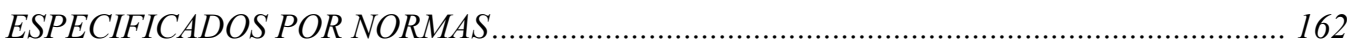

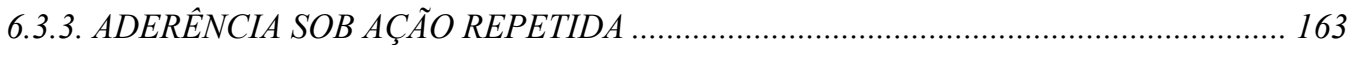

6.3.4. COMPARAÇÃO DO COMPORTAMENTO DA ADERÊNCIA MONOTÔNICA COM

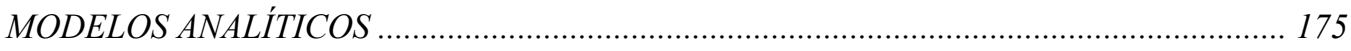

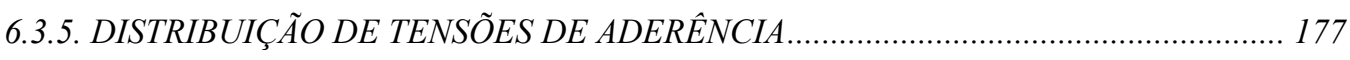

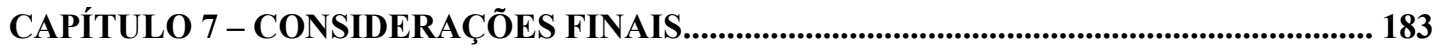

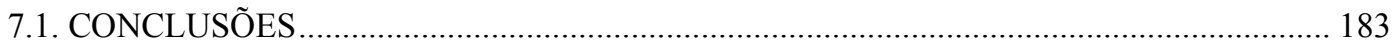

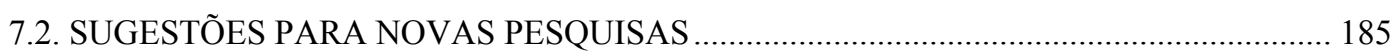

REFERÊNCIAS BIBLIOGRÁFICAS ................................................................................................. 186

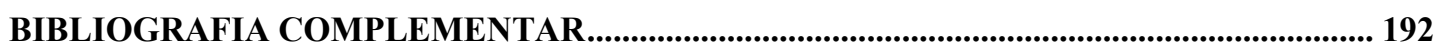




\section{LISTA DE FIGURAS}

Figura 2.1 - Fissuração por tração - FUSCO (1995) ..................................................... 7

Figura 2.2 - Fissuração estabilizada - FUSCO (1995) ............................................... 8

Figura 2.3 - Microfissuração do concreto - GOTO (1971) ........................................ 9

Figura 2.4 - Distribuição das tensões em torno da barra - BRESLER \&

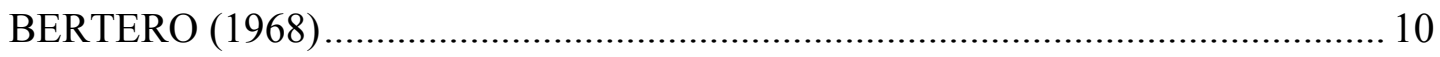

Figura 2.5 - Fissuras de aderência e de fendilhamento - TEPFERS ${ }^{1}$ apud

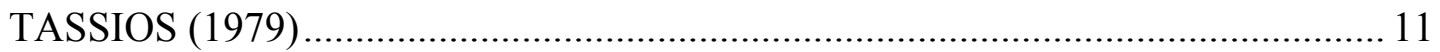

Figura - 2.6 - Esforços reais de ancoragem - FUSCO (1995) ................................... 12

Figura - 2.7 - Tensões entre fissuras de aderência consecutivas - TASSIOS (1979) 12

Figura 2.8 - Forças atuantes ao longo do comprimento de ancoragem de uma barra -

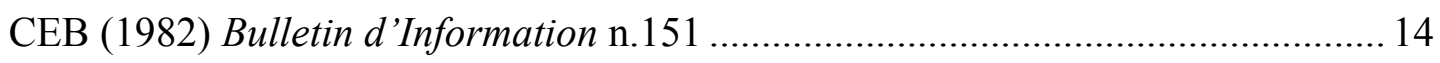

Figura 2.9 - Microfissuração do concreto entorno das barras devido à mobilização da

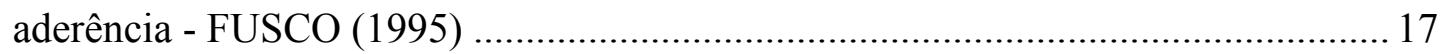

Figura 2.10 - Fendilhamento longitudinal do concreto - FUSCO (1995)................. 18

Figura 2.11 - Curvas esquemáticas da relação $\tau_{\mathrm{b}}$-s para barras lisas e nervuradas -

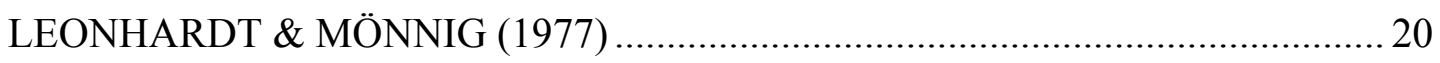

Figura 2.12 - Aderência por adesão - FUSCO (1995) .............................................. 21

Figura 2.13 - Aderência por atrito - FUSCO (1995) ................................................ 22

Figura 2.14 - Aderência mecânica - FUSCO (1995) ............................................... 23

Figura 2.15 - Acabamento superficial de fios e barras lisas - REHM \&

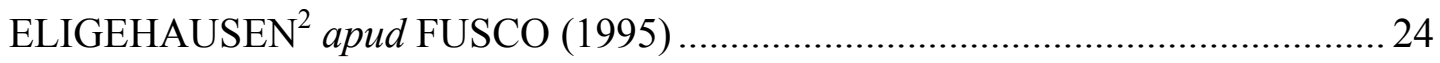


Figura 2.16 - Curva típica da relação $\tau_{\mathrm{b}}$-s - ELIGEHAUSEN et al. (1983) .............. 25

Figura 2.17 - Modelo teórico da curva de aderência - TASSIOS (1979) 26

Figura 2.18 - Possível estágio de ruptura da aderência para concreto confinado e barra nervurada - TASSIOS (1979) 28

Figura 2.19 - Variação das tensões principais e das superfícies de ruptura nos consolos de concreto - REHM ${ }^{3}$ apud LEONHARDT \& MÖNNIG (1977).....

Figura 2.20 - Hipótese do mecanismo da resistência de aderência residual $\tau_{\mathrm{br}}$ TASSIOS (1979)

Figura 2.21 - Mecanismo de aderência sob carregamento monotônico ELIGEHAUSEN et al. (1983)

Figura 2.22 - Relação analítica entre tensão de aderência e deslizamento - Código Modelo CEB-FIP 1990

Figura 2.23 - Influência do diâmetro da barra na resistência de aderência - REHM ${ }^{3}$ apud LEONHARDT \& MÖNNIG (1977).

Figura 2.24 - Influência da posição da barra sobre o comportamento local da aderência - LEONHARDT \& MÖNNIG (1977) 44

Figura 2.25 - Parâmetros geométricos da barra. 46

Figura 2.26 - Comportamento das barras lisas e nervuradas - FUSCO (1995) 52

Figura 2.27 - Distribuição das tensões de aderência no ensaio de arrancamento FUSCO (1995)

Figura 2.28 - Corpos de prova para o ensaio de arrancamento e as respectivas variações a tensão de aderência - LEONHARDT \& MÖNNIG (1977). 54

Figura 2.29 - Corpo-de-prova para o ensaio de arrancamento normatizado pela

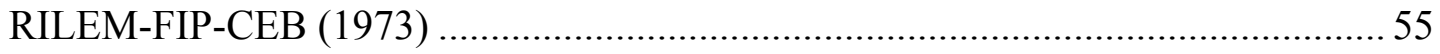

Figura 2.30 - Modelo ASTM C-234 com barra vertical ........................................ 57

Figura 2.31 - Modelo ASTM C-234 com barras horizontais .................................. 57

Figura 2.32 - Dimensões dos modelos ASTM C-234 em função do diâmetro da

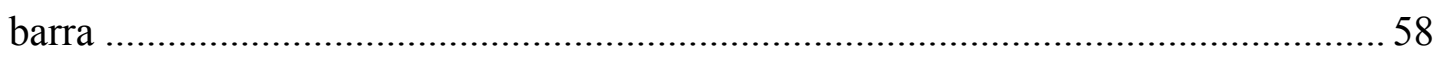

Figura 2.33 - Corpo-de-prova do ensaio de arrancamento segundo REHM ............ 59

Figura 2.34 - Corpo-de-prova do ensaio de duplo arrancamento.............................60

Figura 2.35 - Corpo-de-prova do ensaio de arrancamento modificado.................... 61

Figura 2.36 - Corpo-de-prova para o ensaio das quatro barras................................ 62 
Figura 2.37 - Ensaio por flexão ( $\phi \geq 16$ mm) - RILEM-FIP-CEB (1973) ................ 63

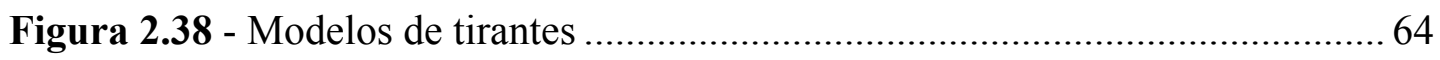

Figura 3.1 - Influência do tipo de concreto na relação $\tau_{\mathrm{b}}-\mathrm{s}-$ MAGNUSSON $^{11}$ apud FIB (2000) Bulletin n.10

Figura 3.2 - Influência da resistência à compressão na tensão de aderência última 78 Figura 3.3 - Modelo analítico para a relação $\tau_{\mathrm{b}}$ - s proposto por HUANG et al. ${ }^{12}$ apud FIB (2000) Bulletin n.10

Figura 3.4 - Influência do posicionamento das barras na aderência - DUCATTI (1993) 86

Figura 4.1 - Deslizamento na extremidade descarregada versus número de ciclos em escala dupla logarítmica $\left(\phi=14 \mathrm{~mm}, \ell=3 \phi, \mathrm{f}_{\mathrm{y}}=500 \mathrm{MPa}, \mathrm{f}_{\mathrm{cc}}=23,5 \mathrm{MPa}, \tau_{\mathrm{b}, \min }=\right.$ $\left.0,1 \tau_{b, \max }\right)-$ REHM \& ELIGEHAUSEN (1979). .93

Figura 4.2 - Influência do carregamento repetido na tensão de aderência última REHM \& ELIGEHAUSEN (1979).

Figura 4.3 - Deslizamento na extremidade descarregada versus número de ciclos do carregamento repetido com amplitude constante em escala dupla logarítmica $(\phi=16$ $\left.\mathrm{mm}, \ell=5 \phi, \mathrm{f}_{\mathrm{y}}=500 \mathrm{MPa}, \mathrm{f}_{\mathrm{cc}}=30 \mathrm{MPa}, \tau_{\mathrm{b}, \min }=0,1 \tau_{\mathrm{b}, \max }\right)-$ BALÁZS, KOCH \& HARRE $^{13}$ apud FIB (2000) Bulletin n.10..... 95

Figura 4.4 - Processo de fadiga da aderência sob carregamento repetido $(\phi=8 \mathrm{~mm}$, $\left.\ell=12 \phi, \mathrm{f}_{\mathrm{y}}=400 \mathrm{MPa}, \mathrm{f}_{\mathrm{cc}}=20 \mathrm{MPa}, \tau_{\mathrm{b}, \min }=0,15 \tau_{\mathrm{b}, \max }\right)$

a) Curva $\tau_{b}$-s sob ação repetida;

b) Diagrama deslizamento-número de ciclos;

c) Curva $\tau_{b}$-s sob ação monotônica - BALÁZS (1991) 96

Figura 4.5 - Crescimento do deslizamento com o número de ciclos $(\phi=16 \mathrm{~mm}, \ell=$ $\left.5 \phi, \mathrm{f}_{\mathrm{y}}=500 \mathrm{MPa}, \mathrm{f}_{\mathrm{cc}}=30 \mathrm{MPa}, \tau_{\mathrm{b}, \min }=0,1 \tau_{\mathrm{b}, \max }\right)-$ KOCH \& BALÁZS (1993) .... 97 Figura 4.6 - Influência do nível de carregamento $\left(\tau_{\mathrm{b}, \max } / \tau_{\mathrm{bu}}\right)$ sobre o número de ciclos necessário para a ruptura da aderência - REHM \& ELIGEHAUSEN (1979). 97 Figura 4.7 - Crescimento do deslizamento sob carregamento repetido crescente periodicamente $\left(\phi=8 \mathrm{~mm}, \ell=12 \phi, \mathrm{f}_{\mathrm{y}}=400 \mathrm{MPa}, \mathrm{f}_{\mathrm{cc}}=20 \mathrm{MPa}, \tau_{\mathrm{b}, \min }=0,15 \tau_{\mathrm{b}, \max }\right)$ BALÁZS (1991) 99 
Figura 4.8 - Aumento de deslizamento em função da história de carregamento $\left(\tau_{\text {MAX }} / \tau_{\text {bu }}=0,4\right) \quad$ a) - b) Amplitude com variação parabólica; c) - d) Amplitude com variação linear; e) - f) Amplitude com variação logarítmica BALÁZS \& $\mathrm{KOCH}^{14}$ apud FIB (2000) Bulletin n.10 .... 100

Figura 4.9 - Aumento do deslizamento, devido a $10^{6}$ e $2 \cdot 10^{6}$ ciclos de carga, em função da história de carregamento $\left(\tau_{\mathrm{MAX}} / \tau_{\mathrm{bu}}=0,4,0,5\right.$ e 0,6) - BALÁZS \& KOCK $^{14}$ apud FIB (2000) Bulletin n.10 101

Figura 4.10 - Aumento do deslizamento sob ciclos com amplitudes aleatórias $\left(\phi=16 \mathrm{~mm}, \ell=5 \phi, \mathrm{f}_{\mathrm{y}}=500 \mathrm{MPa}, \mathrm{f}_{\mathrm{cc}}=30 \mathrm{MPa}, \tau_{\mathrm{MAX}} / \tau_{\mathrm{bu}}=0,6,0,7 \mathrm{e} 0,8, \tau_{\mathrm{b}, \min }=\right.$ $\left.0,1 \tau_{\mathrm{MAX}}\right)$ - BALÁZS \& KOCH (1994) 102

Figura 4.11 - Comparação de curvas $\tau_{b}$-s sob ações monotônica e cíclica alternada a) sem inversão do deslizamento; b) com inversão do deslizamento - HAWKINS et al. (1982) 106

Figura 4.12 - Curvas $\tau_{\mathrm{b}}$-s para diferente amplitudes de deslizamento ELIGEHAUSEN et al. (1983) . 108

Figura 4.13 - Ensaios sob carregamento alternado com deslizamento controlado $\left(\phi=16 \mathrm{~mm}, \ell=2 \phi, \mathrm{f}_{\mathrm{y}}=400 \mathrm{MPa}, \mathrm{f}_{\mathrm{cc}}=25 \mathrm{MPa}\right)$

a) Resultados experimentais;

b) deterioração da tensão de aderência correspondente ao deslizamento controlado;

c) deterioração da resistência de atrito - BALÁZS (1991) 110

Figura 4.14 - Ensaios sob carregamento alternado com força controlada $(\phi=16$ $\left.\mathrm{mm}, \ell=2 \phi, \mathrm{f}_{\mathrm{y}}=400 \mathrm{MPa}, \mathrm{f}_{\mathrm{cc}}=25 \mathrm{MPa}\right)-$ BALÁZS (1991)

Figura 4.15 - Deterioração da aderência devido a deslizamento alternado crescente $\left(\phi=8 \mathrm{~mm}, \ell=6 \phi, \mathrm{f}_{\mathrm{y}}=400 \mathrm{MPa}, \mathrm{f}_{\mathrm{cc}}=25 \mathrm{MPa}\right)-$ BALÁZS (1991)

Figura 4.16 - Comportamento da aderência sob carregamento cíclico alternado ACI COMMITTEE 408 (1991)

Figura 4.17 - Mecanismo de aderência sob carregamento cíclico alternado ELIGEHAUSEN et al. (1983)

Figura 4.18 - Modelo de aderência sob carregamento cíclico alternado TASSIOS (1979)

Figura 4.19 - Ramo de descarregamento da curva $\tau_{\mathrm{b}}$ - $\mathrm{s}$ - CÓDIGO MODELO CEBFIP 1990 
Figura 4.20 - Modelo de aderência sob carregamentos de longa duração e repetido CÓDIGO MODELO CEB-FIP 1990 120

Figura 5.1 - Fôrma para o corpo-de-prova do modelo PT-PILOTO 1 .................... 126

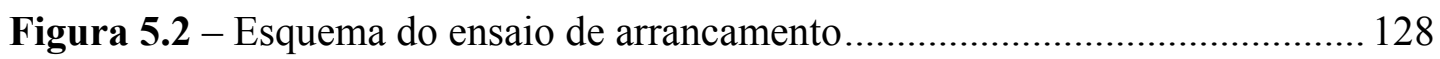

Figura 5.3 - Fôrmas para o ensaio das quatro barras............................................. 129

Figura 5.4 - Gabarito da chapa de aço com formato de estrela de três pontas ........ 130

Figura 5.5 - Placa de apoio das barras perimetrais................................................ 131

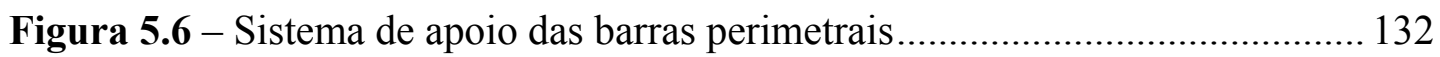

Figura 5.7 - Arranjo de ensaio das quatro barras (modelo 4B-PILOTO 3) ............ 133

Figura 5.8 - Desenho esquemático do corpo-de-prova do ensaio de arrancamento134

Figura 5.9 - Características do corpo-de-prova para o ensaio de arrancamento

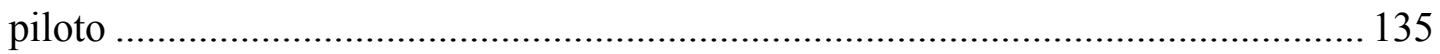

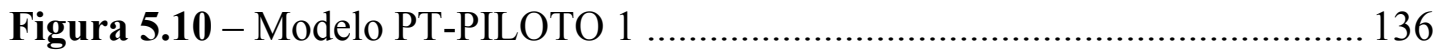

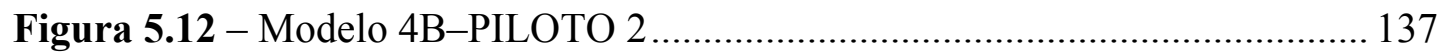

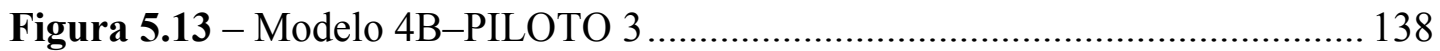

Figura 5.14 - Representação dos extensômetros na barra instrumentada

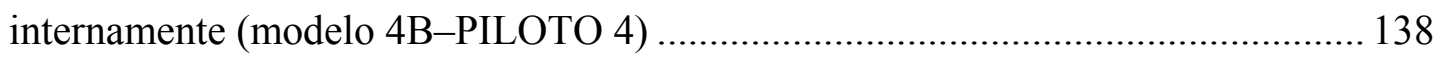

Figura 5.15 - Características geométricas dos modelos da série 7,5 …................ 140

Figura 5.16 - Características geométricas dos modelos da série 12,5 .................. 141

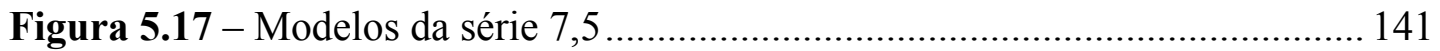

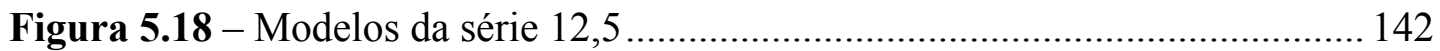

Figura 5.19 - Representação dos extensômetros na barra instrumentada

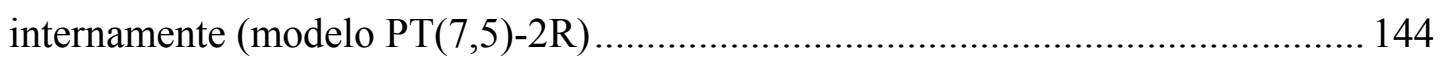

Figura 5.20 - Sulcos na superfície da barra ....................................................... 145

Figura 5.21 - Detalhes do processo de isolação dos extensômetros........................ 146

Figura 5.22 - Detalhe final do processo de isolação de um extensômetro .............. 147

Figura 5.23 - Detalhe da saída dos fios na barra instrumentada internamente....... 147

Figura 6.1 - Curvas monotônicas tensão de aderência-deslizamento dos modelos do plano piloto 151

Figura 6.2 - Ruptura por fendilhamento (PT-PILOTO 1) 152

Figura 6.3 - Ruptura por fendilhamento dos modelos do ensaio das quatro barras 152 
Figura 6.4 - Convenção do eixo x para estabelecimento das equações de deformação

Figura 6.5 - Distribuição de tensões normais na barra central - modelo 4B-PILOTO 4 156

Figura 6.6 - Distribuição de tensões de aderência - modelo 4B-PILOTO 4 157

Figura 6.7 - Curvas monotônicas $\tau_{b}$-s dos modelos da série 7,5 do plano definitivo

Figura 6.8 - Curvas monotônicas $\tau_{\mathrm{b}}$-s dos modelos da série 12,5 do plano definitivo 159

Figura 6.9 - Comparação das curvas monotônicas $\tau_{b}$-s das duas séries de ensaios do plano definitivo 160

Figura 6.10 - Ruptura por fendilhamento dos modelos da série 7,5 ..................... 161

Figura 6.11 - Ruptura por fendilhamento dos modelos da série 12,5 .................... 161

Figura 6.12 - Curva repetida $\tau_{\mathrm{b}}$-s do modelo PT(7,5)-1R ..................................... 164

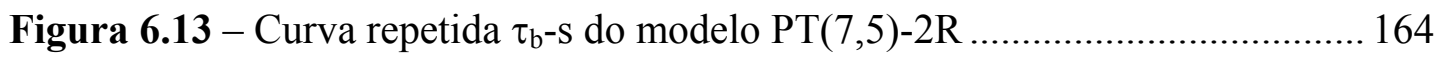

Figura 6.14 - Curva repetida $\tau_{\mathrm{b}}$-s do modelo PT(7,5)-3R .................................... 165

Figura 6.15 - Curva repetida $\tau_{b}-\mathrm{s}$ do modelo PT(7,5)-4R .................................. 165

Figura 6.16 - Curva repetida $\tau_{\mathrm{b}}$-s do modelo PT(12,5)-1R ................................ 166

Figura 6.17 - Curva repetida $\tau_{\mathrm{b}}$-s do modelo PT(12,5)-2R ................................... 166

Figura 6.18 - Curva repetida $\tau_{b}$-s do modelo PT(12,5)-3R ................................ 167

Figura 6.19 - Curva repetida $\tau_{\mathrm{b}}$-s do modelo PT(12,5)-4R ................................. 167

Figura 6.20 - Curvas deslizamento versus número de ciclos em escala dupla logarítmica dos modelos da série 7,5 do plano definitivo. 169

Figura 6.21 - Curvas deslizamento versus número de ciclos em escala dupla logarítmica dos modelos da série 12,5 do plano definitivo

Figura 6.22 - Curvas deslizamento versus número de ciclos em escala linear dos modelos da série 7,5 do plano definitivo 170

Figura 6.23 - Curvas deslizamento versus número de ciclos em escala linear dos modelos da série 12,5 do plano definitivo 171

Figura 6.24 - Curvas monotônicas $\tau_{\mathrm{b}}$-s dos modelos da série 7,5 submetidos previamente a carregamento repetido 
Figura 6.25 - Curvas monotônicas $\tau_{\mathrm{b}}$-s dos modelos da série 12,5 submetidos previamente a carregamento repetido 173

Figura 6.26 - Comparação da média monotônica da série 7,5 como modelo analítico do Código Modelo CEB-FIP 1990 175

Figura 6.27 - Comparação da média monotônica da série 12,5 com modelos analíticos 176

Figura 6.28 - Convenção do eixo x para estabelecimento das equações de deformação do modelo PT(7,5)-2R. 178

Figura 6.29 - Distribuição de tensões normais na barra sob ação monotônica após repetição de 360 ciclos - modelo PT(7,5)-2R

Figura 6.30 - Distribuição de tensões normais na barra no primeiro ciclo de carga $(\mathrm{n}=1)$, para diversos valores de $\mathrm{F}_{\mathrm{t}}$ - modelo PT(7,5)-2R. 179

Figura 6.31 - Distribuição de tensões normais na barra para diversos ciclos de carga com $\mathrm{F}_{\mathrm{t}} \approx 52 \mathrm{kN}\left(\approx 0,6 \cdot \tau_{\mathrm{bu}}\right)-$ modelo $\mathrm{PT}(7,5)-2 \mathrm{R}$ 180

Figura 6.32 - Distribuição de tensões de aderência sob ação monotônica após repetição de 360 ciclos - modelo $\mathrm{PT}(7,5)-2 \mathrm{R}$ 180

Figura 6.33 - Distribuição de tensões de aderência no primeiro ciclo de carga $(n=1)$, para diversos valores de $\mathrm{F}_{\mathrm{t}}$ - modelo PT(7,5)-2R.

Figura 6.34 - Distribuição de tensões de aderência para diversos ciclos de carga com $\mathrm{F}_{\mathrm{t}} \approx 52 \mathrm{kN}\left(\approx 0,6 \cdot \tau_{\mathrm{bu}}\right)-$ modelo $\mathrm{PT}(7,5)-2 \mathrm{R}$ 181 


\section{LISTA DE TABELAS}

Tabela 2.1 - Parâmetros para definição da relação tensão de aderência versus deslizamento em barras nervuradas

Tabela 2.2 - Parâmetros para definição da relação tensão de aderência versus deslizamento de barras lisas 36

Tabela 2.3 - Característica gerais dos ensaios das quatro barras de DUCATTI (1993) 67

Tabela 2.4 - Valores de cálculo da resistência de aderência para boas condições de aderência 72

Tabela 3.1 - Parâmetros do modelo analítico para a relação $\tau_{\mathrm{b}}$ - s proposto por HUANG et al. ${ }^{12}$ apud FIB (2000) Bulletin n.10 80

Tabela 5.1 - Consumo dos materiais utilizados na confecção do concreto 123

Tabela 5.2 - Posição dos extensômetros na barra instrumentada internamente (modelo 4B-PILOTO 4) 139

Tabela 5.3 - Características gerais dos modelos do plano definitivo 143

Tabela 5.4 - Posição dos extensômetros na barra instrumentada internamente modelo PT(7,5)-2R 144

Tabela 5.5 - Instrumentos utilizados nos ensaios ............................................... 148

Tabela 6.1 - Caracterização do concreto ................................................................ 149

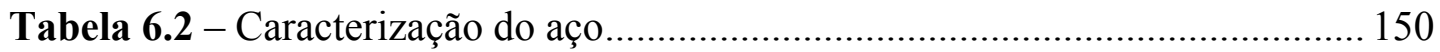

Tabela 6.3 - Resultados dos ensaios com os modelos do plano piloto................... 151 
Tabela 6.4 - Tensões normais e tensões de aderência na barra central do modelo 4BPILOTO 4

Tabela 6.5 - Resultados dos ensaios monotônicos com os modelos do plano definitivo 158

Tabela 6.6 - Comparação do valor de $\tau_{1 \mathrm{R}}$ experimental (série 12,5) com os valores prescritos pelas normas 163

Tabela 6.7 - Resultados dos ensaios monotônicos com os modelos submetidos a carregamento repetido prévio.

Tabela 6.8 - Posição $\mathrm{x}$ na barra instrumentada internamente do modelo PT(7,5)-2R 178 


\section{LISTA DE ABREVIATURAS E SIGLAS}

$\begin{array}{ll}\text { ABNT } & \text { Associação Brasileira de Normas Técnicas } \\ \text { ACI } & \text { American Concrete Institute } \\ \text { ARI } & \text { Alta Resistência Inicial } \\ \text { ASTM } & \text { American Society for Testing and Materials } \\ \text { CA } & \text { Concreto Armado } \\ \text { CAD } & \text { Concreto de Alto Desempenho } \\ \text { CEB } & \text { Comité Euro-International du Béton } \\ \text { CP } & \text { Cimento Portland } \\ \text { EESC } & \text { Escola de Engenharia de São Carlos } \\ \text { EUROCODE } & \text { European Code } \\ \text { FIB } & \text { Fédération Internationale du Béton } \\ \text { FIP } & \text { Fédération Internationale de la Précontrainte } \\ \text { GF } & \text { Fator do extensômetro (Gage Factor) } \\ \text { NBR } & \text { Norma Brasileira Registrada } \\ \text { RILEM } & \text { RÉUNION INTERNATIONALE DES LABORATOIRES } \\ & \text { D’ESSAIS ET DE RECHERCHES SUR LES MATÉRIAUX ET } \\ & \text { LES CONSTRUCTIONS } \\ \text { USP } & \text { Universidade de São Paulo } \\ & \end{array}$




\section{LISTA DE SÍMBOLOS}

\section{LETRAS ROMANAS MINÚSCULAS}

a

$a_{\ell}$

$a_{n}$

$a_{\mathrm{s}}$

$a_{t}$

$a_{1}$

c

d

$\mathrm{d}_{\mathrm{s}}$

e

$f_{b}$
Altura das nervuras transversais

Altura das nervuras longitudinais

Altura da nervura transversal no ponto médio do segmento da nervura transversal considerada

Distância entre a barra central e cada uma das três barras perimetrais (ensaio das quatro barras)

Espaçamento das barras da armadura transversal (estribos)

Coeficiente

Espaçamento entre nervuras transversais, ou seja, a distância entre os centros de duas nervuras transversais consecutivas mensurada paralelamente ao eixo da barra

Distância

Distância de trechos de barras até a fissura principal

Diâmetro equivalente dos ganchos da armadura transversal

Raio da parte do cilindro de concreto não fissurado no modelo de TEPFERS ${ }^{1}$ apud TASSIOS (1979)

Resistência de aderência 


\begin{tabular}{|c|c|}
\hline $\mathrm{f}_{\mathrm{bd}}$ & Resistência de aderência de cálculo \\
\hline$f_{c c}$ & Resistência à compressão do concreto cúbica \\
\hline $\mathrm{f}_{\mathrm{ck}}$ & Resistência à compressão do concreto característica \\
\hline $\mathrm{f}_{\mathrm{cm}}$ & Resistência à compressão do concreto média \\
\hline $\mathrm{f}_{\mathrm{ct}}$ & Resistência do concreto à tração direta \\
\hline $\mathrm{f}_{\mathrm{ctd}}$ & Resistência do concreto à tração direta de cálculo \\
\hline $\mathrm{f}_{\text {ctk,inf }}$ & Resistência à tração do concreto característica inferior \\
\hline $\mathrm{f}_{\mathrm{ctm}}$ & Resistência do concreto à tração direta média \\
\hline $\mathrm{f}_{\mathrm{R}}$ & Área relativa da nervura \\
\hline $\mathrm{f}_{\mathrm{y}}$ & Resistência de escoamento do aço \\
\hline $\mathrm{f}_{\mathrm{yd}}$ & Resistência de escoamento do aço de cálculo \\
\hline $\mathrm{f}_{\mathrm{yk}}$ & Resistência de escoamento do aço característica \\
\hline h & Altura \\
\hline $\mathrm{i}$ & Número de nervuras longitudinais \\
\hline $\mathrm{j}$ & Comprimento do passo da nervura longitudinal \\
\hline $\mathrm{k}$ & Número de fileiras de nervuras transversais no perímetro da barra \\
\hline $\mathrm{k}_{\mathrm{n}}$ & $\begin{array}{l}\text { Fator para carregamento repetido segundo o Código Modelo CEB- } \\
\text { FIP } 1990\end{array}$ \\
\hline $\mathrm{k}_{\mathrm{t}}$ & $\begin{array}{l}\text { Fator para carregamento de longa duração segundo o Código } \\
\text { Modelo CEB-FIP } 1990\end{array}$ \\
\hline $\mathrm{k}_{\mathrm{n}, \mathrm{t}}$ & $\begin{array}{l}\text { Fator para carregamento repetido e para carregamento de longa } \\
\text { duração segundo o Código Modelo CEB-FIP } 1990\end{array}$ \\
\hline$\ell$ & Comprimento de ancoragem \\
\hline $\mathrm{m}$ & $\begin{array}{l}\text { Número de nervuras transversais em uma fileira, mensurado ao } \\
\text { longo da distância considerada }\end{array}$ \\
\hline $\mathrm{n}$ & $\begin{array}{l}\text { Número de barras envolvidas pelos estribos } \\
\text { Número de ciclos }\end{array}$ \\
\hline $\mathrm{p}$ & Pressão transversal \\
\hline $\mathrm{p}_{\mathrm{s}}$ & Pressão transversal exercida pela armadura transversal \\
\hline
\end{tabular}




\begin{tabular}{|c|c|}
\hline $\mathrm{p}_{\mathrm{t}}$ & ressão transversal devida à retração \\
\hline q & $\begin{array}{l}\text { Número de segmentos em que a nervura transversal considerada } \\
\text { foi dividida }\end{array}$ \\
\hline S & Deslizamento entre o aço e o concreto \\
\hline $\mathrm{s}_{\mathrm{A}}, \mathrm{s}_{\mathrm{C}}, \mathrm{s}_{\mathrm{D}}$ & $\begin{array}{l}\text { Aberturas devidas à fissura de cisalhamento no mecanismo de } \\
\text { aderência de ELIGEHAUSEN et al. (1983) }\end{array}$ \\
\hline $\mathrm{s}_{\mathrm{G}}$ & $\begin{array}{l}\text { Deslizamento no modelo para carregamento cíclico alternado de } \\
\text { TASSIOS (1979) }\end{array}$ \\
\hline $\mathrm{s}_{\mathrm{FI}}, \mathrm{s}_{\mathrm{FH}}$ & $\begin{array}{l}\text { Aberturas devidas à fissura de cisalhamento no mecanismo de } \\
\text { aderência sob carregamento cíclico alternado de ELIGEHAUSEN } \\
\text { et al. }(1983)\end{array}$ \\
\hline $\mathrm{s}_{\mathrm{n}, \mathrm{t}}$ & $\begin{array}{l}\text { Deslizamento devido ao carregamento permanente ou a } \\
\text { carregamento repetido, segundo o Código Modelo CEB-FIP } 1990\end{array}$ \\
\hline$s(x)$ & Deslizamento ao longo do comprimento de ancoragem \\
\hline $\mathrm{S}_{\mathrm{y}}$ & $\begin{array}{l}\text { Deslizamento correspondente ao início do escoamento da barra de } \\
\text { aço, segundo HUANG et al. }{ }^{12} \text { apud FIB (2000) Bulletin n. } 10\end{array}$ \\
\hline $\mathrm{s}_{\mathrm{ybr}}$ & $\begin{array}{l}\text { Deslizamento correspondente à tensão de aderência residual para } \\
\text { barras que atingem o limite de escoamento do aço, segundo } \\
\text { HUANG et al. }{ }^{12} \text { apud FIB (2000) Bulletin n. } 10\end{array}$ \\
\hline $\mathbf{S}_{0}$ & Deslizamento na extremidade carregada da armadura \\
\hline $\mathrm{s}_{1}$ & $\begin{array}{l}\text { Deslizamento inicial correspondente à tensão } \tau_{\text {bu }} \text { no modelo } \\
\text { proposto pelo Código Modelo CEB-FIP } 1990\end{array}$ \\
\hline $\mathrm{s}_{2}$ & $\begin{array}{l}\text { Deslizamento final correspondente à tensão } \tau_{\mathrm{bu}} \text { no modelo } \\
\text { proposto pelo Código Modelo CEB-FIP } 1990\end{array}$ \\
\hline $\mathrm{S}_{3}$ & $\begin{array}{l}\text { Deslizamento correspondente à tensão } \tau_{\text {br }} \text { no modelo proposto } \\
\text { pelo Código Modelo CEB-FIP } 1990\end{array}$ \\
\hline $\mathrm{S}_{4}$ & $\begin{array}{l}\text { Deslizamento final, segundo o modelo de HUANG et al. }{ }^{12} \text { apud } \\
\text { FIB (2000) Bulletin n.10 }\end{array}$ \\
\hline $\mathrm{S}_{5}$ & $\begin{array}{l}\text { Deslizamento final para barras que atingem o limite de } \\
\text { escoamento do aço, segundo o modelo de HUANG et al. }{ }^{12} \text { apud } \\
\text { FIB (2000) Bulletin n.10 }\end{array}$ \\
\hline
\end{tabular}




$\begin{array}{ll}\mathrm{s}\left(\tau_{\mathrm{bu}}\right) & \text { Deslizamento correspondente à tensão de aderência última } \\ \mathrm{s}\left(\tau_{0}\right) & \text { Deslizamento correspondente à resistência por adesão } \\ \mathrm{s}_{\mathrm{r}} & \text { Distância entre duas fissuras (principais) } \\ \mathrm{s}_{\mathrm{r}, \text { min }} & \text { Distância mínima entre duas fissuras para que não haja a formação } \\ \mathrm{t} & \text { de uma nova fissura (principal) } \\ \mathrm{u} & \text { Duração do carregamento em horas } \\ \mathrm{v}_{\mathrm{p}} & \text { Perímetro da barra envolvida pelo concreto } \\ \mathrm{x} & \text { Velocidade de carregamento } \\ \mathrm{x}_{1}, \mathrm{x}_{2} & \text { Coordenada de comprimento da armadura } \\ \mathrm{x}_{2} \tau_{\mathrm{bu}} & \text { Coordenadas } \\ \mathrm{x}_{3} \mathrm{~s}\left(\tau_{\mathrm{bu}}\right) & \text { Tensão de aderência última depois de } \mathrm{n} \text { ciclos de carga } \\ & \text { Deslizamento correspondente à tensão de aderência última depois }\end{array}$

\section{LETRAS ROMANAS MAIÚSCULAS}

$\mathrm{A}_{\mathrm{c}}$

$\mathrm{A}_{\mathrm{s}}$

$\mathrm{A}_{\mathrm{st}}$

$\mathrm{A}_{\text {st,min }}$

C

$\mathrm{E}_{\mathrm{c}}$

$\mathrm{E}_{\mathrm{s}}$

$\mathrm{F}_{\max }$
Área da seção transversal de concreto que envolve a armadura

Área da seção transversal da barra de aço

Área de estribo, com dois ramos, contida no comprimento de ancoragem

Área mínima de estribo, com dois ramos, contida no comprimento de ancoragem

Cobrimento de concreto

Força no ensaio de flexão normatizado pela RILEM-FIP-CEB (1973)

Módulo de elasticidade do concreto

Módulo de elasticidade do aço

Força de tração máxima da amplitude do carregamento repetido 


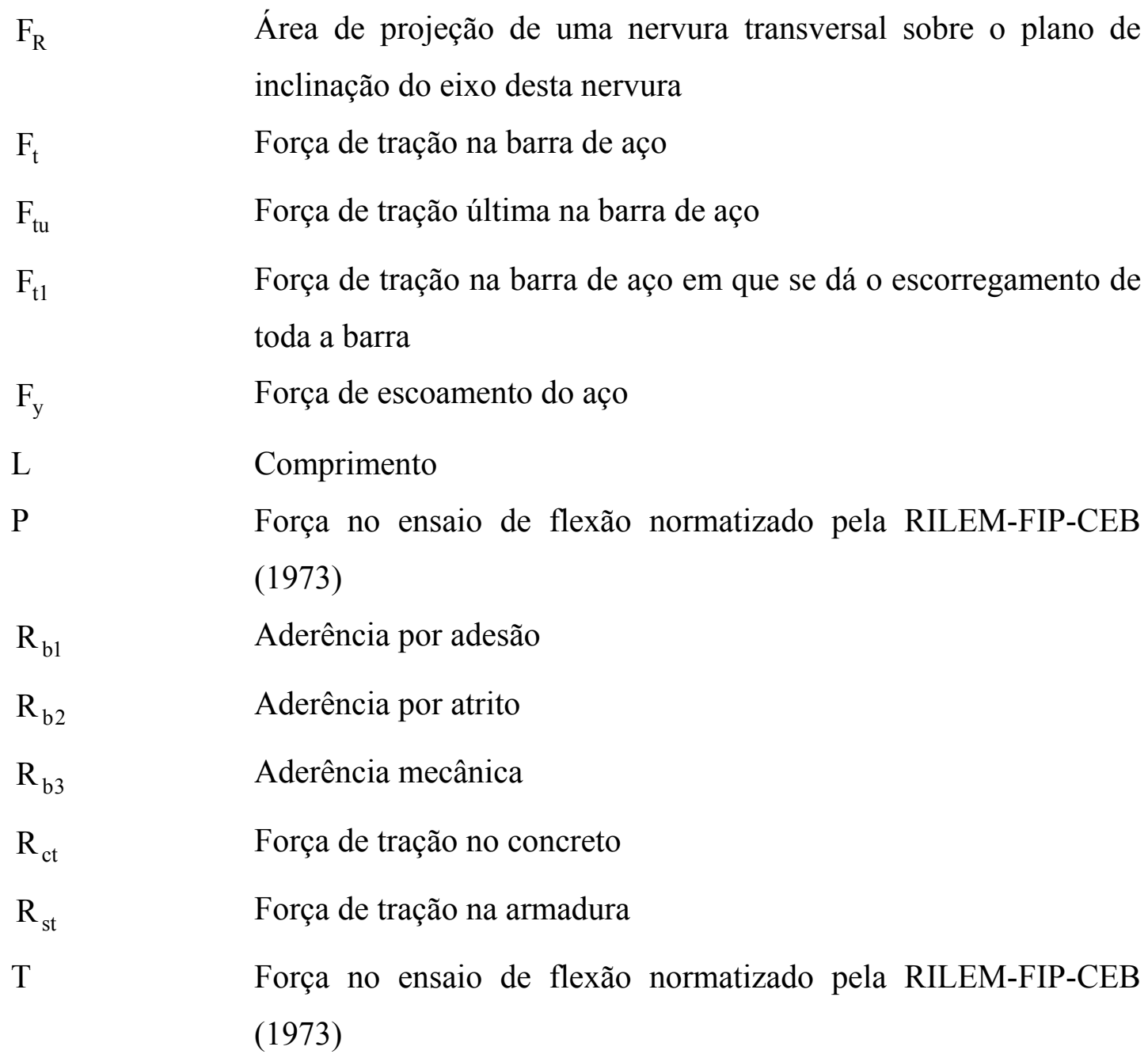

\section{LETRAS GREGAS}

$\begin{array}{ll}\alpha & \text { Coeficiente } \\ \alpha_{\mathrm{e}} & \text { Relação entre os módulos de elasticidade do aço e do concreto } \\ \beta & \text { Ângulo entre as forças que atuam na barra nervurada e no concreto } \\ \beta_{\mathrm{s}} & \text { Ângulo de inclinação do eixo da nervura transversal em relação ao } \\ \gamma & \text { eixo da barra } \\ \gamma_{\mathrm{c}} & \text { Constante geométrica da barra }\end{array}$




\begin{tabular}{|c|c|}
\hline$\varepsilon_{\mathrm{s}}$ & Deformação longitudinal do aço \\
\hline$\zeta$ & Coeficiente \\
\hline$\eta_{\mathrm{b}}$ & Coeficiente de conformação superficial da barra \\
\hline$\eta_{1}, \eta_{2}, \eta_{3}$ & $\begin{array}{l}\text { Coeficientes para cálculo da tensão de aderência do Código } \\
\text { Modelo CEB-FIP } 1990\end{array}$ \\
\hline$\lambda$ & $\begin{array}{l}\text { Fator de redução da tensão de aderência e do deslizamento no } \\
\text { modelo proposto pelo Código Modelo CEB-FIP } 1990\end{array}$ \\
\hline$\mu$ & Coeficiente de atrito \\
\hline$\xi$ & Rigidez de aderência $\left(\tau_{\mathrm{b}} / \mathrm{s}\right)$ \\
\hline$\rho$ & $\begin{array}{l}\text { Relação entre a área da seção transversal de concreto que envolve } \\
\text { a armadura e a área da seção da barra de aço }\end{array}$ \\
\hline$\sigma_{\mathrm{b}}$ & $\begin{array}{l}\text { Tensão mobilizada pelo mecanismo da resistência de aderência } \\
\text { residual, segundo o modelo de TASSIOS (1979) }\end{array}$ \\
\hline$\sigma_{\mathrm{c}}$ & Tensão nas bielas de compressão \\
\hline$\sigma_{\mathrm{ct}}$ & Tensão de compressão no concreto \\
\hline$\sigma_{\mathrm{c}}(\mathrm{x})$ & $\begin{array}{l}\text { Tensão normal no concreto ao longo do comprimento de } \\
\text { ancoragem }\end{array}$ \\
\hline$\sigma_{\mathrm{s}}$ & Tensão de tração no aço \\
\hline$\sigma_{\text {st }}$ & Tensão de tração na armadura \\
\hline$\sigma_{\mathrm{s}}(\mathrm{x})$ & $\begin{array}{l}\text { Tensão normal na armadura ao longo do comprimento de } \\
\text { ancoragem }\end{array}$ \\
\hline$\sigma_{\mathrm{s} 0}$ & Tensão normal na extremidade carregada da armadura \\
\hline$\sigma_{\mathrm{t}}$ & Tensão circunferencial no concreto em torno da barra ancorada \\
\hline$\sigma_{t, \max }$ & $\begin{array}{l}\text { Tensão circunferencial máxima no concreto em torno da barra } \\
\text { ancorada }\end{array}$ \\
\hline$\sigma_{\mathrm{x}}$ & Tensão longitudinal no concreto em torno da barra ancorada \\
\hline$\sigma_{y}$ & Tensão no concreto em torno da barra ancorada \\
\hline$\sigma_{\text {I }}$ & Tensão diagonal responsável pelas fissuras de aderência \\
\hline
\end{tabular}




\begin{tabular}{|c|c|}
\hline A & $\begin{array}{l}\text { Tensão de aderência sob a qual ocorrem as primeiras fissuras de } \\
\text { aderência, segundo o modelo de TASSIOS (1979) }\end{array}$ \\
\hline $\mathrm{b}$ & $\begin{array}{l}\text { Tensão de aderência. Nos ensaios de aderência corresponde ao } \\
\text { valor médio }\end{array}$ \\
\hline$\tau_{B}$ & $\begin{array}{l}\text { Tensão de aderência sob a qual ocorrem as primeiras fissuras de } \\
\text { fendilhamento, segundo o modelo de TASSIOS (1979) }\end{array}$ \\
\hline$\tau_{\mathrm{bm}}$ & ensão de aderência média \\
\hline$\tau_{\mathrm{b}, \max }$ & nsão de aderência máxima de um carregamento repetido \\
\hline$\tau_{\mathrm{b}, \min }$ & nsão de aderência mínima de um carregamento repetido \\
\hline$\tau_{\mathrm{b}}(\mathrm{n})$ & $\begin{array}{l}\text { Tensão de aderência correspondente ao deslizamento máximo } \\
\text { depois de } \mathrm{n} \text { ciclos em determinada direção }\end{array}$ \\
\hline$\tau_{b}(n-1 / 2)$ & $\begin{array}{l}\text { Tensão de aderência correspondente ao deslizamento máximo } \\
\text { (controlado), imposto em uma determinada direção, } \\
\text { imediatamente antes de um descarregamento }\end{array}$ \\
\hline$\tau_{\mathrm{br}}$ & Tensão de aderência residual \\
\hline$\tau_{\mathrm{bu}}$ & Tensão de aderência última \\
\hline$\tau_{\mathrm{b}}(\mathrm{x})$ & Tensão de aderência ao longo do comprimento de ancoragem \\
\hline$\tau_{\mathrm{b}}\left(1^{+}\right)$ & $\begin{array}{l}\text { Tensão de aderência correspondente ao deslizamento máximo } \\
\text { (controlado) alcançado no primeiro ciclo à direita }\end{array}$ \\
\hline$\tau_{\mathrm{f}}$ & Resistência de atrito concreto-concreto \\
\hline$\tau_{\mathrm{f}}(\mathrm{n})$ & ensão de atrito depois do enésimo ciclo em determinada direção \\
\hline$-\tau_{\mathrm{f} 1},-\tau_{\mathrm{f} 2},+\tau_{\mathrm{f} 1}$ & $\begin{array}{l}\text { Tensões de aderência negativa no modelo para carregamento } \\
\text { cíclico alternado de TASSIOS (1979) }\end{array}$ \\
\hline$\tau_{\mathrm{G}}, \tau_{\mathrm{K}}$ & $\begin{array}{l}\text { Tensões de aderência no modelo para carregamento cíclico } \\
\text { alternado de TASSIOS (1979) }\end{array}$ \\
\hline$\tau_{\mathrm{MAX}}$ & $\begin{array}{l}\text { Tensão de aderência máxima alcançada em uma série de ensaios } \\
\text { com carregamento repetido }\end{array}$ \\
\hline$\tau_{\mathrm{y}}$ & $\begin{array}{l}\text { Tensão de aderência correspondente ao início do escoamento da } \\
\text { barra de aço, segundo HUANG et al. }{ }^{12} \text { apud FIB (2000) Bulletin } \\
\text { n.10 }\end{array}$ \\
\hline
\end{tabular}


$\tau_{\text {ybr }}$

Tensão de aderência residual para barras que atingem o limite de escoamento do aço, segundo HUANG et al. ${ }^{12}$ apud FIB (2000) Bulletin n. 10

$\tau_{0}$ Resistência de aderência por adesão

Tensão de aderência na extremidade carregada da armadura

$\tau_{1 \mathrm{R}}$

$\phi$

$\phi_{\text {efetivo }}$

$\varphi$

$\Delta \ell$ Tensão de aderência correspondente ao deslizamento $0,1 \mathrm{~mm}$

Diâmetro nominal da barra de aço

Diâmetro efetivo da barra de aço

Ângulo

Comprimento de cada segmento da nervura transversal no eixo desta nervura 
CASTRO, C.M. (2002). Concreto de alto desempenho: estudo da aderência com a armadura sob ações repetidas. São Carlos, 2002. 194p. Dissertação (Mestrado) Escola de Engenharia de São Carlos, Universidade de São Paulo.

A premissa básica para se ter concreto armado é a existência de aderência entre o concreto e o aço. Vários fatores influenciam o comportamento da aderência, o que torna o fenômeno complexo. Em contraste com o nível de informações sobre o comportamento da aderência, não existem resultados suficientes quanto à aderência em Concreto de Alto Desempenho (CAD) e o efeito da ação repetida no comportamento da ligação açoconcreto. Neste contexto, o objetivo principal deste trabalho foi analisar a aderência em CAD sob ação repetida. Foram realizados ensaios das quatro barras e de arrancamento e desenvolvido método de instrumentação interna de barras. Foram analisadas duas séries de ensaios de arrancamento, que diferiam no grau de confinamento da barra. Quanto à ação repetida, foram analisados o número de ciclos e o nível de carregamento máximo da amplitude. Outro ponto que se teve especial atenção foi a distribuição de tensões de aderência. Verificou-se que o comportamento da aderência em CAD é qualitativamente o mesmo de concretos usuais. Entretanto, devido à natureza frágil do $\mathrm{CAD}$, mesmo em concreto confinado, a ruptura dos modelos foi por fendilhamento. Quanto à distribuição de tensões de aderência, a aplicação de um carregamento repetido prévio não afeta a distribuição de tensões, alterando somente a ordem de grandeza das tensões alcançadas durante o andamento do ensaio.

Palavras-chave: concreto armado, concreto de alto desempenho, aderência, ação repetida. 
CASTRO, C.M. (2002). High performance concrete: study of bond with the reinforcement under repeated actions. São Carlos, 2002. 194p. Dissertação (Mestrado) Escola de Engenharia de São Carlos, Universidade de São Paulo.

The basic premise for having reinforced concrete is the existence of bond between concrete and steel. Various factors influence the behaviour of the bond, which makes the phenomenon complex. In contrast with the level of information about the behaviour of the bond, there are insufficient results concerning bond in High Performance Concrete (HPC) and the effect of repeated action on the behaviour of the steel-concrete ligation. In this context, the main objective of this work was to analyse the bond in HPC under repeated action. Controlled tests were carried out, four bars and pullout and a method of internal instrumentation of the bars was developed. Two series of pull-out test were analysed, which differed in the degree of bar confinement. In reference to repeated action, the number of cycles and the level of maximum load of amplitude were analysed. Another aspect which had special attention was the distribution of bond stress. It was verified that the behaviour of the bond in HPC is qualitatively the same as normal concrete. However, due to the brittle nature of HPC, even in confined concrete, the failures of the models were by splitting. In reference to the distribution of bond stress, the application of a previously repeated load does not affect the distribution of stress, altering only the order of magnitude of the reached stress during the testing.

Keywords: reinforced concrete, high performance concrete, bond, repeated action. 


\section{CAPÍTULO 1}

\section{INTRODUÇÃO}

\subsection{GENERALIDADES}

A premissa básica para se ter concreto armado é a existência de aderência entre o concreto e o aço, quando ambos materiais resistam solidariamente aos esforços a que forem submetidos.

A aderência tem suma importância em relação à capacidade de carga e de serviço das peças de concreto armado. É essencial o conhecimento de seu comportamento para se estabelecerem regras para cálculo de ancoragens e emendas por traspasse das barras da armadura, para cálculo dos deslocamentos considerando a contribuição do concreto tracionado, para controle da abertura das fissuras e, portanto, da quantidade mínima de armadura.

Usualmente a verificação da aderência é feita por meio da tensão de aderência no estado limite último, sendo esta tensão normalmente determinada por ensaios de arrancamento.

A relação tensão de aderência versus deslizamento tradicionalmente é utilizada para se quantificar a eficiência da ligação aço-concreto. Essa relação está associada ao deslocamento relativo entre a barra da armadura e o concreto que a envolve, e representa a variação da tensão na interface do aço com o concreto. A destruição da aderência pode ser definida por valores máximos do deslizamento entre os materiais em questão, geralmente associados a um certo estado de deformação e fissuração. 
Com relação aos carregamentos, pode-se afirmar que a aderência é influenciada por seu histórico. A ação cíclica acarreta diminuição da resistência de aderência e perda de rigidez devido à maior propagação de fissuras.

O efeito dos carregamentos cíclicos tem sido analisado através do estudo da fadiga. Contudo, ultimamente o problema também está sendo pesquisado por meio do estudo da degradação da ligação aço-concreto.

Por fim, outro fato a ser ressaltado é a expressão Concreto de Alto Desempenho (CAD). Essa designação tem sido atribuída a concretos que possuam um desempenho significativamente melhor que aqueles obtidos com concretos de qualidade usual. De modo geral, esse material não apresenta somente resistência mais elevada que os concretos usuais, mas também, dentre outras características, uma boa durabilidade e uma boa trabalhabilidade. Neste trabalho, a expressão CAD é utilizada para referir-se a concretos com alta resistência. Embora não haja consenso, serão considerados como concretos de alto desempenho aqueles com resistência à compressão superior a $50 \mathrm{MPa}$.

\subsection{OBJETIVOS}

O objetivo principal desta pesquisa foi fazer análise da aderência entre o CAD e a armadura, mediante a realização de ensaios de arrancamento sob ação de carregamentos monotônico e repetido.

O intuito foi verificar a influência no comportamento da aderência do grau de confinamento do concreto, do tipo de carregamento e do nível de solicitação máxima da amplitude do carregamento repetido. Para isso, foi analisada a forma de ruptura, a curva tensão de aderência versus deslizamento, a tensão de aderência última, o deslizamento na ruptura da ligação e a distribuição de tensões de aderência. 


\subsection{JUSTIFICATIVAS}

O notório avanço das técnicas de construção, do conhecimento do comportamento dos sistemas estruturais e da tecnologia dos materiais enseja a necessidade de se conhecer o verdadeiro comportamento estrutural do concreto armado.

Atualmente, a introdução de Concretos de Alto Desempenho (CADs) intensifica essa necessidade, que exige avaliação detalhada de seu comportamento para o estabelecimento de regras para projetos.

O comportamento da aderência é fortemente influenciado pela história do carregamento. A despeito deste fato notório, as recomendações dos diversos códigos baseiam-se, de modo geral, em resultados de pesquisas com carregamento estático de curta duração.

Este trabalho é parte de uma linha de pesquisa sobre a ligação aço-concreto, a qual contribui para o desenvolvimento do perfeito conhecimento do comportamento estrutural do concreto armado. O fenômeno aqui estudado é de extrema relevância, haja vista que a própria definição de concreto armado se condiciona à sua existência.

São vários os fatores que influenciam o comportamento da aderência, o que torna este fenômeno complexo e, portanto, justifica a necessidade do desenvolvimento de pesquisas sobre o assunto. 


\section{CAPÍTULO 2}

\section{ADERÊNCIA ENTRE CONCRETO E ARMADURA}

\subsection{GENERALIDADES}

O concreto armado é um material que tem seu comportamento estrutural primordialmente dependente da aderência entre o concreto e a armadura, sendo esta propriedade responsável pela transferência de esforços e compatibilidade de deformações entre os dois materiais, ou seja, fazendo que o conjunto adquira as características próprias do concreto armado.

Geralmente, em regiões das peças que estão sob compressão e em partes não tracionadas da estrutura, o concreto e o aço têm a mesma deformação.

Em regiões sob tração, de forma global, a aderência impede o escorregamento relativo entre as barras da armadura e as fibras vizinhas de concreto. No entanto, o comportamento local é mais complexo; como as fissuras representam descontinuidades, existem deslocamentos relativos entre armadura e concreto.

Para ilustrar o que representa a aderência, pode ser usada uma viga. Se não existir aderência, isto é, se a barra de aço estiver livre para se deformar independente do concreto, as tensões não variam ao longo de seu comprimento e, portanto, essa estrutura não tem comportamento característico de vigas armadas.

Há também o caso em que a armadura está ligada ao concreto somente em suas extremidades. Esta peça que tem comportamento de viga armada é uma estrutura mista de aço e concreto, composta por uma viga de concreto simples e por um tirante de aço embutido na própria viga. Embora as duas barras dessa estrutura 
trabalhem juntas, essa peça não é uma viga de concreto armado, porque não o fazem solidariamente.

\subsection{CAUSAS DAS TENSÕES DE ADERÊNCIA EM ESTRUTURAS}

As tensões de aderência nos elementos estruturais de concreto armado, surgem sempre que ocorrer variação de tensões em um determinado trecho das barras de aço. Segundo LEONHARDT \& MÖNNIG (1977), as causas dessas variações de tensões podem ser as seguintes:

a. Ações externas: Alteram as tensões de tração e compressão nas barras da armadura;

b. Fissuras: Ocasionam altas concentrações de tensões de aderência nas regiões de descontinuidade;

c. Forças de ancoragem nas extremidades das barras: É através da tensão de aderência que a força atuante na barra é transferida ao concreto;

d. Variações de temperatura: Devido à maior condutibilidade térmica do aço, as barras da armadura dilatam-se mais que o concreto, sendo impedidas pela aderência. Em casos extremos, como por exemplo, em incêndios, as tensões de aderência atingem valor elevadíssimo que rompe o cobrimento de concreto;

e. Retração do concreto: Esse fenômeno acarreta tensões de tração no concreto e tensões de compressão nas barras, resultantes do impedimento da deformação de retração do concreto, causado pela presença da barra de aço;

f. Deformação lenta do concreto em peças comprimidas de concerto armado (pilares): Em conseqüência do encurtamento provocado pela deformação lenta, as barras da armadura recebem um acréscimo de tensões de compressão, que aliviam o concreto. 


\subsection{FISSURAÇÃO E ESFORÇOS MOBILIZADOS PELA ADERÊNCIA}

A aderência permite a absorção, pela armadura, das tensões de tração. Essa ligação entre a armadura e o concreto é responsável pelo controle da abertura das fissuras. Assim, quanto maior a aderência, maior a possibilidade de se obter maior número de fissuras com menor abertura individual das mesmas, o que melhora as condições de proteção da armadura.

A seguir será apresentado um modelo representativo da forma de mobilização da aderência em uma peça de concreto armado. Esse modelo apresentado por FUSCO (1995) não considera a microfissuração próxima da fissura principal, que ocasiona deslizamentos localizados.

Para solicitações relativamente baixas, o concreto ainda resiste à tração, convencionando-se que o mesmo esteja no estádio I. Com o aumento das solicitações, o concreto passa para o estádio II quando é atingida a resistência à tração do concreto e, portanto, ocorre a fissuração da peça nas fibras mais tracionadas (Figura 2.1). 


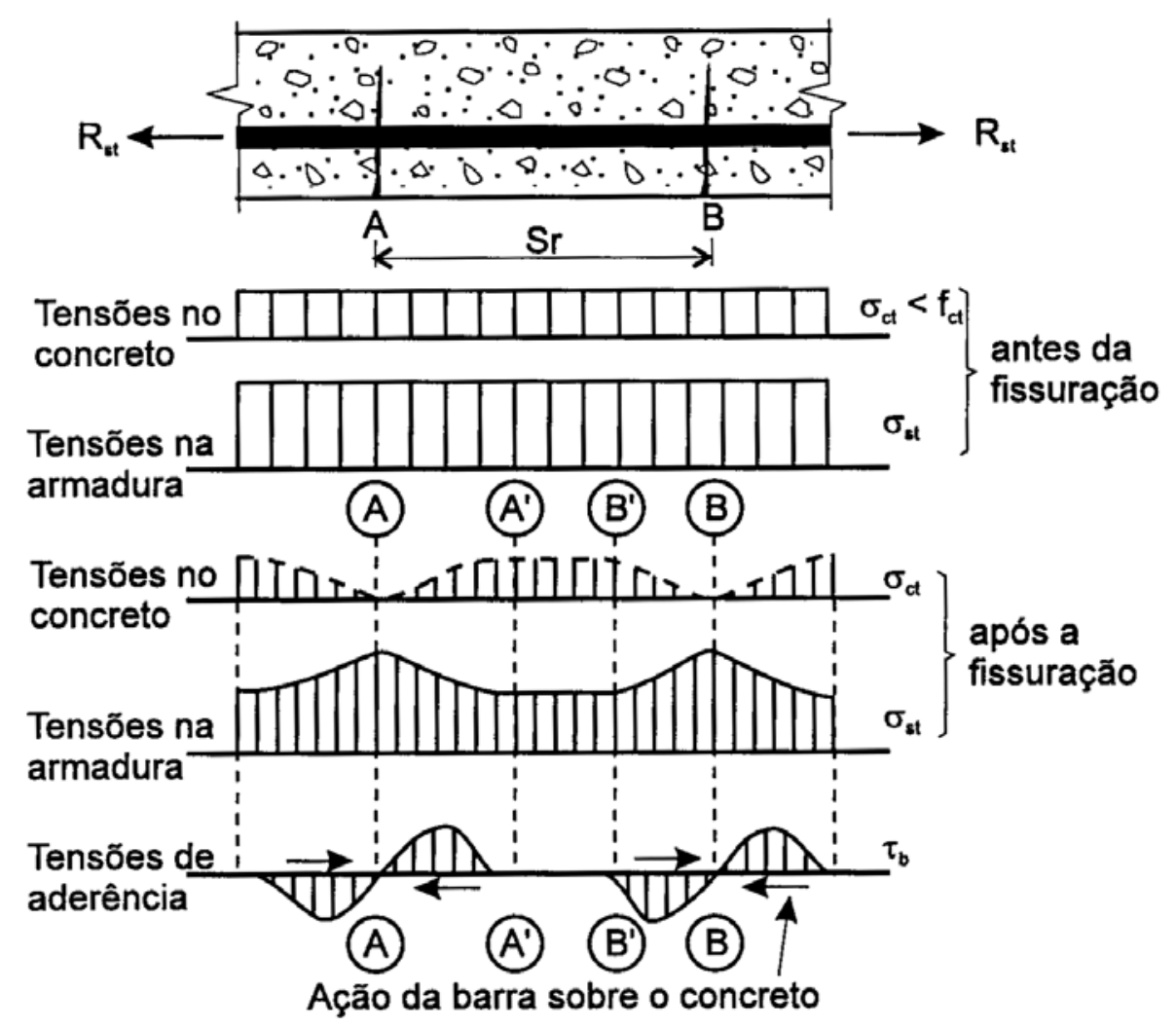

Figura 2.1 - Fissuração por tração

(FUSCO, 1995)

Em uma seção fissurada, todas as tensões são absorvidas apenas pela armadura. Entretanto, é importante salientar que a eventual diminuição ou mesmo a falta de aderência em determinados pontos pode ser compensada pela colaboração de pontos adjacentes.

Entre fissuras, uma parcela das tensões de tração é absorvida pelo próprio concreto através da mobilização das tensões de aderência. Assim, o concreto entre fissuras contribui para a rigidez da peça e esse mecanismo é denominado enrijecimento à tração (tension stiffening).

Na Figura 2.1 considerou-se somente a existência de duas fissuras A e B afastadas entre si da distância $\mathrm{s}_{\mathrm{r}}$. As tensões de aderência são mobilizadas apenas nos trechos $\overline{\mathrm{AA}^{\prime}}$ e $\overline{\mathrm{BB}^{\prime}}$, portanto, no trecho $\overline{\mathrm{A}^{\prime} \mathrm{B}^{\prime}}$ a tensão de tração no concreto $\sigma_{c t}$ é constante. Com o aumento da solicitação externa, cresce a tensão de tração da armadura $\sigma_{\text {st }}$. Dessa forma, pode-se também aumentar a tensão de tração do concreto através da mobilização de tensões de aderência no trecho $\overline{\mathrm{A}^{\prime} \mathrm{B}^{\prime}}$, o que 
possibilita a formação de uma terceira fissura $\mathrm{C}$ entre as fissuras $\mathrm{A}$ e B já existentes (Figura 2.2).

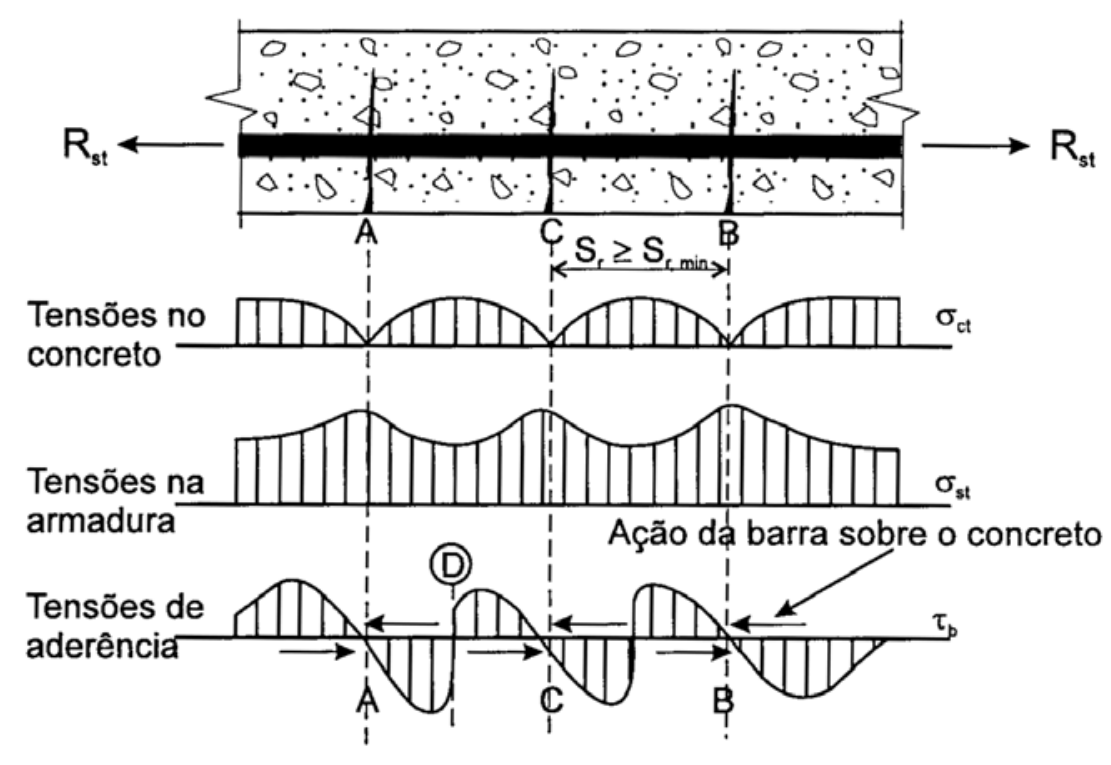

Figura 2.2 - Fissuração estabilizada (FUSCO, 1995)

Com a formação da nova fissura $\mathrm{C}$, a tensão $\sigma_{\mathrm{ct}}$ no concreto dependerá da capacidade de transferência de tensões da armadura para o concreto. Se as tensões de aderência mobilizadas no trecho $\overline{\mathrm{AD}}$ e $\overline{\mathrm{DC}}$ não forem suficientes para que a tensão $\sigma_{c t}$ atinja o limite de ruptura $f_{c t}$, não haverá formação de nova fissura entre A e C, atingindo-se estabilidade.

Em estudo mais detalhado, GOTO (1971) demonstra que há intensa microfissuração do concreto que envolve a barra de aço, conforme ilustra a Figura 2.3 . 


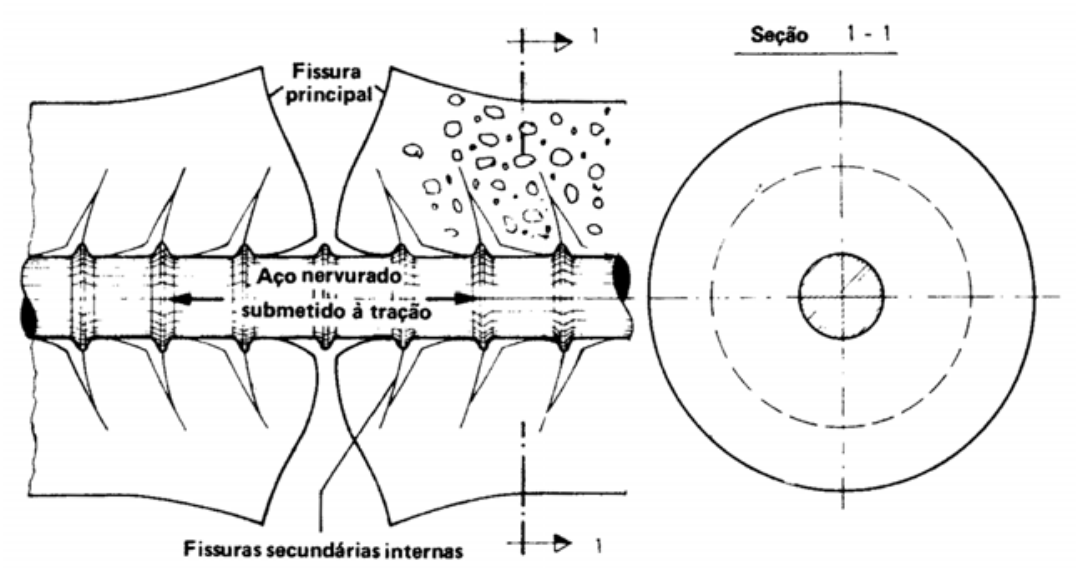

Figura 2.3 - Microfissuração do concreto (GOTO, 1971)

Em cada nervura transversal podem ser observadas fissuras secundárias internas. Decorrentes da mobilização da aderência, essas fissuras, são denominadas fissuras de aderência ou, ainda, transversais. Outro ponto a ser ressaltado é a mudança na orientação dessas fissuras entre duas fissuras principais adjacentes, que justifica a troca de sinais da tensão de aderência verificada nas Figuras 2.1 e 2.2.

FUSCO (1995) faz uma importante menção ao termo microfissuração. Nos estudos de fissuração do concreto estrutural, essa designação não se refere a fissuras realmente microscópicas, mas sim a fissuras de dimensões máximas comparáveis às dimensões do agregado graúdo do concreto.

Com a formação das primeiras fissuras de aderência, a distribuição de tensões na interface aço-concreto depende das condições de carregamento e de contorno. Contudo, de modo geral, observam-se algumas características comuns a todas distribuições, mostradas na Figura 2.4. 

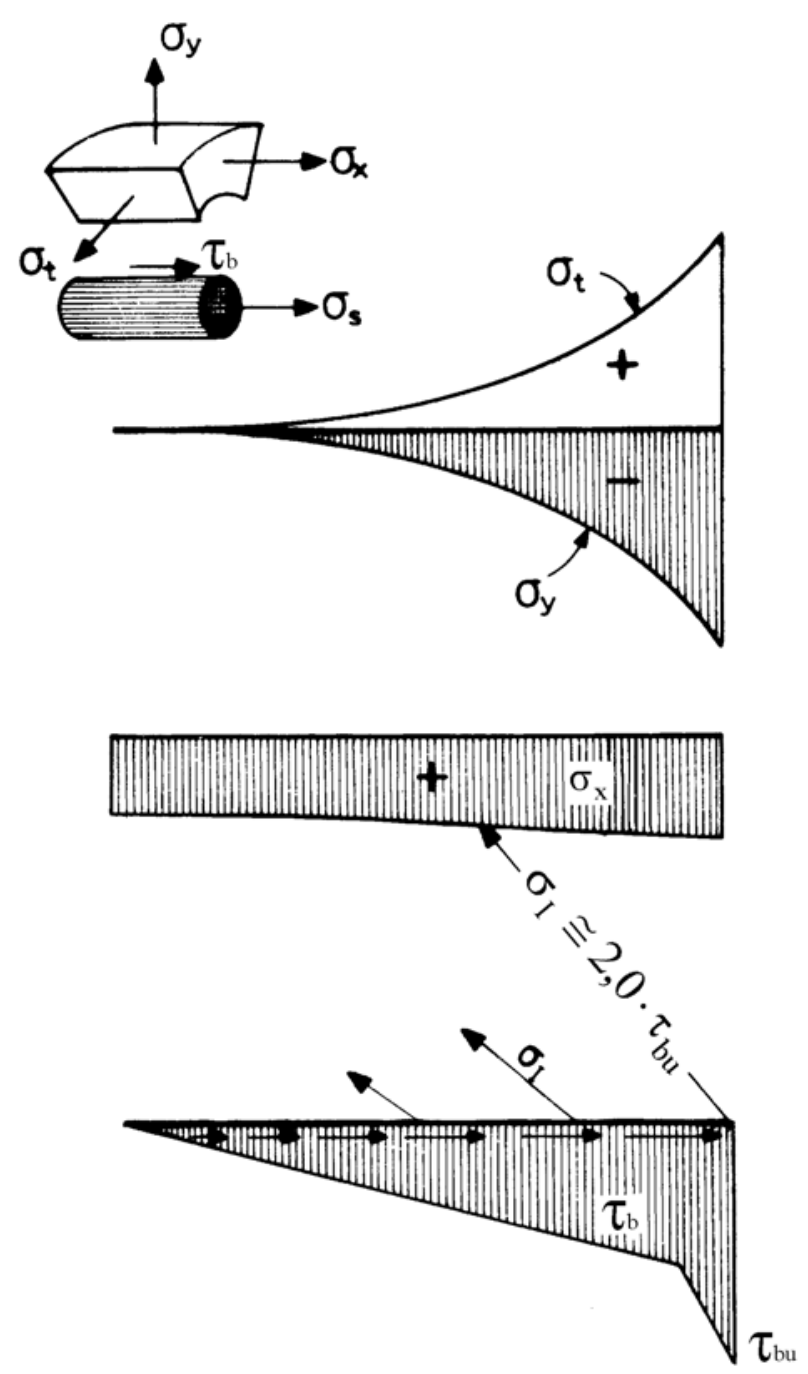

Figura 2.4 - Distribuição das tensões em torno da barra (BRESLER \& BERTERO, 1968)

Na tentativa de arrancamento da barra, surgem tensões longitudinais $\sigma_{\mathrm{x}}$ de tração, relativamente grandes, que atuam no concreto circundante à barra. Do mesmo modo, surgem tensões de compressão radiais $\sigma_{\mathrm{y}}$.

Sob ação combinada de $\tau_{\mathrm{b}}, \sigma_{\mathrm{x}} \mathrm{e} \sigma_{\mathrm{y}}$, mais as possíveis tensões radiais e longitudinais "externas", como por exemplo a pressão de retração, originam-se grandes tensões diagonais de tração $\sigma_{I}$, que provocam fissuras de aderência ao longo da barra.

Simultaneamente à fissuração de aderência, tensões circunferenciais de tração $\sigma_{t}$, tendem a produzir, longitudinalmente, um micro fendilhamento interno, 
mostrado na Figura 2.5. No entanto, para o nível de tensões em questão, os valores de $\sigma_{\mathrm{t}}$ são muito mais baixos que os de $\sigma_{\mathrm{I}}$. Assim, a fissuração de aderência precede o fendilhamento longitudinal.

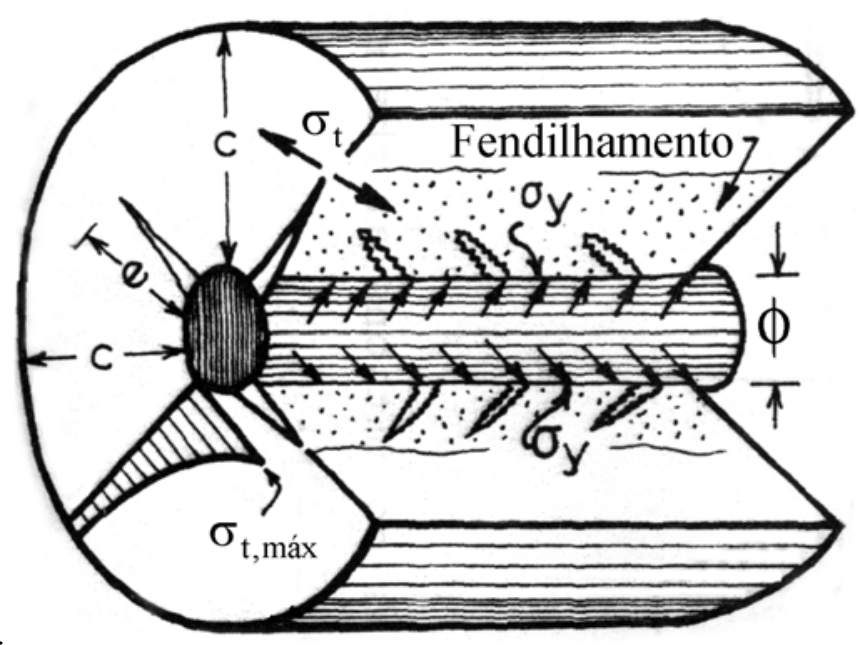

Figura 2.5 - Fissuras de aderência e de fendilhamento (TEPFERS ${ }^{1}$ apud TASSIOS, 1979)

Com intuito prático, a aderência é usualmente considerada como decorrente da mobilização de tensões tangenciais uniformemente distribuídas na interface açoconcreto. Pode-se considerar que a solidarização por aderência das barras de aço ao concreto, decorre da mobilização de tensões diagonais de compressão $\sigma_{c}$ e de tensões circunferenciais de tração $\sigma_{t}$.

1 TEPFERS, R. (1973). A theory of bond applied to overlapped tensile reinforcement splices for deformed bars. Chalmers University, Division of Concrete Structures. Publication 73:2 apud TASSIOS (1979). 


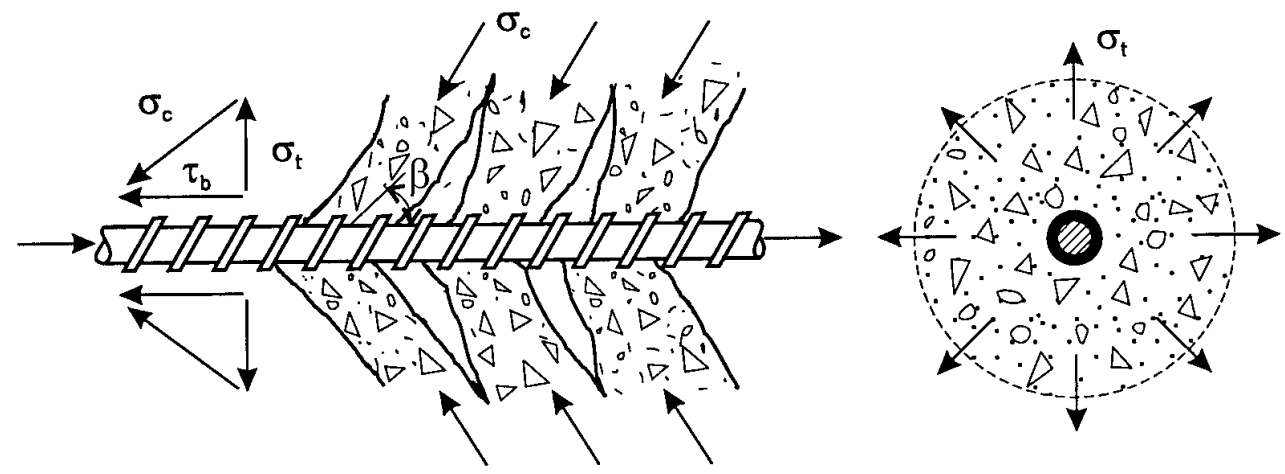

Figura - 2.6 - Esforços reais de ancoragem (FUSCO, 1995)

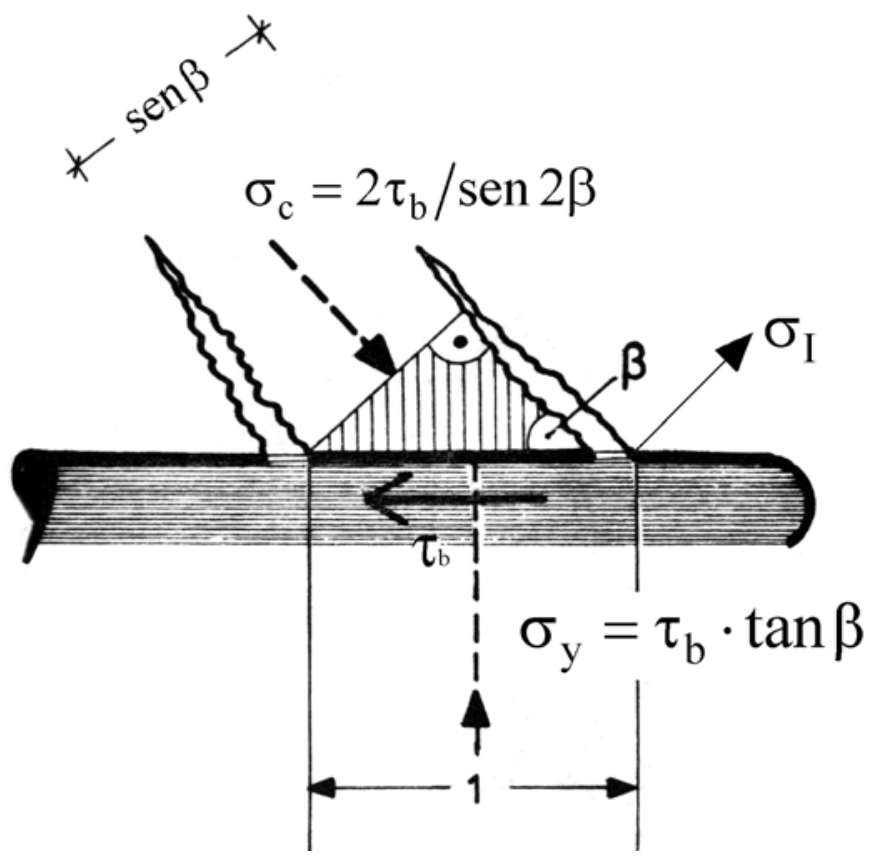

Figura - 2.7 - Tensões entre fissuras de aderência consecutivas (TASSIOS, 1979)

As Figuras 2.6 e 2.7 mostram os esforços de ancoragem que verdadeiramente ocorrem. Devido à fissuração de aderência, quando se atinge a resistência de aderência última, a transmissão de esforços pode ser idealizada como feita por meio de bielas comprimidas de concreto, delimitadas pelas fissuras de aderência. 


\subsection{DISTRIBUIÇÃO DAS TENSÕES DE ADERÊNCIA AO LONGO DA ANCORAGEM}

A distribuição das tensões de aderência não segue leis simples, porque depende de fenômenos como retração, fluência e fissuração do concreto.

A tensão de aderência varia ao longo do comprimento de ancoragem. Essa variação é mais pronunciada para carregamentos baixos. Para grandes carregamentos as propriedades da aderência mudam de tal modo que se têm, aproximadamente, tensões de aderência uniformemente distribuídas. Isso se deve ao aumento da deformabilidade do concreto com o aumento do carregamento.

Entretanto, para uma barra ancorada no concreto, também pode ocorrer fissuração longitudinal com o aumento do deslizamento, e as forças de aderência podem fendilhar o concreto na região de ancoragem, antes de se atingir o nível de carregamento que tornaria as tensões de aderência uniformemente distribuídas.

A seguir será mostrado como se pode determinar a distribuição de tensões e deformação ao longo de zonas de ancoragem em concreto armado. Esta teoria apresentada pelo CEB (1982) Bulletin d'Information n.151, é baseada nos deslocamentos reais ou deformações locais na zona de aderência próxima à superfície da armadura. A referida publicação ainda salienta que as tensões ao longo do comprimento de ancoragem também podem ser estimadas através da consideração da fissuração, devendo ter atenção especial com as fissuras do cobrimento da armadura.

A Figura 2.8 apresenta as forças atuantes numa barra tracionada imersa no concreto. 


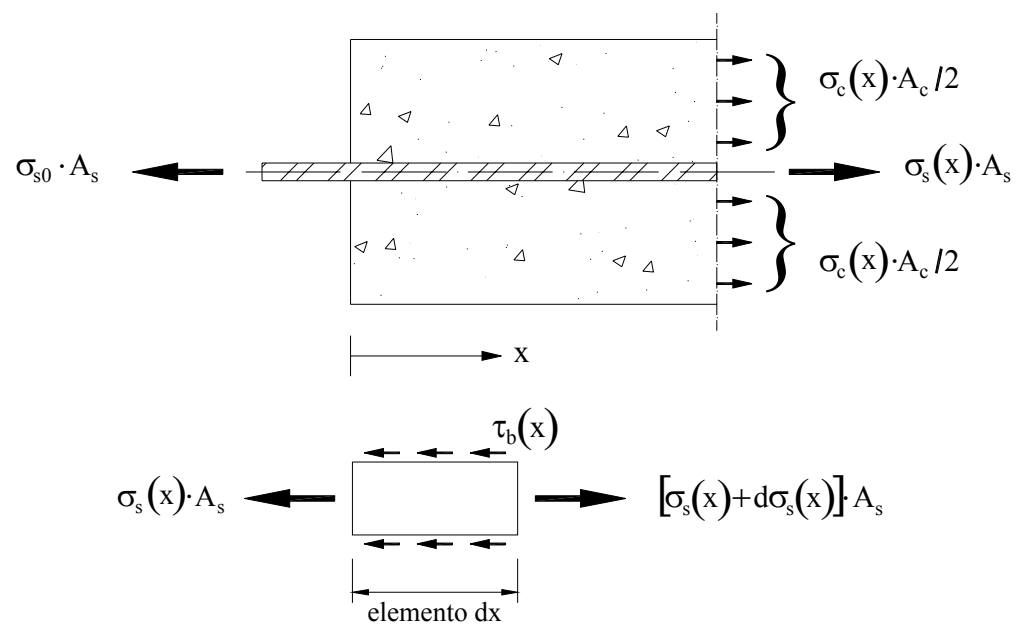

Figura 2.8 - Forças atuantes ao longo do comprimento de ancoragem de uma barra

(CEB, 1982 Bulletin d'Information $\mathrm{n} .151$ )

onde:

$\sigma_{\mathrm{s} 0} \quad$ Tensão normal na extremidade carregada da armadura;

$\sigma_{\mathrm{s}}(\mathrm{x}) \quad$ Tensão normal na armadura ao longo do comprimento de ancoragem;

$\sigma_{\mathrm{c}}(\mathrm{x}) \quad$ Tensão normal no concreto ao longo do comprimento de ancoragem;

$\tau_{\mathrm{b}}(\mathrm{x}) \quad$ Tensão de aderência ao longo do comprimento de ancoragem;

$\mathrm{A}_{\mathrm{s}} \quad$ Área da seção transversal da armadura;

$\mathrm{A}_{\mathrm{c}} \quad$ Área da seção transversal de concreto que envolve a armadura;

x Coordenada de comprimento da armadura.

Assim, a condição de equilíbrio para ancoragem é:

$\sigma_{\mathrm{s} 0} \cdot \mathrm{A}_{\mathrm{s}}=\sigma_{\mathrm{s}}(\mathrm{x}) \cdot \mathrm{A}_{\mathrm{s}}+\sigma_{\mathrm{c}}(\mathrm{x}) \cdot \mathrm{A}_{\mathrm{c}}$

A condição de equilíbrio para o elemento infinitesimal é:

$$
\frac{\mathrm{d} \sigma_{\mathrm{s}}(\mathrm{x})}{\mathrm{dx}}=\frac{4}{\phi} \cdot \tau_{\mathrm{b}}(\mathrm{x}) \quad \frac{\mathrm{d} \sigma_{\mathrm{c}}(\mathrm{x})}{\mathrm{dx}}=-\frac{4}{\phi} \cdot \tau_{\mathrm{b}}(\mathrm{x})
$$

A tensão de aderência $\tau_{\mathrm{b}}(\mathrm{x})$ depende do deslizamento $\mathrm{s}(\mathrm{x})$ entre o aço e o concreto. A função

$\tau_{\mathrm{b}}(\mathrm{x})=\mathrm{f}[\mathrm{s}(\mathrm{x})]$ 
é medida em ensaios. Geralmente a lei $\tau_{\mathrm{b}}(\mathrm{x})=\mathrm{f}[\mathrm{s}(\mathrm{x})]$ é aplicável para um elemento, mas, por extrapolação, é utilizada em todo comprimento de ancoragem.

A variação do deslizamento ao longo do comprimento $d x$ é a diferença entre a deformação do aço e a do concreto

$$
\frac{\mathrm{ds}(\mathrm{x})}{\mathrm{dx}}=\frac{\sigma_{\mathrm{s}}(\mathrm{x})}{\mathrm{E}_{\mathrm{s}}}-\frac{\sigma_{\mathrm{c}}(\mathrm{x})}{\mathrm{E}_{\mathrm{c}}}
$$

A diferenciação da Equação 2.3 e a substituição da Equação 2.2 resultam:

$$
\begin{aligned}
& \frac{\mathrm{d}^{2} \mathrm{~s}(\mathrm{x})}{\mathrm{dx}^{2}}=\frac{4}{\phi} \cdot \frac{1}{E_{\mathrm{s}}} \cdot \tau_{\mathrm{b}}(\mathrm{x}) \cdot\left(1+\alpha_{\mathrm{e}} \cdot \rho\right) \\
& \operatorname{com} \alpha_{\mathrm{e}}=\frac{\mathrm{E}_{\mathrm{s}}}{\mathrm{E}_{\mathrm{c}}} \text { e } \rho=\frac{\mathrm{A}_{\mathrm{s}}}{\mathrm{A}_{\mathrm{c}}} .
\end{aligned}
$$

Sob condições reais $\alpha_{\mathrm{e}}$ não é constante, porém assim é considerada, com o propósito de simplificar o equacionamento.

Inserindo a Equação 2.3 na 2.5 obtém-se uma equação diferencial para s(x)

$$
\begin{aligned}
& \frac{d^{2} s(x)}{d x^{2}}=a_{1} \cdot f[s(x)] \\
& \operatorname{com~} a_{1}=\frac{4}{\phi} \cdot \frac{1}{E_{s}} \cdot\left(1+\alpha_{e} \cdot \rho\right)
\end{aligned}
$$

A solução exata da Equação 2.6 para as leis de aderência envolve cálculos trabalhosos. Assim, será apresentada a seguir uma solução mais simples através das funções:

$$
\begin{aligned}
& \tau_{\mathrm{b}}=\tau_{0} \\
& \tau_{\mathrm{b}}=\xi \cdot \mathrm{s}
\end{aligned}
$$

A Equação 2.7 descreve o comportamento da aderência para barras lisas, desprezando-se as deformações do concreto.

$$
\tau_{\mathrm{b}}(\mathrm{x})=\text { constante }=\tau_{0}
$$




$$
\begin{aligned}
& \sigma_{\mathrm{s}}(\mathrm{x})=\sigma_{\mathrm{s} 0}+\tau_{0} \cdot \mathrm{x} \cdot \frac{4}{\phi} \\
& \mathrm{s}(\mathrm{x})=\mathrm{s}_{0}+\frac{\sigma_{\mathrm{s}}(\mathrm{x})+\sigma_{\mathrm{s} 0}}{\mathrm{E}_{\mathrm{s}}} \cdot \frac{\mathrm{x}}{2}
\end{aligned}
$$

O CEB (1982) Bulletin d'Information n.151 enfatiza que a Equação 2.8 considera o comportamento elástico do concreto entre nervuras. Se for adotado para $\xi$ o módulo tangente, da relação entre a tensão de aderência e o deslizamento, a solução será conduzida para um valor máximo do comportamento real. Uma aproximação melhor é obtida utilizando-se para $\xi$ o módulo secante. Para situação próxima à ruptura, a Equação 2.8 fornece grosseira aproximação do comportamento da aderência.

\subsection{MODOS DE RUPTURA}

A destruição da aderência é um processo que, geralmente, está associado a um determinado estado de deformação e fissuração. Dependendo das características da interação entre a barra de aço e o concreto, dois modos de ruptura podem ser tradicionalmente considerados: ruptura por arrancamento e ruptura por fendilhamento.

No primeiro caso, a ruptura da aderência é principalmente devida ao corte do concreto entre as nervuras, propiciando o arrancamento da barra. Esse tipo de ruptura está principalmente relacionado à resistência do concreto e ao tipo e geometria das nervuras.

FUSCO (1995) salienta que a ruptura da aderência não se dá por simples deslizamento da barra de aço dentro do concreto, visto que os esforços mobilizados pela aderência, criam no concreto uma região microfissurada no entorno das barras (Figura 2.9). 


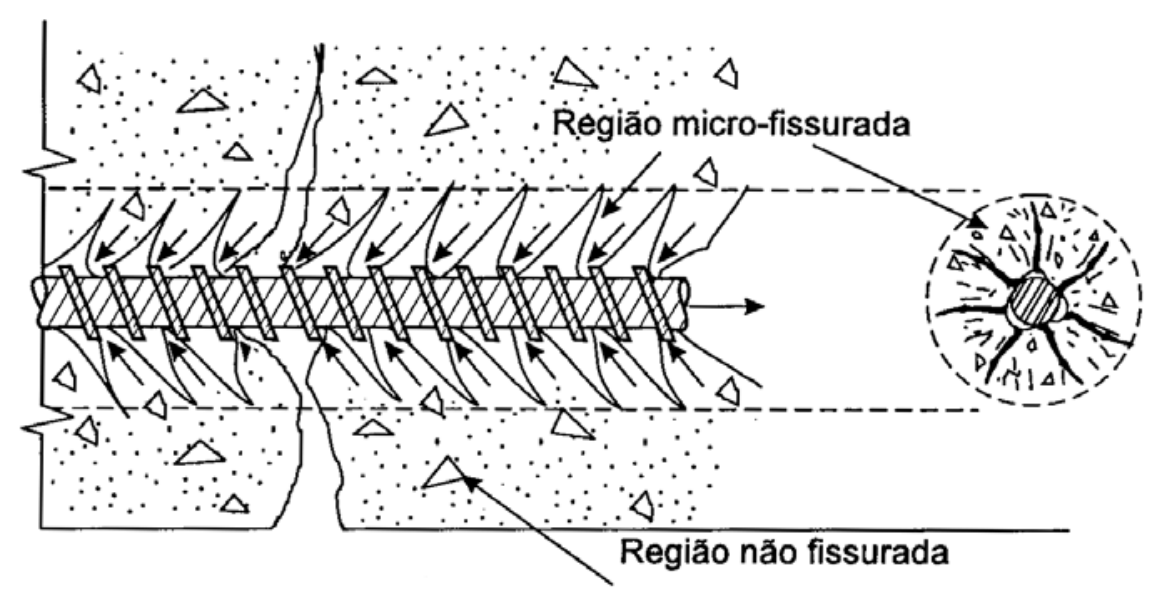

Figura 2.9 - Microfissuração do concreto entorno das barras devido à mobilização da aderência

(FUSCO, 1995)

Dessa forma, somente ocorreria o arrancamento da barra por simples processo de deslizamento progressivo, se houvesse a pulverização de todo o material existente entre as nervuras da barra de aço.

Nas barras lisas, esse processo é mais fácil por serem muito pequenas as irregularidades da superfície. Nas barras nervuradas isso somente será possível quando o fendilhamento longitudinal do concreto for impedido. As tensões circunferenciais de tração devem ser contidas pelo confinamento da armadura, decorrente de armaduras transversais ou do próprio concreto.

O segundo modo de ruptura ocorre quando os esforços de tração provocam fendilhamento longitudinal do concreto circunvizinho à barra, que tende a se propagar em direção às bordas. A capacidade de aderência exaure-se logo que a fissuração radial atinge a superfície externa do elemento estrutural e rompe o cobrimento de concreto (Figura 2.10). A ruptura por fendilhamento é brusca e, normalmente, ocorre sem aviso prévio, manifestando-se em situações onde a armadura não esteja confinada. 


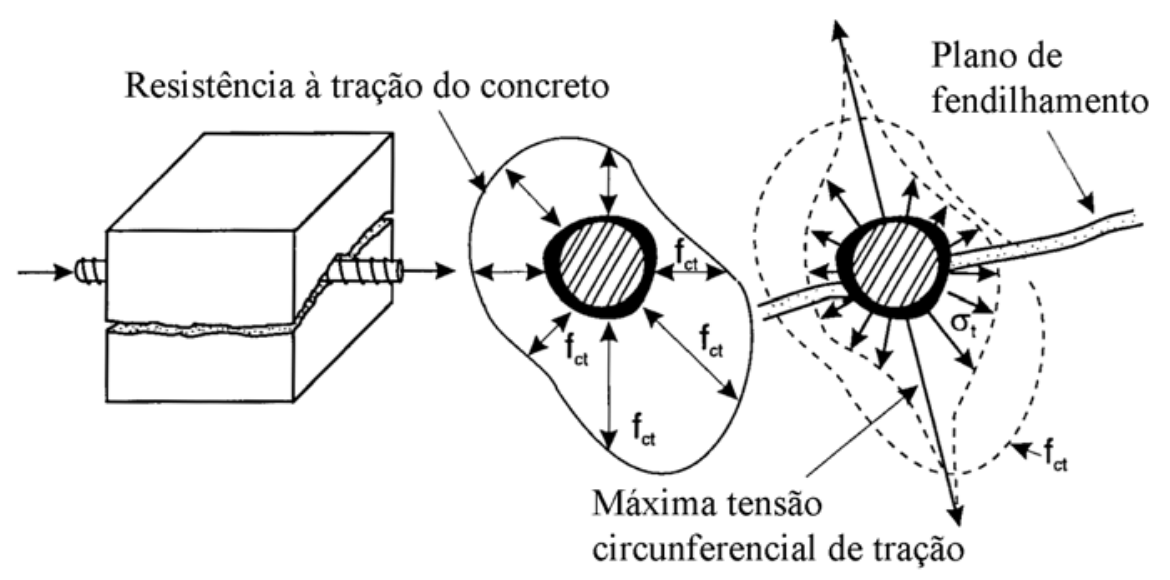

Figura 2.10 - Fendilhamento longitudinal do concreto (FUSCO, 1995)

O plano de fendilhamento, que depende da orientação das fissuras, é influenciado pelo número de barras e suas configurações dentro do elemento. Em uma viga, por exemplo, o plano potencial é o paralelo ao eixo das barras devido ao fato de a tensão circunferencial de tração máxima atuar perpendicularmente ao eixo das barras.

Deve-se lembrar que somente em ensaios experimentais, representando curtos comprimentos de ancoragem ou de emenda por traspasse, é possível estudar, separadamente, esses dois modos de ruptura, porque em estruturas reais é provável que ocorra fendilhamento em maior ou menor intensidade. Nos casos de arrancamento, freqüentemente pode-se observar um fendilhamento parcial, embora pequenas e delgadas fissuras radiais prejudiquem a eficiência da aderência. Outro ponto a ser destacado é o comportamento último da aderência predominantemente acompanhado pela extração da barra.

Assim, em situações de projeto, os modos de ruptura são mais complexos, podendo ser resumidos como a seguir:

a. Ruptura por arrancamento com ou sem fendilhamento parcial do concreto, ou seja, as fissuras de fendilhamento não são visíveis. Isto ocorre sob alto grau de confinamento e/ou grande cobrimento de concreto.

b. Ruptura por arrancamento induzido pelo fendilhamento total ou parcial, onde as fissuras de fendilhamento são visíveis. Este modo de ruptura ocorre sob confinamento moderado e/ou limitado cobrimento de 
concreto, onde o cisalhamento do concreto entre nervuras é acompanhado pelo deslizamento entre o concreto e o aço nas faces das nervuras.

c. Ruptura provocada pelo fendilhamento do cobrimento de concreto. Esta situação ocorre onde não haja confinamento e/ou com limitado cobrimento de concreto.

Os modos de ruptura para carregamentos monotônico e cíclico, com um número de ciclos relativamente pequeno (low-cycle), são idênticos. Para carregamento com muitos ciclos (high-cycle) podem ocorrer modos de ruptura similares; entretanto, deve-se considerar, também, a possibilidade de ruptura por fadiga do aço e do concreto.

\subsection{COMPORTAMENTO DA ADERÊNCIA}

\subsubsection{GENERALIDADES}

Inicialmente é apropriado distinguir o comportamento local em uma seção transversal de uma barra ancorada e o comportamento global de uma região de ancoragem.

O comportamento local, caracterizado pela tensão de aderência na interface e o correspondente deslizamento local, descreve a interação seccional entre a barra da armadura e o concreto circunvizinho. Quando a tensão de aderência alcança o pico e diminui com o aumento do deslizamento, caracteriza-se a ruptura da aderência local.

O comportamento global sintetiza o comportamento local ao longo de uma ou mais barras ancoradas em uma região. O comportamento global é caracterizado pela força de ancoragem total, em uma barra ou grupo de barras, e pelo deslizamento final correspondente ao máximo carregamento de uma região de ancoragem. A força máxima que pode ser resistida em uma região de ancoragem é referida como capacidade de ancoragem. 


\subsubsection{MECANISMOS DE RESISTÊNCIA DA ADERÊNCIA}

A resistência de aderência é oriunda de vários fenômenos que intervêm na ligação aço-concreto. Usualmente é feita uma separação esquemática dos mecanismos resistentes, podendo a aderência ser decomposta em aderência por adesão, aderência por atrito e aderência mecânica.

Apesar de não ser possível determinar experimentalmente cada componente isoladamente, alguns autores apresentam curvas esquemáticas da relação tensão de aderência versus deslizamento $\left(\tau_{\mathrm{b}}-\mathrm{s}\right)$ separando esses mecanismos resistentes. Um exemplo representativo do comportamento local de barras lisas e nervuradas é mostrado na Figura 2.11. As curvas representam situações em que a ruptura se dá pelo arrancamento da barra, ou seja, em situações com suficiente confinamento para evitar o fendilhamento.

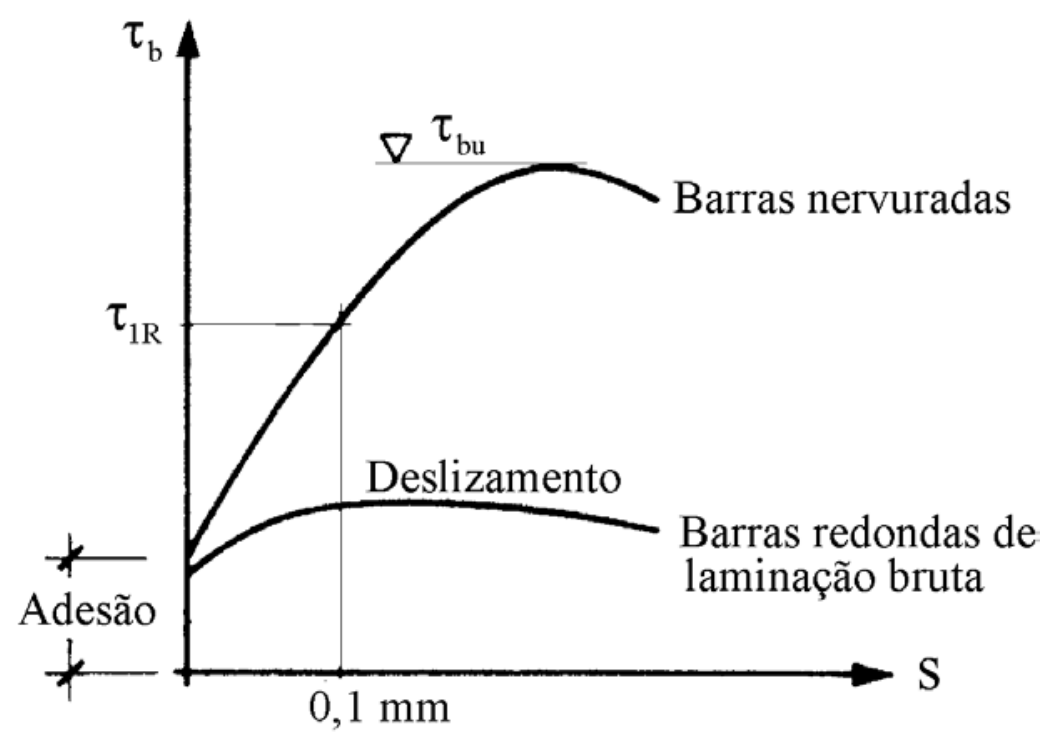

Figura 2.11 - Curvas esquemáticas da relação $\tau_{b}$-s para barras lisas e nervuradas (LEONHARDT \& MÖNNIG, 1977)

De modo geral, a variação inicial muito inclinada do diagrama $\tau_{b}-\mathrm{s}$ corresponde à aderência por adesão; o trecho inclinado corresponde à aderência mecânica e o trecho plano, característico de barras lisas, corresponde à aderência por 
atrito. Se o diagrama $\tau_{\mathrm{b}}-\mathrm{s}$ for horizontal ou descendente, a aderência foi destruída e a barra desliza com resistência ao atrito insuficiente.

\subsubsection{ADERÊNCIA POR ADESÃO}

A adesão é a aderência química que surge durante as reações de pega do cimento em decorrência das ligações físico-químicas na interface de ambos os materiais: aço e concreto. Essa parcela também depende da rugosidade e da limpeza da superfície das armaduras.

Pode ser constatada pela resistência de adesão $R_{b 1}$ que se opõe à separação de um bloco concretado diretamente sobre uma chapa de aço, conforme ilustrado na Figura 2.12.

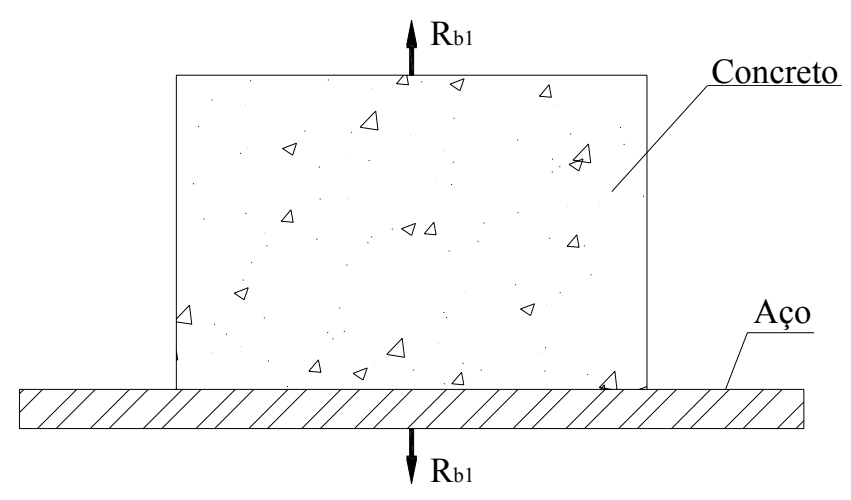

Figura 2.12 - Aderência por adesão (FUSCO, 1995)

A adesão é destruída quando ocorrem deslocamentos relativos entre os dois materiais, ainda que muito pequenos. 


\subsubsection{ADERÊNCIA POR ATRITO}

A ação de forças de atrito, existentes entre os dois materiais, manifesta-se quando há tendência ao deslocamento relativo entre o aço e o concreto. Essa parcela depende do coeficiente de atrito entre os materiais que é alto, segundo LEONHARDT \& MÖNNIG (1977), devido à rugosidade da superfície do aço ( $\mu=$ 0,3 a 0,6). Entretanto, a contribuição do atrito na resistência de aderência somente tem importância para barras lisas.

A aderência por atrito se manifesta devido à pressão transversal $p_{t}$ decorrente da retração. A barra de aço que restringe as deformações do concreto faz surgir essa pressão transversal que é exercida pelo concreto sobre a barra. Outros fatores podem ser citados como de grande relevância para o aumento da capacidade de aderência por atrito. A presença de confinamento e de compressão transversal externa, usualmente encontrada nos apoios diretos das vigas, aumenta essa parcela de aderência.

A aderência por atrito pode ser verificada através de ensaios de arrancamento, conforme apresentado na Figura 2.13. Neste caso existe também uma parcela de aderência por adesão, mas segundo FUSCO (1995), a força de arrancamento $\mathrm{R}_{\mathrm{b} 2}$ é expressivamente superior aos limites que podem ser previstos a partir da resistência $\mathrm{R}_{\mathrm{b} 1}$. Assim, os ensaios sugerem que esse acréscimo na resistência de aderência seja devido às forças de atrito existentes entre o aço e o concreto.
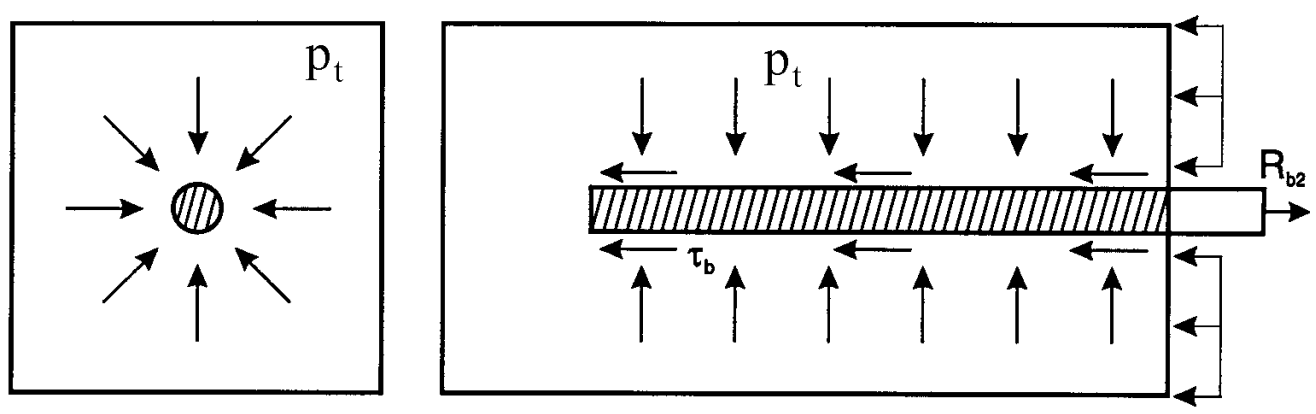

Figura 2.13 - Aderência por atrito

(FUSCO, 1995) 


\subsubsection{ADERÊNCIA MECÂNICA}

A aderência mecânica é decorrente da presença de saliências na superfície da barra, que funcionam como peças de apoio. Quando a barra é tracionada e tende a deslizar, são mobilizadas tensões de compressão que surgem perpendicularmente às saliências (Figura 2.14).

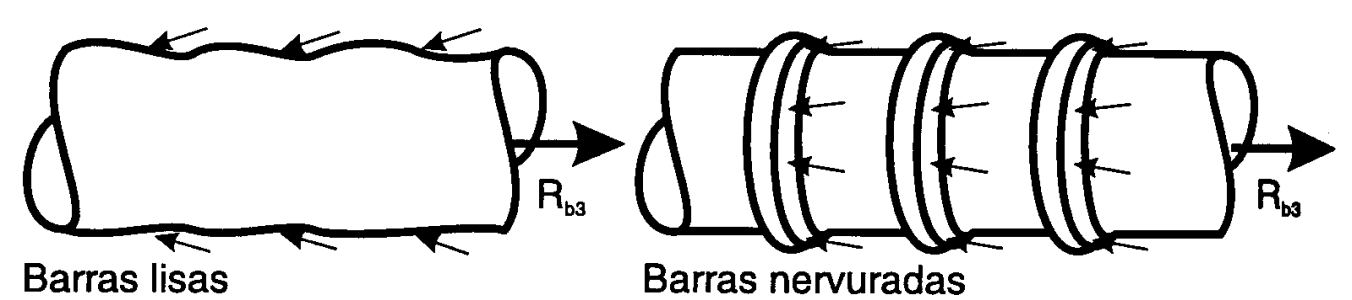

Figura 2.14 - Aderência mecânica (FUSCO, 1995)

Nas barras nervuradas, a aderência mecânica é a principal responsável pela solidariedade das barras ao concreto. $\mathrm{O}$ valor da resistência de aderência mecânica dessas barras depende da forma e da inclinação das nervuras, da altura e da distância livre entre elas.

Nas barras lisas, existe o efeito da aderência mecânica, devido às irregularidades superficiais inerentes ao processo de laminação, conforme constatado pela investigação realizada por REHM \& ELIGEHAUSEN² apud FUSCO (1995), apresentada na Figura 2.15.

${ }^{2}$ REHM, G.; ELIGEHAUSEN, R. (1973). Einfluss von dauerlast und ermüdungsbeanspruchung auf das rissverhalten von stahlbetonbauteilen unter ubernoiegender biege beanspruchung. CEB, Bulletin d'Information n. 89 apud FUSCO (1995). 

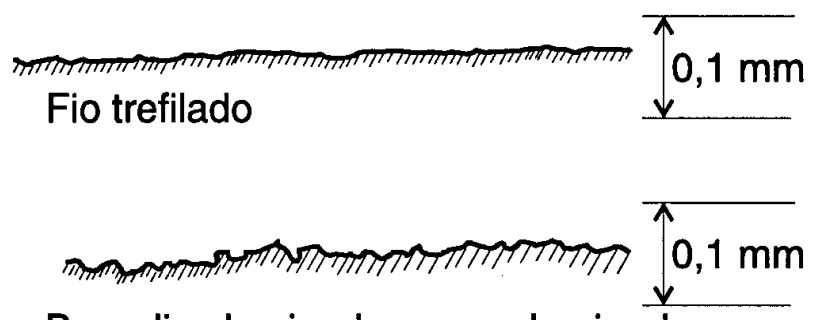

Barra lisa laminada - como laminada

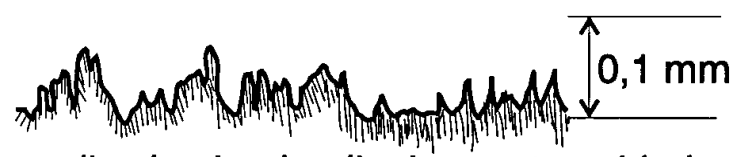

Barra lisa laminada - ligeiramente oxidada

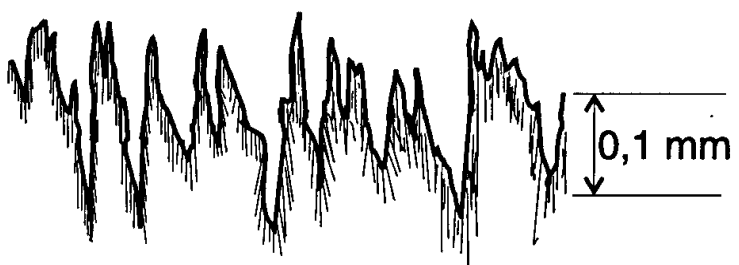

Barra lisa laminada - muito enferrujada

Figura 2.15 - Acabamento superficial de fios e barras lisas (REHM \& ELIGEHAUSEN ${ }^{2}$ apud FUSCO, 1995)

\subsubsection{MODELOS TEÓRICOS}

Com o intuito de entender o mecanismo de funcionamento da aderência, para diferentes níveis de carregamento será analisado o desenvolvimento das tensões e dos respectivos deslizamentos. Na literatura existem diversos modelos do comportamento da aderência, alguns dos quais serão mencionados a seguir.

Primeiramente, como referência, na Figura 2.16 é apresentada uma curva típica da relação tensão de aderência e correspondente deslizamento local, obtida em ensaio de arrancamento com deformação controlada. 


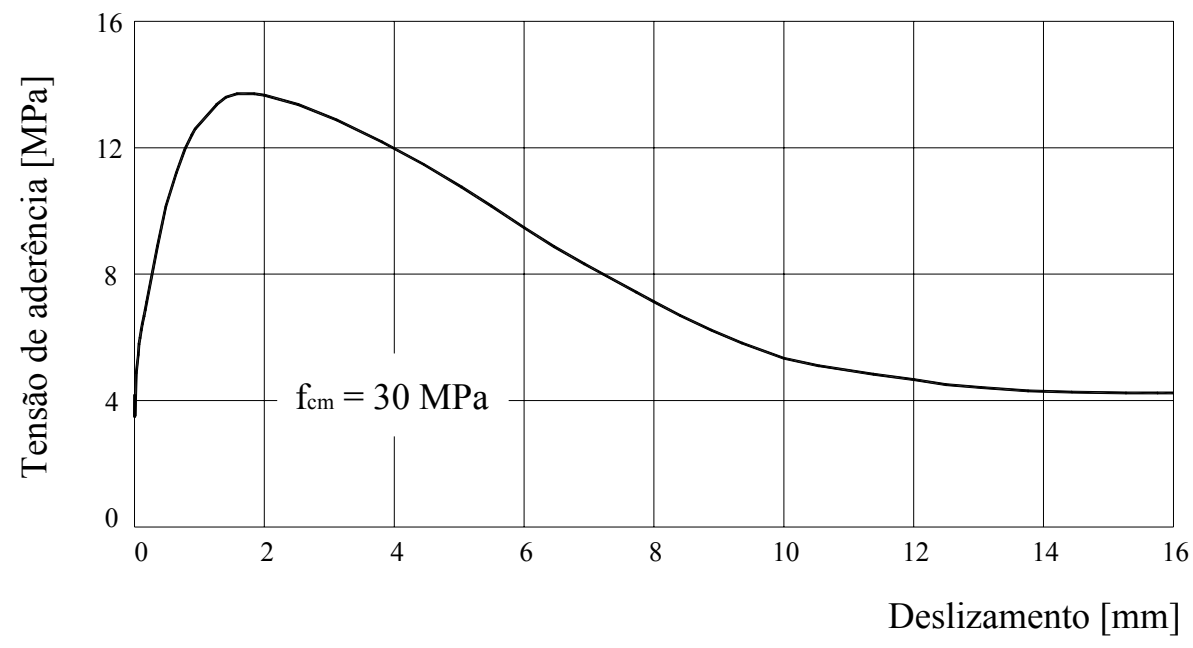

Figura 2.16 - Curva típica da relação $\tau_{\mathrm{b}}$-S (ELIGEHAUSEN et al., 1983)

Os deslizamentos em parte são causados pelas deformações elásticas do concreto. No entanto, para grandes carregamentos, esses deslizamentos decorrem do esmagamento do concreto entre as nervuras.

A Figura 2.17 representa o modelo teórico de TASSIOS (1979). Segundo o autor, para pequenas solicitações ocorrem deslizamentos extremamente pequenos, da ordem de poucos microns. Nessa fase, o mecanismo de resistência é devido à aderência química, resistindo a tensões de até 1,5 MPa. Para tensões da ordem de 0,6 $\mathrm{MPa}$, praticamente não há deslizamentos. Com o aumento do carregamento, a tensão de aderência também aumenta e alcança o nível $\tau_{0}$, quando ocorre a ruptura da adesão. 


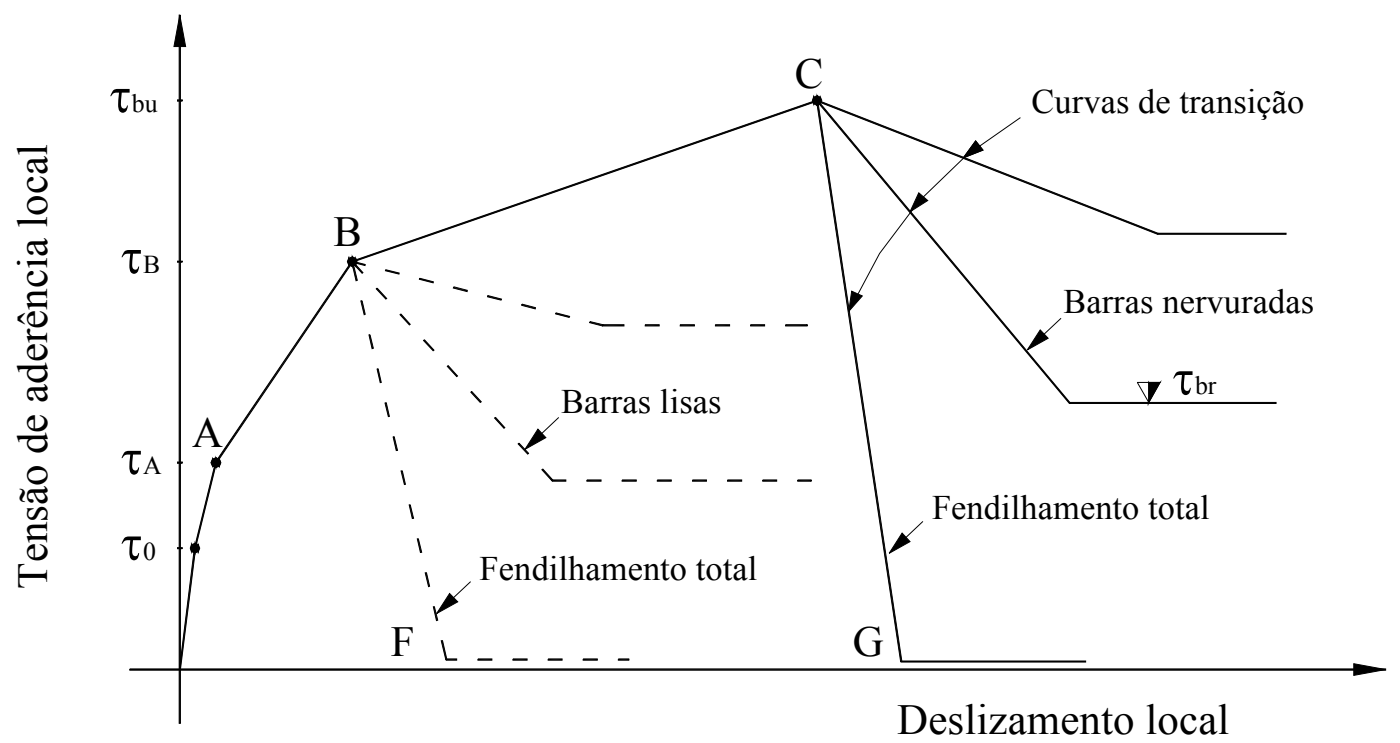

Figura 2.17 - Modelo teórico da curva de aderência

(TASSIOS, 1979)

Para níveis mais altos, há mobilização do engrenamento mecânico, tanto para barras nervuradas, quanto para barras lisas. Quando a tensão $\tau_{\mathrm{A}}$ é atingida, são registradas as primeiras fissuras de aderência. Essa fissuração de aderência modifica a rigidez da ligação e pode ser constatada pela menor inclinação da curva.

Provavelmente para tensões menores que $\tau_{\mathrm{A}}$, os pequenos deslizamentos locais da barra dependem somente da deformabilidade do concreto simples e, portanto, a inclinação do primeiro ramo da curva $\tau_{b}-\mathrm{s}$ da Figura 2.17 pode ser considerada vertical.

A partir da tensão $\tau_{\mathrm{A}}$ também inicia-se o fendilhamento, à medida que $\mathrm{o}$ carregamento aumenta, as fissuras de fendilhamento se propagam radial e longitudinalmente.

Em seguida, devido a deslizamentos maiores, há destruição parcial do engrenamento mecânico e são mobilizadas forças de atrito. Assim, mesmo barras lisas são capazes de compensar, embora parcialmente, a parcela perdida do engrenamento mecânico por parte da resistência por atrito. Nas barras lisas, isso permanece até o nível de tensão $\tau_{\mathrm{B}}$ para o qual é provável que a resistência de atrito seja esgotada ou se torne insuficiente. Dessa forma, a ruptura se dá pelo arrancamento da barra e deixa um orifício quase intacto no concreto. É importante 
salientar que existe pequena possibilidade de ocorrer rompimento do concreto pelo fendilhamento, representado pelo ramo BF da Figura 2.17.

No caso das barras nervuradas, o efeito do engrenamento mecânico é maior, e dificilmente é perdido. Portanto, somente um fendilhamento generalizado, ramo descendente BF da Figura 2.17, pode findar este estágio de aderência. Essa situação ocorre quando não há confinamento suficiente; caso contrário, prossegue a mobilização da aderência com perda de rigidez para tensões acima de $\tau_{B}$. Assim sendo, no nível de tensões entre $\tau_{\mathrm{B}} \mathrm{e} \tau_{\mathrm{bu}}$, as barras nervuradas apresentam deslizamento crescente devido ao esmagamento do concreto entre as nervura.

Quando a tensão de aderência se aproxima do valor máximo resistente, correspondente à tensão $\tau_{\mathrm{bu}}$ da Figura 2.17, ocorre pulverização do concreto entre nervuras. Nesta fase, a tensão de aderência ainda aumenta devido à compactação do concreto pulverizado. Isso ocorre até que os dentes de concreto, ao longo de todo o comprimento de ancoragem, tenham sido pulverizados.

TASSIOS (1979) apresenta na Figura 2.18 um possível estágio final de ruptura para barras nervuradas, nas quais se considera que o principal mecanismo remanescente seja o engrenamento mecânico promovido pelas nervuras. O referido autor assume que a tensão de aderência última $\left(\tau_{\mathrm{bu}}\right)$ seja controlada pela ruptura das bielas de compressão que se apóiam nas nervuras. Essas bielas, entre as fissuras (de aderência) consecutivas, são carregadas por tensão de compressão aproximadamente igual a $2 \cdot \tau_{\mathrm{bu}}$. No entanto, deve-se ressaltar que as fissuras longitudinais (fendilhamento) isolam as bielas de concreto que, neste estágio, são carregadas por compressão quase não confinada, devido à considerável destruição do concreto circunvizinho à barra. Dessa forma, o autor salienta que a degradação total da aderência ocorre com a ruptura dessas bielas de compressão. Contudo, esse tipo de ruptura das bielas ainda não foi suficientemente observado em experimentos (CEB, 1982 Bulletin d'Information n.151). 


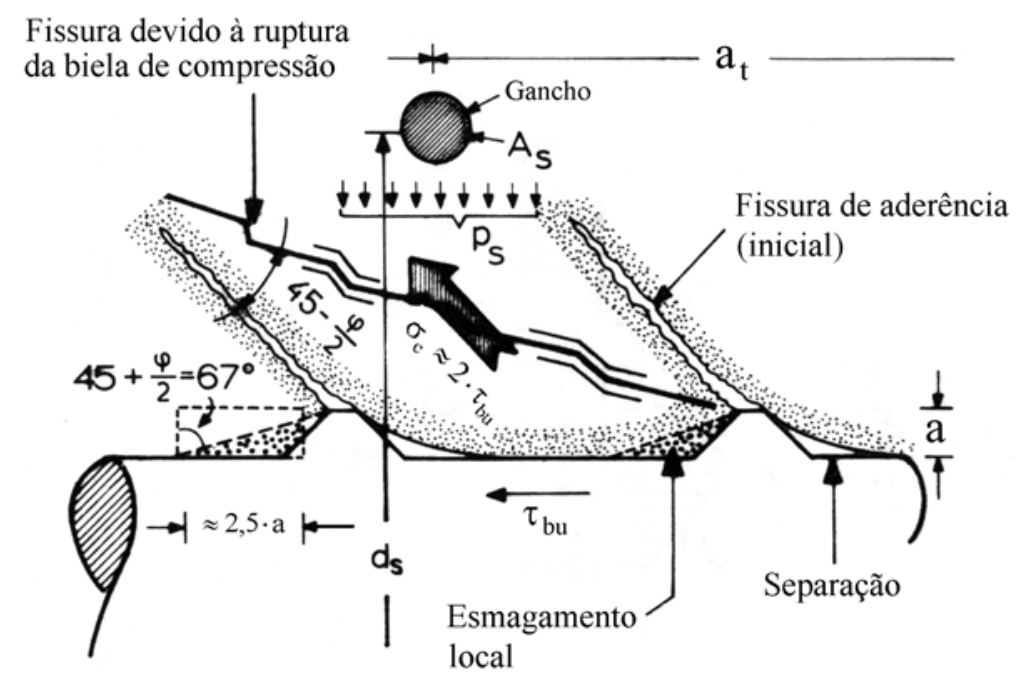

Figura 2.18 - Possível estágio de ruptura da aderência para concreto confinado e barra nervurada

(TASSIOS, 1979)

De acordo com LEONHARDT \& MÖNNIG (1977), devido ao engrenamento mecânico entre a superfície da armadura e o concreto, formam-se "consolos de concreto" que, quando a tensão de aderência última se aproxima, são mobilizados ao corte em parte ou em todo comprimento (Figura 2.19). A extensão dessas fissuras depende da relação entre a altura das nervuras (a) e a distância entre elas (c). 

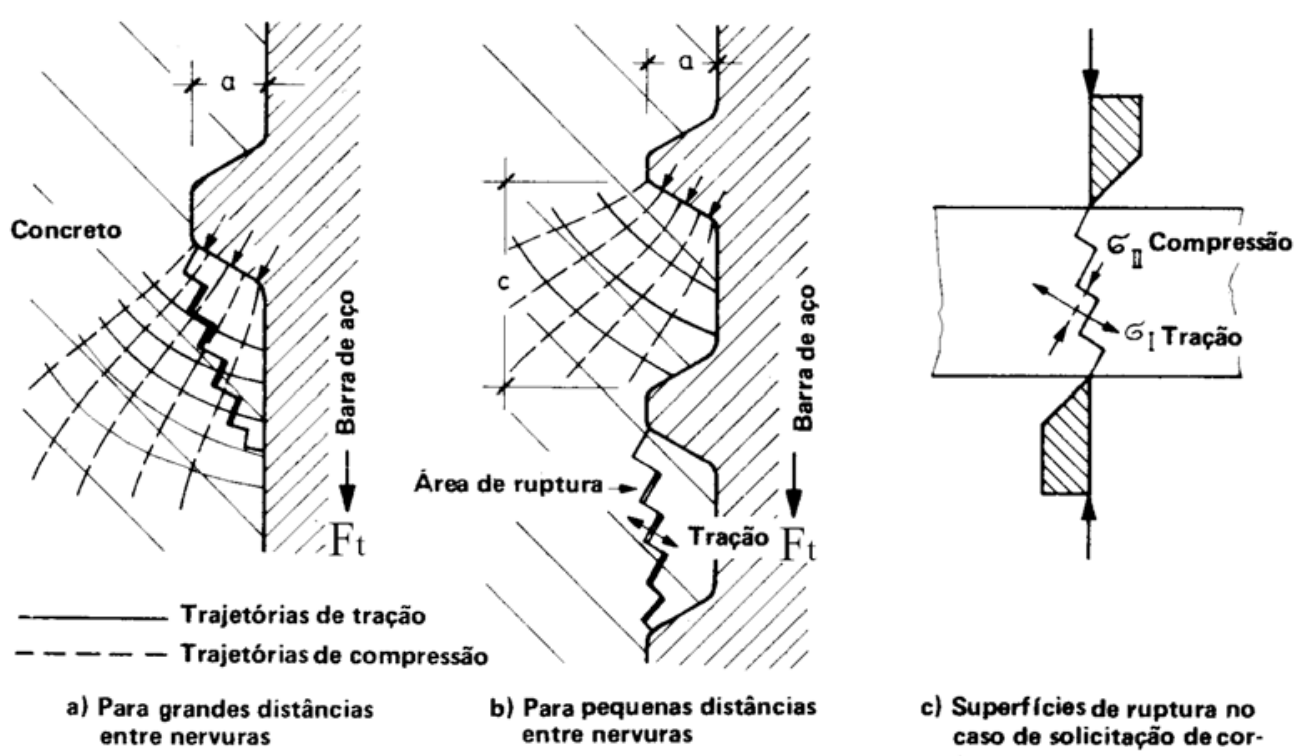

c) Superfícies de ruptura no caso de solicitação de cor-

Figura 2.19 - Variação das tensões principais e das superfícies de ruptura nos consolos de concreto (REHM ${ }^{3}$ apud LEONHARDT \& MÖNNIG, 1977)

Se as fissuras de cisalhamento, ou seja, as superfícies de ruptura dos consolos de concreto, ocorrerem somente em parte do comprimento, as forças de aderência serão aumentadas devido ao efeito de cunha. Entretanto, essa resistência somente é alcançada se o concreto circunvizinho à barra for relativamente espesso ou se existir suficiente confinamento promovido por armadura transversal.

A superfície de ruptura do consolo de concreto seccionado, no caso do concreto que é um material frágil, é uma superfície denteada, conforme mostrado na Figura 2.19. Essa superfície corresponde às direções das tensões principais de tração e compressão, a ruptura é iniciada através da ruptura por tração, na direção das tensões principais, produzindo deslocamento transversal com efeito de fendilhamento sobre o concreto envolvente, até que os "dentes" possam deslizar uns sobre os outros.

Atingida a tensão $\tau_{\mathrm{bu}}$, segundo TASSIOS (1979), o último mecanismo existente é o atrito concreto-concreto. Nessa situação o comportamento da aderência pode ser acompanhado por meio de ensaios de deformação controlada, nos quais

${ }^{3}$ REHM, G. (1969). Kriterien zur beurteilung von bewehrungsstäben mit hochwertigen verbund. Stahlbetonbau. Berlin, W. Ernst u. Sohn. p.79-96 apud LEONHARDT \& MÖNNIG (1977). 
observa-se abrupto decréscimo de tensões, até certo valor denominado tensão de aderência residual $\tau_{\mathrm{br}}$. No caso da tensão de aderência última ser acompanhada de fendilhamento total da peça de concreto, a tensão de aderência residual é quase nula e corresponde à situação representada pelo ramo CG da Figura 2.17.

Para todos os ramos descendentes da curva teórica $\tau_{\mathrm{b}}-\mathrm{s}$, há grande incerteza sobre o nível de resistência residual de aderência e a correspondente curva de transição. No entanto, TASSIOS (1979) apresenta na Figura 2.20 um possível modelo do mecanismo resistente de $\tau_{\mathrm{br}}$. Esse modelo representa situações com deslizamentos muito grandes, quando o fendilhamento não conduz à completa desintegração do concreto adjacente à barra; essa situação somente é possível por meio de um mínimo de armadura transversal.

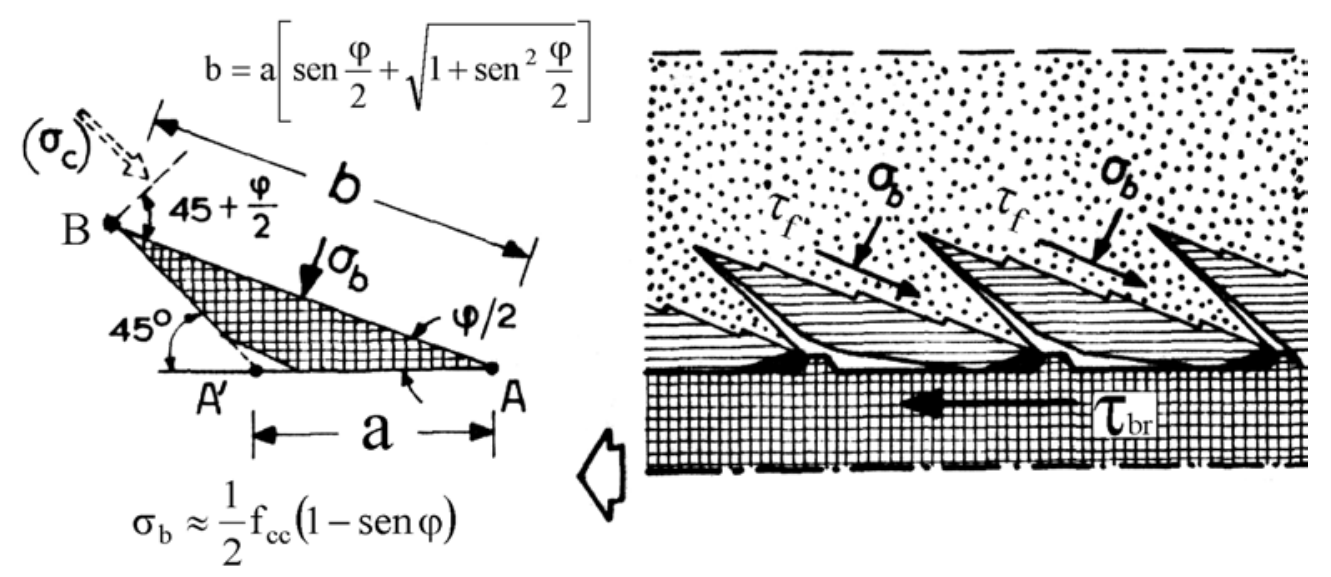

Figura 2.20 - Hipótese do mecanismo da resistência de aderência residual $\tau_{\mathrm{br}}$ (TASSIOS, 1979)

$\mathrm{Na}$ Figura 2.20 o "dente" de concreto formado, quase triangular, tem a tendência de se mover juntamente com a barra. O principal mecanismo de oposição a esse movimento é devido ao engrenamento concreto-concreto ao longo da fissura $\mathrm{AB}$, originada da ruptura das bielas de compressão.

Outro modelo que se pode apresentar é o exposto por ELIGEHAUSEN et al. (1983), que analisa, qualitativamente, o comportamento da aderência submetida a carregamento monotônico. Na Figura 2.21 o referido modelo é mostrado esquematicamente. 


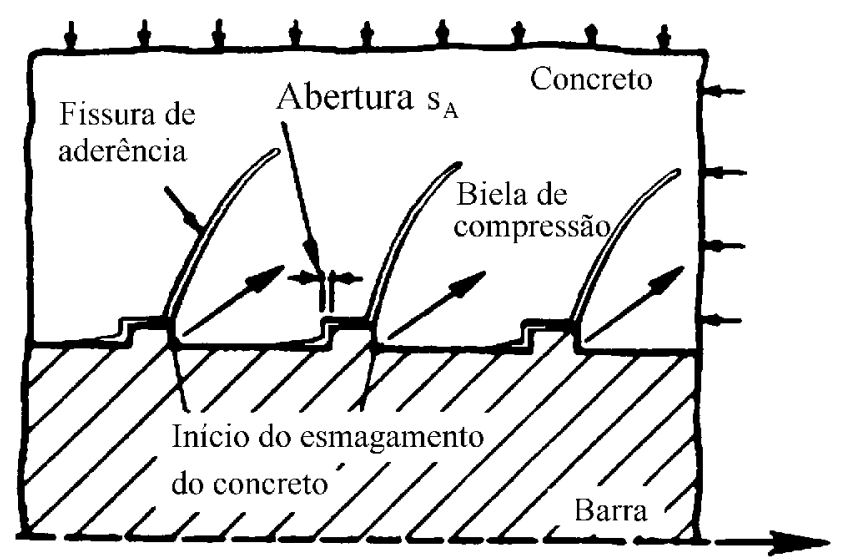

(a)

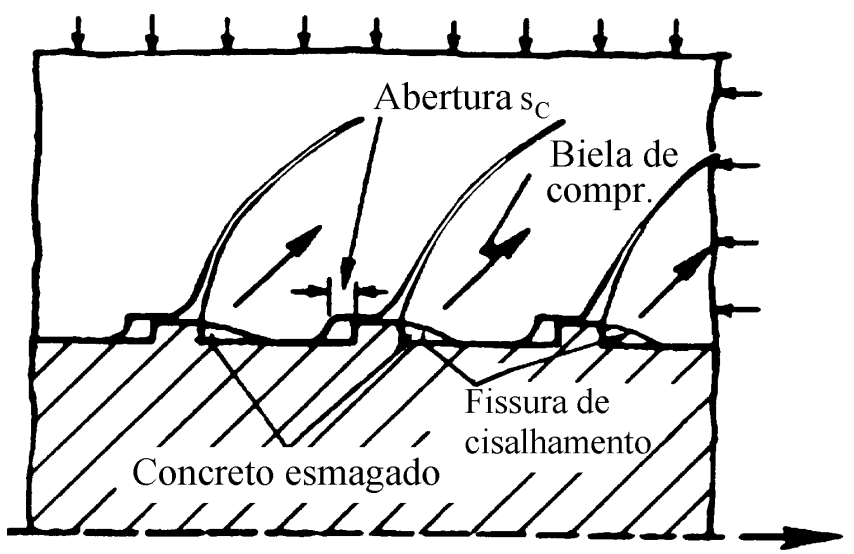

(b)

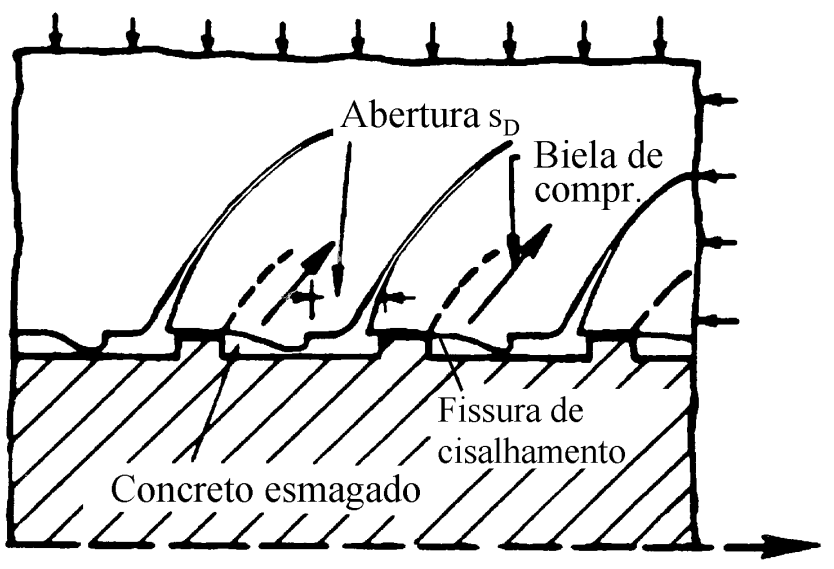

(c)
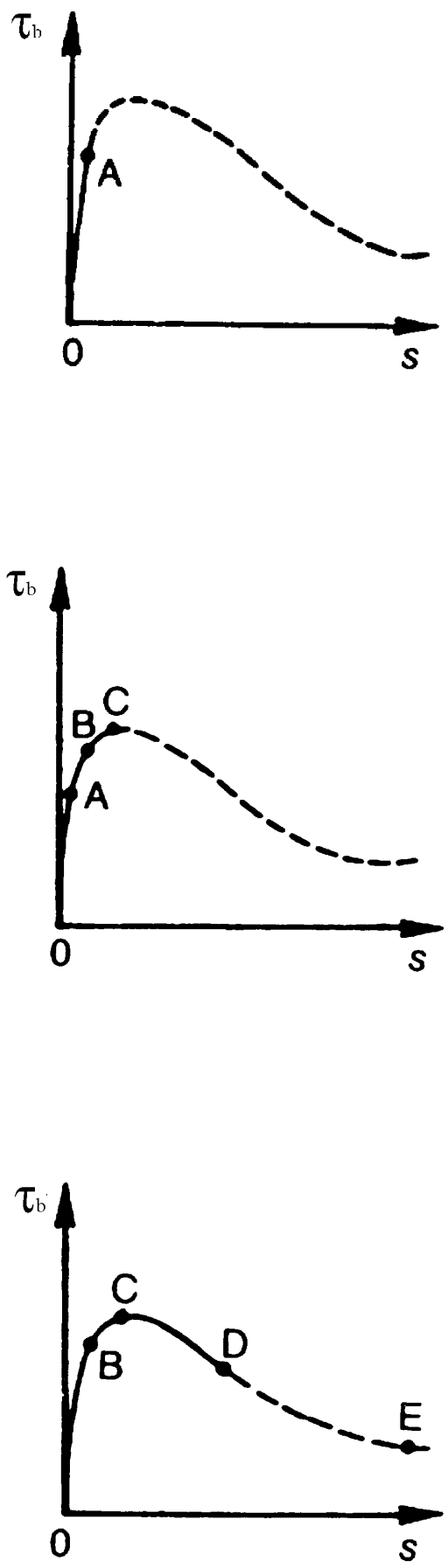

Figura 2.21 - Mecanismo de aderência sob carregamento monotônico (ELIGEHAUSEN et al., 1983)

Para pequenas tensões de aderência (ponto A), as fissuras de cisalhamento começam a se propagar a partir do topo das nervuras, seu crescimento e tamanho são 
controlados pela pressão de confinamento exercida, por exemplo, por armadura transversal. A transferência de forças ocorrerá principalmente pelo engrenamento mecânico, com um ângulo de inclinação baixo $\left(\approx 30^{\circ}\right)$.

Com aumento do carregamento, ocorre esmagamento local do concreto em frente às nervuras, reduzindo a inclinação da tangente à curva (ponto B). Quando é atingida a tensão de aderência última (ponto C) as fissuras de cisalhamento estendem-se ao longo de um comprimento aproximadamente igual a quatro vezes a altura da nervura. Neste estágio, a transferência de forças ocorre com um ângulo de aproximadamente $45^{\circ}$. A partir desse ponto, aumentando-se o deslizamento a tensão de aderência decresce lentamente.

Quando as fissuras de cisalhamento atingem a base da nervura adjacente (ponto D), as tensões de aderência decrescem um pouco mais rápidas. No momento em que o deslizamento torna-se igual ao espaçamento entre as nervuras, apenas uma parcela do atrito passa a mobilizar a aderência (ponto E).

De modo geral, a tensão de aderência última aumenta proporcionalmente com a resistência à compressão do concreto. Em investigação experimental com intuito de analisar os efeitos do confinamento e da resistência à compressão do concreto no comportamento local da aderência de barras nervuradas em nós de concreto armado, SOROUSHIAN et al. (1991) concluíram que a tensão de aderência última aumenta praticamente proporcional à raiz quadrada da resistência à compressão.

$\mathrm{Na}$ verdade, geralmente é admitido que a tensão de aderência última aumenta proporcionalmente à resistência à tração do concreto e proporcional à raiz quadrada da resistência à compressão $\left(\right.$ ou à $\left.\mathrm{f}_{\mathrm{cm}}^{2 / 3}\right)$. Para exemplificar esse fato, observe a seguinte expressão proposta por ELIGEHAUSEN et al. (1983).

$\tau_{\mathrm{bu}}=13,5 \cdot\left(\frac{\mathrm{f}_{\mathrm{cm}}}{30}\right)^{\zeta}$

onde $\zeta$ varia entre $1 / 2$ e $2 / 3$. DUCATTI (1993) salienta que se a ruptura da aderência ocorrer por arrancamento, a tensão de aderência última é proporcional à $\mathrm{f}_{\mathrm{cm}}{ }^{\zeta}$ com $\zeta$ variando entre 0,5 e 1,0 . 
A expressão 2.12 com $\zeta$ igual a 1/2 foi adotada pelo Código Modelo CEBFIP 1990 (CEB, 1991 Bulletin d'Information n.203-205), para a tensão de aderência última em concreto confinado em boas condições de aderência. Em caso de outras condições de aderência a tensão de aderência última é admitida como sendo $50 \%$ do valor da expressão 2.12 .

Para carregamento monotônico, as tensões de aderência entre o concreto e a armadura podem ser representadas pela curva da Figura 2.22 e calculadas em função do deslizamento relativo s, de acordo com as seguintes equações:

$$
\begin{array}{ll}
\tau_{\mathrm{b}}=\tau_{\mathrm{bu}} \cdot\left(\frac{\mathrm{s}}{\mathrm{s}_{1}}\right)^{\alpha} & \text { para } 0 \leq \mathrm{s} \leq \mathrm{s}_{1} \\
\tau_{\mathrm{b}}=\tau_{\mathrm{bu}} & \text { para } \mathrm{s}_{1}<\mathrm{s} \leq \mathrm{s}_{2} \\
\tau_{\mathrm{b}}=\tau_{\mathrm{bu}}-\left(\tau_{\mathrm{bu}}-\tau_{\mathrm{br}}\right) \cdot\left(\frac{\mathrm{s}-\mathrm{s}_{2}}{\mathrm{~s}_{3}-\mathrm{s}_{2}}\right) & \text { para } \mathrm{s}_{2}<\mathrm{s} \leq \mathrm{s}_{3} \\
\tau_{\mathrm{b}}=\tau_{\mathrm{br}} & \text { para } \mathrm{s}>\mathrm{s}_{3}
\end{array}
$$

onde:

$\tau_{\mathrm{bu}} \quad$ Tensão de aderência última;

$\alpha$ Coeficiente a ser escolhido no intervalo $0 \leq \alpha \leq 1$ conforme a forma de se considerar a relação $\tau_{b}-s$, começando com tensões de aderência constantes $(\alpha=0)$ até uma relação $\tau_{\mathrm{b}}-\mathrm{s}$ com incrementos lineares da tensão de aderência $(\alpha=1)$. 


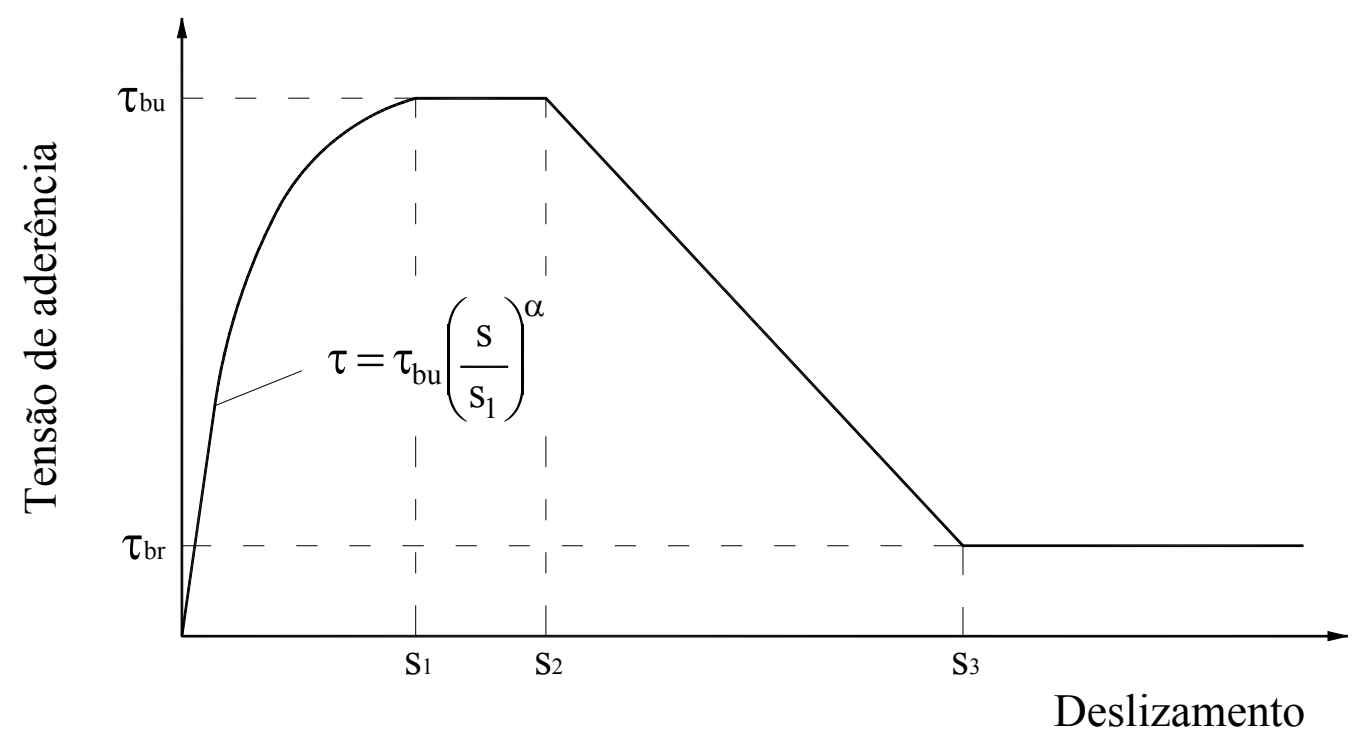

Figura 2.22 - Relação analítica entre tensão de aderência e deslizamento (Código Modelo CEB-FIP 1990)

Segundo o Código Modelo CEB-FIP 1990, o diagrama da Figura 2.22 pode ser considerado uma curva estatística média aplicável em grande número de casos. A primeira parte da curva refere-se ao estágio em que as nervuras penetram no concreto, caracterizado pelo esmagamento local e microfissuração. O patamar horizontal correspondente ao nível máximo de tensão, denominada tensão de aderência última $\tau_{\mathrm{bu}}$, que ocorre somente para concreto confinado, caracterizado pelo avançado estágio de esmagamento do concreto e pela ruptura por cisalhamento do concreto entre nervuras. $\mathrm{O}$ ramo descendente representa a redução da resistência de aderência devida à ocorrência de fissuras por fendilhamento ao longo da armadura. $\mathrm{O}$ ramo horizontal final corresponde à resistência residual, garantida com a colocação de armadura transversal, mantendo certo grau de integridade da aderência.

Com o aumento da área relativa da nervura $f_{R}$ a tensão $\tau_{b u}$ aumenta e o valor do deslizamento característico $\mathrm{s}_{1}$ diminui. Além disso, a rigidez do ramo ascendente da curva tensão de aderência versus deslizamento, depende do grau de confinamento do concreto. Entretanto, esses fatores foram desconsiderados.

Na Tabela 2.1 são apresentados os parâmetros utilizados nesse modelo, distinguidas duas situações conforme o modo de ruptura. 
Tabela 2.1 - Parâmetros para definição da relação tensão de aderência versus deslizamento em barras nervuradas

\begin{tabular}{|c|c|c|c|c|}
\hline \multirow{3}{*}{ Parâmetro } & \multicolumn{2}{|c|}{ Concreto não confinado $*$} & \multicolumn{2}{|c|}{ Concreto confinado $* *$} \\
\hline & \multicolumn{2}{|c|}{ Condições de aderência } & \multicolumn{2}{|c|}{ Condições de aderência } \\
\hline & 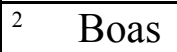 & ${ }^{3}$ Demais casos & Boas & ${ }^{5}$ Demais casos \\
\hline $\mathrm{s}_{1}$ & \multicolumn{2}{|c|}{$0,6 \mathrm{~mm}$} & \multicolumn{2}{|c|}{$1,0 \mathrm{~mm}$} \\
\hline $\mathrm{S}_{2}$ & \multicolumn{2}{|c|}{$0,6 \mathrm{~mm}$} & \multicolumn{2}{|c|}{$3,0 \mathrm{~mm}$} \\
\hline $\mathrm{s}_{3}$ & $1,0 \mathrm{~mm}$ & $2,5 \mathrm{~mm}$ & \multicolumn{2}{|c|}{ Espaço livre entre as nervuras } \\
\hline$\alpha$ & \multicolumn{2}{|r|}{0,4} & \multicolumn{2}{|c|}{0,4} \\
\hline$\tau_{\mathrm{bu}}$ & $2,0 \cdot \sqrt{f_{c k}}$ & $1,0 \cdot \sqrt{f_{c k}}$ & $2,5 \cdot \sqrt{f_{c l}}$ & $1,25 \cdot \sqrt{f_{c k}}$ \\
\hline$\tau_{\mathrm{br}}$ & $0,3 \cdot \sqrt{f_{c k}}$ & $0,15 \cdot \sqrt{f_{c k}}$ & $1,0 \cdot \sqrt{f_{c k}}$ & $0,5 \cdot \sqrt{f_{c k}}$ \\
\hline
\end{tabular}

* Ruptura por fendilhamento do concreto

** Ruptura por arrancamento da barra

Os valores das colunas 2 e 3 são válidos para cobrimento de concreto $\mathrm{C}=\phi$, e armadura transversal $\mathrm{A}_{\mathrm{st}}$ maior que o valor mínimo dado por:

$\mathrm{A}_{\mathrm{st}, \min }=0,25 \cdot \mathrm{n} \cdot \mathrm{A}_{\mathrm{s}}$

onde:

$\mathrm{A}_{\mathrm{st}} \quad$ Área de estribos, com dois ramos, contida no comprimento de ancoragem;

n Número de barras envolvidas pelos estribos;

$\mathrm{A}_{\mathrm{s}} \quad$ Área de uma barra.

As colunas 4 e 5 são válidas para concreto confinado (caracterizado por cobrimento $\mathrm{C} \geq 5 \cdot \phi$, espaçamento entre barras maior que $10 \cdot \phi$ ou armadura transversal regularmente espaçada com uma área $\mathrm{A}_{\mathrm{st}}>\mathrm{n} \cdot \mathrm{A}_{\mathrm{s}}$ ) ou com grande pressão transversal $(\mathrm{p} \geq 7,5 \mathrm{MPa}$ como pressão transversal média sob carga de projeto). 
Para situações de $\mathrm{A}_{\mathrm{st}, \min }<\mathrm{A}_{\mathrm{st}}<\mathrm{n} \cdot \mathrm{A}_{\mathrm{s}}$ ou $0<\mathrm{p}<7,5 \mathrm{MPa}$, os valores de $\mathrm{s}_{1}$, $\mathrm{s}_{3}, \tau_{\mathrm{bu}}$ e $\tau_{\mathrm{br}}$ podem ser interpolados linearmente, entre os valores para concreto confinado e não confinado. Se uma armadura transversal $\mathrm{A}_{\mathrm{st}}>\mathrm{A}_{\mathrm{st} \text {,min }}$ ocorrer simultaneamente com uma pressão transversal, os efeitos devem ser sobrepostos.

Os valores da Tabela 2.1 são válidos para trechos das barra que estão a uma distância $\mathrm{d}>5 \cdot \phi$ da fissura principal mais próxima. Para partes da barra de armadura que estão à distância $\mathrm{d} \leq 5 \cdot \phi$ dessa fissura, a tensão de aderência $\tau_{\mathrm{b}}$ e o deslizamento s devem ser reduzidos pelo fator $\lambda$, dado pela seguinte expressão:

$$
\lambda=0,2 \cdot \frac{\mathrm{d}}{\phi} \leq 1
$$

$\mathrm{Na}$ Tabela 2.2 estão apresentados os parâmetros válidos para barras lisas, tanto para concreto confinado quanto para não confinado.

Tabela 2.2 - Parâmetros para definição da relação tensão de aderência versus deslizamento de barras lisas

\begin{tabular}{|c|c|c|c|c|}
\hline \multirow{3}{*}{ Parâmetro } & \multicolumn{2}{|c|}{ Aço trefilado a frio } & \multicolumn{2}{|c|}{ Aço laminado a quente } \\
\hline & \multicolumn{2}{|c|}{ Condições de aderência } & \multicolumn{2}{|c|}{ Condições de aderência } \\
\hline & Boas & Demais casos & Boas & Demais casos \\
\hline $\mathrm{s}_{1}=\mathrm{s}_{2}=\mathrm{s}_{3}$ & \multicolumn{2}{|c|}{$0,01 \mathrm{~mm}$} & \multicolumn{2}{|c|}{$0,1 \mathrm{~mm}$} \\
\hline$\alpha$ & \multicolumn{2}{|c|}{0,5} & \multicolumn{2}{|r|}{0,5} \\
\hline$\tau_{\mathrm{bu}}=\tau_{\mathrm{br}}$ & $0,1 \cdot \sqrt{\mathrm{f}_{\mathrm{ck}}}$ & $0,05 \cdot \sqrt{f_{c k}}$ & $0,3 \cdot \sqrt{f_{c k}}$ & $0,15 \cdot \sqrt{f_{c k}}$ \\
\hline
\end{tabular}

Os valores das Tabelas 2.1 e 2.2 são aplicáveis somente para estados de tensão nos quais o concreto não está sujeito à tração lateral.

O Código Modelo CEB-FIP 1990 ressalta que é considerável a dispersão entre diferentes séries de ensaios, especialmente para pequenos valores de deslizamentos. Pode haver variações de tensões de aderência em até 30\%. Essa dispersão é devida ao uso de diferentes corpos-de-prova nos ensaios, que criam diferentes estados de tensão no concreto circunvizinho à barra, às diferentes técnicas 
de medidas e às diferentes velocidades de carregamento e de deformação. A heterogeneidade do concreto e a geometria das barras da armadura têm, também, influência significativa na relação $\tau_{b}$-s. Assim, deve-se levar em consideração essa dispersão, pelo menos onde seja necessária maior precisão.

\subsubsection{ADERÊNCIA SOB COMPRESSÃO}

No caso da ancoragem de barras comprimidas, devido à própria compressão longitudinal da peça, existe maior integridade do concreto. Em principio, de acordo com o CEB (1982) Bulletin d'Information n.151, são verificados os mesmos estágios do comportamento da aderência para barras de armaduras comprimidas. No primeiro estágio há pequena diferença na adesão conforme a armadura esteja tracionada ou comprimida. Quanto ao atrito, nos casos de compressão, devido ao efeito de POISSON, são mobilizadas deformações laterais no concreto e no aço que aumentam a pressão interfacial e, conseqüentemente, há melhoria na performance da aderência. Este efeito é diminuído tão logo tenha inicio o engrenamento mecânico e se desenvolva a fissuração longitudinal.

Quando se solicita a barra à compressão paralela ao seu eixo, a fissuração de aderência é controlada e a resistência ao fendilhamento do cobrimento de concreto diminui. Portanto, a ruptura à compressão da aderência geralmente é devida à ruptura do apoio das nervuras da barra no concreto. Esse modo de ruptura é caracterizado pela formação de fissuras de cisalhamento que produzem "dentes" de concreto nos apoios de cada nervura. Quando o fendilhamento do concreto é controlado pela presença de intenso confinamento devido à armadura, é alcançada a ruptura total, como no caso das barras tracionadas, ou seja, pelo corte ou cisalhamento do concreto, entre as nervuras.

De acordo com o raciocínio acima, sob as mesmas condições, a curva tensão de aderência versus deslizamentos de barras tracionadas e comprimidas, para tensões na armadura abaixo do escoamento, não devem ser muito diferentes; a ruptura é devida ao corte do concreto entre as nervuras. Isso foi comprovado de forma teórica 
e experimental, respectivamente, por ELIGEHAUSEN et al. (1983) e REHM ${ }^{4}$ apud CEB (1982) Bulletin d'Information n.151. Entretanto, se a armadura atingir o escoamento, o comportamento da aderência pode ser significativamente diferente, devido ao efeito de POISSON, que reduz o diâmetro das barras tracionadas e aumenta, significativamente, a pressão interfacial no caso de barras comprimidas (VIWATHANATEPA et al. ${ }^{5}$ apud CEB, 1982 Bulletin d'Information n.151).

Outro ponto a ser realçado, segundo o CEB (1982) Bulletin d'Information n.151, é o fato de a ancoragem comprimida ser intensificada pelo efeito de ponta da barra, no concreto. Isto porque, neste caso, a resistência do concreto assume valores muito grandes devido ao carregamento de uma área parcial muito pequena. A ruptura do apoio da ponta das barras é devida ao esmagamento do concreto, onde há suficiente confinamento, ou à ação simultânea do puncionamento do concreto sob influência do efeito de ponta e do fendilhamento do concreto circunvizinho à barra.

\subsection{FATORES QUE INFLUENCIAM COMPORTAMENTO DA ADERÊNCIA}

O comportamento da aderência depende de uma variedade de fatores físicos e mecânicos, os quais referem-se, basicamente, à armadura, ao concreto e ao estado de tensão de ambos os materiais. Esses fatores influenciam a resistência e a ductilidade das ancoragens, tanto no estado limite último quanto no estado limite de serviço.

O Código Modelo CEB-FIP (1990) faz uma distinção entre fatores relativos ao comportamento local da aderência e fatores relacionados à resposta global. O comportamento local da aderência é controlado pelas condições básicas de aderência como, por exemplo, posição de concretagem e direção relativa do carregamento com

4 REHM, G. (1961). Über die grundlagen des verbundes zwischen stahl und beton. Deutscher Ausschuss für Stahlbeton. Heft 138, p.59 apud CEB (1982) Bulletin d'Information n.151.

${ }^{5}$ VIWATHANATEPA, S.; POPOV, E.P.; BERTERO, V.V. (1979). Effects of generalized loadings on bond of reinforcing bars embedded in well confined concrete. Report n.UCB/EERC 79-22, Earthquake Engineering Research Center. University of California, Berkeley, Aug. apud CEB (1982) Bulletin d'Information n.151. 
direção de concretagem. O comportamento global de uma região de ancoragem é influenciado por vários fatores relacionados ao seu confinamento, como arranjo transversal das barras ancoradas e arranjo da armadura transversal.

$\mathrm{Na}$ seqüência, são enumerados os principais fatores que governam o comportamento da aderência (local e global), e nos próximos itens serão fornecidos maiores detalhes de alguns desses fatores.

a. Propriedades do concreto (resistência, composição granulométrica);

b. Conformação superficial da barra da armadura (lisa, nervurada, tipo e geometria das nervuras, estado da superfície das barras);

c. Classe do aço;

d. Tensão de escoamento do aço (se houver escoamento da armadura);

e. Número de barras em uma mesma camada;

f. Inclinação das barras durante a concretagem (vertical, inclinada, horizontal);

g. Posição das barras na seção de concreto durante a concretagem (em cima, no centro, embaixo);

h. Relação entre direção da concretagem e direção do carregamento (deslizamento na mesma direção ou em direção oposta à concretagem);

i. Cobrimento e espaçamento das barras da armadura (arranjo transversal das barras ancoradas);

j. Quantidade e posição da armadura transversal;

k. Comprimento de ancoragem;

1. Tipo, velocidade e duração do carregamento;

m. Número de ciclos e amplitude do carregamento cíclico;

n. Temperatura.

\subsubsection{RESISTÊNCIA DO CONCRETO}

Em situações onde ocorre completo fendilhamento, o comportamento da aderência é fortemente influenciado pela capacidade de confinamento do concreto circunvizinho à barra e, portanto, influenciado pela resistência à tração do concreto. 
A ruptura por fendilhamento ocorre justamente quando as tensões circunferenciais de tração alcançam ou excedem a resistência à tração do concreto.

A resistência à compressão é importante para resistir às forças diagonais, exercidas pelas nervuras.

\subsubsection{RETRAÇÃO DO CONCRETO}

A retração do concreto cria tensões de compressão transversais à armadura. Essa compressão resulta do impedimento da deformação do concreto, causado pela presença da barra. Por equilíbrio, as tensões de compressão criam tensões de tração longitudinal na região de ancoragem da armadura, que aumenta o efeito de fendilhamento decorrente das forças de ancoragem e pode diminuir a tensão de aderência última.

\subsubsection{PRESSÃO TRANSVERSAL SOBRE A BARRA}

A pressão transversal pode ser devida à retração do concreto ou ao efeito de confinamento exercido pela armadura ou pelo próprio concreto. A compressão transversal à armadura tem efeito duplamente favorável no comportamento da aderência: aumenta a resistência de aderência por atrito e compensa os esforços circunferenciais de tração, gerados pela ligação dos dois materiais e, assim, retarda a ruptura por fendilhamento.

Em concretos usuais, o comportamento da aderência e a tensão de aderência última são consideravelmente influenciados pelo grau de confinamento do concreto adjacente à barra. De acordo com UNTRAUER \& HENRY (1965), a ação de forças de compressão transversal majora a capacidade última de resistência ao arrancamento da armadura e diminui o deslizamento para determinado carregamento, ou seja, aumenta também a rigidez de aderência. Entretanto, a tensão de aderência última aumenta com o aumento do confinamento até certo limite, além desse ponto, o grau de confinamento não tem nenhum efeito. 


\subsubsection{ARMADURA DE CONFINAMENTO}

Esse tipo de armadura é recomendável, e pode ser constituída por barras retas, estribos ou espirais. A eficácia dessa armadura depende do tipo, quantidade e posição em relação à barra ancorada, assim como do modo de ruptura.

A influência da armadura de confinamento é maior quando ela cruza as fissuras por fendilhamento e restringe suas aberturas. No entanto, não é muito significativa a influência dessa armadura na resistência última de aderência, caso ocorra ruptura por arrancamento, e na resistência de aderência residual (ELIGEHAUSEN et al., 1983).

\subsubsection{COBRIMENTO E ESPAÇAMENTO DAS BARRAS DA} ARMADURA

A influência do cobrimento da armadura e do espaçamento entre suas barras, está associada ao confinamento pelo concreto, sendo a utilização de valores adequados essenciais para se evitar a ruptura por fendilhamento. De acordo com a FIB (2000) Bulletin n.10, sem pressão transversal decorrente de cargas externas ou reações de apoio, ou sem armadura transversal suficiente, um cobrimento de aproximadamente três vezes o diâmetro da barra parece ser necessário para admitir ruptura por arrancamento, tanto para concreto usual quanto para CAD.

\subsubsection{DIÂMETRO DA BARRA}

Como existe relação direta entre força de tração na armadura e área de sua seção transversal, e como a força de aderência entre aço e concreto depende do perímetro da armadura, é indispensável haver adequada relação área-perímetro. Haja vista que o perímetro é função linear do diâmetro e a área é função quadrática do mesmo. Além disso, a seção circular é a de maior área para dado perímetro. 
Desta forma, as barras com diâmetros menores têm melhor comportamento que as barras mais grossas. Outra explicação sugerida por SOROUSHIAN \& CHOI (1989) seria volume maior de material poroso na interface entre concreto e aço, nas barras de maior diâmetro. Entretanto, o diâmetro da barra tem pouca influência sobre a resistência de aderência, conforme mostra a Figura 2.23.

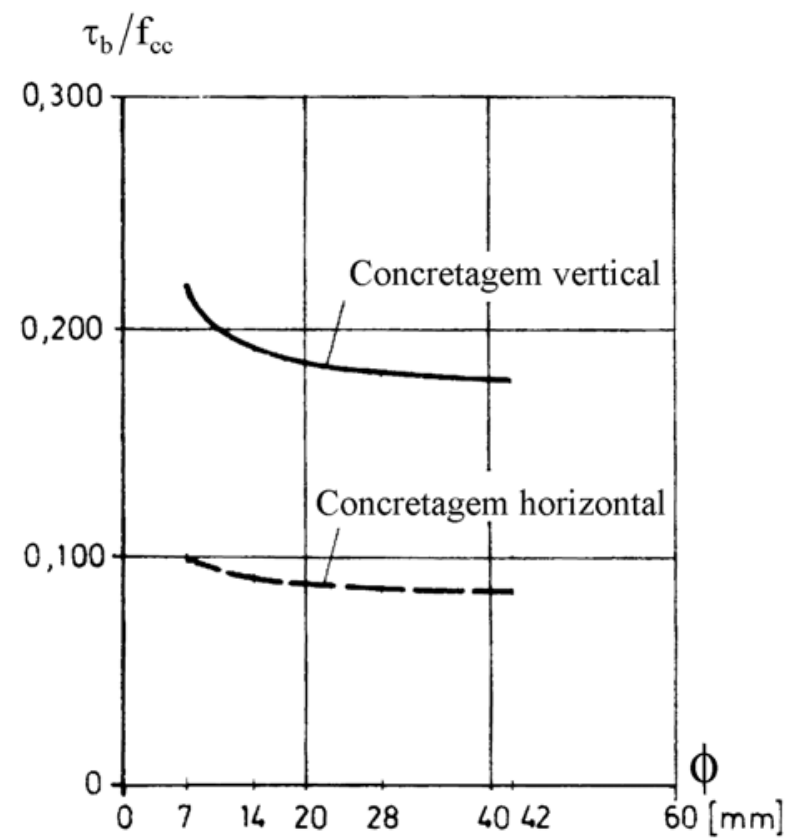

Figura 2.23 - Influência do diâmetro da barra na resistência de aderência (REHM ${ }^{3}$ apud LEONHARDT \& MÖNNIG, 1977)

\subsubsection{POSIÇÃO E INCLINAÇÃO DAS BARRAS DURANTE A CONCRETAGEM}

A posição e a inclinação das barras durante a concretagem influenciam significativamente o comportamento da aderência. A resistência e a rigidez de aderência são maiores para barras concretadas na posição vertical e carregadas na direção contrária ao lançamento do concreto e para barras concretadas na posição horizontal, mas não muito acima da face inferior da peça. Barras concretadas na vertical e carregadas na direção de concretagem e barras horizontais bem acima da 
face inferior da peça apresentam comportamento da aderência inferior ao do primeiro grupo.

Isso é devido, principalmente, à exsudação do excesso de água de amassamento, que acarreta a formação de poros devido ao acúmulo de água na metade inferior das barras horizontais e debaixo das nervuras nas barras verticais. Para as barras horizontais, o efeito pode ser intensificado, pois quanto mais distante da face inferior da peça maior o efeito da exsudação. Outro fato a ser considerado é o melhor adensamento do concreto nas camadas inferiores da peça, que contribui para melhor aderência. Quanto às barras verticais, como há formação de poros debaixo das nervuras, se essas barras estiverem carregadas na direção de concretagem haverá redução na altura efetiva dos "consolos" de concreto formados pela mobilização da aderência.

Segundo MARTIN \& NOAKOWSKI ${ }^{6}$ apud CEB (1982) Bulletin d'Information n.151, a relação entre tensão de aderência de barras moldadas verticalmente e carregadas na direção contrária à concretagem e tensão de aderência de barras moldadas horizontalmente no meio de modelos com $200 \mathrm{~mm}$ de altura é, aproximadamente, 2,2 para pequenos valores de deslizamentos e próximo de 1,5 para o carregamento último.

${ }^{6}$ MARTIN, H.; NOAKOWSKI, P. (1981). Verbundverhalten von betonstählen, untersuchungen auf der grundlage von ausziehversuchen. Deutscher Ausschuss für Stahlbeton. Heft 319 apud CEB (1982) Bulletin d'Information n.151. 


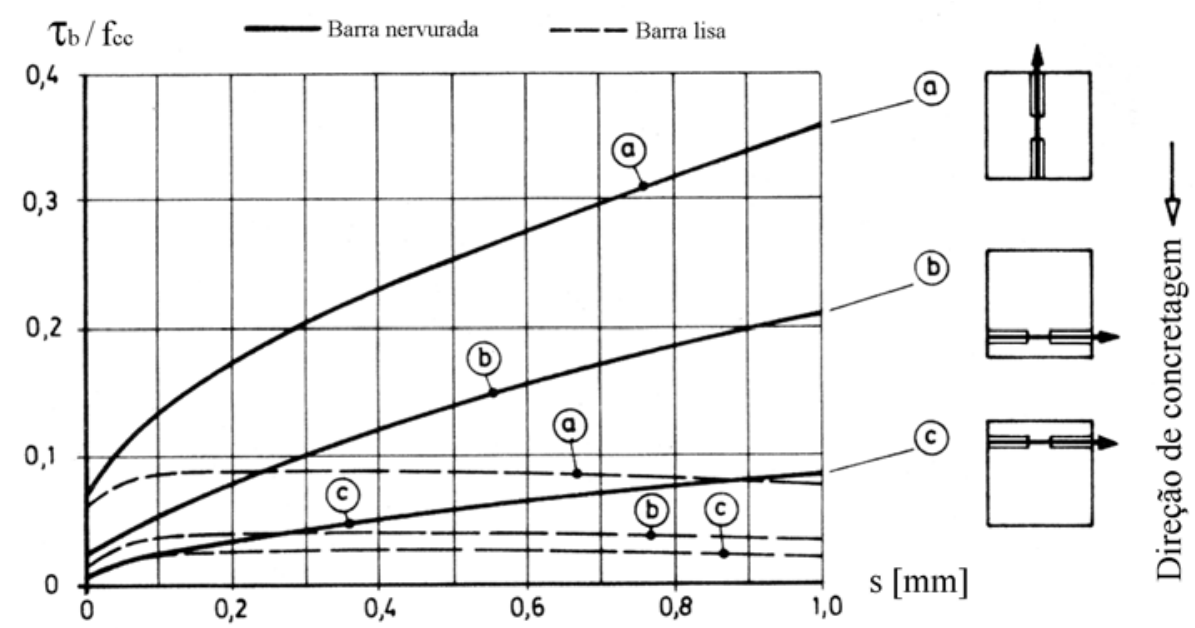

Figura 2.24 - Influência da posição da barra sobre o comportamento local da aderência

(LEONHARDT \& MÖNNIG, 1977)

\subsubsection{TIPO E GEOMETRIA DAS NERVURAS}

Segundo FUSCO (1976), as nervuras são elementos descontínuos de ligação. Entretanto, devido a seu grande número e seu pequeno afastamento relativo, tudo se passa como se houvesse ligação contínua de características melhoradas. Essas nervuras são indispensáveis para que se possam aproveitar as resistências mais elevadas do aço, assegurando uma ligação aço-concreto mais efetiva e confiável.

Entretanto, a eficácia das barras nervuradas é maior em relação ao problema de ancoragem que em relação à fissuração.

Conforme sua posição em relação ao eixo da barra, as nervuras são de dois tipos: longitudinais, paralelas ao eixo da barra, e transversais ou oblíquas, inclinadas em relação ao mencionado eixo.

As nervuras transversais são as mais importantes; têm a função de promover o engrenamento mecânico responsável por parcela da resistência de aderência. É possível grande combinação entre forma, inclinação e espaçamento das nervuras oblíquas. As nervuras longitudinais têm a função de impedir o giro da barra dentro do concreto. De acordo com a NBR 7480/1996, as barras devem ter pelo menos duas nervuras longitudinais contínuas e diametralmente opostas, exceto no caso em que as 
nervuras transversais estejam dispostas de forma a se oporem ao giro da barra dentro do concreto.

De modo geral, com o intuito de garantir um desempenho satisfatório das barras no concreto armado, as normas especificam parâmetros como forma e dimensões das nervuras, espaçamento entre elas e inclinação de suas faces e de seu eixo em relação ao corpo da barra.

Com o objetivo de parametrizar a influência do padrão das nervuras sobre o comportamento local da aderência, existe o parâmetro $f_{R}$ denominado área relativa da nervura. Esse parâmetro $f_{R}$ é definido como o quociente entre a área da nervura projetada na direção longitudinal da barra e a superfície lateral da barra. O método mais refinado para calcular a área relativa da nervura $f_{R}$ é apresentado pela FIB (1999) Bulletin n.1, sendo representado pela seguinte expressão:

$\mathrm{f}_{\mathrm{R}}=\frac{1}{\pi \cdot \phi} \cdot \sum_{\mathrm{n}=1}^{\mathrm{k}} \frac{\frac{1}{\mathrm{~m}} \cdot \sum_{\mathrm{l}=1}^{\mathrm{m}} \mathrm{F}_{\mathrm{R}(\mathrm{n}, \mathrm{l})} \cdot \operatorname{sen} \beta_{\mathrm{s}(\mathrm{n}, \mathrm{l})}}{\mathrm{c}_{(\mathrm{n})}}+\frac{1}{\mathrm{j} \cdot \phi} \cdot \sum_{\mathrm{n}=1}^{\mathrm{i}} \mathrm{a}_{\ell(\mathrm{n})}$

onde:

$\phi \quad$ Diâmetro da barra;

$\beta_{\mathrm{s}} \quad$ Ângulo de inclinação do eixo da nervura transversal em relação ao eixo da barra;

c Espaçamento entre nervuras transversais, ou seja, a distância entre os centros de duas nervuras transversais consecutivas mensurada paralelamente ao eixo da barra;

$\mathrm{a}_{\ell} \quad$ Altura da nervura longitudinal;

j Comprimento do passo da nervura longitudinal;

$\mathrm{k} \quad$ Número de fileiras de nervuras transversais no perímetro da barra;

m Número de nervuras transversais em uma fileira, mensurado ao longo de um determinado comprimento;

i Número de nervuras longitudinais; 
$\mathrm{F}_{\mathrm{R}} \quad$ Área de projeção de uma nervura transversal sobre o plano de inclinação do eixo desta nervura, definido como (ver Figura 2.25):

$\mathrm{F}_{\mathrm{R}}=\sum_{\mathrm{n}=1}^{\mathrm{q}}\left(\mathrm{a}_{\mathrm{n}} \cdot \Delta \ell\right)$

onde:

q Número de segmentos em que a nervura transversal considerada foi dividida;

$\Delta \ell \quad$ Comprimento de cada segmento da nervura transversal no eixo desta nervura;

$\mathrm{a}_{\mathrm{n}}$ Altura da nervura transversal no ponto médio do segmento da nervura transversal considerada.
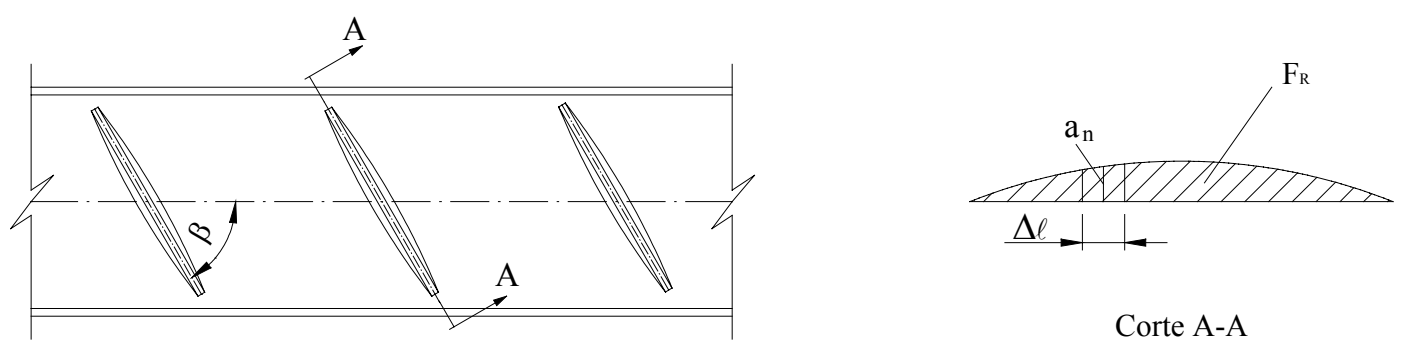

Figura 2.25 - Parâmetros geométricos da barra

A forma mais simples em que a área relativa da nervura $f_{R}$ pode ser calculada é:

$\mathrm{f}_{\mathrm{R}}=\frac{\gamma \cdot \mathrm{a}}{\mathrm{c}}$

onde:

$\gamma \quad$ Constante geométrica da barra (normalmente igual a 0,5 )

a Altura da nervura transversal, isto é, distância do ponto mais alto da nervura até a superfície do núcleo da barra, mensurado normalmente ao eixo da barra;

c Espaçamento da nervura transversal. 
Quanto ao comportamento da aderência, é possível obter através do parâmetro $f_{R}$, medida de comparação entre barras de perfis diferentes. Contudo, o uso desse parâmetro deve ser criterioso, porque usado como único critério pode conduzir a objetivos contraproducentes como, por exemplo, escolha de barras com forte efeito do fendilhamento em detrimento daquelas com melhor desempenho a esse fenômeno. Isso porque é possível grande combinação entre forma, inclinação e espaçamento das nervuras.

MARTIN \& NOAKOWSKI ${ }^{6}$ apud CEB (1982) Bulletin d'Information n.151 constataram, através de grande número de ensaios, que quando se aumenta o parâmetro $f_{R}$ a resistência e a rigidez de aderência também são aumentadas. No entanto, a aderência se torna mais frágil, porque a carga última é alcançada para deslizamentos cada vez menores.

Segundo MARTIN ${ }^{7}$ apud CEB (1982) Bulletin d'Information n.151, o aumento no valor de $\mathrm{f}_{\mathrm{R}}$ também aumenta consideravelmente a fissuração de fendilhamento. Valores de $\mathrm{f}_{\mathrm{R}}$ entre 0,05 e 0,08 são mais apropriados do ponto de vista da resistência de aderência e fissuração por fendilhamento.

Se o valor de $\mathrm{f}_{\mathrm{R}}$ for mantido constante, a altura da nervura e a distância entre elas pode ser modificada sem que haja significativa influência no comportamento da aderência (SORETZ \& HÖLZENBEIN, 1979 e REHM ${ }^{8}$ apud CEB, 1982 Bulletin d'Information n.151).

Da mesma forma, os autores supracitados constataram que no intervalo de $45^{\circ}$ a $90^{\circ}$, a inclinação das nervuras em relação ao eixo da barra não influencia, consideravelmente, o comportamento da aderência.

Variando a inclinação das faces da nervura em relação à superfície da barra no intervalo de $45^{\circ}$ a $90^{\circ}$, ou seja, variando a seção transversal da nervura de um retângulo a um trapézio com faces inclinadas de $45^{\circ}$, também não haverá influência

7 MARTIN, H. (1973). Zusammenhang zwischan oberflächenbeschaffenheit, verbund und springwirkung von bewehrungsstählen unter kurzzeitbelastungen. Deutscher Ausschuss für Stahlbeton. Heft 228 apud CEB (1982) Bulletin d'Information n.151.

${ }^{8}$ REHM, G. (1961). Über die grundlagen des verbundes zwischen stahl und beton. Deutscher Ausschuss für Stahlbeton. Heft 138, p.59 apud CEB (1982) Bulletin d'Information n.151. 
significativa no comportamento da aderência (LUTZ \& GERGELY, 1967; SORETZ \& HÖLZENBEIN, 1979 e REHM ${ }^{8}$ apud CEB, 1982 Bulletin d'Information n.151).

SORETZ \& HÖLZENBEIN (1979) estudaram a possibilidade da redução simultânea da altura das nervuras e da distância entre elas, mantendo-se constante o valor de $\mathrm{f}_{\mathrm{R}}$. Isso porque obteriam uma situação mais favorável do ponto de vista do efeito de fendilhamento, além de facilitar o processo de laminação. De modo geral, essa situação não modifica o comportamento da aderência, no entanto, a influência da posição da barra, durante a concretagem, aumenta com a diminuição da altura das nervuras (REHM ${ }^{8}$ apud CEB, 1982 Bulletin d'Information n.151).

A geometria e o tamanho das nervuras influenciam não somente a capacidade de aderência, mas também a flexibilidade das barras, ou seja, a capacidade de dobramento.

SORETZ \& HÖLZENBEIN (1979) mostraram que a flexibilidade em barras nervuradas diminui quando se aumenta a altura das nervuras. A flexibilidade é melhorada quando o ângulo de inclinação das nervuras em relação ao eixo das barras decresce. Uma boa flexibilidade é alcançada para inclinações desse ângulo no intervalo entre $65^{\circ}$ e $55^{\circ}$.

Esse fato também é ressaltado por LEONHARDT \& MÖNNIG (1977) quando os mesmos enfatizam que nervuras transversais com inclinação de $60^{\circ}$, em relação ao eixo da barra, são mais favoráveis que nervuras perpendiculares. Também é ressaltada a necessidade de, em toda a seção transversal, as nervuras oblíquas não estarem ligadas às nervuras longitudinais, devendo terminar antes destas.

É interessante mencionar que a NBR 7480/1996 prescreve que os eixos das nervuras transversais devem formar, com a direção do eixo da barra, um ângulo igual ou superior a $45^{\circ}$. 


\subsubsection{TEMPERATURA}

O efeito térmico na resistência de aderência foi estudado por HERTZ ${ }^{9}$ apud CEB (1982) Bulletin d'Information n.151. Até certo nível de temperatura, a resistência de aderência acompanha a redução da resistência à compressão. Acima de $400^{\circ} \mathrm{C}$ a resistência de aderência é reduzida em comparação à resistência de compressão. A relação entre resistência de aderência e resistência à compressão reduz de $65 \%$ a $400^{\circ} \mathrm{C}$ para $35 \%$ a $600^{\circ} \mathrm{C}$ e, para esta temperatura, a resistência à compressão é aproximadamente $10 \%$ da resistência em temperaturas normais. Entre $600^{\circ} \mathrm{C}$ e $800^{\circ} \mathrm{C}$ a resistência de aderência é praticamente nula.

\subsection{ENSAIOS DE ADERÊNCIA}

\subsubsection{GENERALIDADES}

No estudo da aderência entre concreto e armadura, podem ser considerados dois problemas distintos: o problema de ancoragem das armaduras e o problema da fissuração das peças de concreto.

Nas ancoragens por aderência, o ponto fundamental é determinar o comprimento necessário para que haja transferência dos esforços da armadura para o concreto, mantendo-se a integridade do concreto na região da ancoragem, a resistência e a rigidez da barra aos esforços para os quais foi calculada no trecho em que está integralmente ancorada, e a resistência das barras remanescentes no trecho em que a barra ancorada foi suprimida.

Quanto à fissuração das peças de concreto armado, objetiva-se a manutenção das aberturas das fissuras abaixo de limites aceitáveis.

${ }^{9}$ HERTZ. K. (1980). Armeringsstäls forankring ved höje temperaturer. Instituttet for husbygning, Danmarks Tekniske Höjskole, Rapport n.138. Lyngby. p.103 apud CEB (1982) Bulletin d'Information n.151. 
Dessa forma, é preciso que os ensaios sejam procedidos atentando-se às peculiaridades do fenômeno que se quer estudar. A seguir, nos próximos itens deste trabalho, serão apresentados os principais ensaios de aderência.

\subsubsection{ENSAIO DE ARRANCAMENTO}

Tendo em vista a ancoragem das barras de aço, a determinação da resistência de aderência normalmente é feita por meio de ensaios de arrancamento. Os resultados desses ensaios usualmente são apresentados na forma de curvas $\tau_{\mathrm{b}}-\mathrm{s}$, onde a tensão de aderência e o deslizamento são mensurados na extremidade livre da barra. Vários tipos de ensaios de arrancamento com pequenos comprimentos de ancoragem foram feitos com o intuito de estimar essa relação local para vários tipos de armadura e resistências do concreto.

Normalmente, os cobrimentos de concreto nesses modelos eram suficientemente espessos para prevenir fissuras de fendilhamento ao longo dos espécimes, ou seja, as condições de aderência eram estudadas sob um razoável grau de confinamento, embora essa situação nem sempre seja alcançada, especialmente quando se adotam as mesmas dimensões para modelos de arrancamento com barras de grandes diâmetros.

Tendo em vista as dimensões do modelo, é difícil medir a variação de tensão ao longo do comprimento de aderência. Em aproximações tradicionalmente adotadas no dimensionamento de regiões de ancoragem, assume-se que na ruptura as tensões de aderência são uniformemente distribuídas ao longo do comprimento de ancoragem. Essa hipótese é razoável do ponto de vista prático, simplificando o modelo de cálculo. Em aplicações usuais sob confinamento moderado, essa hipótese tem certo respaldo em relação ao comportamento real da ancoragem. Quando forças mobilizadas pela aderência aumentam, desenvolvem-se ao longo das barras ancoradas, fissuras radiais e longitudinais. Isso resulta em perda de rigidez do concreto adjacente à barra e uma redistribuição de tensões na região de ancoragem. As tensões de aderência serão cada vez mais uniformemente distribuídas antes da ruptura. Além disso, em ensaios de arrancamento com pequenos comprimentos de 
ancoragem assume-se que a distribuição de tensões de aderência é sempre uniforme, pois o comprimento de ancoragem é razoavelmente pequeno em relação ao espaçamento entre as nervuras transversais.

Os resultados dos ensaios de arrancamento geralmente são representados por valores médios da tensão de aderência, supondo-se que, na iminência do arrancamento, todo o comprimento da barra transferiu a tensão nela atuante para a massa de concreto. Dessa forma, a capacidade de aderência admitida para determinada situação é bem menor que a tensão de aderência que pode ser obtida dentro desses pequenos comprimentos de ancoragem. Portanto, esses valores médios, são dados pela seguinte expressão:

$$
\tau_{\mathrm{b}}=\frac{\mathrm{F}_{\mathrm{t}}}{\mathrm{u} \cdot \ell}
$$

onde:

$\tau_{\mathrm{b}} \quad$ Tensão de aderência média;

$\mathrm{F}_{\mathrm{t}} \quad$ Intensidade da força que solicita a barra;

u Perímetro da barra envolvida pelo concreto;

$\ell \quad$ Comprimento de ancoragem.

Segundo LEONHARDT \& MÖNNIG (1977), a resistência de aderência de cálculo $\mathrm{f}_{\mathrm{bd}}$ é definida como a tensão de aderência $\tau_{1 \mathrm{R}}$ para a qual ocorre um deslizamento na extremidade livre da barra de $0,1 \mathrm{~mm}$. Assim, a resistência $\mathrm{f}_{\mathrm{bd}}$ pode ser representada pela expressão abaixo:

$\mathrm{f}_{\mathrm{bd}}=\frac{\mathrm{F}_{\mathrm{t}}(\mathrm{s}=0,1 \mathrm{~mm})}{\mathrm{u} \cdot \ell}$

Entretanto, a resistência de aderência efetiva, ou seja, a tensão de aderência última $\tau_{b u}$ é muito maior que o valor de cálculo, especialmente para barras nervuradas, atinge até o dobro desse valor e alcança deslizamentos de até $1 \mathrm{~mm}$. Para o dimensionamento, por questões de segurança, devido à grande dispersão dos 
valores da resistência de aderência, recomenda-se um valor bastante afastado da resistência efetiva.

Em ensaios de arrancamento, FUSCO (1995) faz observações relevantes, como as da Figura 2.26, que mostra os deslizamentos da seção inicial A da barra e da seção final B, durante o carregamento.

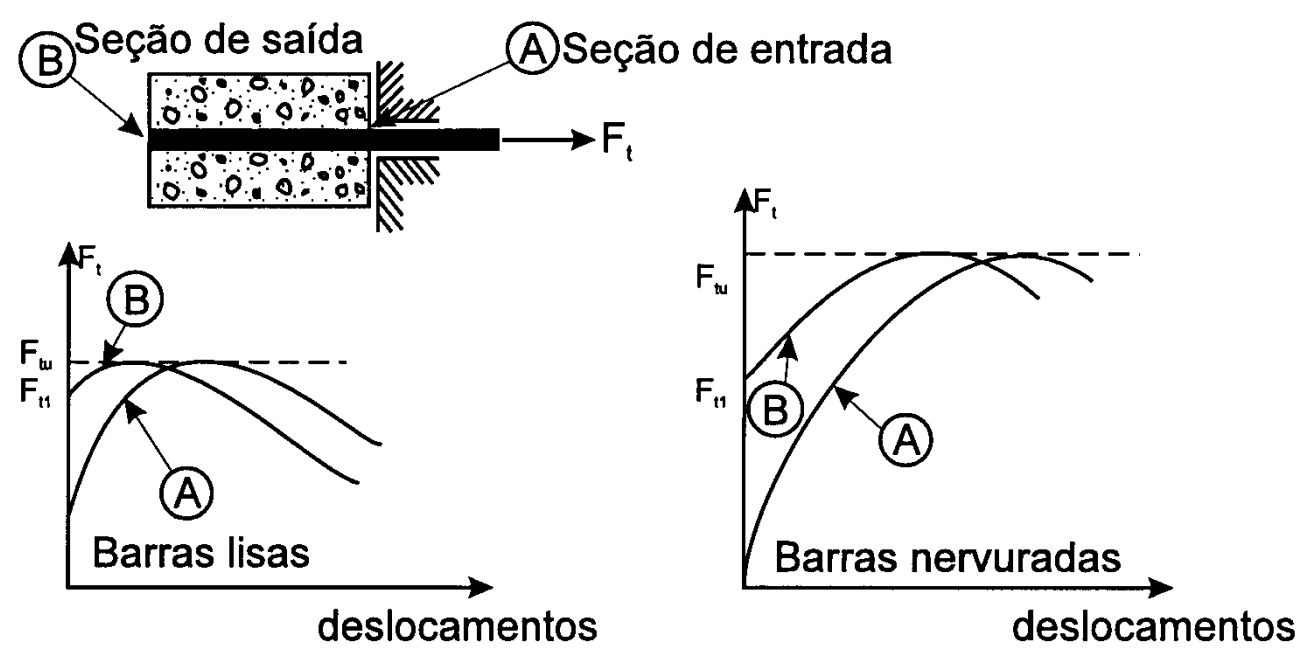

Figura 2.26 - Comportamento das barras lisas e nervuradas (FUSCO, 1995)

Desde o início do ensaio foram observados deslocamentos da seção inicial A; entretanto, somente a partir de uma força $F_{t 1}$ é que se dá o escorregamento de toda a barra. Iniciado esse escorregamento, a força de aderência ainda pode aumentar, e esse aumento é maior para as barras de alta aderência. Isso porque as barras nervuradas possuem maior capacidade de mobilização da aderência mecânica.

Esse fato justifica a obrigatoriedade do emprego de ganchos de extremidade nas barras lisas, pois o gancho inibe o início do escorregamento, e garante segura ancoragem.

Nas barras nervuradas, a partir do início do escorregamento, a capacidade de ancoragem aumenta progressivamente. Entretanto, para barras lisas, iniciado o escorregamento total da barra, logo é atingida a força última de ancoragem, a partir da qual a capacidade de ancoragem progressivamente vai desaparecendo.

O comportamento teórico das tensões de aderência em ensaio de arrancamento está mostrado na Figura 2.27. 


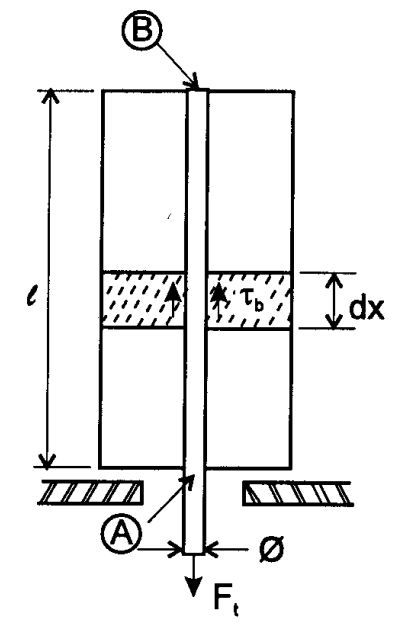

(a)

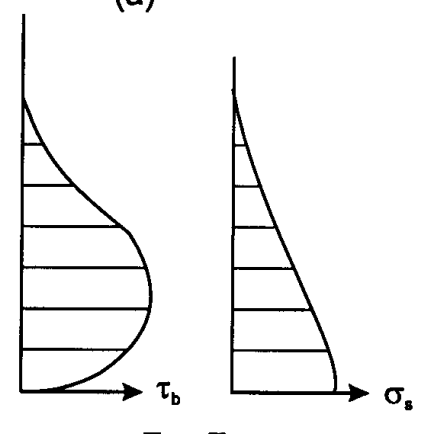

$F_{t}<F_{t u}$

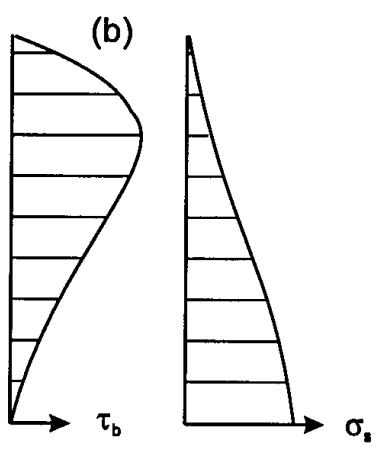

$F_{t}=F_{t u}$

Figura 2.27 - Distribuição das tensões de aderência no ensaio de arrancamento (FUSCO, 1995)

Neste ensaio, sob ação de uma força de tração $F_{t}$, age na barra uma tensão $\sigma_{\mathrm{s}}$ progressivamente transferida ao concreto, mediante as tensões de aderência.

Quando se tem uma força $F_{t}$ menor que a força de tração última $F_{t u}$, a aderência é mobilizada em apenas uma parte do comprimento total da barra. A tensão de aderência atinge seu valor máximo onde o diagrama de $\sigma_{\mathrm{s}}$ apresenta um ponto de inflexão. No caso de $\mathrm{F}_{\mathrm{t}}=\mathrm{F}_{\mathrm{tu}}$, quando ocorre a ruptura, a aderência é mobilizada em todo o comprimento da barra, atingindo a máxima capacidade de aderência entre os dois materiais. Essas situações estão ilustradas, respectivamente, nas letras a e b da Figura 2.27.

A tensão $\sigma_{\mathrm{s}}$ diminui à medida que a seção transversal ocupa posições mais afastadas da seção que coincide com a extremidades do bloco de concreto. Este fato é decorrente da aderência que permite a transferência das tensões atuantes na barra para o concreto.

Outro ponto bastante interessante é salientado por LEONHARDT \& MÖNNIG (1977), conforme apresentado na letra a da Figura 2.28, os autores mostraram que devido ao impedimento à deformação transversal na placa de apoio e através da compressão por efeito de arco, uma compressão transversal atua sobre a barra e provoca aderência por atrito adicional. 


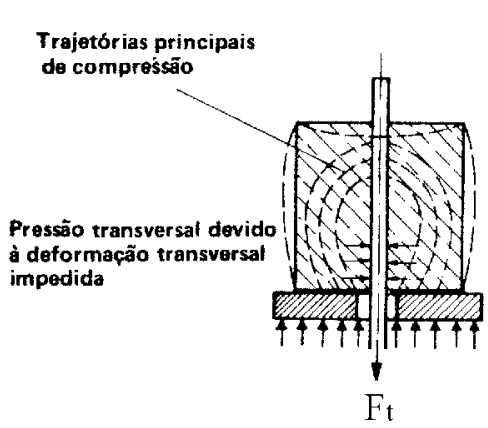

a) Corpo de prova inadequado com a indicação esquemática da com.
pressão por efeito de arco $e$ da pressão por efeito de arco
compressão transversal

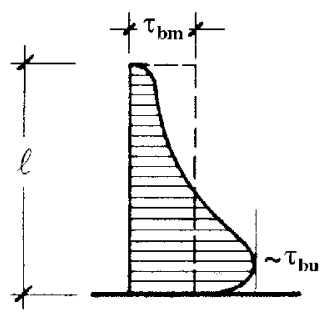

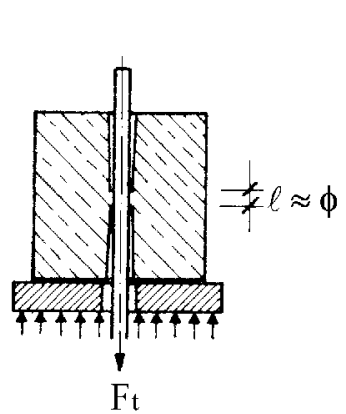

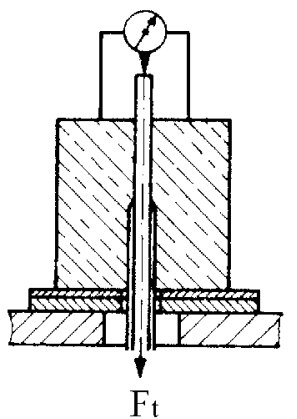
b) Corpo de prova segundo
REHM $^{13}$

c) Corpo de prova de acordo com
as recomendacões do RILEM/ as recomendacoōos

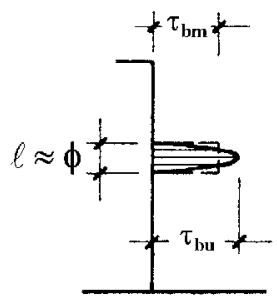

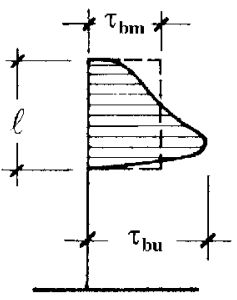

Figura 2.28 - Corpos de prova para o ensaio de arrancamento e as respectivas variações a tensão de aderência (LEONHARDT \& MÖNNIG, 1977)

Através de trechos sem aderência, essas influências nos corpos de prova b e c, da Figura 2.28, são diminuídas. REHM ${ }^{10}$ apud LEONHARDT \& MÖNNIG (1977) adotou por algum tempo o corpo de prova $b$, com o intuito de obter valores de aderência para um elemento de comprimento $\mathrm{dx}=\phi$. Assim, a pressão transversal é muito pequena, visto que a força de tração, no pequeno comprimento de aderência, é muito pequena.

Os resultados dos ensaios de arrancamento são consideravelmente influenciados pelo tamanho e forma do corpo de prova, assim como posição e comprimento do trecho de aderência da barra.

${ }^{10}$ REHM, G. (1961). Über die grundlagen des verbundes zwischen stahl und beton. Deutscher Ausschuss für Stahlbeton. Heft 138, p.1-59 apud LEONHARDT \& MÖNNIG (1977). 


\subsubsection{ENSAIO DE ARRANCAMENTO RILEM-FIP-CEB (1973)}

Um dos ensaios de arrancamento mais difundido é o proposto pela RILEMFIP-CEB (1973), denominado pull-out-test, conforme apresentado na Figura 2.29.

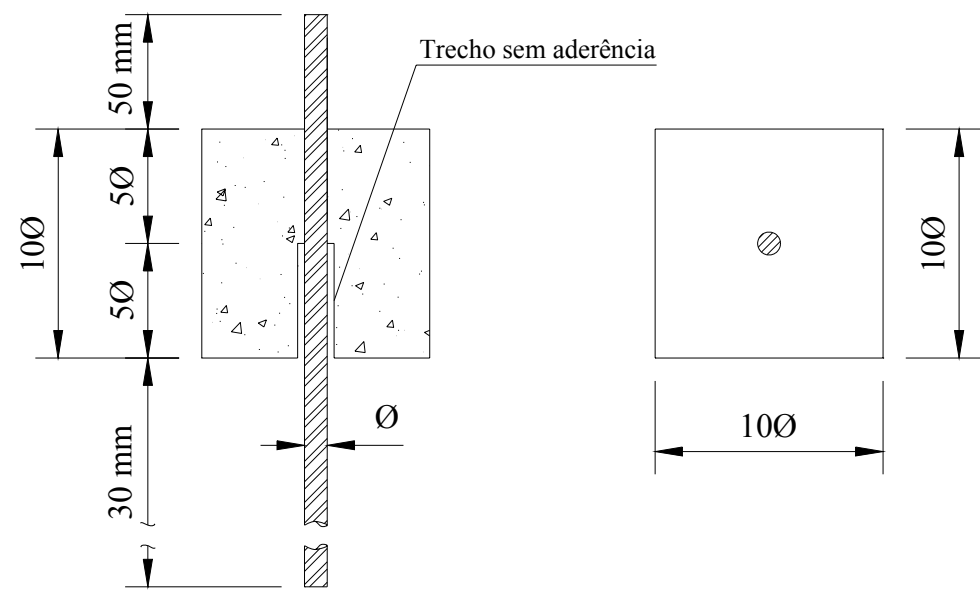

Figura 2.29 - Corpo-de-prova para o ensaio de arrancamento normatizado pela RILEM-FIP-CEB (1973)

O modelo utilizado consiste de um cubo de concreto com uma barra de aço no centro. A barra de aço é extraída do corpo-de-prova, tracionando o lado em contato com a placa de apoio, sendo medido o deslocamento da barra em relação ao concreto na extremidade descarregada.

O corpo-de-prova deve ser moldado com o eixo da barra na horizontal. A resistência à compressão média do concreto, mensurada em cilindros $15 / 30 \mathrm{~cm}$, deve estar entre 27 a $33 \mathrm{MPa}$. A velocidade de carregamento deve ser determinada para cada diâmetro, pela seguinte expressão:

$\mathrm{v}_{\mathrm{p}}=5 \cdot \phi^{2} \quad[\mathrm{kgf} / \mathrm{s}]$

o diâmetro da barra deve estar expresso em centímetros.

A RILEM-FIP-CEB (1973) assume como referência à tensão de aderência para um concreto com resistência à compressão de $30 \mathrm{MPa}$ obtida de cilindros 15/30 $\mathrm{cm}$. Como é admitida tolerância na resistência $\mathrm{f}_{\mathrm{cm}}$ de até $10 \%$, as forças de tração $\mathrm{F}_{\mathrm{t}}$ 
encontradas no ensaio são transformadas linearmente pela seguinte expressão em tensão de aderência correspondendo a resistência à compressão do concreto de 30 MPa.

$\tau_{\mathrm{b}}=0,0637 \frac{\mathrm{F}_{\mathrm{t}}}{\phi^{2}} \frac{30}{\mathrm{f}_{\mathrm{cm}}}$

onde se tem as seguintes unidades de medida: $\tau_{\mathrm{b}}[\mathrm{MPa}], \mathrm{F}_{\mathrm{t}}[\mathrm{kN}], \phi[\mathrm{mm}]$ e $\mathrm{f}_{\mathrm{cm}}$ $[\mathrm{MPa}]$

\subsubsection{ENSAIO DE ARRANCAMENTO ASTM C-234}

A designação ASTM C-234 refere-se ao método de ensaio de aderência proposto pela ASTM (1991). Segundo a referida associação, valores da aderência medidos através deste método não servem para propósito de projeto estrutural e, as dimensões e tipos de aço não são suas variáveis mais importantes. O método é adaptável ao uso em pesquisa variando-se as condições de acordo com os objetivos do estudo.

Os corpos-de-prova para este ensaio são de dois tipos: um contendo a barra de aço embutida verticalmente e outro com as barras embutidas horizontalmente.

Os espécimes do primeiro tipo têm formato cúbico com $150 \mathrm{~mm}$ de aresta, com barra posicionada verticalmente ao longo do eixo central do cubo. A barra deve projetar sua extremidade inferior cerca de $10 \mathrm{~mm}$ abaixo do fundo do corpo-de-prova e a extremidade superior um comprimento tal que possibilite atravessar os blocos de apoio do dispositivo de ensaio e seja ancorada nas garras da prensa. 


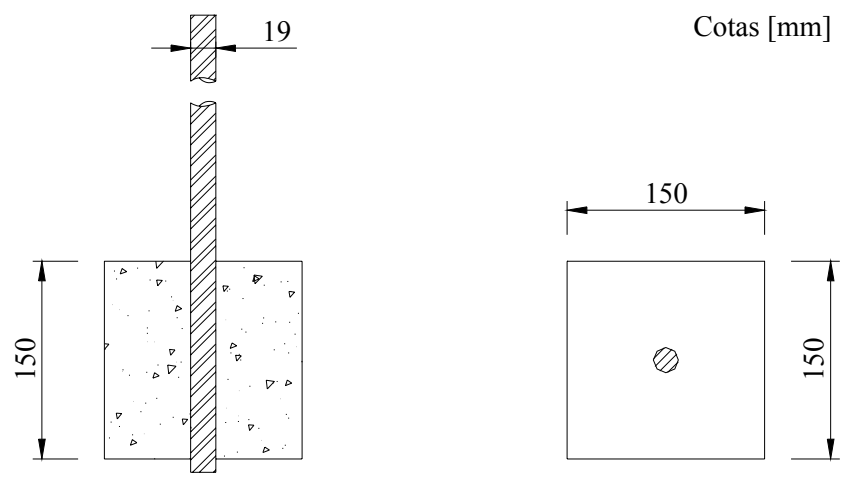

Figura 2.30 - Modelo ASTM C-234 com barra vertical

Os corpos-de-prova do segundo tipo têm formato prismático e medem 150x150x300 mm, com eixo maior na vertical. As duas barras são concretadas perpendicularmente ao eixo da altura do prisma. As alturas dessas barras horizontais em relação à base do prisma devem ser de $75 \mathrm{~mm}$ e $225 \mathrm{~mm}$. Ambas devem ter comprimento tal que projete suas extremidades para fora das faces do corpo-de-prova como descrito para o primeiro tipo de corpo-de-prova. Deve ser providenciada ranhura ou fenda, em cada uma das faces opostas do prisma, paralela aos eixos das barras e na metade de sua altura. Essas ranhuras devem ter pelo menos $13 \mathrm{~mm}$ de profundidade e servem para facilitar a divisão do prisma em dois cubos através da ruptura por flexão passando pelo plano de enfraquecimento que as contém. Dessa forma, resultam em dois corpos-de-prova cúbicos, um superior e um inferior, ambos com o eixo da barra perpendicular à direção de moldagem.

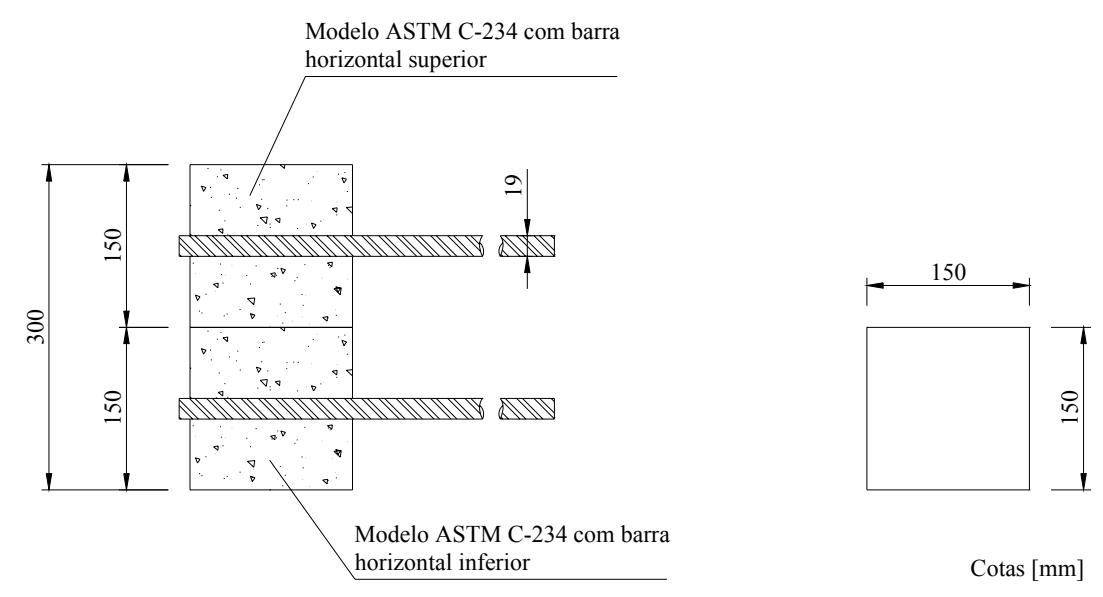

Figura 2.31 - Modelo ASTM C-234 com barras horizontais 
Nesse método de ensaio é usada barra de aço com diâmetro nominal de 19 mm. A Figura 2.32 apresenta as dimensões dos corpos-de-prova propostos pela ASTM (1991) em função do diâmetro nominal da barra.
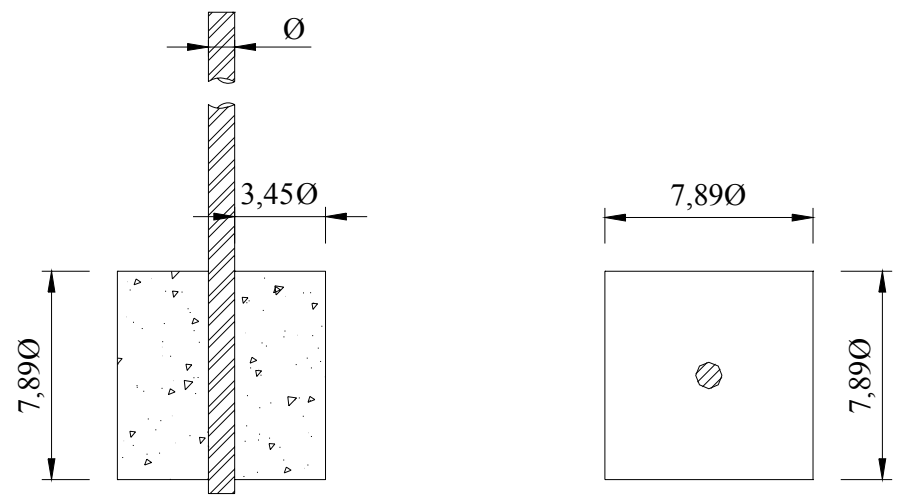

Figura 2.32 - Dimensões dos modelos ASTM C-234 em função do diâmetro da barra

Quanto à velocidade de aplicação do carregamento, a ASTM (1991) salienta que esta não deve ser maior que $22 \mathrm{kN} / \mathrm{min}$, ou então, quando se controla deslocamento, não deve ser superior a $1,27 \mathrm{~mm} / \mathrm{min}$.

\subsubsection{ENSAIO DE ARRANCAMENTO SEGUNDO REHM}

O ensaio de arrancamento utilizado por REHM, mostrado na Figura 2.33, consiste em um cilindro (ou um prisma) de concreto com uma barra centrada. Essa barra é concretada com trechos sem aderência nas duas extremidades do corpo-deprova. 


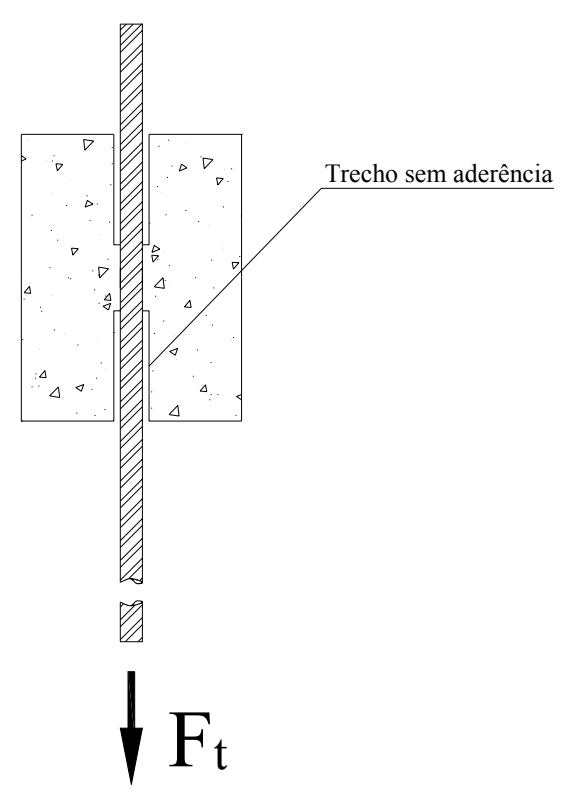

Figura 2.33 - Corpo-de-prova do ensaio de arrancamento segundo REHM

\subsubsection{ENSAIO DE DUPLO ARRANCAMENTO}

O corpo-de-prova do ensaio de duplo arrancamento está apresentado na Figura 2.34. De maneira simplista, pode-se considerar que o modelo se constitui em dois corpos-de-prova do ensaio de arrancamento, ligados por dois tirantes de concreto. 


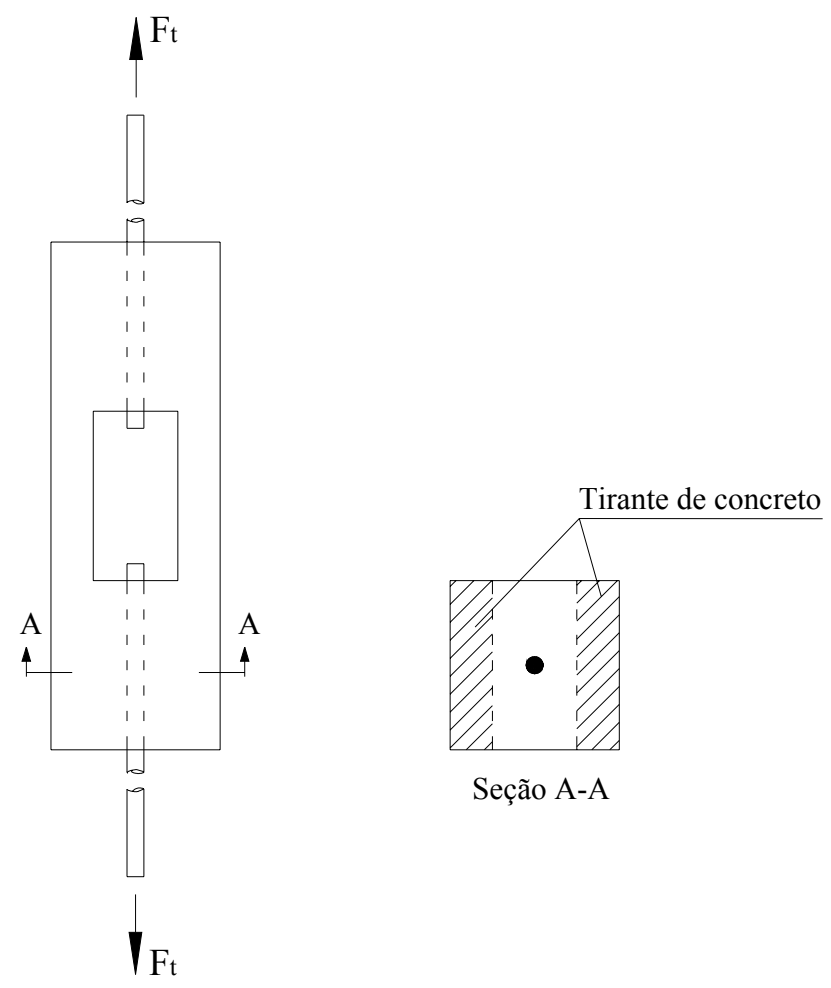

Figura 2.34 - Corpo-de-prova do ensaio de duplo arrancamento

Segundo LARANJEIRAS (1976), as vantagens desse tipo de ensaio em relação ao ensaio de arrancamento seriam:

a. Eliminação das pressões laterais sobre a barra, existentes nos ensaios de arrancamento. Oferecendo condições mais desfavoráveis à ação da carga repetida;

b. Permitir, pelo arrancamento simultâneo de duas barras, melhor controle sobre as leituras e instrumentação durante o ensaio e, presumivelmente, diminuir a dispersão dos resultados;

c. Constituir-se em método ainda mais simples de ensaio, por dispensar o dispositivo que é necessário para sustentação do corpo-de-prova do ensaio de arrancamento. 


\subsubsection{ENSAIO DE ARRANCAMENTO MODIFICADO}

O modelo consiste de um prisma de concreto com duas barras de aço embutidas (Figura 2.35).
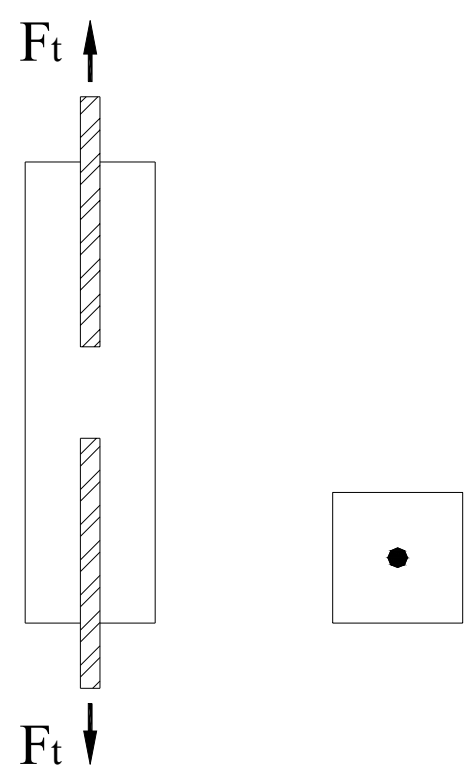

Figura 2.35 - Corpo-de-prova do ensaio de arrancamento modificado

As duas barras são puxadas em direções opostas. Essa configuração simula barras em zonas de tração de vigas e vigas parede.

Outra variante desse ensaio foi proposta por CHAPMAN \& SHAH (1987). No modelo desses autores, as duas barras têm diferentes comprimentos aderentes. Dessa forma, quando as barras são solicitadas, a menor é arrancada do concreto.

\subsubsection{ENSAIO DAS QUATRO BARRAS}

Com o intuito de eliminar as interferências das tensões de compressão impostas ao concreto nos ensaios de arrancamento, alguns pesquisadores propuseram várias modificações nesse ensaio. 
O ensaio das quatro barras consiste em uma emenda por traspasse, ligando três barras a uma central, envolvidas por um cilindro de concreto, conforme mostrado na Figura 2.36.

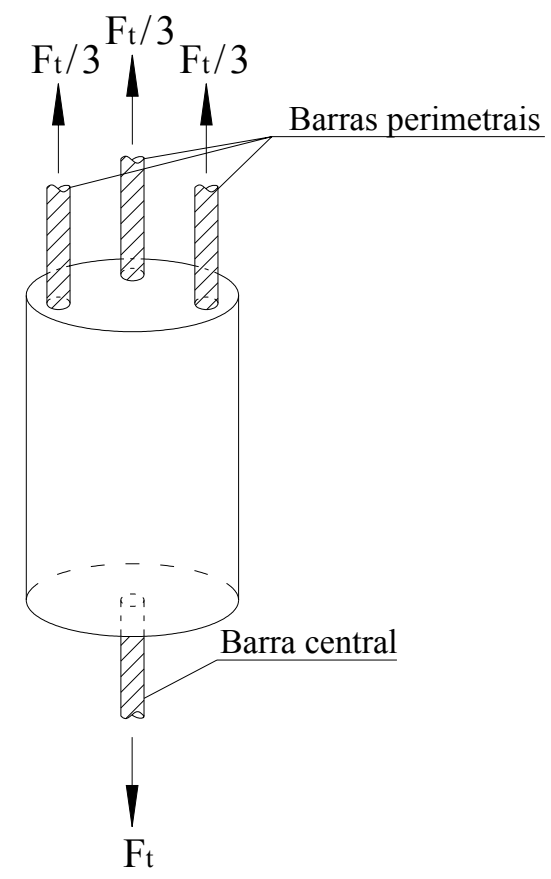

Figura 2.36 - Corpo-de-prova para o ensaio das quatro barras

No ensaio das quatro barras, a barra central é tracionada e o cilindro de concreto é mantido imóvel pela força reativa exercida pelas três barras perimetrais.

\subsubsection{ENSAIO DE TRAÇÃO EM VIGAS}

Devido à compressão longitudinal do concreto, verificada no ensaio de arrancamento, freqüentemente é posto em discussão o uso de um corpo-de-prova do tipo viga para determinar a capacidade de ancoragem das barras. Isso porque essa compressão longitudinal não existe na zona de ancoragem da armadura de tração das vigas fletidas. No entanto, a complexidade da montagem do ensaio por flexão proposto pela RILEM-FIP-CEB (1973), denominado beam test, dificulta sua execução. Na Figura 2.37 é apresentado o modelo para barras com diâmetro maior ou igual a $16 \mathrm{~mm}$. 


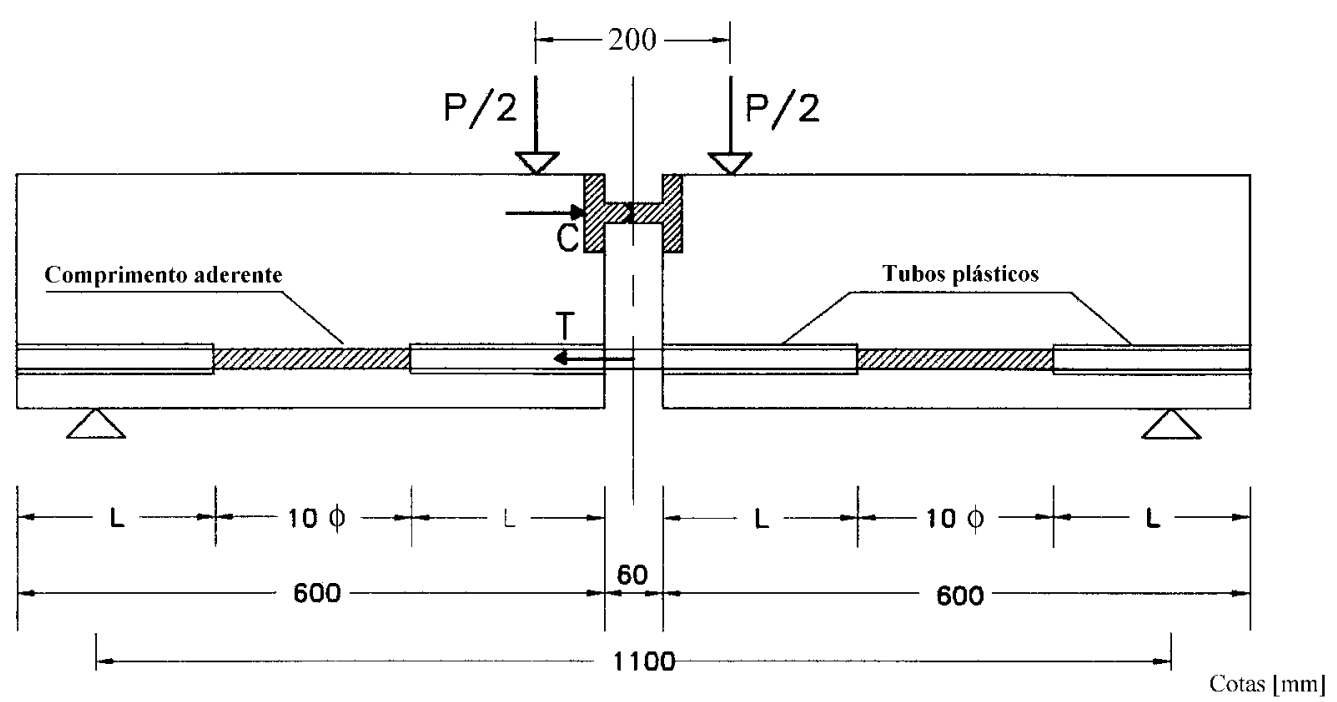

Figura 2.37 - Ensaio por flexão $(\phi \geq 16 \mathrm{~mm})$

* RILEM-FIP-CEB (1973) *

Esse ensaio baseia-se na modificação da aderência na flexão, em função de alterações da força na barra da armadura devidas à variação de momento fletor.

\subsubsection{ENSAIO TIRANTE}

Este ensaio consiste em aplicar, nas duas extremidades de uma barra envolvida por concreto, duas forças opostas de tração.

$\mathrm{Na}$ Figura 2.38 são apresentados modelos de tirantes que podem ser utilizados. 

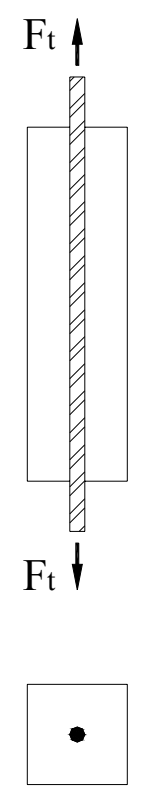

Tirante Prismático

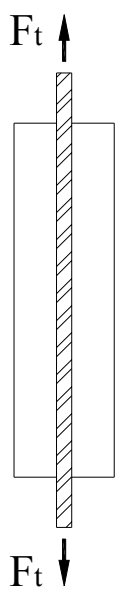

Tirante Cilíndrico

Figura 2.38 - Modelos de tirantes

A maioria dos autores admite que este tipo de ensaio reproduz satisfatoriamente, as condições reais de solicitações da parte tracionada das vigas.

BARBOSA (1998) enfatiza que os ensaios de tirantes usualmente conduzem à observação da fissuração por intermédio da determinação do espaçamento mínimo, médio e máximo das fissuras ao longo do ensaio e do total de fissuras possíveis que efetivamente são formadas.

Esse tipo de ensaio apresenta uma grande dificuldade que é o aparecimento de aberturas de fissuras que não se desenvolvem linear nem perpendicularmente à linha média do tirante, bem como não apresentam abertura regular.

A NBR 7477/1982 estabelece que a determinação do coeficiente de conformação superficial deve ser feita através de ensaios de fissuração em tirantes de concreto armado com uma só barra ou fio. Esses tirantes devem ter seção transversal quadrada. 


\subsubsection{ANÁLISE DO COMPORTAMENTO DOS DIVERSOS TIPOS DE ENSAIO}

No estudo da aderência, os vários tipos de ensaios utilizados pelos autores no decorrer dos anos representam uma grande dificuldade. Para ensaio de aderência não existe padronização consagrada e difundida internacionalmente. Dessa forma, os experimentos diferenciam-se na composição dos materiais empregados, na geometria dos modelos, na tecnologia de produção, no processo de cura, no equipamento e no arranjo de ensaio, etc.

Devido à inevitável dispersão dos ensaios de aderência, é necessária análise estatística dos resultados experimentais. Um dos problemas, conforme salienta o CEB (1982) Bulletin d'Information n.151, é como e onde mensurar o deslizamento entre a armadura e o concreto. Não é apenas uma questão de precisão, confiabilidade e posição de medição, mas, também, uma questão de comprimento de medida e distância entre dispositivos de medição.

$\mathrm{Na}$ realidade, a relação $\tau_{\mathrm{b}}-\mathrm{s}$ pode ser completamente diferente de um caso para outro. Os dados experimentais obtidos são muito influenciados pelas condições de contorno, principalmente pela forma e dimensão dos modelos.

Diante do exposto, constata-se que mesmo para carregamento estático não é possível quantificar a contribuição de todos os fatores que influenciam o comportamento da aderência. Em estudo que tenha como escopo o efeito do carregamento repetido, é preciso especial atenção na avaliação dos resultados para não confundir esse efeito com os efeitos de outros fatores.

Neste item, é apresentada uma análise de alguns tipos de ensaio de aderência. Para tanto, como referência principal, será utilizado o trabalho realizado por DUCATTI (1993).

No desenvolvimento de sua tese, o referido autor realizou ensaios de arrancamento ASTM C-234, ensaios das quatro barras e ensaios com tirantes cúbicos com arestas de $15 \mathrm{~cm}$ e cilindros com diâmetro de $21 \mathrm{~cm}$. O autor observou que a tensão de aderência obtida no ensaio dos tirantes foi bem menor que as obtidas nos ensaios ASTM C-234 e nos das quatro barras. Isso se deve ao confinamento 
acarretado pelo atrito da placa de apoio com o corpo-de-prova de concreto no ensaio ASTM C-234 e na presença de três barras perimetrais no ensaio das quatro barras.

No ensaio com tirantes, as duas extremidades da barra de aço são tracionadas, o que proporciona um esforço de tração axial mais uniformemente distribuído, uniformidade essa facilitada pelo não confinamento do concreto circunvizinho e que, portanto, evita a concentração da compressão das nervuras sobre os consolos de concreto que estão à sua frente impedindo seu deslocamento e posterior esmagamento.

Nos ensaios ASTM C-234, todos os modelos apresentaram ruptura brusca do cubo de concreto em torno da barra de aço em três ou quatro partes, ou seja, romperam-se por fendilhamento. A argamassa em frente à face da nervura das barras, no lado de aplicação da carga, foi esmagada.

Nos ensaios das quatro barras, a maioria dos modelos teve o concreto rompido segundo um dos três planos verticais que contém a barra central e uma das barras perimetrais.

A carga foi aplicada nos tirantes até que qualquer dos extensômetros utilizados na instrumentação da barra apresentasse problema de funcionamento. Assim, é provável que com essa carga se inicie a fissuração do concreto e, portanto, esse ponto é caracterizado pela tensão e deformação máximas do aço.

Ao contrário do ensaio ASTM C-234, o ensaio com tirantes não apresentou esmagamento da argamassa em frente às nervuras. $\mathrm{O}$ concreto circunvizinho à barra deformou-se com o aço até determinado valor para, em seguida, sofrer fissuração transversal, mesmo sem apresentar fissuração por fendilhamento.

Com a instrumentação utilizada, DUCATTI (1993) observou que tanto no ensaio das quatro barras quanto no dos tirantes, os trechos finais da barra são responsáveis por grande parte da resistência de aderência.

DUCATTI (1993) trabalhou com diversos valores de resistência à compressão do concreto. Os ensaios ASTM C-234 foram executados aos 28 dias, com resistência média à compressão do concreto da ordem de 50, 55, 65, 70, 80 e 85 MPa. Nos ensaios das quatro barras, a ordem de grandeza dessa propriedade foi de 90 e $50 \mathrm{MPa}$. Os ensaios com os tirantes realizados com 30 dias, com resistência $\mathrm{f}_{\mathrm{cm}}$ da ordem de 95 e $75 \mathrm{MPa}$ para tirantes cúbicos e de $75 \mathrm{MPa}$ para tirantes cilíndricos. 
Os valores da resistência à compressão apresentados são médias dos resultados de séries de 3 corpos-de-prova. As propriedades mecânicas do concreto foram medidas em corpos-de-prova cilíndricos, com $105 \mathrm{~mm}$ de diâmetro e $210 \mathrm{~mm}$ de altura.

A espessura de concreto adjacente à barra, é fixa para os ensaios ASTM C234, igual a $3,25 \phi$. Nos ensaios com tirantes foram utilizados os seguintes valores: $2,5 \phi, 3,45 \phi, 3,7 \phi$ e $5,5 \phi$. A Tabela 2.3 apresenta as características gerais do ensaio das quatro barras, como: diâmetros, distância $\mathrm{a}_{\mathrm{s}}$ entre a barra central e cada uma das três barras perimetrais, resistência à compressão do concreto, bem como o modo de ruptura.

Tabela 2.3 - Características gerais dos ensaios das quatro barras DUCATTI (1993)

\begin{tabular}{|c|c|c|c|}
\hline $\begin{array}{c}\phi \\
{[\mathbf{m m}]}\end{array}$ & $\mathbf{a}_{\mathrm{s}}$ & $\begin{array}{c}\mathbf{f}_{\mathrm{cm}} \\
{[\mathrm{MPa}]}\end{array}$ & Modo de ruptura \\
\hline \multirow{5}{*}{25} & \multirow{2}{*}{$2 \phi$} & 89,2 & \multirow{5}{*}{ Fendilhamento } \\
\hline & & 48,7 & \\
\hline & $2,8 \phi$ & 89,2 & \\
\hline & \multirow{2}{*}{$3,6 \phi$} & 89,2 & \\
\hline & & 48,7 & \\
\hline \multirow{5}{*}{19} & \multirow{2}{*}{$2,63 \phi$} & 88,0 & \multirow{3}{*}{$\begin{array}{l}\text { A barra central rompeu-se, o corpo-de-prova } \\
\text { apresentou fissuração por fendilhamento e } \\
\text { fissuração transversal em quase toda a seção do } \\
\text { cilindro de concreto. }\end{array}$} \\
\hline & & 46,5 & \\
\hline & $3,68 \phi$ & 88,0 & \\
\hline & \multirow{2}{*}{$4,74 \phi$} & 88,0 & Ensaio paralisado por motivo de segurança. \\
\hline & & 46,5 & Arrancamento \\
\hline \multirow{4}{*}{12,5} & \multirow{2}{*}{$5,6 \phi$} & 88,0 & \multirow{2}{*}{ Fendilhamento } \\
\hline & & 46,5 & \\
\hline & \multirow{2}{*}{$7,2 \phi$} & 88,0 & \multirow{2}{*}{ Rompimento da barra central } \\
\hline & & 46,5 & \\
\hline
\end{tabular}

Com o objetivo de comparar as curvas de aderência obtidas através do ensaio ASTM C-234 e do ensaio das quatro barras, o referido autor preparou 4 séries de 3 
corpos-de-prova cada uma, com um concreto de resistência $\mathrm{f}_{\mathrm{cm}}=88 \mathrm{MPa}$ e $\mathrm{f}_{\mathrm{ctm}}=6,5 \mathrm{MPa}$ aos 28 dias. O diâmetro nominal da barra utilizado foi de $19 \mathrm{~mm}$ e o comprimento de ancoragem $15 \mathrm{~cm}$.

Observou-se que a curva do ensaio das quatro barras tem andamento quase paralelo às curvas do ensaio ASTM C-234 referente às diversas posições da barra. No entanto, o ensaio das quatro barras apresentou, para um determinado deslizamento, valores de $\tau_{\mathrm{b}}$ cerca de $15 \%$ maiores, se comparados com os obtidos do ensaio ASTM C-234. A espessura da camada de concreto circunvizinho à barra foi de aproximadamente $6,5 \mathrm{~cm}$ para o ensaio ASTM C-234 e, no ensaio das quatro barras, aproximadamente $9 \mathrm{~cm}$.

Quanto aos ensaios de aderência propostos pela RILEM-FIP-CEB (1973), ou seja, o ensaio de arrancamento e o de ancoragem em viga, o CEB (1982) Bulletin d'Information n.151 esclarece que esses ensaios não fornecem informações claras da tendência ao fendilhamento do concreto que envolve as barras da armadura.

As diferenças entre os ensaios de arrancamento ASTM C-234 e o normatizado pela RILEM-FIP-CEB (1973) estão no grau de confinamento da barra e no comprimento de ancoragem. Primeiramente, para o corpo-de-prova da RILEMFIP-CEB (1973), a influência do confinamento causado pela placa de apoio é consideravelmente diminuída com o trecho sem aderência. Para esse ensaio, é normal utilizar diferentes diâmetros de barras, e em qualquer situação, o cobrimento de concreto é igual a 4,5 . Para o ensaio ASTM C-234, o diâmetro da barra normatizado é $19 \mathrm{~mm}$ e o corpo-de-prova é um cubo com $150 \mathrm{~mm}$ de aresta e, assim,

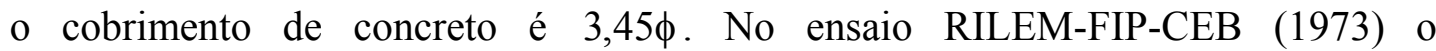
comprimento de ancoragem é $5 \phi$ e no ensaio ASTM C-234 é 7,89 $\phi$. 


\subsection{PRESCRIÇÕES DAS NORMAS SOBRE ADERÊNCIA}

\subsubsection{CÓDIGO MODELO CEB-FIP 1990}

O Código Modelo CEB-FIP 1990 é um documento que tem por objetivo delinear os princípios que devem nortear os códigos de diversos países. Neste item serão apresentadas especificações quanto à aderência da versão apresentada pelo CEB (1991) Bulletin d'Information n.203-205.

Este código aplica-se a concretos com resistência característica à compressão de até $80 \mathrm{MPa}$. Entretanto, é salientado que são limitadas as prescrições quanto ao comportamento de concreto com resistência característica superior a $50 \mathrm{MPa}$, e nestes casos é preciso usar, com precaução, as informações estabelecidas.

Entretanto, segundo o CEB (1995) Bulletin d'Information n.228, as informações relatadas abaixo também são aplicáveis a concreto de alto desempenho. A referida publicação acrescentou ao Código Modelo CEB-FIP 1990 mais quatro classes de resistência do concreto, a mais elevada é normatizada em $100 \mathrm{MPa}$. A justificativa apresentada limita-se a reconhecer que o nível de conhecimento é suficiente para sugerir regras válidas até $100 \mathrm{MPa}$.

Mais recentemente, o texto do Código Modelo CEB-FIP 1990 foi atualizado pela FIB (1999) Bulletin n.1. Nesta publicação são incorporadas as modificações introduzidas pelo CEB (1995) Bulletin d'Information n.228 e mantidas as demais especificações quanto à aderência.

A influência da posição da barra durante a concretagem é considerada através da definição de regiões favoráveis ou desfavoráveis quanto à aderência. São considerados em boa situação quanto à aderência, os trechos das barras que estejam em uma das seguintes posições:

a. Com inclinação entre $45^{\circ}$ e $90^{\circ}$ com a horizontal;

b. Com inclinação inferior a $45^{\circ}$ com a horizontal, desde que estejam até 25 $\mathrm{cm}$ da face inferior do elemento estrutural ou no mínimo a $30 \mathrm{~cm}$ abaixo da face superior. 
Os trechos das barras em outras posições e quando do uso de formas deslizantes devem ser considerados em má situação quanto à aderência.

A resistência de aderência de cálculo na ancoragem de armaduras passivas deve ser obtida pela seguinte expressão:

$\mathrm{f}_{\mathrm{bd}}=\eta_{1} \cdot \eta_{2} \cdot \eta_{3} \cdot \mathrm{f}_{\mathrm{ctd}}$

onde $\mathrm{f}_{\text {ctd }}$ é o valor de cálculo da resistência à tração do concreto, $\eta_{1}$ leva em consideração a conformação superficial das barras, $\eta_{2}$ considera a zona de aderência em que a barra se encontra e $\eta_{3}$ leva em conta o diâmetro da barra. Os valores para cada um dos coeficientes estão apresentados abaixo:

$$
\begin{aligned}
& \eta_{1}=\left\{\begin{array}{l}
1,0 \text { para barras lisas }(\mathrm{CA}-25 \text { ou CA }-60 \text { usual }) \\
1,4 \text { para barras dentadas }(\mathrm{CA}-60 \text { dentado }) \\
2,25 \text { para barras nervuradas }(\mathrm{CA}-50 \text { usual })
\end{array}\right. \\
& \eta_{2}=\left\{\begin{array}{l}
1,0 \text { para situações de boa aderência } \\
0,7 \text { para situações de má aderência }
\end{array}\right. \\
& \eta_{3}=\left\{\begin{array}{l}
1,0 \text { para } \phi \leq 32 \mathrm{~mm} \\
\frac{132-\phi}{100}(\phi \text { em } \mathrm{mm}) \text { para } \phi>32 \mathrm{~mm}
\end{array}\right.
\end{aligned}
$$

$\mathrm{Na}$ falta de determinação experimental, a resistência à tração do concreto pode ser avaliada por meio da seguinte equação:

$$
\mathrm{f}_{\text {ctd }}=\frac{\mathrm{f}_{\text {ctk, inf }}}{1,5}
$$


onde $\mathrm{f}_{\mathrm{ctk}, \text { inf }}=0,95 \cdot\left(\frac{\mathrm{f}_{\mathrm{ck}}}{10}\right)^{2 / 3}$. Outra forma de se expressar o valor de $\mathrm{f}_{\mathrm{ctk}, \mathrm{inf}}$ é a seguinte: $\mathrm{f}_{\mathrm{ctk}, \text { inf }}=0,68 \cdot \mathrm{f}_{\mathrm{ctm}}$ onde $\mathrm{f}_{\mathrm{ctm}}=1,4 \cdot\left(\frac{\mathrm{f}_{\mathrm{ck}}}{10}\right)^{2 / 3}$.

A FIB (1999) Bulletin n.1 propõe a expressão 2.28 para estimar a resistência à tração do concreto. Essa expressão é baseada em pesquisas recentes incluindo resultados com CAD.

$$
\mathrm{f}_{\mathrm{ctm}}=2,12 \cdot \ln \left(\frac{1+\mathrm{f}_{\mathrm{cm}}}{10}\right)
$$

\subsubsection{EUROCODE 2}

Esta norma aplica-se a concretos com resistência característica à compressão de até $50 \mathrm{MPa}$.

As condições de aderência são consideradas boas nos trechos das barras que estejam em uma das seguintes posições:

a. Com inclinação entre $45^{\circ}$ e $90^{\circ}$ com a horizontal;

b. Inclinação inferior a $45^{\circ}$ com a horizontal, desde que em elementos estruturais com altura na direção de concretagem até $25 \mathrm{~cm}$. Caso contrário $(\mathrm{h}>25 \mathrm{~cm})$, os trechos das barras devem estar na metade inferior da peça ou localizados no mínimo $30 \mathrm{~cm}$ abaixo da face superior.

Os trechos das barras em outras posições são considerados em situação de má aderência.

Nas condições de boa aderência, os valores de cálculo para a resistência de aderência são dados na Tabela 2.4. Esses valores de $\mathrm{f}_{\mathrm{bd}}$ são calculados com $\gamma_{\mathrm{c}}=1,5$ e apresentados em MPa. 
Tabela 2.4 - Valores de cálculo da resistência de aderência para boas condições de aderência

\begin{tabular}{|c|c|c|c|c|c|c|c|c|c|}
\hline $\mathbf{f}_{\text {ck }}$ & $\mathbf{1 2}$ & $\mathbf{1 6}$ & $\mathbf{2 0}$ & $\mathbf{2 5}$ & $\mathbf{3 0}$ & $\mathbf{3 5}$ & $\mathbf{4 0}$ & $\mathbf{4 5}$ & $\mathbf{5 0}$ \\
\hline Barras lisas & 0,9 & 1,0 & 1,1 & 1,2 & 1,3 & 1,4 & 1,5 & 1,6 & 1,7 \\
\hline Barras de alta aderência & 1,6 & 2,0 & 2,3 & 2,7 & 3,0 & 3,4 & 3,7 & 4,0 & 4,3 \\
\hline
\end{tabular}

Estes valores são derivados das seguintes expressões:

a. Barras lisas

$$
\mathrm{f}_{\mathrm{bd}}=\frac{0,36 \cdot \sqrt{\mathrm{f}_{\mathrm{ck}}}}{\gamma_{\mathrm{c}}}
$$

b. Barras de alta aderência

$$
\mathrm{f}_{\mathrm{bd}}=\frac{2,25 \cdot \mathrm{f}_{\mathrm{ctk}, \text { inf }}}{\gamma_{\mathrm{c}}}
$$

onde:

$\gamma_{c} \quad$ Coeficiente de minoração da resistência do concreto igual a 1,5;

$\mathrm{f}_{\text {ctk, inf }}$ Resistência à tração característica inferior do concreto, determinada da mesma forma proposta pelo Código Modelo CEB-FIP 1990.

Nos casos de situações de má aderência, os valores da resistência de aderência devem ser multiplicados pelo coeficiente 0,7 .

As especificações do EUROCODE 2 são basicamente as mesmas do Código Modelo CEB-FIP 1990. A expressão utilizada pelo EUROCODE 2 para as barras de alta aderência representa a mesma situação especificada pelo Código Modelo CEBFIP 1990 para barra nervurada com $\phi \leq 32 \mathrm{~mm}$. Quanto a resistência de aderência para barras lisas, a expressão utilizada pelo EUROCODE 2 representa a situação especificada pelo Código Modelo CEB-FIP 1990 para barra lisa, $\phi \leq 32 \mathrm{~mm} \mathrm{e}$ resistência $f_{c k}$ igual a $30 \mathrm{MPa}$. 


\subsubsection{NBR 6118/1978 (NB-1)}

A NBR 6118/1978 considera boa situação quanto à aderência os trechos das barras que estejam em uma das seguintes posições:

a. Com inclinação maior que $45^{\circ}$ sobre a horizontal;

b. Horizontais ou com inclinação menor que $45^{\circ}$ sobre a horizontal, desde que localizadas no máximo $30 \mathrm{~cm}$ acima da face inferior do elemento ou da junta de concretagem mais próxima, para elementos estruturais com $\mathrm{h} \leq 60 \mathrm{~cm}$; ou desde que localizados no mínimo $30 \mathrm{~cm}$ abaixo da face superior do elemento ou da junta de concretagem mais próxima, para elementos estruturais com $\mathrm{h}>60 \mathrm{~cm}$.

Os trechos das barras em outras posições são considerados em situação de má aderência.

Em situações de boa aderência, os valores de cálculo da resistência de aderência são apresentados a seguir:

a. Na ancoragem e nas emendas por traspasse

$$
\begin{array}{ll}
\mathrm{f}_{\mathrm{bd}}=0,28 \cdot \sqrt{\mathrm{f}_{\mathrm{cd}}} & \text { para } \eta_{\mathrm{b}} \leq 1,0 \\
\mathrm{f}_{\mathrm{bd}}=0,42 \cdot \sqrt[3]{\mathrm{f}_{\mathrm{cd}}{ }^{2}} & \text { para } \eta_{\mathrm{b}} \geq 1,5
\end{array}
$$

b. Para deslizamento em peças fletidas

$$
\begin{array}{ll}
\mathrm{f}_{\mathrm{bd}}=0,51 \cdot \sqrt{\mathrm{f}_{\mathrm{cd}}} & \text { para } \eta_{\mathrm{b}} \leq 1,0 \\
\mathrm{f}_{\mathrm{bd}}=0,74 \cdot \sqrt[3]{\mathrm{f}_{\mathrm{cd}}^{2}} & \text { para } \eta_{\mathrm{b}} \geq 1,5
\end{array}
$$

onde:

$\eta_{\mathrm{b}} \quad$ Coeficiente de conformação superficial da barra;

$\mathrm{f}_{\mathrm{cd}}$ Resistência à compressão de cálculo do concreto, dada pela relação $\frac{\mathrm{f}_{\mathrm{ck}}}{\gamma_{\mathrm{c}}}$, com coeficiente de ponderação da resistência do concreto (no estado limite último) para combinações normais $\gamma_{c}$ igual a 1,4 . 
No cálculo de $f_{b d}$ não se deve considerar $\eta_{b}$ maior que 1,5. Para $1,0<\eta_{\mathrm{b}}<1,5$, o valor da resistência de aderência deve ser determinado por interpolação linear.

Em situações de má aderência, os valores de cálculo da resistência de aderência devem ser divididos por 1,5.

\subsubsection{PROJETO DE REVISÃO DA NBR 6118/2001}

Esta norma aplicar-se-á a concretos de massa específica normal com resistência à compressão até $50 \mathrm{MPa}$.

O método de cálculo é o mesmo proposto pelo Código Modelo CEB-FIP 1990. No entanto, existem diferenças na definição de situações favoráveis ou desfavoráveis quanto à aderência, na resistência de aderência em elementos estruturais fletidos e no coeficiente de ponderação da resistência do concreto $\left(\gamma_{\mathrm{c}}=1,4\right)$.

Quanto à influência da posição da barra durante a concretagem, o projeto de revisão da NBR 6118/2001 considera em boa situação quanto à aderência as mesmas situações especificadas pela NBR 6118/1978, apenas fazendo menção quanto ao uso de formas deslizantes. Nesse caso, deve-se considerar má situação quanto à aderência.

No deslizamento da armadura em elementos estruturais fletidos, deve ser adotado o valor da resistência de aderência $f_{b d}$ multiplicado por 1,75. 


\section{CAPÍTULO 3}

\section{ADERENCIA EM CONCRETO DE ALTO DESEMPENHO}

\subsection{GENERALIDADES}

Em contraste com o nível de informações sobre o comportamento da aderência em concretos usuais, não existem resultados suficientes relativos à aderência em Concretos de Alto Desempenho.

A maioria das pesquisas permite concluir que o melhor desempenho das propriedades do material resulta em comportamento da aderência mais rígido e também em aumento da tensão de aderência última. Assim, o CAD tem efeito favorável no comportamento local da aderência.

Entretanto, visto que a redistribuição de tensões é impedida pelo comportamento mais frágil, a tensão de aderência será menos uniforme em $\mathrm{CAD}$, sendo esse fato desfavorável quanto ao comportamento global de regiões de ancoragem. O próprio comportamento mais frágil do material pode também resultar em rupturas globais muito frágeis.

Vários tipos de ensaios de arrancamento com pequenos comprimentos aderentes têm sido estudados. Os modelos de concreto eventualmente fendilham antes que a barra seja arrancada. De acordo com a FIB (2000) Bulletin n.10, a ruptura por fendilhamento observada nesses modelos não é um fenômeno local relativo à ação da aderência, mas pode ser uma ruptura global causada pelo campo de tensão criado no modelo pelos arranjos de ensaio e carregamento. Dessa forma, os 
resultados desses tipos de ensaios podem ser difíceis de interpretar e de estabelecer regras para projeto.

\subsection{COMPORTAMENTO LOCAL DA ADERÊNCIA}

Para se comparar o comportamento local da aderência em concreto confinado será utilizado o trabalho experimental realizado por MAGNUSSON ${ }^{11}$ apud FIB (2000) Bulletin n.10. O autor utilizou ensaios de arrancamento com corpos-de-prova cilíndricos com diâmetros de 300 e 350 mm, dependendo do diâmetro nominal da barra $\phi: 16$ e $20 \mathrm{~mm}$, respectivamente. O comprimento dos corpos-de-prova foi constante e igual a $260 \mathrm{~mm}$. Os corpos-de-prova tinham trechos sem aderência nas duas extremidades, dessa forma o trecho aderente fica exatamente no centro do cilindro. Esse comprimento aderente foi de 2,5 vezes o diâmetro nominal da barra. A resistência à compressão do concreto foi aproximadamente $25 \mathrm{MPa}$ para concreto usual e aproximadamente $100 \mathrm{MPa}$ para CAD.

Como normalmente se considera, foi analisado o comportamento local da aderência $\left(\tau_{b}-s\right)$, com a tensão de aderência representada pelo valor médio ao longo do comprimento de ancoragem e o deslizamento mensurado na extremidade descarregada.

A influência da alta resistência do concreto na relação $\tau_{b}-s$ é exemplificada na Figura 3.1, para barras nervuradas de $16 \mathrm{~mm}$ de diâmetro e com $\mathrm{f}_{\mathrm{yk}}=500 \mathrm{MPa}$. As curvas representam comportamento médio de 4 modelos similares para o CAD e 5 modelos similares para concreto usual. É evidente que a tensão de aderência última aumenta consideravelmente em CAD comparando-se com concreto usual. Contudo, o comportamento geral é bastante semelhante para os dois tipos de concreto.

11 MAGNUSSON, J. (1997). Bond and anchorage of deformed bars in high-strength concrete. Chalmers University of Technology, Division of Concrete Structures. Licentiate Thesis, Publication 97:1, Göteborg, Nov., 234p. 


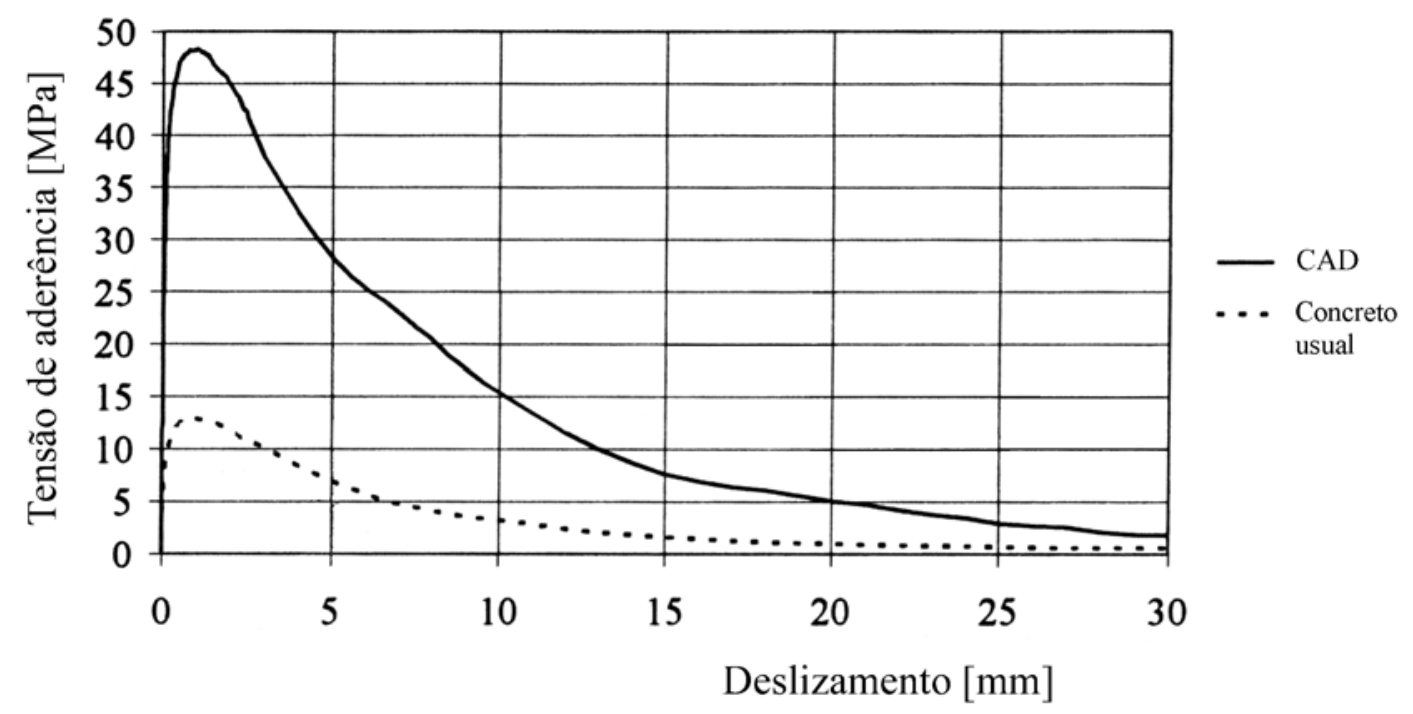

Figura 3.1 - Influência do tipo de concreto na relação $\tau_{\mathrm{b}}-\mathrm{s}$

(MAGNUSSON ${ }^{11}$ apud FIB, 2000 Bulletin n.10)

Baseado em resultados experimentais com ensaios de arrancamento semelhantes aos mencionados anteriormente, HUANG et al. ${ }^{12}$ apud FIB (2000) Bulletin n.10 propuseram para relacionar tensão de aderência última e resistência à compressão do concreto a seguinte expressão:

$\tau_{\mathrm{bu}}=0,45 \cdot \mathrm{f}_{\mathrm{cm}}$

De certa forma, essa expressão contradiz experiência anterior com concretos usuais. De acordo com FIB (2000) Bulletin n.10, a expressão 3.1 parece ser razoavelmente válida tanto para CAD quanto para concreto usual. No entanto, segundo a mesma publicação, a expressão 2.12 proposta por ELIGEHAUSEN et al. (1983), a qual considera a tensão de aderência última proporcional à raiz quadrada da resistência à compressão do concreto $\left(\right.$ ou a $\left.\mathrm{f}_{\mathrm{cm}}^{2 / 3}\right)$, apresenta resultados satisfatórios apenas para concretos usuais.

${ }^{12}$ HUANG, Z.; ENGSTRÖM, B.; MAGNUSSON, J. (1996). Experimental and analytical studies of the bond behavior of deformed bars in high strength concrete. Fourth International Symposium on the Utilization of high strength/high performance concrete. Proceedings, vol. 3, Laboratories des Ponts et Chaussées, Paris, 1996, p.1115-24 apud FIB (2000) Bulletin n.10. 
A despeito dessa consideração, EZELDIN \& BALAGURU (1989) constataram que mesmo com a presença de sílica ativa, a tensão de aderência última continua proporcional à raiz quadrada de $\mathrm{f}_{\mathrm{cm}}$. Os autores estudaram $\mathrm{o}$ comportamento da aderência em ensaios com tirantes de duas barras ( com diferentes comprimentos aderentes). Foram utilizados concretos (usual e de alto desempenho) com e sem sílica ativa. $\mathrm{O}$ estudo se concentrou em concretos reforçados com fibras de aço.

Outro autor que também ressalta a proporcionalidade da $\tau_{b u}$ com a raiz quadrada de $\mathrm{f}_{\mathrm{cm}}$ é DUCATTI (1993). Em ensaios ASTM C-234, com resistência à compressão do concreto variando entre 50 e $90 \mathrm{MPa}$, o autor confirmou ser adequada para CAD a equação 2.12, proposta para concretos usuais.

A Figura 3.2 mostra a influência da resistência à compressão do concreto na tensão de aderência última, conforme os dados experimentais de DUCATTI (1993).

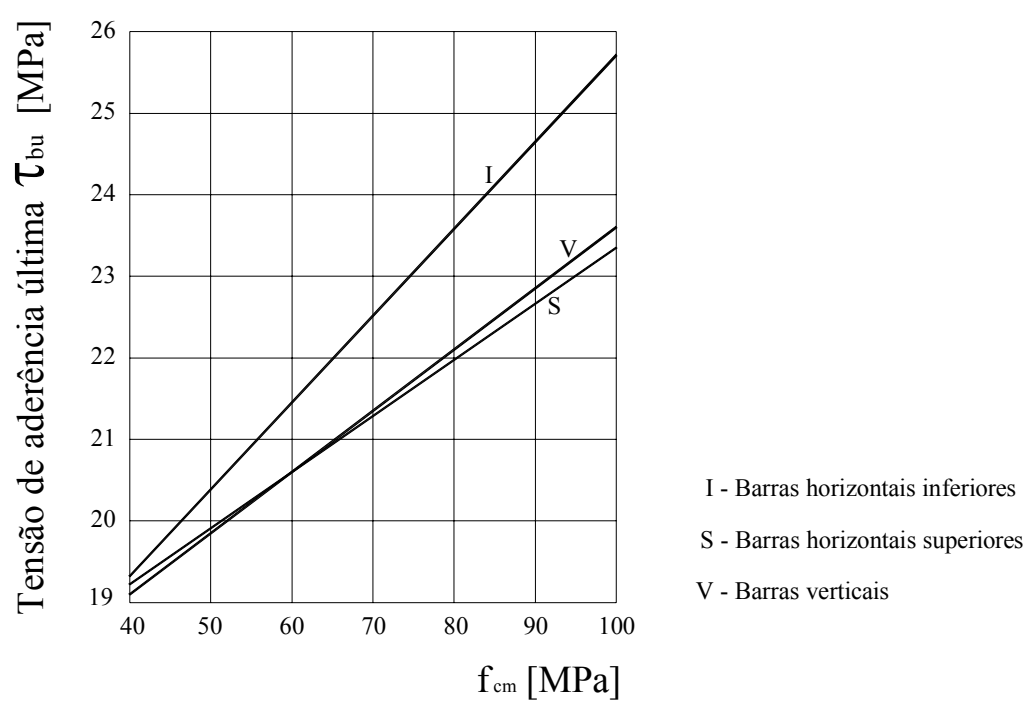

Figura 3.2 - Influência da resistência à compressão na tensão de aderência última (DUCATTI, 1993)

Deve ser ressaltado que nos ensaios de arrancamento ASTM C-234, o comprimento aderente é de $150 \mathrm{~mm}$ ou $7,89 \phi$, ou seja, maior que o normalmente utilizado $(\ell \leq 5 \phi)$ para se considerar a distribuição de tensões uniforme. Nos ensaios 
de DUCATTI (1993), devido a comprimentos aderentes longos e a alta resistência do concreto, todas as barras atingiram a tensão de escoamento $\left(\mathrm{f}_{\mathrm{yk}}=605 \mathrm{MPa}\right)$.

Outro ponto que se deve discutir é o comportamento da aderência quando a barra de aço escoa. Normalmente essa situação não ocorre em ensaios de aderência, entretanto, o escoamento da barra da armadura pode modificar consideravelmente o comportamento da aderência.

HUANG et al. ${ }^{12}$ apud FIB (2000) Bulletin n.10 propuseram um modelo simplificado para o comportamento local da aderência, válido para barras nervuradas em concreto confinado (concreto usual ou de alto desempenho), onde a barra pode escoar ou não antes da ruptura por arrancamento. O modelo proposto é mostrado na Figura 3.3 e os parâmetros apresentados na Tabela 3.1.

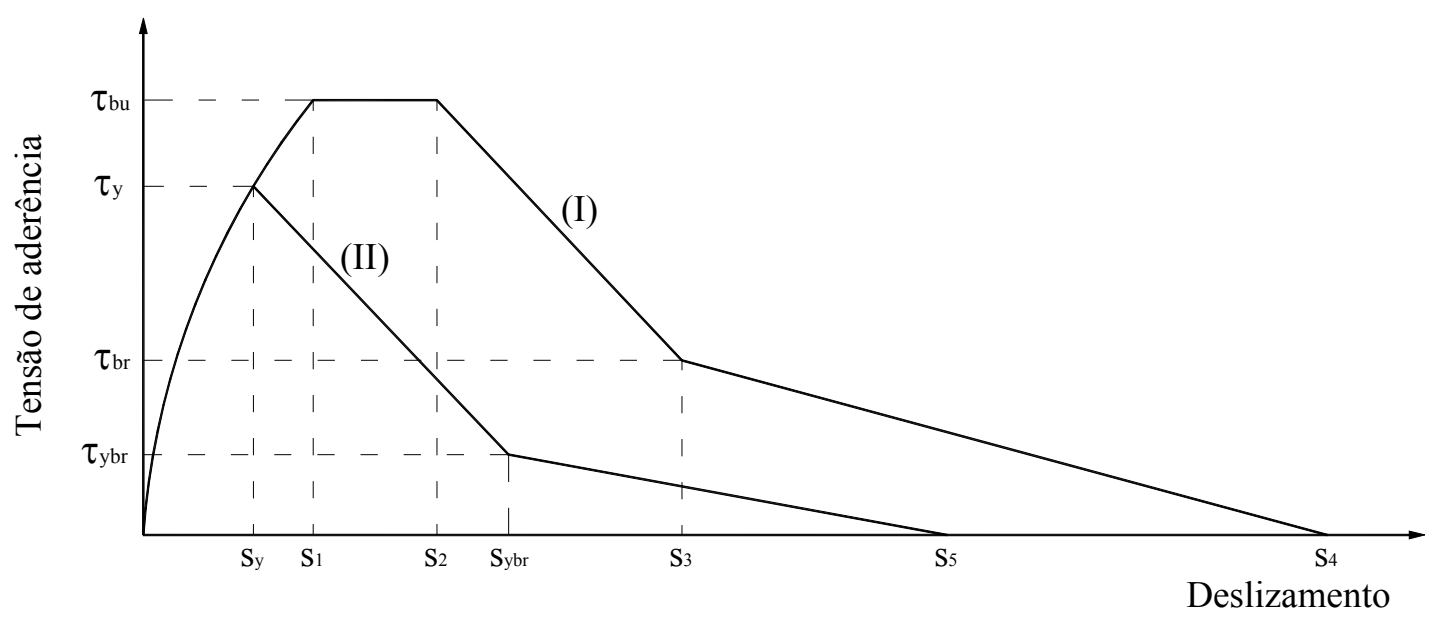

Figura 3.3 - Modelo analítico para a relação $\tau_{\mathrm{b}}$ - $\mathrm{s}$ proposto por HUANG et al. ${ }^{12}$ apud FIB (2000) Bulletin n.10 
Tabela 3.1 - Parâmetros do modelo analítico para a relação $\tau_{\mathrm{b}}$ - s proposto por HUANG et al. ${ }^{12}$ apud FIB (2000) Bulletin n.10

\begin{tabular}{|c|c|c|c|c|}
\hline \multirow{3}{*}{ Parâmetros } & \multicolumn{2}{|c|}{ Concreto usual } & \multicolumn{2}{|c|}{ CAD } \\
\hline & \multicolumn{2}{|c|}{ Condições de aderência } & \multicolumn{2}{|c|}{ Condições de aderência } \\
\hline & Boas & Demais casos & Boas & Demais casos \\
\hline $\mathrm{s}_{1}$ & \multicolumn{2}{|c|}{$1,0 \mathrm{~mm}$} & \multicolumn{2}{|c|}{$0,5 \mathrm{~mm}$} \\
\hline $\mathrm{S}_{2}$ & \multicolumn{2}{|c|}{$3,0 \mathrm{~mm}$} & \multicolumn{2}{|c|}{$1,5 \mathrm{~mm}$} \\
\hline $\mathrm{s}_{3}$ & \multicolumn{2}{|c|}{ Espaço livre entre nervuras } & \multicolumn{2}{|c|}{ Espaço livre entre nervuras } \\
\hline $\mathrm{S}_{4}$ & \multicolumn{2}{|c|}{$3 \cdot s_{3}$} & \multicolumn{2}{|c|}{$3 \cdot s_{3}$} \\
\hline$\alpha$ & \multicolumn{2}{|c|}{0,4} & \multicolumn{2}{|c|}{0,3} \\
\hline$\tau_{\mathrm{bu}}$ & $0,45 \cdot \mathrm{f}_{\mathrm{cm}}$ & $0,225 \cdot \mathrm{f}_{\mathrm{cm}}$ & $0,45 \cdot f_{\mathrm{cm}}$ & $0,225 \cdot \mathrm{f}_{\mathrm{cm}}$ \\
\hline$\tau_{\mathrm{br}}$ & \multicolumn{2}{|c|}{$0,4 \cdot \tau_{\mathrm{bu}}$} & \multicolumn{2}{|c|}{$0,4 \cdot \tau_{\mathrm{bu}}$} \\
\hline $\mathrm{S}_{\mathrm{ybr}}$ & \multicolumn{2}{|c|}{$\mathrm{s}_{\mathrm{y}}+2,5 \mathrm{~mm}$} & \multicolumn{2}{|c|}{$\mathrm{s}_{\mathrm{y}}+0,25 \mathrm{~mm}$} \\
\hline $\mathrm{S}_{5}$ & \multicolumn{2}{|c|}{$2 \cdot s_{3}$} & \multicolumn{2}{|c|}{$2 \cdot s_{3}$} \\
\hline$\tau_{\mathrm{ybr}}$ & \multicolumn{2}{|c|}{$0,2 \cdot \tau_{\mathrm{bu}}$} & \multicolumn{2}{|c|}{$0,2 \cdot \tau_{\mathrm{bu}}$} \\
\hline
\end{tabular}

O modelo proposto é basicamente o mesmo concebido pelo Código Modelo CEB-FIP 1990. No entanto, o modelo original foi modificado quanto ao comportamento da aderência em CAD e a deterioração da aderência devida ao escoamento da barra.

No caso de barras em regime elástico, a relação (I) da Figura 3.3 deve ser aplicada. Para concreto usual, esse modelo tem duas diferenças em relação ao Código Modelo CEB-FIP 1990. Primeiramente, a tensão de aderência última é determinada através da equação 3.1 no caso de boas condições de aderência, e metade do valor dessa expressão para outras condições de aderência. A segunda diferença é quanto ao quarto trecho, o qual representa a fase final (engrenamento concreto-concreto). O modelo em questão (Figura 3.3) considera uma função decrescente, em vez de constante como no Código Modelo CEB-FIP 1990.

Para o trecho ascendente, tanto o modelo proposto quanto o do Código Modelo CEB-FIP 1990 utilizam expressões do mesmo tipo: 
$\tau_{\mathrm{b}}=\tau_{\mathrm{bu}} \cdot\left(\frac{\mathrm{s}}{\mathrm{s}_{1}}\right)^{\alpha} \quad$ para $\mathrm{s} \leq \mathrm{s}_{1}$

No entanto, o Código Modelo CEB-FIP 1990 utiliza indiscriminadamente $\alpha=0,4$. $\mathrm{O}$ modelo da Figura 3.3, para considerar o comportamento mais rígido do $\mathrm{CAD}$, considera $\alpha=0,3$.

A relação (II) da Figura 3.3 representa a situação onde é atingida a tensão de escoamento da barra de aço. Os valores do ponto inicial $\left(\tau_{\mathrm{y}}, \mathrm{s}_{\mathrm{y}}\right)$ do trecho (II) depende da resposta global da região de ancoragem e deve ser determinada para cada seção ao longo da barra. Quando o comprimento mobilizado pela aderência, ou seja, o comprimento com tensão de aderência, é igual ao comprimento aderente, a seção da extremidade descarregada (em corpo-de-prova de arrancamento) começa a deslizar. Nesse caso, os valores do ponto inicial $\left(\tau_{\mathrm{y}}, \mathrm{s}_{\mathrm{y}}\right)$ será diferente para as várias seções ao longo da barra, o que significa que todas as seções na região onde se atingiu a tensão de escoamento da barra terá diferentes relações $\tau_{\mathrm{b}}-\mathrm{s}$.

Por fim, quanto ao modelo analítico para o comportamento local da aderência apresentado pelo Código Modelo CEB-FIP 1990, apesar de inicialmente proposto para concretos usuais, segundo o CEB (1995) Bulletin d'Information n.228, as informações contidas nesse Código são aplicáveis a CAD. Entretanto, é ressaltado que os valores numéricos dos parâmetros do modelo deveriam ser mais bem ajustados.

Nesse sentido, os resultados experimentais de DUCATTI (1993), obtidos através de ensaios de arrancamento ASTM C-234 em CAD, apresentaram os seguintes valores médios dos parâmetros dos dois modelos discutidos anteriormente:

$$
\left\{\begin{array}{l}
\mathrm{s}_{1}=0,255 \pm 0,55 \mathrm{~mm} \\
\frac{\tau_{\mathrm{bu}}}{\sqrt{\mathrm{f}_{\mathrm{cm}}}}=2,5 \pm 0,5 \\
\alpha=0,471 \pm 0,103
\end{array}\right.
$$


Quanto ao comportamento local da aderência em concreto não confinado, observa-se que a ruptura por fendilhamento é mais frágil em CAD do que em concreto usual. Isso se deve ao fato de a tensão de aderência ser variável ao longo da barra e pela relativa incapacidade do CAD em redistribuir tensões ao longo da barra.

\subsection{INFLUÊNCIA DA SÍLICA ATIVA}

É controverso o efeito da sílica ativa no comportamento da aderência. A introdução de sílica ativa aumenta a resistência do concreto, com comportamento da aderência mais rígido e maior resistência de aderência. Entretanto, no caso de ruptura por fendilhamento, a sílica ativa parece ter influência negativa na resistência de aderência.

GJORV et al. (1990) estudaram o efeito da sílica ativa condensada no comportamento mecânico da aderência e sobre a microestrutura da zona de transição entre concreto e barra de aço. O comportamento mecânico foi estudado por meio de ensaios de arrancamento ASTM C-234, com quatro níveis de resistência à compressão do concreto $(35,42,63$ e $84 \mathrm{MPa})$, com o uso, em cada nível de resistência, de três diferentes quantidades de sílica ativa condensada: 0,8 e $16 \%$ da massa de cimento. Foram utilizadas barras lisas e nervuradas com diâmetro de 19 $\mathrm{mm}$. No caso de barras nervuradas a ruptura ocorreu por fendilhamento.

O efeito da sílica ativa condensada na zona de transição aço-pasta de cimento foi estudado com o uso de microscópio eletrônico de varredura e análise por difração dos raios $\mathrm{X}$.

A adição da sílica ativa condensada em quantidades crescentes até $16 \%$ da massa de cimento produziu efeito positivo na resistência de aderência, especialmente para a classe de concreto com alta resistência à compressão.

A presença da sílica ativa condensada afeta a morfologia e a micro estrutura da zona de transição aço-pasta de cimento, e assim, reduz porosidade e espessura da zona de transição. Segundo GJORV et al. (1990), o efeito da sílica ativa condensada pode ser explicado pelos seguintes mecanismos: 
a. Redução de água livre na interface aço-concreto durante a moldagem dos corpos-de-prova;

b. Redução da orientação preferencial dos cristais de hidróxido de cálcio na zona de transição aço-pasta de cimento;

c. Densificação da zona de transição devido à reação pozolânica entre hidróxido de cálcio e sílica ativa condensada.

Em sua tese, DUCATTI (1993) concluiu que no CAD, a sílica ativa aumenta a resistência de aderência. Para os três consumos de cimento utilizados nos ensaios de arrancamento ASTM C-234, observou-se que uma tendência do teor de 10\% de sílica ativa em relação à massa de cimento otimizar a resistência de aderência, pois, a partir desse teor o aumento da quantidade de sílica ativa faz diminuir a velocidade do ganho de resistência de aderência, principalmente nos traços com consistência mais fluída (abatimento $>200 \mathrm{~mm}$ ).

HWANG et al. (1994) também estudaram o efeito da sílica ativa sobre o desempenho das barras nervuradas em CADs. Oito vigas divididas em quatro pares foram analisadas para comparar a capacidade de emendas por traspasse em regiões com momento fletor negativo constante. Para cada par, foi moldada uma viga com concreto sem sílica ativa e outra com concreto com $10 \%$ de massa de cimento substituída por igual quantidade de massa de sílica ativa. As barras principais $\left(f_{y d}=478 \mathrm{MPa}\right)$ tinham diâmetro de $29 \mathrm{~mm}$ e o comprimento da emenda foi de 300 mm. Os cobrimentos de concreto das barras principais eram iguais ao diâmetro da barra e a distância livre entre duas emendas foi igual a duas vezes o diâmetro da barra. A resistência à compressão do concreto, avaliada por corpos-de-prova cilíndricos de $15 \times 30 \mathrm{~cm}$, variou entre 60 e $80 \mathrm{MPa}$, a relação entre água e materiais cimentícios foi 0,28 ou 0,33 . Em cada par de vigas a resistência à compressão do concreto, bem como a resistência à tração, sempre foram maiores no concreto com sílica ativa. Não obstante, em cada par, a tensão de aderência média para o carregamento máximo era sempre menor no concreto com sílica ativa. A capacidade da emenda por traspasse foi sempre determinada por uma ruptura por fendilhamento antes que as barras escoassem. Houve fissuras de fendilhamento longitudinal ao longo das barras emendadas até o limite do cobrimento de concreto. 
Os autores compararam seus resultados com os de ensaios similares disponíveis na literatura e concluíram que a degradação da aderência foi atribuída à menor adesão entre concreto e aço, devido à presença da sílica ativa. A comparação mostrou que a tensão de aderência última, proporcional à raiz quadrada da resistência à compressão do concreto, pode ser diminuída em até $15 \%$ devido à presença de sílica ativa. HWANG et al. (1994) argumentaram que a diminuição da resistência por atrito, devida à menor adesão, ao longo da interface da nervura transversal, resulta em diminuição da tensão de aderência e em aumento do efeito do fendilhamento. Assim o resultado é redução na resistência de aderência, no caso de ruptura local por fendilhamento. Após os ensaios, foi removido o cobrimento de concreto e as barras foram inspecionadas. Somente nos modelos sem sílica ativa foram encontradas partículas de concreto firmemente aderidas à barra entre as nervuras.

HAMAD \& ITANI (1998) fizeram uma série de ensaios similares, com o intuito de estudar o efeito da sílica ativa nas características da aderência em concreto de alto desempenho. A série de ensaio foi feita com dezesseis vigas com emendas por traspasse em regiões com momento fletor positivo constante. Duas barras $\left(f_{y d}=426 \mathrm{MPa}\right.$ ) com diâmetro de $25 \mathrm{~mm}$ foram emendadas com comprimento de traspasse igual a $305 \mathrm{~mm}$. A análise do efeito da sílica ativa foi observada através da substituição do cimento pela sílica ativa nas seguintes percentagens: 0, 5, 10, 15 e $20 \%$ em relação a massa. Outras variáveis foram analisadas, a posição da barra durante a concretagem (superior ou inferior) e duas dosagens de superplastificante: 2 ou 4 litros por $100 \mathrm{~kg}$ de materiais cimentícios. O cobrimento de concreto foi de 38 mm correspondente a 1,5 vezes o diâmetro da barra. O espaçamento livre entre duas emendas foi 3 vezes o diâmetro da barra. A resistência à compressão do concreto variou, de modo geral, entre 65 e $85 \mathrm{MPa}$. A relação entre água e materiais cimentícios variou entre 0,33 e 0,37. A ruptura das emendas deveu-se ao fendilhamento das barras. O resultado indicou que a substituição de 5 a $20 \%$ do cimento por igual percentagem de massa de sílica ativa resulta, em média, em redução de $10 \%$ da tensão de aderência última, em qualquer posição da barra ou dosagem de superplastificante.

A propósito das pesquisas descritas anteriormente, as conclusões divergentes são devidas ao fato de os autores terem efetuado ensaios representativos de distintas 
situações, ou seja, GJORV et al. (1990) e DUCATTI (1993) analisaram o comportamento da aderência em ensaios de arrancamento ASTM C-234 que possui razoável grau de confinamento, HWANG et al. (1994) e HAMAD \& ITANI (1998) estudaram a aderência em emendas por traspasse em vigas de concreto.

É importante observar os argumentos de GJORV et al. (1990) e HWANG et al. (1994) quando explicam o efeito da sílica ativa no comportamento da aderência. Com base nas duas explicações pode-se inferir que, apesar da diminuição da porosidade e espessura da zona de transição, a sílica ativa diminui a adesão entre o concreto e o aço e, conseqüentemente, diminuiu a aderência por atrito.

\subsection{INFLUÊNCIA DA POSIÇÃO DA BARRA}

A posição das barras na seção de concreto durante a concretagem (horizontal ou vertical e inferior ou superior), tem menor influência sobre o comportamento da aderência do CAD do que nos concretos de resistência usual, conforme DUCATTI (1993). Uma explicação para esse fato seriam as baixas exsudação e retração plástica apresentada pelos CADs em estado fresco. O autor salienta que esses resultados foram obtidos em ensaios de arrancamento ASTM C-234, no qual é manipulada pequena quantidade de concreto que propicia moldagem cuidadosa e fixação rígida das barras nas fôrmas.

O autor observou a influência da posição da barra no comportamento da aderência dos CADs de mesmo traço. Os corpos-de-prova com barras horizontais inferiores forneceram melhor desempenho do que os corpos-de-prova com barras verticais e com barras horizontais superiores, os dois últimos não mostraram diferença significativa no desempenho da aderência.

Resultado similar foi observado por BARBOSA (1998), que apresentou em sua tese um estudo experimental e numérico sobre concreto de alto desempenho com análise da aderência e do comportamento de vigas fletidas. No estudo experimental sobre a aderência, utilizou ensaios de arrancamento ASTM C-234 com níveis de resistência à compressão do concreto em torno de 70, 80, 85 e $95 \mathrm{MPa}$. A autora concluiu que a posição relativa da barra, durante a concretagem, teve maior 
influência na tensão de aderência correspondente ao deslizamento de $0,1 \mathrm{~mm}$, valor convencionado como resistência de aderência de cálculo, do que a tensão de aderência última.

Esta conclusão pode ser complementada pela Figura 3.4 de DUCATTI (1993), que apresenta, qualitativamente, a influência na aderência do posicionamento das barras na aderência. Pode-se notar a tendência das tensões de aderência $\tau_{1 R}$ correspondentes ao deslizamento de $0,1 \mathrm{~mm}$ se igualarem para as três barras quando se aproxima da resistência à compressão do concreto em torno de $80 \mathrm{MPa}$.
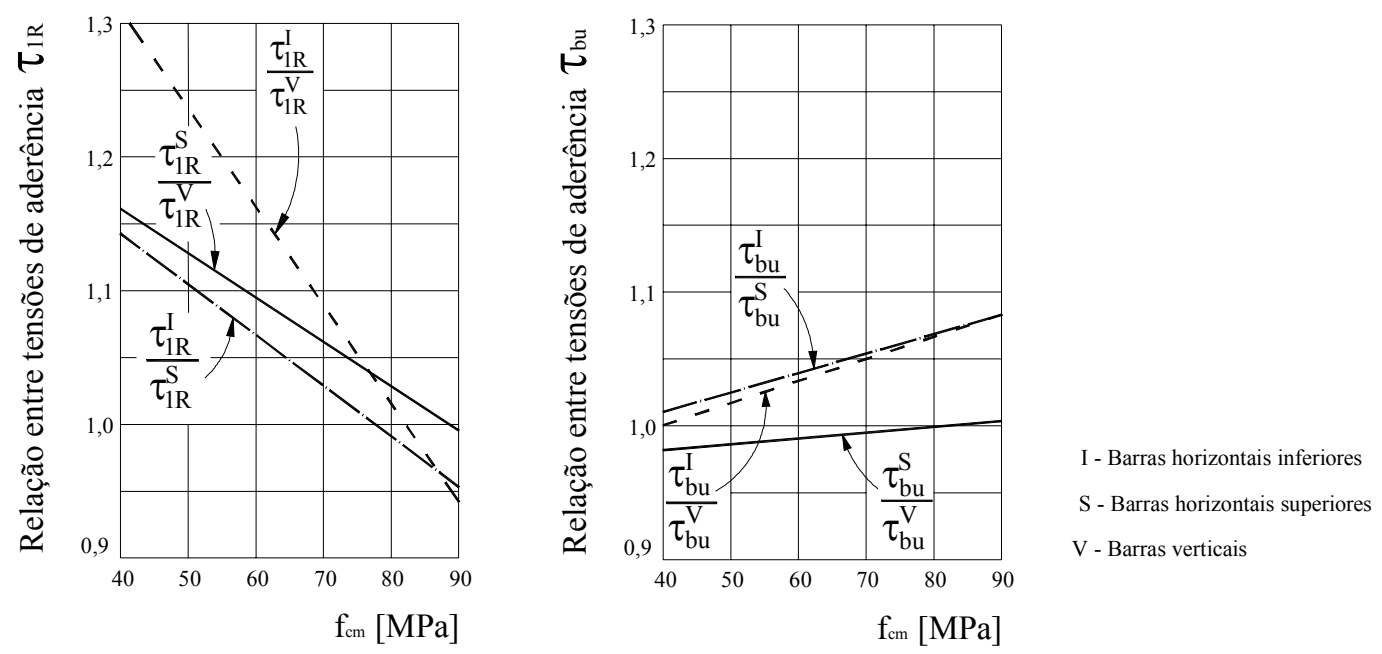

Figura 3.4 - Influência do posicionamento das barras na aderência

(DUCATTI, 1993)

DUCATTI (1993) e BARBOSA (1998) chegaram a resultados semelhantes, no entanto, com metodologias um pouco diferentes para os modelos ASTM C-234 com barras verticais. O primeiro solicitou a barra no mesmo sentido da concretagem, o segundo solicitou-a em sentido contrário.

BARBOSA (1998) justifica que a pouca sensibilidade da ligação CADarmadura em relação ao sentido de concretagem, deve-se aos seguintes fatores:

a. Maior compacidade dos Concretos de Alto Desempenho em relação aos concretos de resistência usual;

b. Ao fato de as barras concretadas em posição vertical terem sido arrancadas no sentido contrário ao de sua concretagem, o que seria desfavorável à resistência de aderência. 
Essa segunda justificativa deve ser analisada com muito cuidado, pois nas barras verticais, a exsudação provoca maior formação de poros sob as nervuras e, portanto, quando essas barras verticais são carregadas na direção de concretagem, há redução na altura efetiva dos consolos de concreto formados pela mobilização da aderência, assim, esse efeito é desfavorável à aderência. Entretanto, alguns autores afirmam que a redução da altura dos consolos é positiva porque aumenta a uniformidade da distribuição de tensão de aderência próxima à ruptura.

A FIB (2000) Bulletin n.10 salienta que, em concreto com resistência usual, as barras moldadas na parte inferiores de uma peça têm melhor desempenho na aderência que barras na parte superior. No entanto, a despeito das conclusões de DUCATTI (1993) e BARBOSA (1998), em Concreto de Alto Desempenho diversas pesquisas têm mostrado que barras superiores são melhores quanto à aderência que barras moldadas na parte inferior.

Deve-se salientar que as observações mencionadas pela FIB (2000) Bulletin n.10 estão fundamentadas em pesquisas com emendas por traspasse em vigas, e que os pesquisadores brasileiros realizaram ensaios de arrancamento ASTM C-234.

AZIZINAMINI et al. (1993) realizou uma série de ensaios com emendas por traspasse em vigas de concreto, agrupadas em pares com idêntico detalhamento e resistência similar, mas com barras emendadas em diferentes posições (superior ou inferior) em relação à peça. Portanto, submetida às mesmas condições, cada emenda das barras moldadas na parte inferior pôde ser comparada às emendas de barras na parte superior da viga. O CAD foi dosado com relação entre água e materiais cimentícios entre 0,21 e 0,27, a consistência variou entre 190 e 270 mm. O diâmetro das barras emendadas foi $35 \mathrm{~mm}$. O cobrimento de concreto foi igual a uma vez o diâmetro.

Em todos os casos ocorreu ruptura frágil devido ao fendilhamento. A tensão de aderência última foi proporcional à raiz quadrada da resistência à compressão média do concreto $\mathrm{f}_{\mathrm{cm}}$, e foram comparadas a capacidade das emendas nas partes superiores e inferiores de vigas similares. Em um par de vigas foi utilizado concreto com resistência usual (35 e $40 \mathrm{MPa}$ ). O modelo com barras emendadas na parte superior apresentou menor tensão de aderência (aproximadamente 8\%) em relação ao modelo com barras emendadas na parte inferior. Entretanto, em três pares de vigas 
com Concreto de Alto Desempenho ( $f_{c m}$ entre 75 e $100 \mathrm{MPa}$ ), as vigas com barras emendadas na parte superior apresentam emendas com capacidade ligeiramente melhor que o das vigas com barras emendadas na parte inferior, entre 1 e $8 \%$. Baseado nas observações do comportamento dos modelos de CADs, os autores admitiram que, na ruptura, as distribuições de tensões de aderência ao longo das emendas foram menos uniformes nos CADs que no concreto com resistência usual. Isto pode ser explicado pela maior capacidade portante dos consolos mobilizados pela aderência no Concreto de Alto Desempenho e pelo fato de a resistência ao fendilhamento, que está relacionada à resistência à tração do concreto, não aumentar proporcionalmente com a resistência à compressão. Dessa forma, segundo os autores, nas barras moldadas na parte superior, a exsudação exerceria influência positiva nos CADs. Isto porque os poros na metade inferior dessas barras iriam diminuir a capacidade portante dos consolos e, assim, maior uniformidade da distribuição de tensão de aderência seria obtida na ruptura.

Em estudo similar HAMAD \& ITANI (1998) também concluíram que, para vigas de CAD sem sílica ativa, barras emendadas na parte superior das peças têm emendas com maior capacidade que barras moldadas na parte inferior. Esse resultado foi validado para duas dosagens de superplastificante utilizadas na pesquisa (2 e 4 litro por $100 \mathrm{~kg}$ de cimento).

\subsection{INFLUÊNCIA DO SUPERPLASTIFICANTE}

As características do concreto são consideravelmente influenciadas pelo uso dos superplastificantes. Dessa forma, a natureza do produto e sua dosagem também podem influenciar na resistência de aderência.

CARRASQUILLO (1988) realizou ensaios de arrancamento com várias dosagens de superplastificante, com dois tipos do produto: um à base de naftaleno e outro à base de melamina. Os resultados foram comparados com concreto de resistência usual sem superplastificante. A autora concluiu que a adição dos superplastificantes à base de naftaleno provoca um aumento na resistência do concreto e, conseqüentemente, melhora seu desempenho quanto à aderência. $\mathrm{O}$ 
emprego de superplastificante à base de melamina não influencia na resistência do concreto.

No estudo executado por HAMAD \& ITANI (1998) os autores concluíram que o aumento da dosagem de superplastificante de 2 para 4 litros, para cada $100 \mathrm{~kg}$ de materiais cimentícios, tem efeito negativo na capacidade das emendas por traspasse das barras moldadas na parte inferior da viga e efeito positivo nas barras superiores. 


\section{CAPÍTULO 4}

\section{ADERÊNCIA SOB AÇÕES CÍCLICAS}

\subsection{GENERALIDADES}

O carregamento cíclico produz deterioração progressiva da aderência que pode conduzir à ruptura em níveis de tensão mais baixos que a tensão última monotônica. A acumulação do dano da aderência é causada supostamente pela propagação de microfissuras e esmagamento progressivo do concreto em frente às nervuras, com aumento do deslizamento.

Quanto à natureza, as ações nas estruturas podem ser estáticas ou dinâmicas. As ações estáticas atuam permanentemente com valores constantes ou com pequenas variações em torno de sua média, praticamente durante toda a vida da construção. De modo geral, o carregamento estático é caracterizado por parâmetro crescente, como força ou deslocamento; de longa duração ou de curta duração (monotônico). Quanto às ações dinâmicas, uns de seus vários tipos são as cíclicas, caracterizadas por determinada amplitude e intensidade de tensão ou deslizamento.

Geralmente carregamentos cíclicos são divididos em duas categorias. A primeira categoria é caracterizada por número relativamente baixo de ciclos (lowcycle), ou história de carregamento que inclui poucos ciclos de carga ou deslizamento, mas com alta intensidade correspondente ao estado limite último. Os terremotos e tempestades são exemplos desse tipo de carregamento. A segunda categoria caracteriza-se por grande número de ciclos (high-cycle), ou seja, história de carregamento com vários ciclos, mas com baixa intensidade, correspondente ao nível 
de carga de serviço. Esse tipo de carregamento conduz à situação clássica de fadiga. Exemplo para esta segunda categoria: cargas móveis, vibrações de maquinaria, carregamento de vento e ondas do mar. Não existe nenhum limite entre essas duas categorias de carregamento cíclico.

O comportamento da aderência sob carregamento cíclico pode ser subdividido de acordo com o tipo de tensão aplicada. O primeiro tipo de carregamento é o repetido ou unidirecional, no qual a tensão na barra da armadura não troca de sentido (tração ou compressão) e corresponde ao caso típico de fadiga. O segundo tipo é o carregamento cíclico alternado ou reverso, onde a barra é submetida, alternadamente, a tensões de tração e compressão. Tensões reversas são casos típicos de carregamento sísmico.

\subsection{AÇÕES REPETIDAS COM AMPLITUDE CONSTANTE}

A principal característica da aderência sob ação de cargas repetidas é sua deterioração progressiva, observada por incremento no deslizamento não proporcional ao aumento do carregamento, ou seja, a ação cíclica provoca redução na rigidez de aderência (definida pela relação $\tau_{\mathrm{b}} / \mathrm{s}$ ) (BRESLER \& BERTERO, 1968). Este efeito desfavorável sobre a aderência pode provocar, nas peças de concreto armado, aumento progressivo na abertura de fissuras, e diminuir a vida útil da estrutura.

LARANJEIRAS (1976) estudou o fenômeno da aderência com intuito de analisar a influência da manutenção, repetição e história de carregamento. $\mathrm{Na}$ investigação realizada no Laboratório Nacional de Engenharia Civil de Lisboa, foram utilizados corpos-de-prova de duplo arrancamento.

$\mathrm{O}$ autor realizou quatro séries de ensaios, com resistência à compressão do concreto, mensurada em cubos com aresta de $20 \mathrm{~cm}$, de 28,5 a 34,9 MPa. Cada série de ensaio tinha três corpos-de-prova. Foram utilizadas barras com $20 \mathrm{~mm}$ de diâmetro. Os ensaios sob ação repetida foram realizados com freqüência de 5,55 Hz. O deslizamento foi medido na extremidade livre (ou descarregada) das duas barras de cada corpo-de-prova. 
Em cada série, um dos corpos-de-prova foi ensaiado sob carregamento monotônico até a ruptura. Os outros dois corpos-de-prova foram ensaiados sob carregamento repetido, obedecendo ao seguinte procedimento:

a. Elevação e subseqüente manutenção do carregamento em valor pré-fixado e por tempo suficiente para reduzir sensivelmente os efeitos dessa manutenção sobre os acréscimos de deslizamentos. Esse tempo de manutenção variou entre 25 e 90 minutos;

b. Em seguida, foram aplicados ciclos de carga com número de repetições maior que $10^{5}$. O nível mínimo da amplitude $\left(\tau_{\mathrm{b}, \min }\right)$ foi a tensão correspondente a $10 \mathrm{kN}$ e $\mathrm{o}$ nível máximo $\left(\tau_{\mathrm{b}, \max }\right)$ foi a tensão correspondente ao carregamento máximo já atingido no primeiro estágio. Esse nível $\tau_{\mathrm{b} \text {,max }}$ foi a variável mais importante do estudo, cuja grandeza foi sempre inferior a 70\% da tensão de aderência última monotônica;

c. Por fim, elevação da carga em ensaio monotônico, a partir do valor superior já atingido, até a ruptura.

Em todos os ensaios, os corpos-de-prova romperam-se por fendilhamento do concreto. Apesar das diferenças, por vezes acentuadas, dos resultados de modelos ensaiados sob as mesmas condições, o autor destaca algumas conclusões. A manutenção e a repetição do carregamento diminuíram a rigidez da aderência e os deslizamentos foram irreversíveis.

Os resultados obtidos por LARANJEIRAS (1976) indicam que os deslizamentos provocados pela ação repetida crescem progressivamente. O aumento do deslizamento é mais rápido no início e com incrementos gradativamente menores à medida que cresce o número de repetições, tendendo a estabilizar em um valor final.

Para o mesmo número de repetições, quanto maior o nível máximo da amplitude $\left(\tau_{b, \max }\right)$ tanto maiores são os acréscimos de deslizamentos resultantes. Dessa forma, esses acréscimos são proporcionais à grandeza do nível máximo da amplitude. 
REHM \& ELIGEHAUSEN (1979) estudaram o comportamento da aderência sob carregamento repetido com amplitude constante. De acordo com seus resultados, a curva deslizamento versus número de ciclos em escala dupla logarítmica é aproximadamente linear (Figura 4.1).

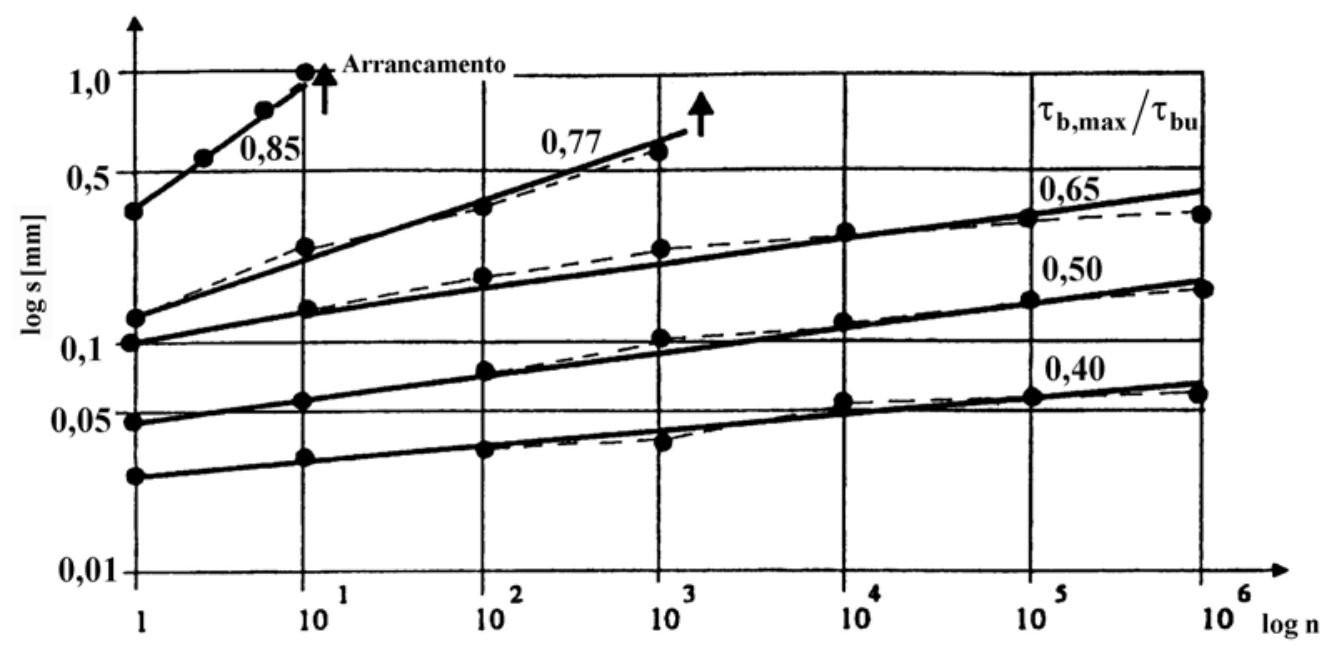

Figura 4.1 - Deslizamento na extremidade descarregada versus número de ciclos em escala dupla logarítmica

$$
\left(\phi=14 \mathrm{~mm}, \ell=3 \phi, \mathrm{f}_{\mathrm{y}}=500 \mathrm{MPa}, \mathrm{f}_{\mathrm{cc}}=23,5 \mathrm{MPa}, \tau_{\mathrm{b}, \min }=0,1 \tau_{\mathrm{b}, \max }\right):
$$

(REHM \& ELIGEHAUSEN, 1979)

Os autores também concluíram que se a ruptura por fadiga da aderência não ocorrer, após aplicar ciclos de carga e recarregar o corpo-de-prova com carregamento monotônico, a curva $\tau_{b}-\mathrm{s}$ retoma seu comportamento monotônico. Dessa forma, em comparação ao comportamento da aderência sob carregamento monotônico, os ciclos iniciais não influenciam negativamente a aderência próxima ao carregamento último, conforme mostrado na Figura 4.2. 


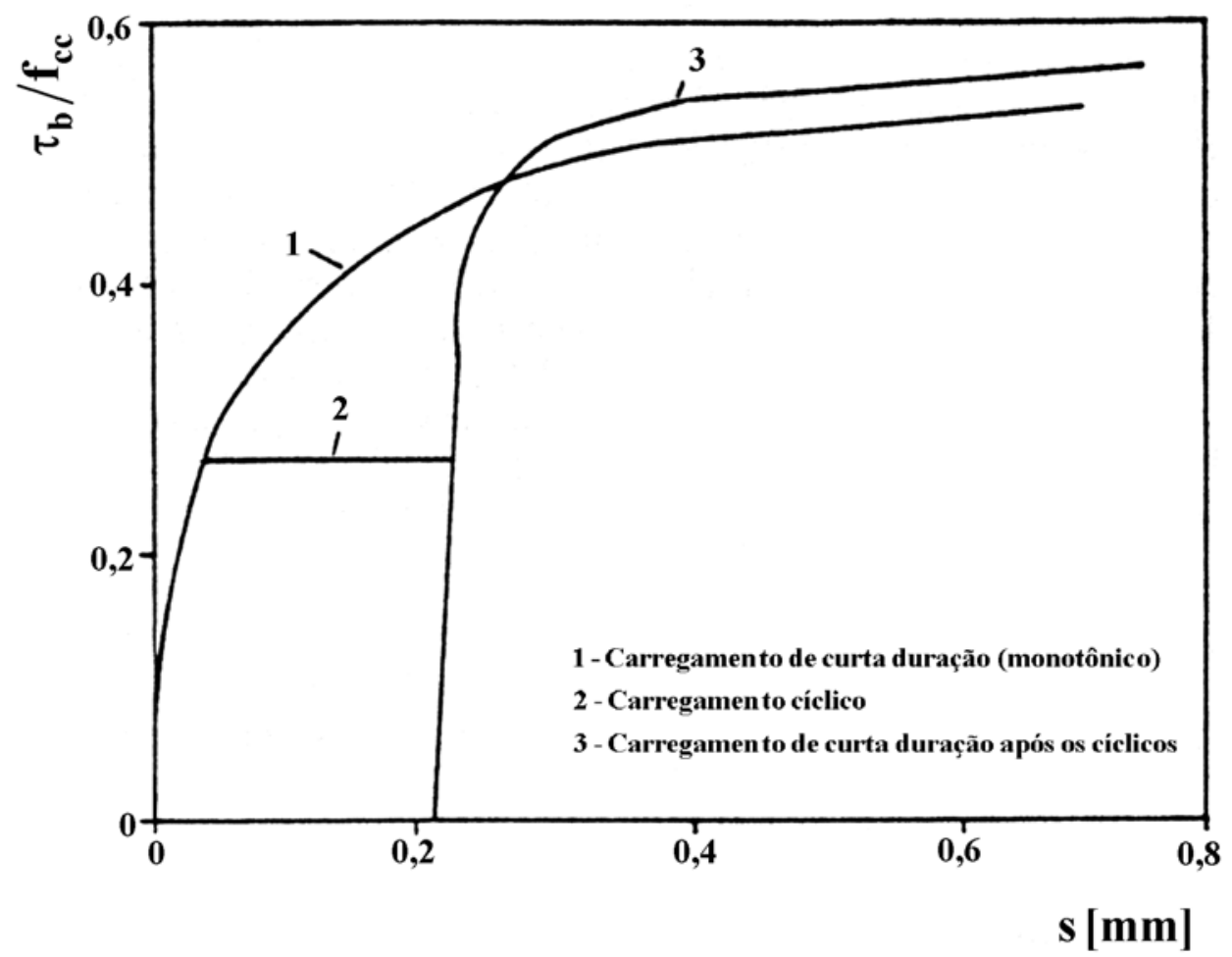

Figura 4.2 - Influência do carregamento repetido na tensão de aderência última (REHM \& ELIGEHAUSEN, 1979)

Ensaios semelhantes, sob carregamento repetido com amplitude constante, foram realizados por BALÁZS, HOCH \& HARRE ${ }^{13}$ apud FIB (2000) Bulletin n.10. Até 2 milhões de ciclos de carga, nenhum ensaio findou-se com ruptura por arrancamento sob amplitude com carregamento máximo $\left(\tau_{\mathrm{b}, \max }\right)$ até $50 \%$ da tensão de aderência última monotônica, conforme a Figura 4.3.

13 BALÁZS, G.L.; KOCH, R.; HARRE, W. (1994). Verbund von stahl in beton unter betriebsbeanspruchung. Deutscher Ausschuss für Stahlbeton 30. Forschungs-kolloquium, 0405. Nov. 1994. Stuttgart, p.167-76 apud FIB (2000) Bulletin n.10. 


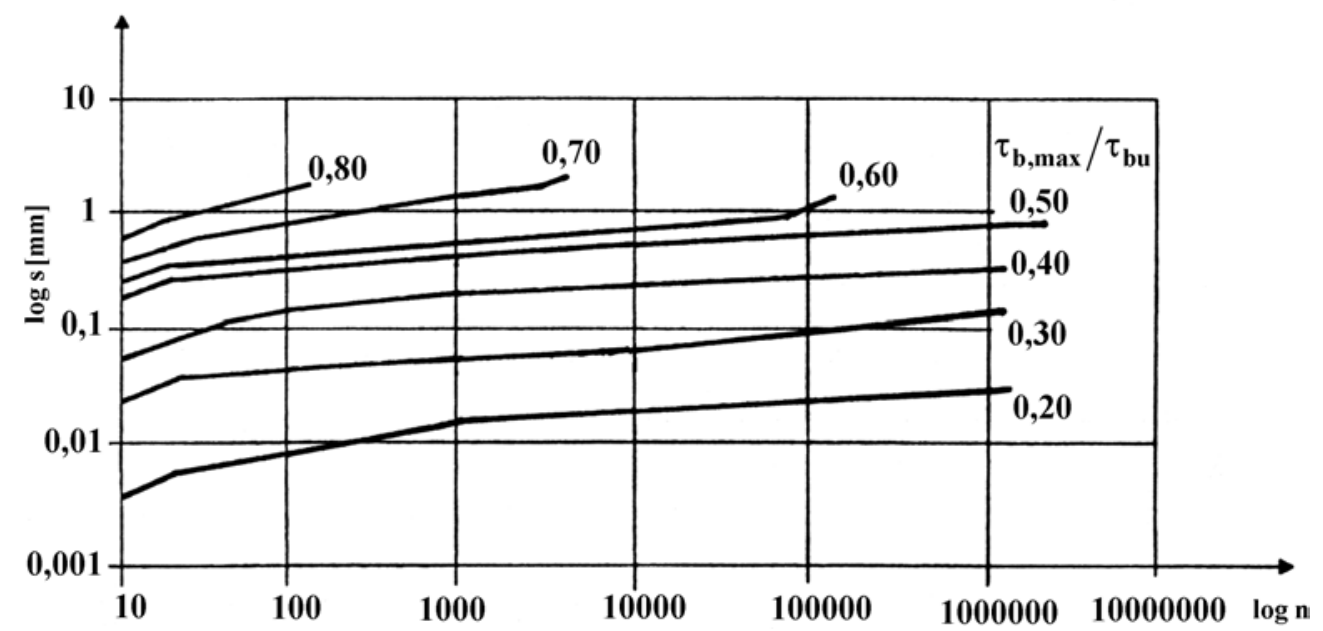

Figura 4.3 - Deslizamento na extremidade descarregada versus número de ciclos do carregamento repetido com amplitude constante em escala dupla logarítmica

$\left(\phi=16 \mathrm{~mm}, \ell=5 \phi, \mathrm{f}_{\mathrm{y}}=500 \mathrm{MPa}, \mathrm{f}_{\mathrm{cc}}=30 \mathrm{MPa}, \tau_{\mathrm{b}, \min }=0,1 \tau_{\mathrm{b}, \max }\right):$

(BALÁZS, KOCH \& HARRE ${ }^{13}$ apud FIB, 2000 Bulletin n.10)

Considerando a ruptura da aderência sob carregamento repetido com amplitude constante, BALÁZS (1991) desenvolveu pesquisa através de ensaios de arrancamento. Conforme a Figura 4.4a, o autor observou que inicialmente a velocidade de deslizamento é decrescente, posteriormente permanece constante e, por fim, cresce rapidamente antes da ruptura por arrancamento. Essa terceira fase tem inicio após ser alcançado o deslizamento $s\left(\tau_{\text {bu }}\right)$ correspondente a tensão de aderência última sob carregamento monotônico. Se o deslizamento $s\left(\tau_{\mathrm{bu}}\right)$ não for ultrapassado, a ruptura é evitada. Esse comportamento foi encontrado independentemente do nível de carregamento (representado pela relação entre o nível de tensão máxima da amplitude do carregamento repetido e a tensão de aderência última monotônica: $\left.\tau_{\mathrm{b}, \max } / \tau_{\mathrm{bu}}\right)$ ou número de ciclos. Portanto, $\mathrm{s}\left(\tau_{\mathrm{bu}}\right)$ pode ser utilizado como critério seguro para análise da ruptura da aderência por fadiga. 


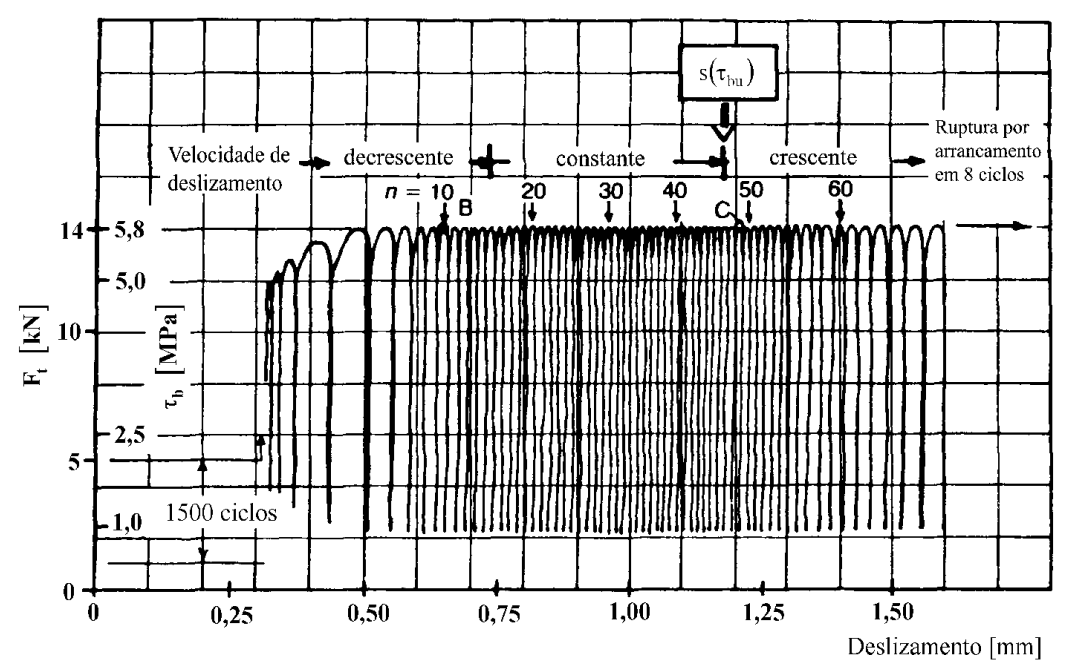

(a)

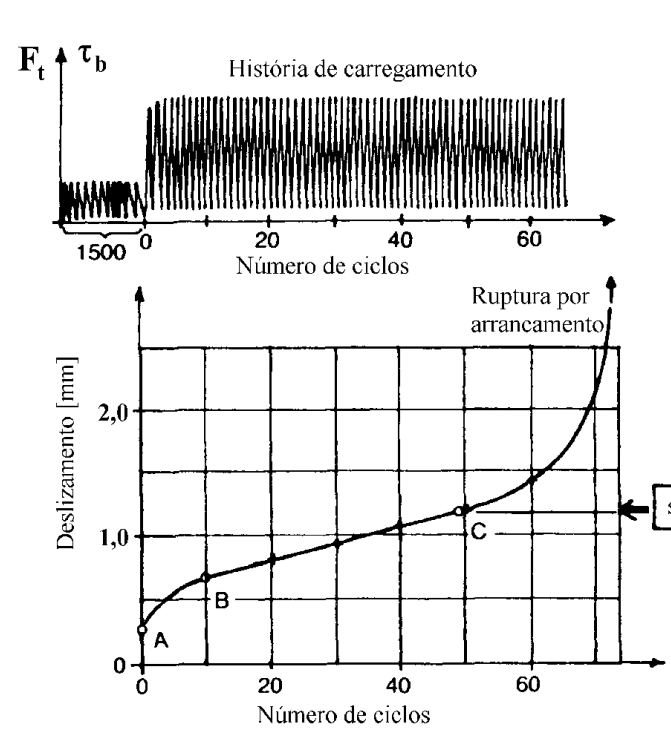

(b)

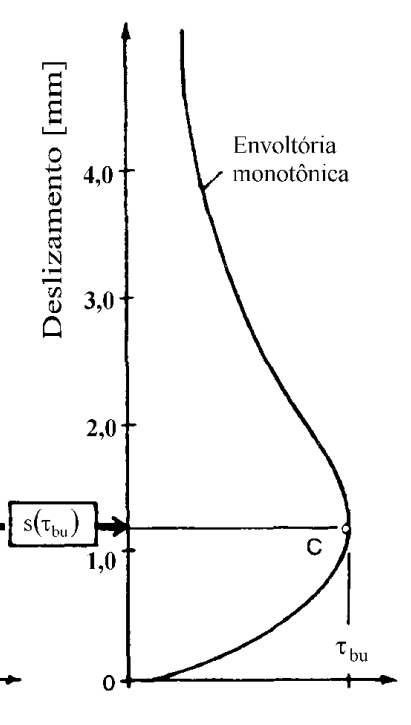

(c)

Figura 4.4 - Processo de fadiga da aderência sob carregamento repetido $\left(\phi=8 \mathrm{~mm}, \ell=12 \phi, \mathrm{f}_{\mathrm{y}}=400 \mathrm{MPa}, \mathrm{f}_{\mathrm{cc}}=20 \mathrm{MPa}, \tau_{\mathrm{b}, \min }=0,15 \tau_{\mathrm{b}, \max }\right)$

a) Curva $\tau_{b}$-s sob ação repetida; b) Diagrama deslizamento-número de ciclos;

c) Curva $\tau_{b}$-s sob ação monotônica

(BALÁZS, 1991)

Como também se pode observar na Figura 4.4b, a curva deslizamento versus número de ciclos em escala linear contém três trechos: um côncavo, um linear e outro convexo. A velocidade de deslizamento durante as três fases é função do nível de carregamento $\left(\tau_{\mathrm{b}, \max } / \tau_{\mathrm{bu}}\right)$, conforme resultados de KOCH \& BALÁZS (1993) mostrados na Figura 4.5. 
(a)

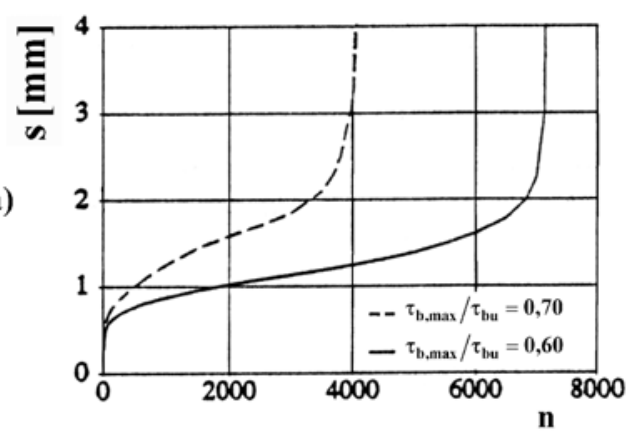

(b)

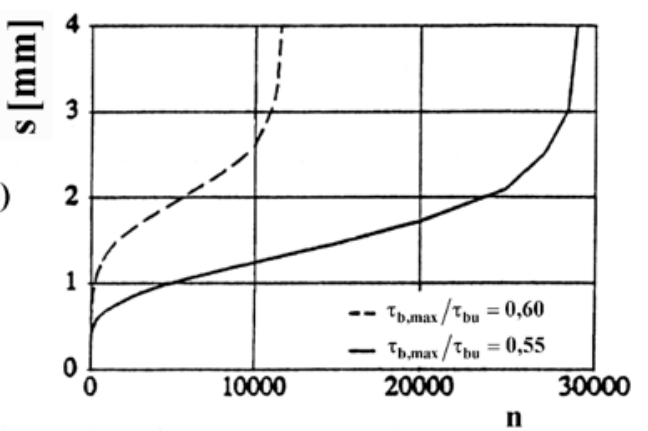

Figura 4.5 - Crescimento do deslizamento com o número de ciclos $\left(\phi=16 \mathrm{~mm}, \ell=5 \phi, \mathrm{f}_{\mathrm{y}}=500 \mathrm{MPa}, \mathrm{f}_{\mathrm{cc}}=30 \mathrm{MPa}, \tau_{\mathrm{b}, \min }=0,1 \tau_{\mathrm{b}, \max }\right)$ (KOCH \& BALÁZS, 1993)

A Figura 4.6 apresenta resultados de REHM \& ELIGEHAUSEN (1979), indicados pela relação entre o nível de tensão do carregamento repetido $\left(\tau_{\mathrm{b} \text {,max }} / \tau_{\mathrm{bu}}\right)$ versus o número de ciclos de carga na ruptura. Nenhuma influência da resistência do concreto $(23,5 \mathrm{MPa}$ e $48 \mathrm{MPa})$ e do diâmetro da barra $(8,14,28 \mathrm{~mm})$ foi observada. A tensão de aderência última para $10^{6}$ ciclos de carga foi observada com $\tau_{\mathrm{b}, \max } / \tau_{\mathrm{bu}}=0,65$.

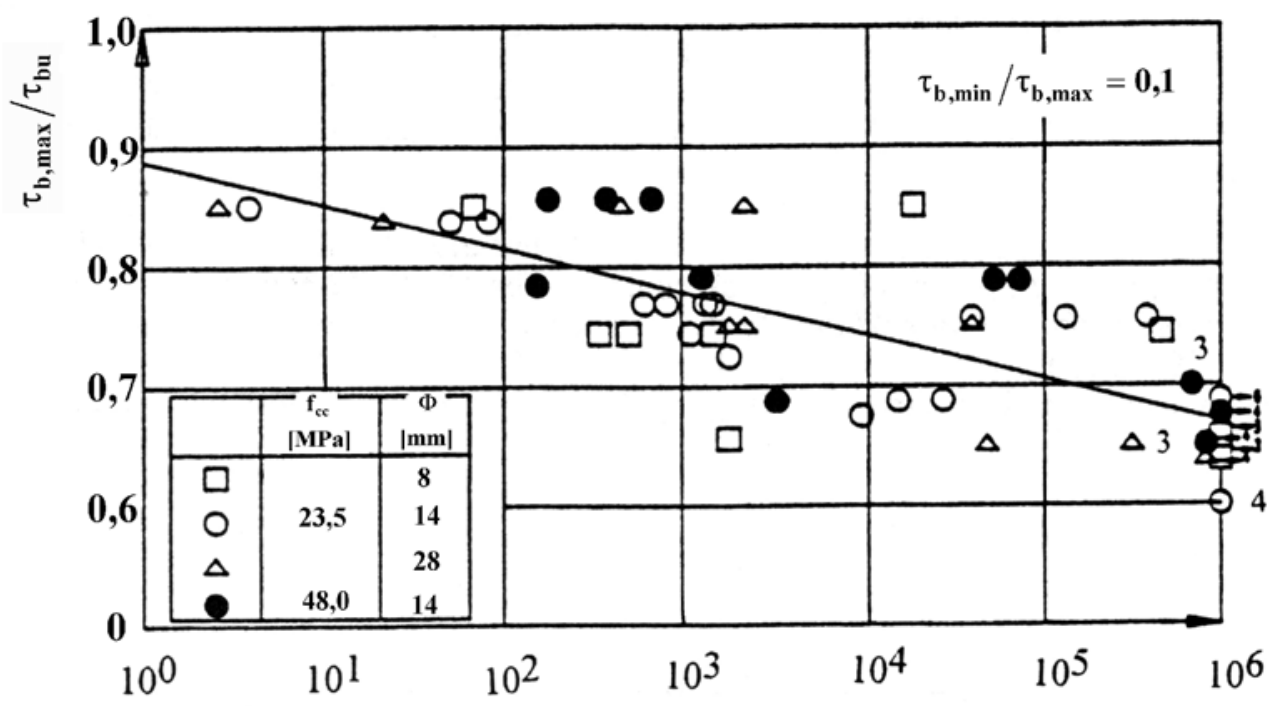

Número de ciclos

Figura 4.6 - Influência do nível de carregamento $\left(\tau_{\mathrm{b}, \max } / \tau_{\mathrm{bu}}\right)$ sobre o número de ciclos necessário para a ruptura da aderência

(REHM \& ELIGEHAUSEN, 1979) 
A influência de carregamentos repetidos no comportamento da aderência também foi analisada por VALLE (1994). A investigação não incluía a ruptura por carregamento repetido. A aderência foi "envelhecida" com a aplicação de carregamento repetido e, posteriormente, o corpo-de-prova foi rompido sob ação monotônica para se comparar seu desempenho com os de outros corpos-de-prova ensaiados simplesmente por carregamento monotônico.

A autora realizou a pesquisa através de ensaios das quatro barras. Os ensaios foram realizados sob controle de deslocamento, dessa forma, a medida que os ciclos eram aplicados, a amplitude de deslocamento era mantida constante e a de carregamento não. Como conseqüência, em alguns corpos-de-prova, surgiram forças de compressão. A precisão do equipamento de ensaio não permitia amplitudes de deslocamentos menores que $1 \mathrm{~mm}$. Foram utilizadas freqüências de 1 e $5 \mathrm{~Hz}$.

Nos ensaios foram analisados variáveis como a distância entre a barra central e as barras perimetrais, o comprimento de ancoragem da barra central e os carregamentos estático e repetido.

Através dessa pesquisa concluiu-se que o carregamento repetido prévio diminui a tensão de aderência última. Segundo VALLE (1994), isso se deve ao fato de a ação repetida causar a ruptura dos pontos de ligação mais frágeis. Também foram observados maiores deslizamentos, mensurados na extremidade descarregada da barra central, correspondentes aos carregamentos últimos. Isso seria ocasionado pelo deslizamento residual provocado pela carga repetida.

\subsection{AÇÕES REPETIDAS COM AMPLITUDE VARIÁVEL}

BALÁZS (1991) verificou que a história do carregamento tem significativa influência no deslizamento. Conforme a Figura 4.7, o crescimento periódico da força máxima de uma amplitude $\left(\mathrm{F}_{\max }\right)$ produz maior velocidade de deslizamento na parte linear intermediária. 


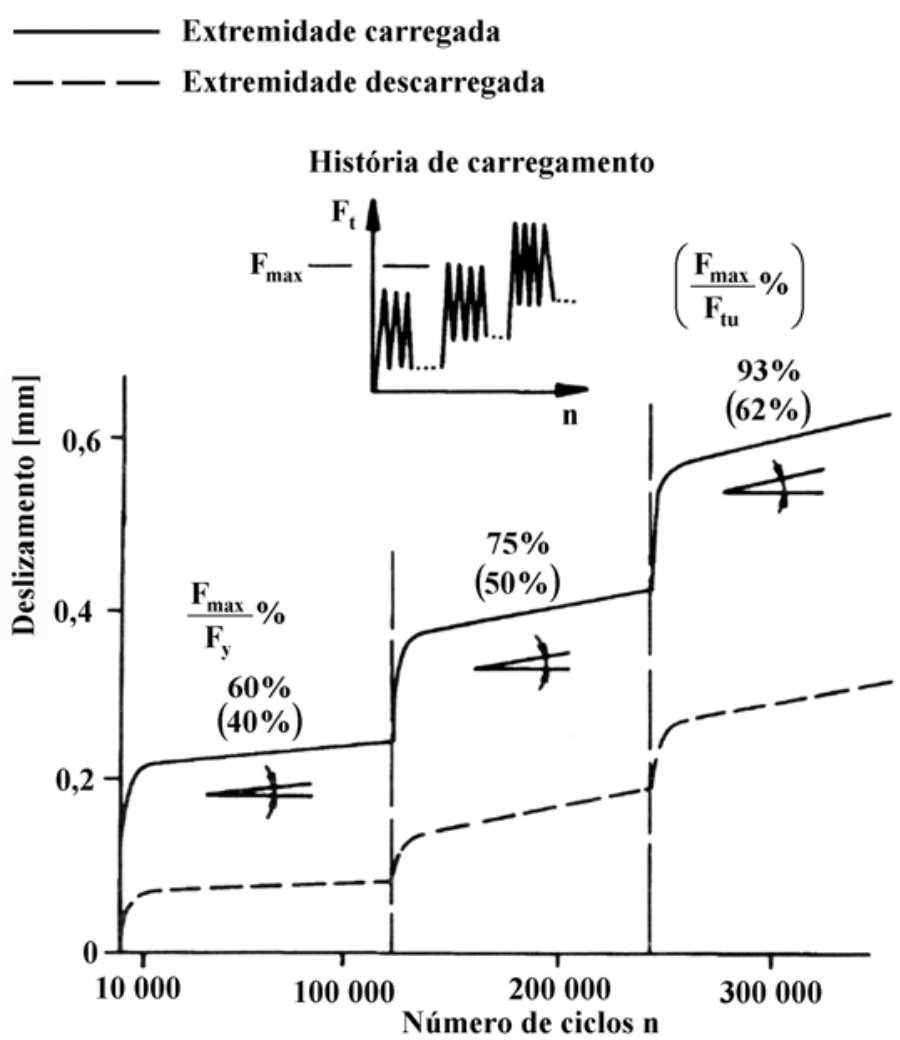

Figura 4.7 - Crescimento do deslizamento sob carregamento repetido crescente periodicamente $\left(\phi=8 \mathrm{~mm}, \ell=12 \phi, \mathrm{f}_{\mathrm{y}}=400 \mathrm{MPa}, \mathrm{f}_{\mathrm{cc}}=20 \mathrm{MPa}, \tau_{\mathrm{b}, \min }=0,15 \tau_{\mathrm{b}, \max }\right)$ (BALÁZS, 1991)

Em estudo experimental, BALÁZS \& $\mathrm{KOCK}^{14}$ apud FIB (2000) Bulletin n.10, analisaram modelos do ensaio de arrancamento sob carregamento repetido com amplitude variável. O nível de carregamento máximo da amplitude $\left(\tau_{\mathrm{b} \text {,max }}\right)$ aumentava ou diminuía com variação linear, parabólica ou logarítmica. A história de carregamento e a relação deslizamento por número de ciclos de carga estão indicadas na Figura 4.8. 

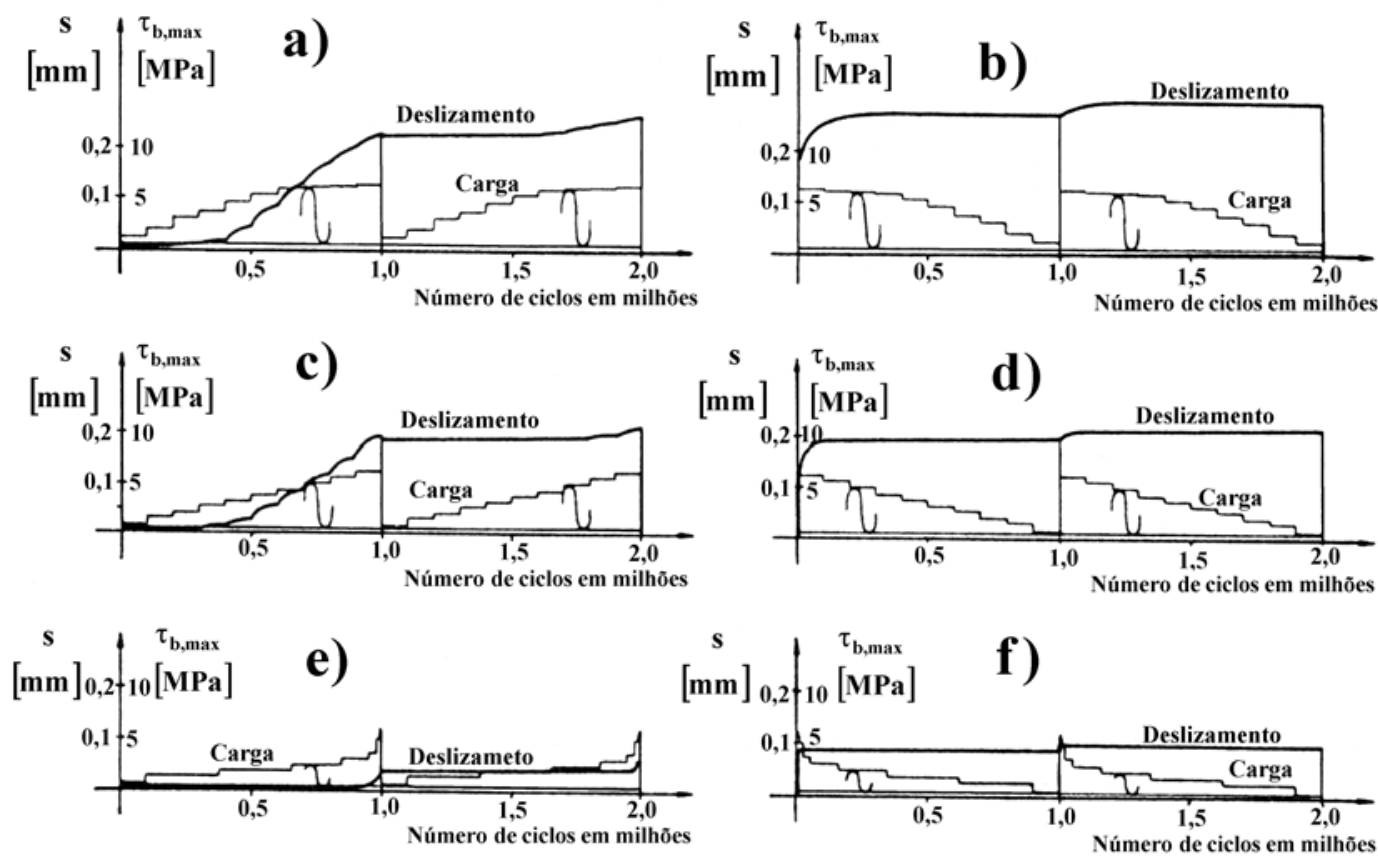

Figura 4.8 - Aumento de deslizamento em função da história de carregamento

$\left(\tau_{\mathrm{MAX}} / \tau_{\mathrm{bu}}=0,4\right) \quad$ a) $\left.-\mathrm{b}\right)$ Amplitude com variação parabólica;

c) - d) Amplitude com variação linear; e) - f) Amplitude com variação logarítmica (BALÁZS \& $\mathrm{KOCH}^{14}$ apud FIB, 2000 Bulletin n.10)

$\mathrm{O}$ ensaio foi dividido em dois blocos com a mesma seqüência de carregamento e totalizando 1 milhão de ciclos cada. Cada bloco consiste em 10 subblocos com amplitude constante.

Com seqüência de amplitudes crescente (Figuras 4.8a, 4.8c e 4.8e) o primeiro bloco de carregamento produziu deslizamento crescente com taxas maiores a cada aumento de $\tau_{\mathrm{b}, \max }$. No segundo bloco, os ciclos com níveis de carregamento menores que o máximo já atingido $\left(\tau_{\mathrm{MAX}}\right)$ não contribuíram para aumentar o deslizamento.

Com seqüência de amplitudes decrescente (Figuras 4.8b, 4.8d e 4.8f) um significativo aumento do deslizamento nos dois blocos foi produzido somente pelo maior nível de carregamento $\left(\tau_{\mathrm{MAX}}\right)$, ou seja, pelo maior valor dentre os diversos níveis de $\tau_{\mathrm{b}, \max }$. Níveis menores não aumentaram os deslizamentos. O mesmo desenvolvimento do deslizamento foi observado nos dois blocos.

${ }^{14}$ BALÁZS, G.L.; KOCH, R. (1992). Influence of load history on bond behavior. Proceedings of the "Bond in Concrete" Conference Riga 1992, 7-1.-7-10 apud FIB (2000) Bulletin n.10. 
A Figura 4.9 compara o crescimento do deslizamento, alcançado durante $1 \mathrm{e}$ 2 milhões de ciclos de carga, em função da história do carregamento. As histórias de carregamento foram definidas numericamente pela relação entre a integral da curva de $\tau_{\mathrm{b}, \max }$ pela integral da curva com amplitude constante, igual ao maior nível de carregamento $\left(\tau_{\mathrm{MAX}}\right)$ alcançado durante o plano de trabalho. Essa relação descreve a intensidade do ciclo de carga. Assim, o valor obtido foi denominado Fator de Intensidade do Ciclo de Carga. A Figura 4.9 indica que o ciclo de carga com maior fator de intensidade apresenta a maior taxa de crescimento do deslizamento.

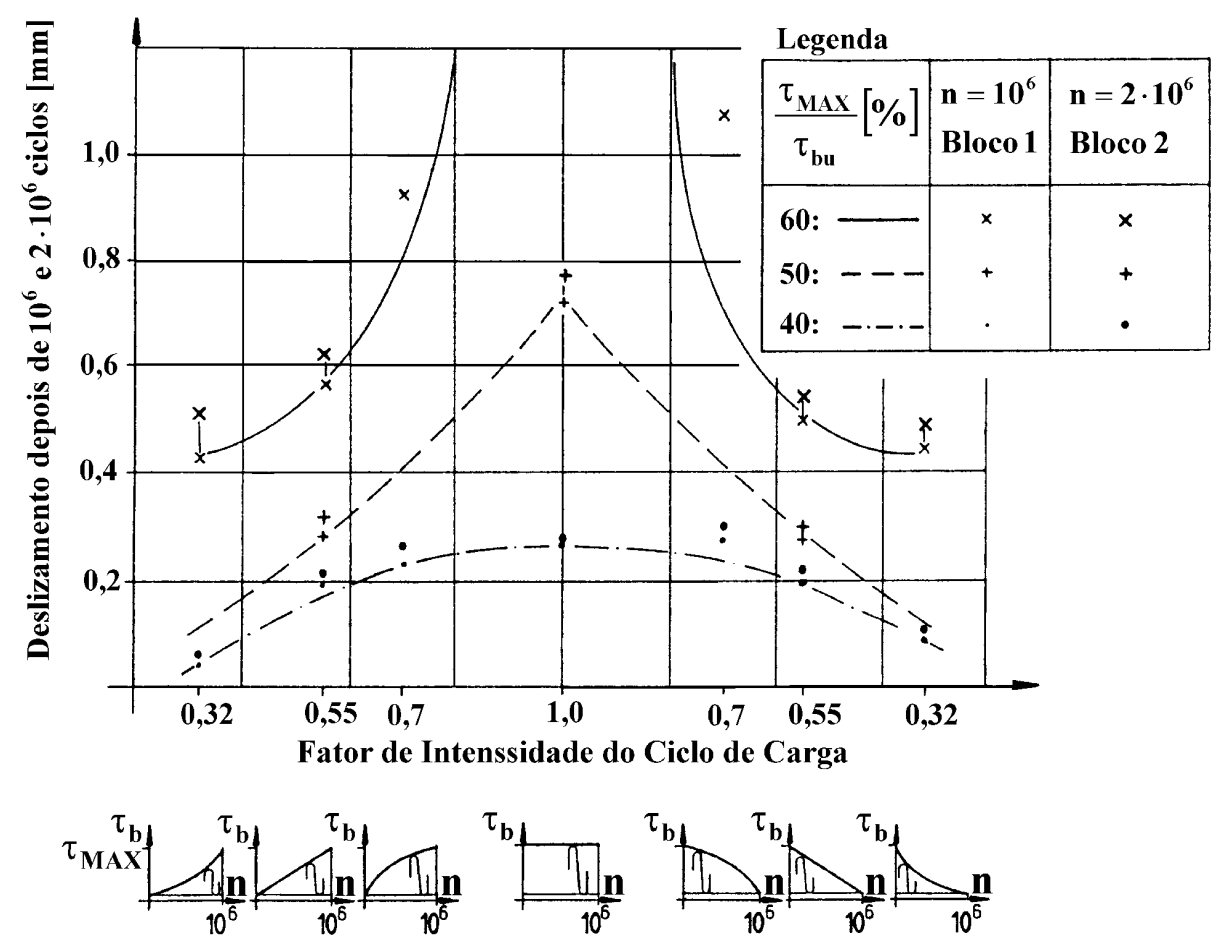

Figura 4.9 - Aumento do deslizamento, devido a $10^{6}$ e $2 \cdot 10^{6}$ ciclos de carga, em função da história de carregamento $\left(\tau_{\mathrm{MAX}} / \tau_{\mathrm{bu}}=0,4,0,5\right.$ e 0,6$)$ (BALÁZS \& KOCK ${ }^{14}$ apud FIB, 2000 Bulletin n.10)

BALÁZS \& KOCK (1994) analisaram o comportamento de modelos de ensaio de arrancamento através de três séries de ensaios sob carregamento repetido com amplitudes com níveis máximos $\left(\tau_{\mathrm{b} \text {,max }}\right)$ gerados aleatoriamente. Em cada série, a história de carregamento foi composta por 200 blocos com mesma amplitude e com 10.000 ciclos de carga. Na Figura 4.10 esses valores máximos da amplitude para determinado bloco estão indicados em função do maior nível de carregamento 
$\left(\tau_{\mathrm{MAX}}\right)$ alcançado na série $\left(0 \leq \tau_{\mathrm{b}, \max } / \tau_{\mathrm{MAX}} \leq 1\right)$. As três séries estão divididas por terem diferentes percentagens para o maior nível de tensão atingida em relação a tensão de aderência última monotônica $\left(\tau_{\mathrm{MAX}} / \tau_{\mathrm{bu}}=0,6,0,7 \mathrm{e} 0,8\right)$. Para cada série, o valor mínimo da amplitude $\left(\tau_{\mathrm{b}, \min }\right)$, para todos os blocos, foi estabelecido em $10 \%$ do maior nível de carregamento alcançado $\left(\tau_{\mathrm{b}, \min }=0,1 \cdot \tau_{\mathrm{MAX}}\right)$.

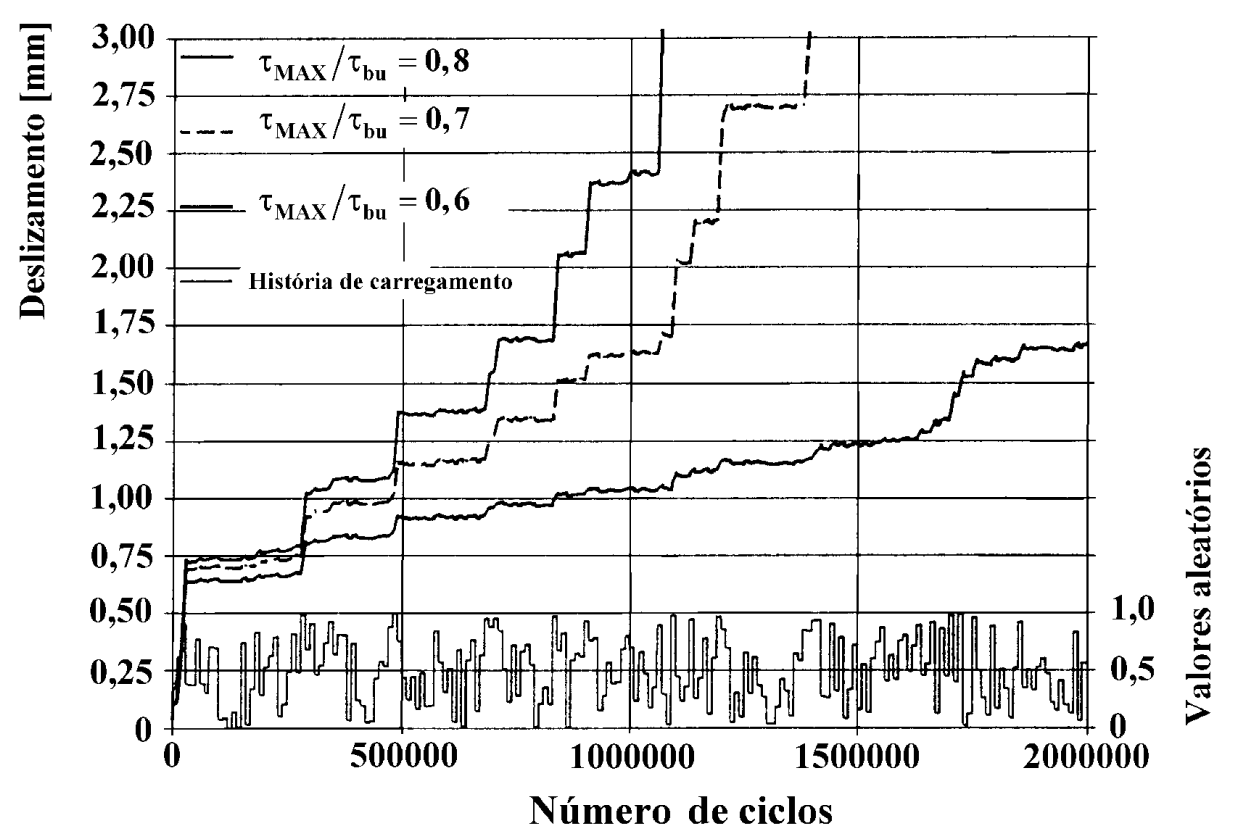

Figura 4.10 - Aumento do deslizamento sob ciclos com amplitudes aleatórias $\left(\phi=16 \mathrm{~mm}, \ell=5 \phi, \mathrm{f}_{\mathrm{y}}=500 \mathrm{MPa}, \mathrm{f}_{\mathrm{cc}}=30 \mathrm{MPa}\right.$, $\tau_{\mathrm{MAX}} / \tau_{\mathrm{bu}}=0,6,0,7$ e $\left.0,8, \tau_{\mathrm{b}, \min }=0,1 \tau_{\mathrm{MAX}}\right)$

(BALÁZS \& KOCH, 1994)

A Figura 4.10 apresenta uma comparação entre o desenvolvimento do deslizamento em função do número de ciclos de cargas para cada uma das três séries. A comparação indica claramente que somente há considerável aumento do deslizamento quanto se atinge ou aproxima-se do maior nível de carga previsto $\left(\tau_{\mathrm{MAX}}\right)$. A contribuição para níveis de carregamento menores é quase desprezível. 


\subsection{CARREGAMENTO DE LONGA DURAÇÃO}

De acordo com os resultados de LARANJEIRAS (1976), a manutenção do carregamento aumenta os deslizamentos, mais rapidamente nos primeiros minutos e mais lentamente com o passar do tempo, tendendo a estabilizar em um valor final. Esses acréscimos nos deslizamentos com o tempo de manutenção do carregamento são proporcionais à magnitude do carregamento. Resultados semelhantes também foram obtidos por KOCH \& BALÁZS (1993).

A manutenção e repetição do carregamento têm qualitativamente a mesma influência no comportamento da aderência. No entanto, os aumentos de deslizamentos provocados pela repetição de carga estabilizam-se em valores sensivelmente maiores do que os provocados pela manutenção do carregamento. Isso para níveis de carregamento máximo da amplitude igual ao carregamento de longa duração.

Segundo LARANJEIRAS (1976), o valor da tensão de aderência $\left(\tau_{1 \mathrm{R}}\right)$ correspondente ao deslizamento de $0,1 \mathrm{~mm}$ sob carregamento monotônico, é reduzido em aproximadamente $20 \%$ devido ao efeito da manutenção do carregamento e em cerca de $30 \%$ devido ao efeito da repetição desse mesmo carregamento, ou seja, devido ao efeito da repetição de carregamento com nível máximo da amplitude igual ao carregamento de longa duração.

REHM \& ELIGEHAUSEN (1979) concluíram que a ação repetida pode ser considerada como acelerador do tempo em relação à ação de longa duração. Os comportamentos da aderência sob essas duas ações são semelhantes, podendo o crescimento do deslizamento devido essas ações serem expresso por uma mesma expressão matemática.

A coincidência do mesmo efeito qualitativo da manutenção e repetição do carregamento sobre o comportamento da aderência indica, claramente, segundo LARANJEIRAS (1976), que os efeitos causados nos dois casos são de mesma natureza. Assim, esses carregamentos incidem do mesmo modo sobre o mecanismo que decorre a aderência. $\mathrm{O}$ autor apresentou um modelo de mecanismo do comportamento da aderência sob manutenção e repetição do carregamento. No 
entanto, LARANJEIRAS (1976) diz que esse modelo necessita de melhor comprovação experimental.

Conforme evidenciado no estudo de GOTO (1971) em ensaios de tirantes, ao tracionar a barra, criam-se sistematicamente fissuras de aderência no concreto a partir de cada nervura transversal da barra, que se propagam inclinadamente em relação ao eixo da barra. Essa fissuração de aderência acompanha as direções das isostáticas das tensões de compressão que os flancos das nervuras transversais exercem sobre o concreto. Essas isostáticas podem ser observadas na Figura 2.19.

A inclinação dessas fissuras de aderência permite vislumbrar a inclinação das tensões diagonais de compressão, resultante cuja componente radial ou circunferencial se constitui na força de fendilhamento e cuja componente tangencial, paralela à barra, se constitui na força de corte do concreto entre as nervuras, de cuja ação resultam os deslizamentos.

Os consolos de concreto que se configuram entre as nervuras, como conseqüência da fissuração de aderência, irão determinar a resistência aos deslizamentos da barra. Esses deslizamentos são decorrentes das deformações desses consolos. A deformabilidade dos consolos está condicionada à extensão e inclinação das fissuras de aderência, as quais dependem, dentre outros parâmetros, do nível de carregamento, da qualidade do concreto, do grau de confinamento e dos efeitos da repetição e da manutenção do carregamento.

De acordo com LARANJEIRAS (1976), o efeito da manutenção e da repetição do carregamento seria basicamente o de aumentar a deformabilidade dos consolos de concreto, prolongando a fissuração de aderência. Ao efeito da manutenção do carregamento se associam os devidos à deformação lenta do concreto. Ao efeito da repetição do carregamento se associa o efeito da perda da adesão entre o concreto e o aço.

A perda de adesão foi observada no estudo de GOTO (1971), após $10^{3}$ repetições a tinta injetada nos corpos-de-prova penetrava ao longo de quase toda a superfície de contato aço-concreto. Com a perda dessa parcela, segundo LARANJEIRAS (1976), as pressões se concentram sobre os flancos das nervuras transversais, aumentando a deformação dos consolos (ou o deslizamento). 
O deslizamento é irreversível, porque é contido pelo atrito que se desenvolve entre as superfícies em contato e pelo efeito de travamento nas fissuras existentes. Esse deslizamento residual confere uma capacidade de resistir ao mesmo carregamento que o provocou, ou a outro que lhe seja equivalente, sem acréscimo do deslizamento da barra.

\subsection{CARGA DE IMPACTO}

Com base nos poucos estudos realizados são apresentadas algumas considerações da influência da carga de impacto sob o comportamento da aderência, segundo o CEB (1982) Bulletin d'Information n.151.

Se ocorrer ruptura por arrancamento a tensão de aderência última aumenta com o aumento na velocidade de carregamento (em ensaios com controle de carga) ou com o aumento na velocidade de deslizamento (em ensaios com controle de deslocamento). Em estudo de GVELESIANI ${ }^{15}$ apud CEB (1982) Bulletin d'Information n.151, foi observado aumento de $20 \%$ da tensão de aderência última decorrente de carga de impacto em relação ao carregamento monotônico.

Cargas de impacto excedem a tensão de aderência última monotônica, produzindo a ruptura da aderência somente depois da aplicação de alguns ciclos de carga ou se o carregamento máximo é mantido constante por um pequeno período.

Relativamente, comprimentos de ancoragem maiores acarretam menor aumento da tensão de aderência última relativa a cargas de impacto.

A rigidez de aderência (declividade do ramo ascendente da relação $\tau_{b}-s$ ) aumenta com o aumento da velocidade de carregamento ou deslocamento.

A probabilidade de ruptura por fendilhamento é muito maior se comparada com o carregamento monotônico. Dessa forma, ter-se-ia uma menor tensão de aderência última.

${ }^{15}$ GVELESIANI, T.V. (1971). Bond strength at impact load. (In Russian). Bond between steel and concrete symposium, Moscow, 1971 apud CEB (1982) Bulletin d'Information n.151. 


\subsection{CARREGAMENTO ALTERNADO}

\subsubsection{GENERALIDADES}

No caso de ação cíclica alternada, o tipo de controle do carregamento (controle de força ou deslocamento) e a freqüência do carregamento são parâmetros que influenciam bastante o comportamento da aderência.

O caso mais comum de carregamento cíclico alternado é o sismo, que representa uma situação intermediária entre ensaios com controle de carga e deslocamento e é caracterizado por uma alta freqüência (CEB, 1996 Bulletin d'Information n.230).

\subsubsection{COMPORTAMENTO DA ADERÊNCIA}

Carregamento cíclico alternado produz degradação da resistência e da rigidez de aderência mais rigorosa que o mesmo número de ciclos de ação repetida.

Conforme HAWKINS et al. (1982), a deterioração da aderência é maior para total inversão do deslizamento, ou seja, quando o carregamento não produz deslizamento somente em um sentido, como ilustra a Figura 4.11.
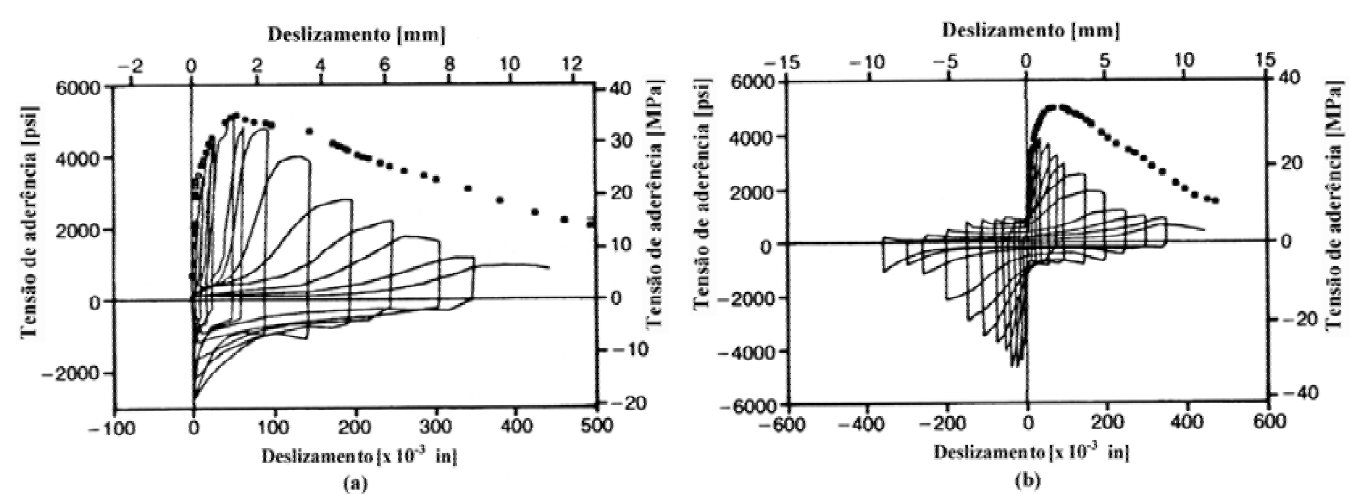

Figura 4.11 - Comparação de curvas $\tau_{\mathrm{b}}$-s sob ações monotônica e cíclica alternada a) sem inversão do deslizamento; b) com inversão do deslizamento (HAWKINS et al., 1982) 
Segundo ELIGEHAUSEN et al. (1983), a degradação da aderência depende principalmente do deslizamento máximo (e não da máxima tensão) alcançado previamente em cada uma das direções de carregamento, da diferença entre esses deslizamentos máximos e do número de ciclos, conforme observa-se na Figura 4.12. Outros parâmetros significativos são o padrão de nervura, resistência do concreto e o confinamento. 


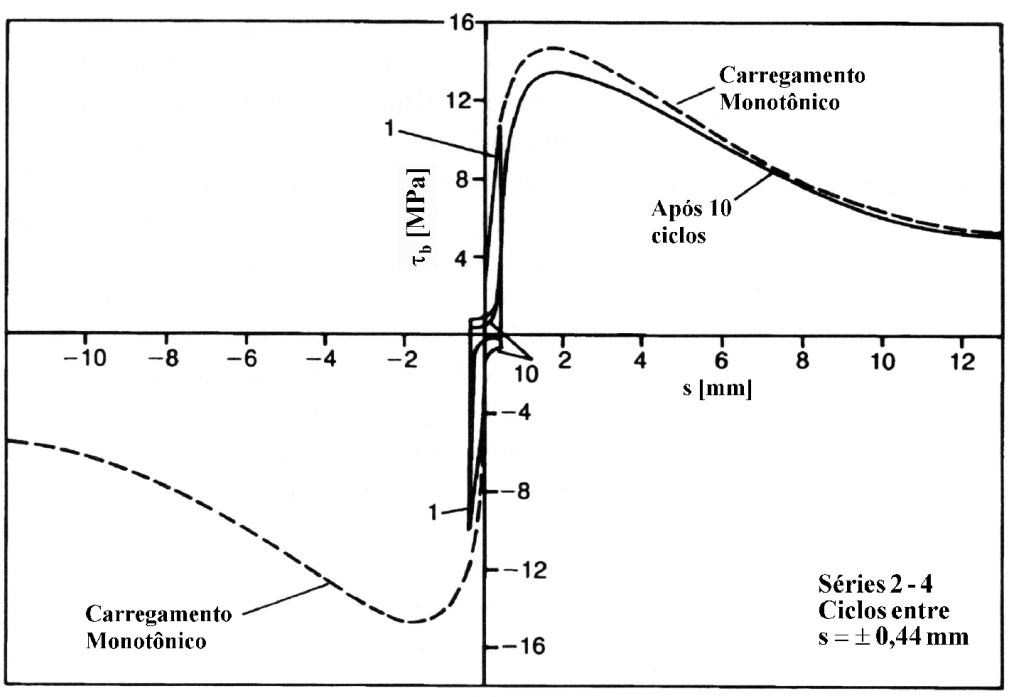

(a)

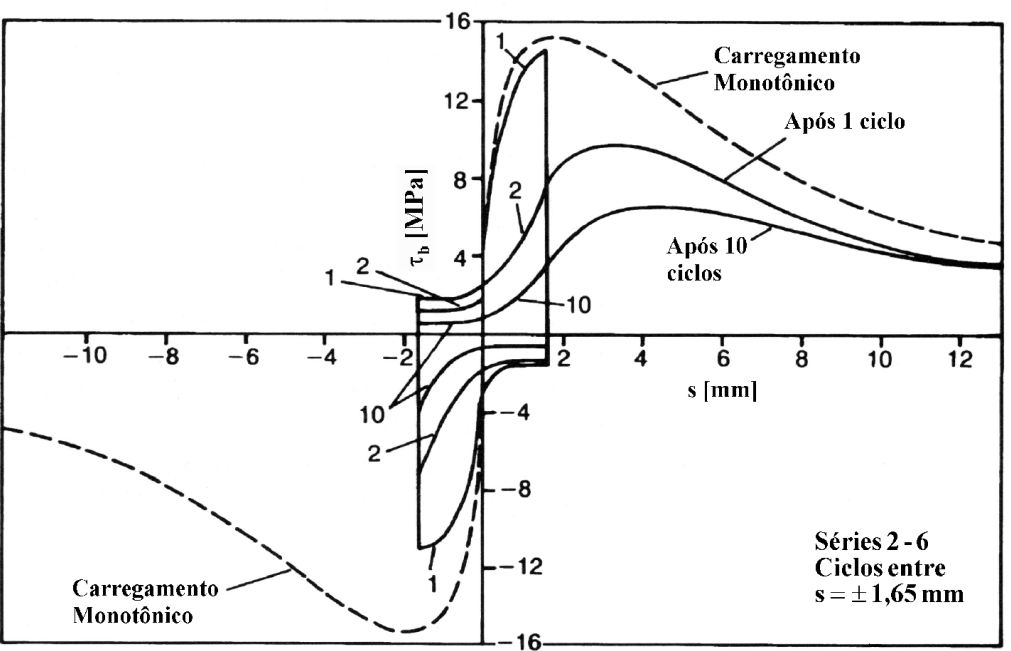

(b)

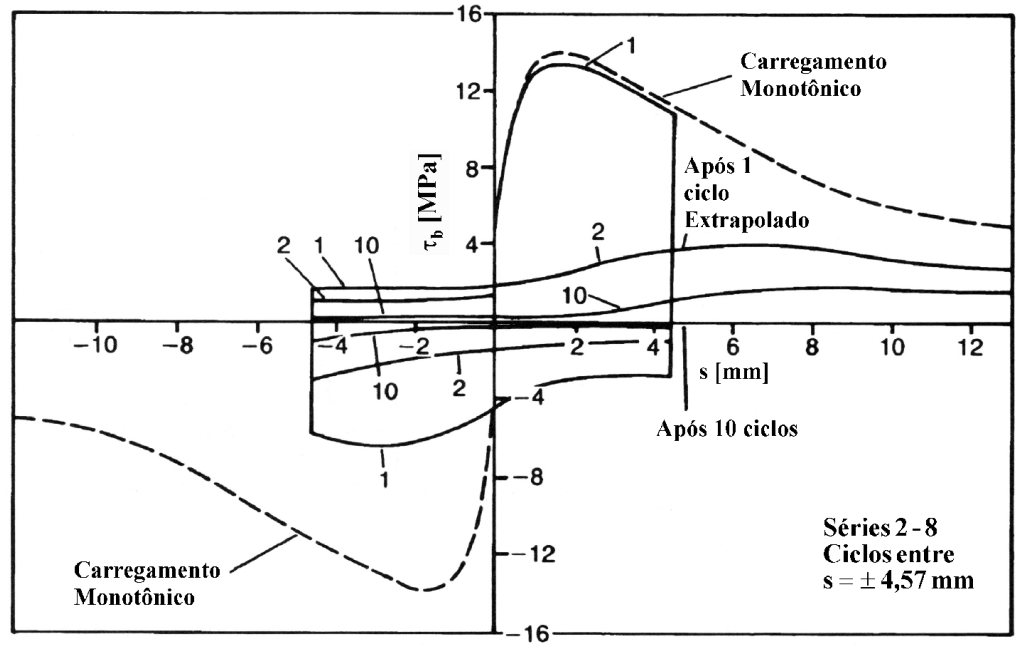

(c)

Figura 4.12 - Curvas $\tau_{b}$-s para diferente amplitudes de deslizamento (ELIGEHAUSEN et al., 1983) 
Segundo os autores, se a tensão de aderência, correspondente ao deslizamento máximo (controlado), alcançada durante os ciclos não exceder 70 ou $80 \%$ da tensão de aderência última monotônica, o desenvolvimento da curva $\tau_{\mathrm{b}}-\mathrm{s}$ não é significativamente influenciada até os 10 primeiros ciclos (Figura 4.12a). A tensão de aderência para o deslizamento máximo alcançado sob ação cíclica alternada diminui moderadamente com o aumento do número de ciclos.

Quando a tensão de aderência máxima atingida durante o carregamento cíclico alternado ultrapassa $80 \%$ da tensão de aderência última monotônica, a deterioração da aderência se torna significativa, conforme se observa nas Figuras $4.12 \mathrm{~b}$ e $4.12 \mathrm{c}$. Com o aumento do deslizamento controlado, a deterioração da aderência também aumenta.

BALÁZS (1991) analisou o comportamento da aderência sob ação cíclica alternada através de ensaios com controle da velocidade de força e deslocamento.

Com controle de deslocamento, conforme mostra a Figura 4.13, à medida que se aplicavam os ciclos diminuía a tensão de aderência correspondente ao deslizamento máximo (controlado) e a resistência de atrito $\left(\tau_{\mathrm{f}}\right)$, ou seja, o ramo horizontal entre o descarregamento e o carregamento na outra direção. 


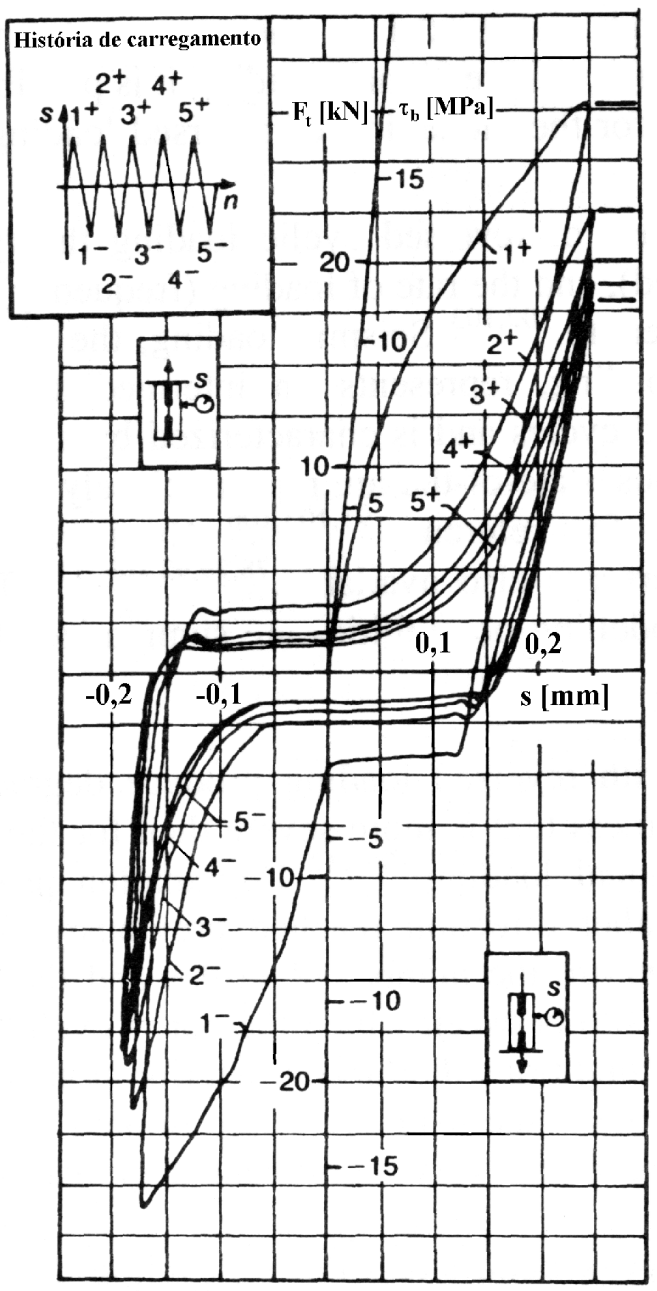

(a)

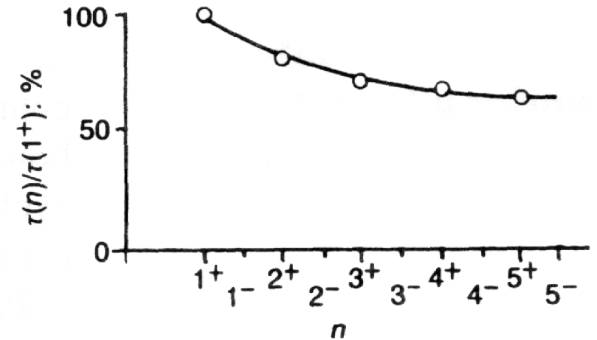

(b)

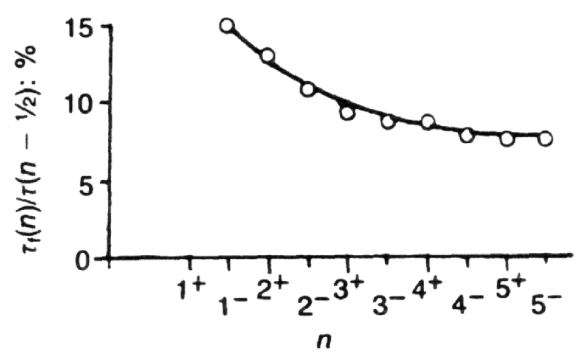

(c)

Figura 4.13 - Ensaios sob carregamento alternado com deslizamento controlado $\left(\phi=16 \mathrm{~mm}, \ell=2 \phi, \mathrm{f}_{\mathrm{y}}=400 \mathrm{MPa}, \mathrm{f}_{\mathrm{cc}}=25 \mathrm{MPa}\right)$

a) Resultados experimentais;

b) deterioração da tensão de aderência correspondente ao deslizamento controlado; c) deterioração da resistência de atrito

(BALÁZS, 1991)

Na Figura 4.13 os ciclos são representados com sinal positivo ou negativo, conforme a direção onde se impõe o deslizamento controlado. A direção (direita) onde se aplica o primeiro carregamento foi designada pelo símbolo positivo. Dessa forma, o ciclo $1^{+}$representa o primeiro ciclo com deslizamento para direita e assim por diante. Os ciclos com deslizamento na direção contrária (esquerda) são representados com sinal negativo.

Na Figura $4.13 \mathrm{~b}$ é apresentada a deterioração da tensão de aderência $\tau_{\mathrm{b}}(\mathrm{n})$ correspondente ao deslizamento máximo depois de n ciclos em determinada direção. 
Sendo representada a redução dessa tensão $\tau_{\mathrm{b}}(\mathrm{n})$ em relação à tensão de aderência $\tau_{\mathrm{b}}\left(1^{+}\right)$correspondente ao deslizamento máximo (controlado) alcançado no primeiro ciclo à direita. Na Figura 4.13c é apresentado a deterioração da resistência de atrito. É mostrada a redução da resistência de atrito $\tau_{\mathrm{f}}(\mathrm{n})$, depois do enésimo ciclo em determinada direção, em relação a tensão de aderência $\tau_{b}(n-1 / 2)$, correspondente ao deslizamento máximo, imposto na direção em questão, imediatamente antes do descarregamento.

Nos ensaios com velocidade de força controlada (Figura 4.14), houve notável aumento no deslizamento, o qual acarretou dano significativo no concreto que envolve a barra. Quanto maior a força atingida em um ciclo, maior o aumento do deslizamento.

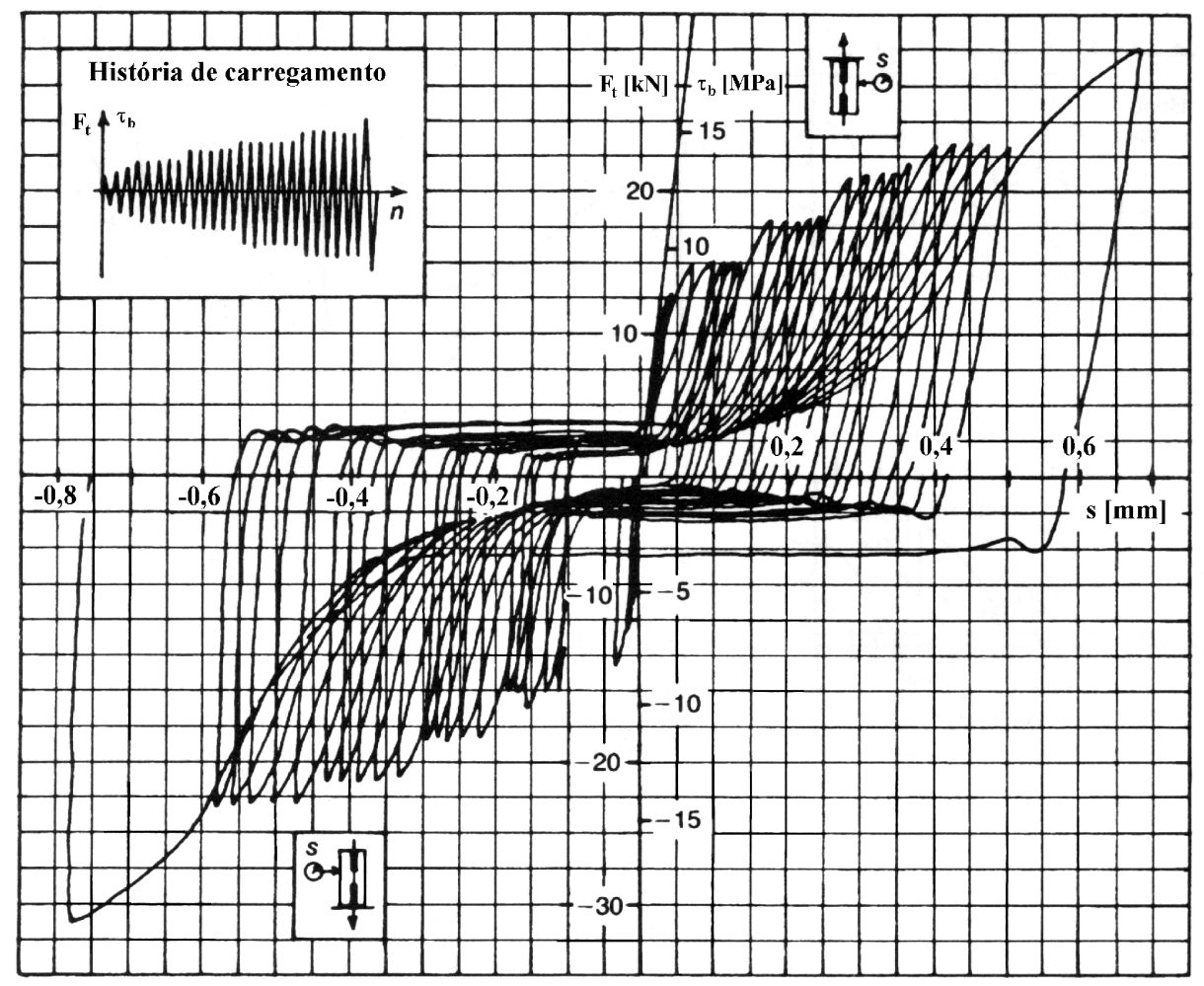

Figura 4.14 - Ensaios sob carregamento alternado com força controlada $\left(\phi=16 \mathrm{~mm}, \ell=2 \phi, \mathrm{f}_{\mathrm{y}}=400 \mathrm{MPa}, \mathrm{f}_{\mathrm{cc}}=25 \mathrm{MPa}\right)$

(BALÁZS, 1991)

Carregando modelos com deslizamentos crescentes tem-se um efeito acumulativo na deterioração da tensão e rigidez de aderência (comparando-se com o 
comportamento monotônico), como indicado na Figura 4.15. Alguns ciclos adicionais com deslizamentos menores do que o máximo previamente atingido, não influenciam significativamente o comportamento da aderência.

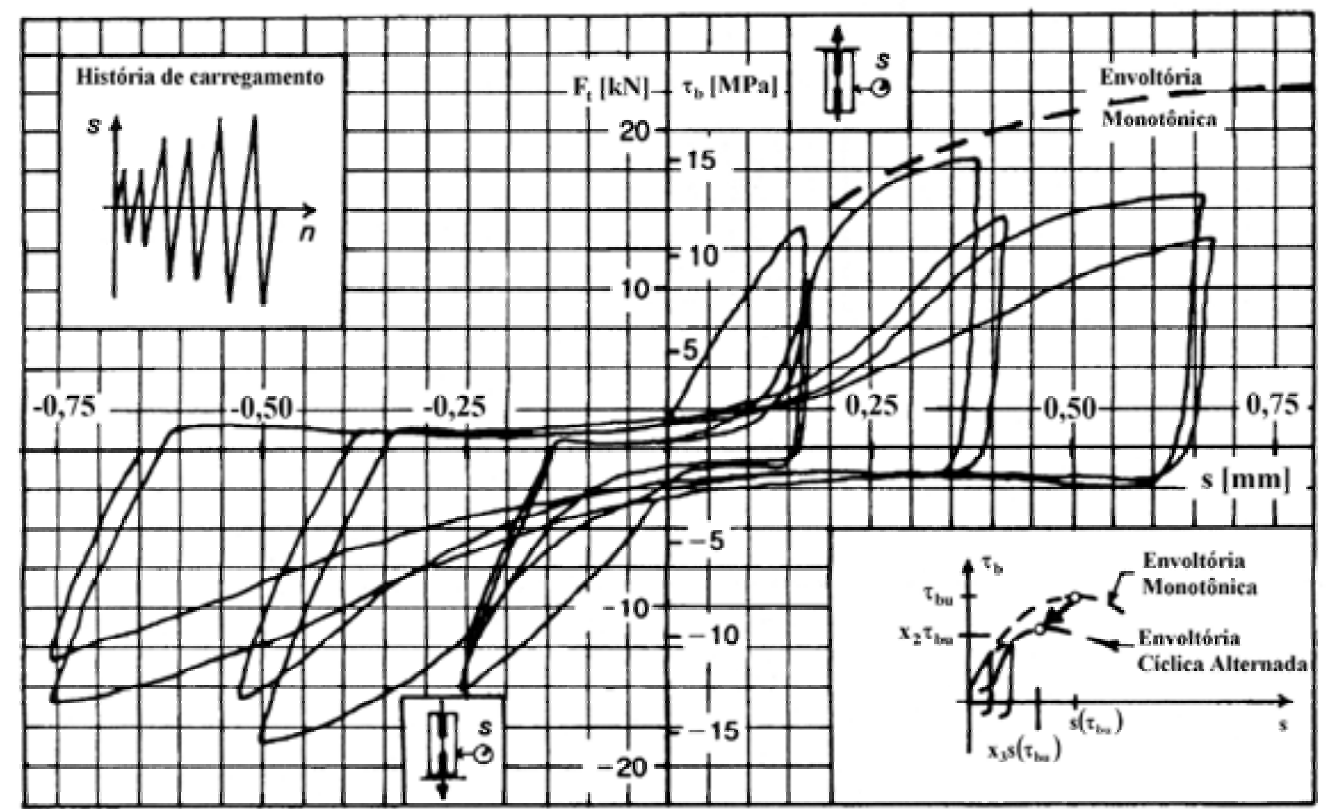

Figura 4.15 - Deterioração da aderência devido a deslizamento alternado crescente $\left(\phi=8 \mathrm{~mm}, \ell=6 \phi, \mathrm{f}_{\mathrm{y}}=400 \mathrm{MPa}, \mathrm{f}_{\mathrm{cc}}=25 \mathrm{MPa}\right)$

(BALÁZS, 1991)

O ACI COMMITTEE 408 (1991) apresenta uma pequena descrição do comportamento da aderência sob ação cíclica alternada com poucos ciclos de carga, mas com alta intensidade. A parte inicial da curva $\tau_{b}-s$ acompanha a envoltória monotônica. Se o nível máximo da amplitude for maior que aproximadamente metade da tensão de aderência última monotônica, surgirá um deslizamento residual significativo. Na Figura 4.16 é apresentado uma ilustração desse comportamento. 


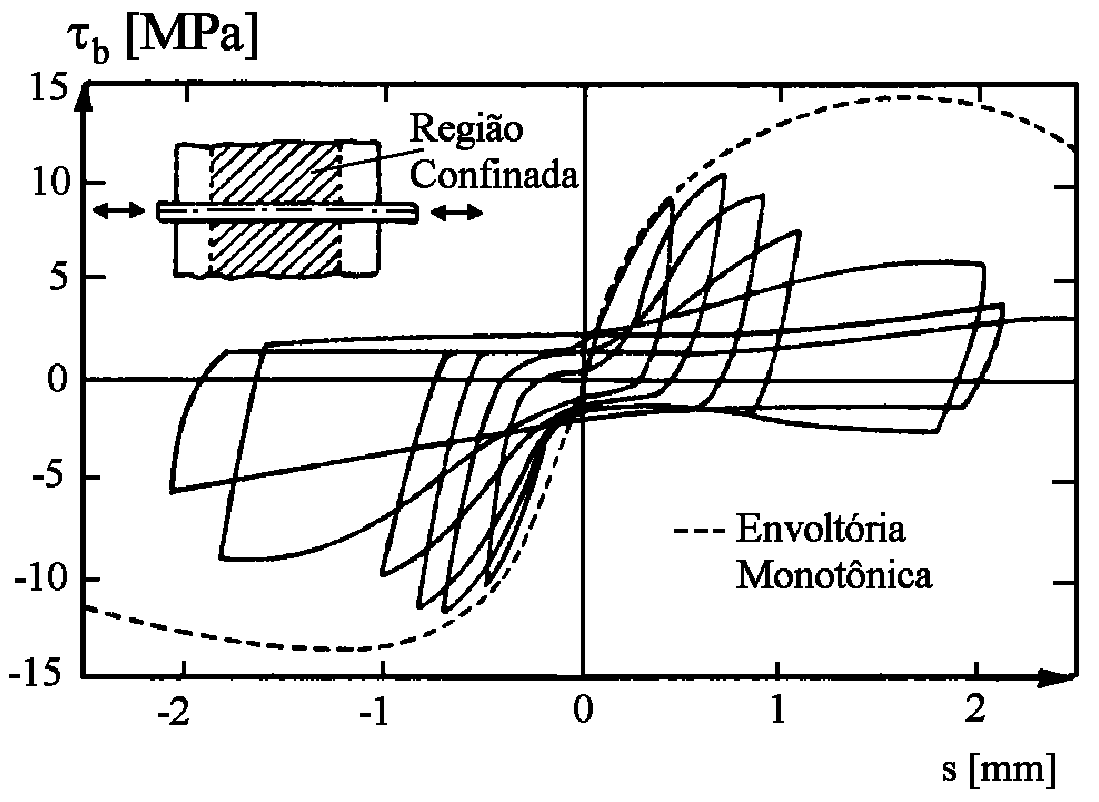

Figura 4.16 - Comportamento da aderência sob carregamento cíclico alternado (ACI COMMITTEE 408, 1991)

De acordo com a publicação, com carregamento em uma segunda direção, a barra se deslocará inicialmente como corpo rígido, mobilizando posteriormente o atrito e o engrenamento mecânico. À medida que os ciclos são aplicados, o concreto entre as nervuras vai sendo esmagado e cortado. As principais diferenças entre o comportamento da aderência sob ações monotônica e cíclica são que nesta, a adesão é supostamente perdida depois do primeiro ciclo, e a parcela da aderência devida à resistência por atrito diminui com a aplicação dos ciclos.

A acumulação do dano da aderência é supostamente causada pelo crescimento progressivo de microfissuras e esmagamento do concreto em frente às nervuras.

O comportamento da aderência sob ação cíclica alternada pode ser entendido através do modelo de ELIGEHAUSEN et al. (1983). Segundo os autores, sob ação cíclica alternada (Figura 4.17), o trecho inicial da curva $\tau_{\mathrm{b}}-\mathrm{s}$ acompanha a curva monotônica. Entretanto, o comportamento da aderência sob ação cíclica alternada é sensível ao nível do deslizamento no qual ocorre a inversão do carregamento. Três possíveis modelos qualitativos são propostos, dependendo da formação ou não de fissuras de cisalhamento. 

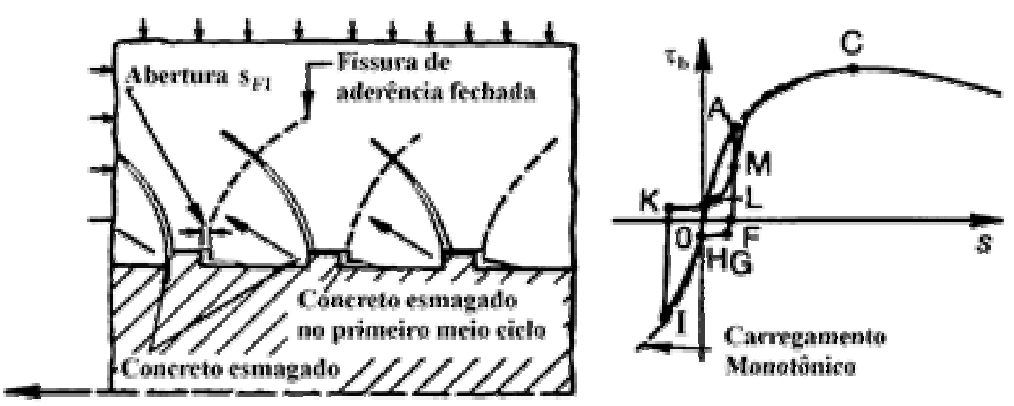

(a)
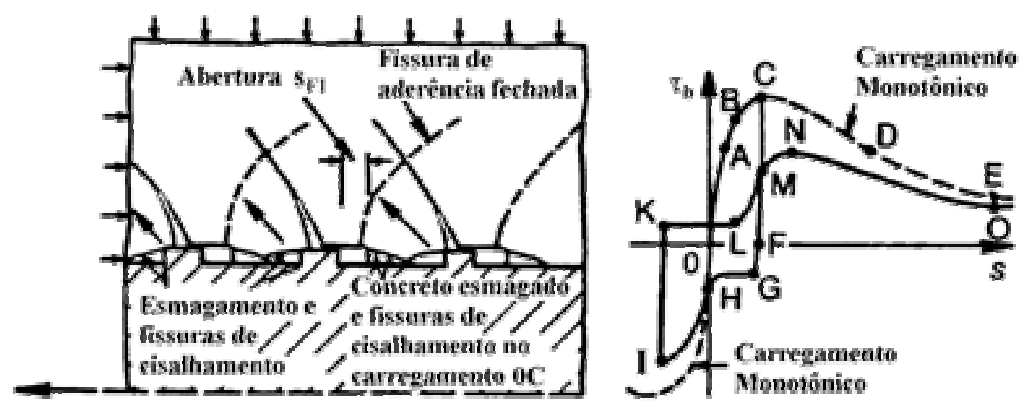

(b)

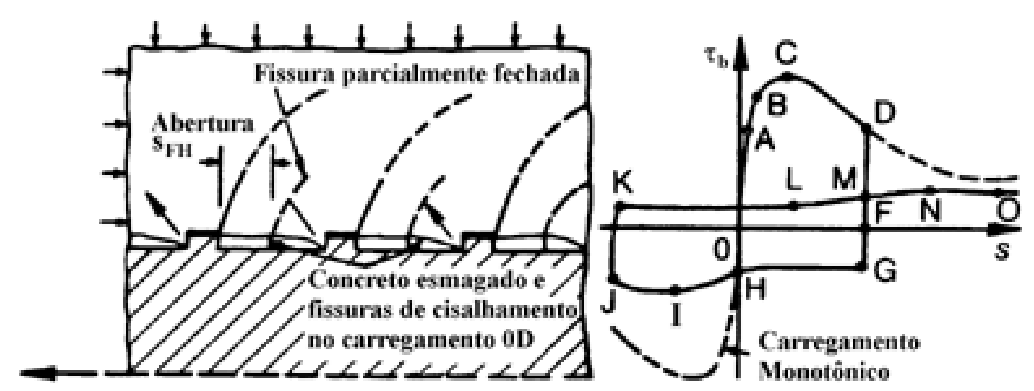

(c)

Figura 4.17 - Mecanismo de aderência sob carregamento cíclico alternado (ELIGEHAUSEN et al., 1983) 
No primeiro estágio (Figura 4.17a), supõe a inversão do deslizamento em um valor arbitrário antes de surgir fissuras de cisalhamento. Inicialmente, a curva $\tau_{\mathrm{b}}-\mathrm{s}$ acompanha o envoltória monotônica. $\mathrm{O}$ trecho de descarregamento é extremamente rígido (trecho $\mathrm{AF}$ ), porque somente uma pequena parte do deslizamento é causado pela deformação inelástica do concreto. $\mathrm{O}$ trecho $0 \mathrm{AF}$ corresponde ao primeiro meio ciclo.

Quando o deslizamento na direção contrária é imposto à barra, a aderência se desenvolve devido ao atrito (trecho $\mathrm{FH}$ ). A inclinação dessa parte da curva é pequena devido à superfície do concreto circunvizinho a barra ser lisa. Como as fissuras de aderência se fecham, a rigidez se torna pouco diferente da envoltória monotônica (ponto I).

A partir desse ponto I, cujo deslizamento é aproximadamente igual nas duas direções, a curva de descarregamento (trecho IKL) é muito semelhante a correspondente inicial (trecho AFH). A maior diferença é o ponto onde as tensões de aderência começam a crescer novamente (ponto L), o qual é deslocado para direita da origem. Isso se deve à fissuração de aderência anterior e ao esmagamento do concreto em frente às nervuras. $\mathrm{O}$ engrenamento mecânico vai gradualmente se mobilizando, restabelecendo-se completamente no ponto M. Com o aumento do carregamento a curva segue até a envoltória monotônica.

A Figura $4.17 \mathrm{~b}$ apresenta o segundo modelo, no qual o descarregamento é feito após a formação de fissuras de cisalhamento, e portanto próximo do deslizamento correspondente a tensão de aderência última. $O$ trecho de descarregamento é semelhante ao do primeiro caso até o ponto F. Devido ao maior dano no concreto, a resistência de atrito mobilizada é um pouco maior (ponto G).

Quando o carregamento é invertido, o engrenamento mecânico nessa segunda direção é menor, devido às fissuras de cisalhamento induzidas pelo primeiro meio ciclo. As fissuras de aderência criadas no primeiro meio ciclo fecham-se com uma tensão maior que a correspondente do primeiro modelo (ponto $\mathrm{H}$ ), ocasionando formação precoce de fissuras de aderência na direção oposta. Devido essas fissuras de aderência e as fissuras de cisalhamento existentes ao longo da barra, nessa segunda direção tem-se uma envoltória reduzida (trecho $\mathrm{HI}$ ) e uma redução na capacidade de aderência (ponto I). A partir desse pico, descarregando e recarregando 
na outra direção (trecho IKLMN), a rigidez e a tensão de aderência última são reduzidas, pois somente o concreto não esmagado remanescente entre as nervuras resiste ao cisalhamento. A tensão de aderência correspondente ao ponto $\mathrm{N}$ é substancialmente menor que a do ponto $\mathrm{C}$, e menor que a do ponto $\mathrm{I}$.

Se o descarregamento ocorrer depois de atingir a tensão de aderência última (ponto C), ELIGEHAUSEN et al. (1983) apresentam um terceiro modelo mostrado na Figura 4.17c. Como ocorreu grande degradação, a resistência de atrito (ponto G) é maior que nos outros dois casos previstos. Neste estágio o concreto entre as nervuras foi completamente cisalhado, dessa forma, é insignificante a parcela de força que pode ser transmitida por aderência quando o carregamento é invertido (trecho HIJ). Devido à grande perda do engrenamento mecânico, o descarregamento e recarregamento na direção oposta (trecho JKLMN) resultam em uma capacidade de aderência muito pequena, sendo a maior parte mobilizada pelo atrito.

\subsection{MODELOS ANALÍTICOS}

\subsubsection{MODELO DE TASSIOS}

O modelo de TASSIOS (1979) para a degradação da aderência sob ação cíclica alternada com deslizamento controlado é apresentado na Figura 4.18. Inicialmente, para melhor entendimento deve-se ressaltar que o modelo sob ação monotônica desse autor está detalhado no item 2.6.3 desta dissertação. 

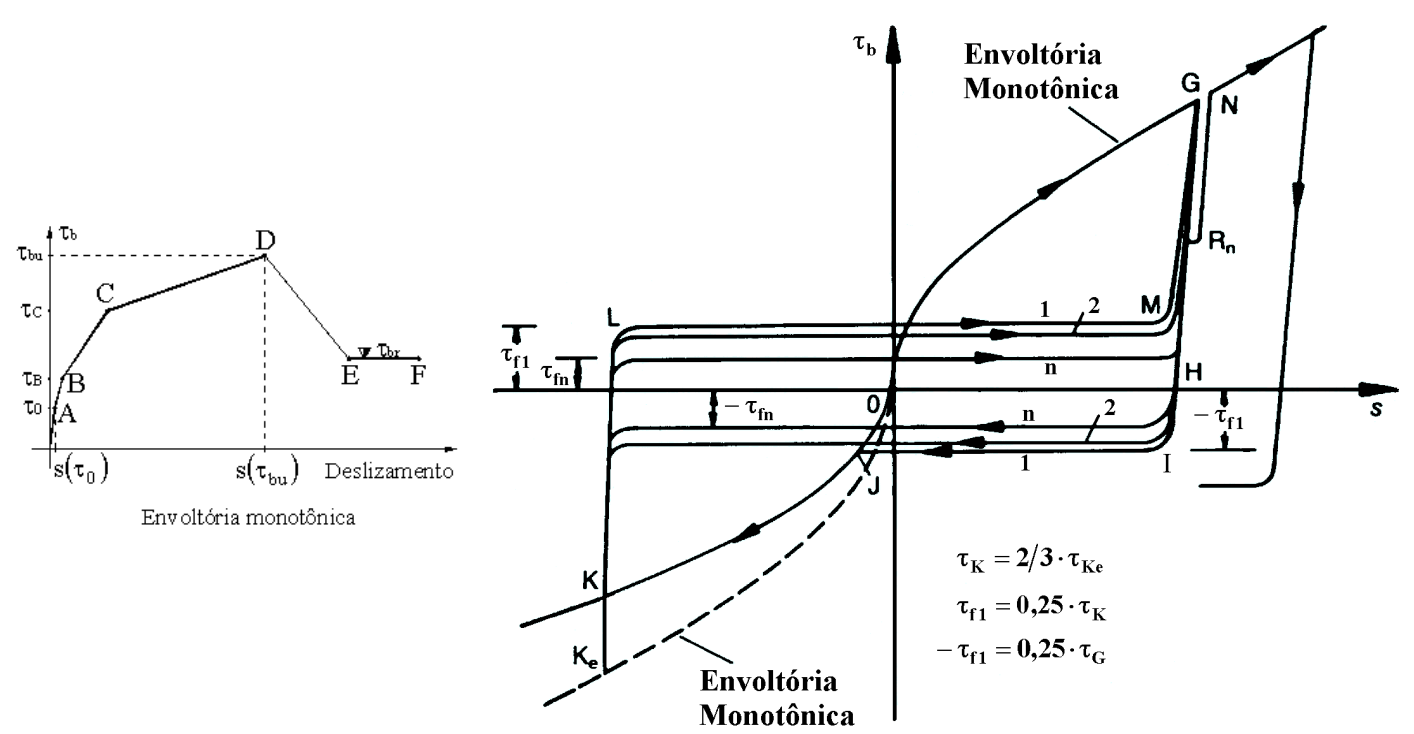

Figura 4.18 - Modelo de aderência sob carregamento cíclico alternado

(TASSIOS, 1979)

Após atingir, por exemplo, o nível de tensão de aderência $\tau_{\mathrm{G}}$ com deslizamento entre $\mathrm{s}\left(\tau_{0}\right)$ e $\mathrm{s}\left(\tau_{\mathrm{bu}}\right)$ da curva $\tau_{\mathrm{b}}-\mathrm{s}$ monotônica, o trecho de descarregamento GH possui, como primeira aproximação, a mesma inclinação do trecho inicial da envoltória monotônica referente à aderência por adesão.

Os valores da tensão de aderência para carregamento na direção reversa diminuem $1 / 3$ se comparados com a envoltória monotônica antimétrica $\left(\tau_{\mathrm{K}}=2 / 3 \tau_{\mathrm{G}}\right)$.

Quando se impõe deslizamento na direção oposta, aparecerá uma tensão de aderência negativa $-\tau_{\mathrm{f} 1}=0,25 \cdot \tau_{\mathrm{G}}$. Essa tensão de aderência mantém-se constante até atingir o ponto de intersecção com a curva monotônica antimétrica reduzida $0 \mathrm{~K}$. $\mathrm{O}$ autor justifica o fato de a tensão $-\tau_{\mathrm{f} 1}$ manter-se constante, devido à hipótese da tensão normal $\sigma_{\mathrm{y}}$ permanecer inalterada. $\mathrm{O}$ ângulo $\beta$ entre o eixo da barra e as fissuras de aderência é assumido como $45^{\circ}$, assim, para se manter o equilíbrio de forças entre fissuras de aderência consecutivas, conforme apresentado na Figura 2.7, o valor da componente $\sigma_{\mathrm{y}}$ é igual a $\tau_{\mathrm{G}}$.

Com a imposição de deslizamento na direção oposta, as fissuras de aderência fecham-se gradualmente. Admite-se que essas fissuras fecham-se completamente quando o deslizamento previamente aplicado seja retirado. 
Aumentando-se o deslizamento na direção oposta, o concreto adjacente à barra é suposto intacto novamente, visto que as fissuras de aderência são fechadas e submetidas somente à compressão. Entretanto, as fissuras de fendilhamento abertas no ponto $\mathrm{G}$ permanecem abertas devido à tensão normal $\sigma_{\mathrm{y}}$ permanecer supostamente constante. Justificando o fato de a curva $\tau_{b}-s$ sob ação de deslizamento na direção oposta não acompanhar exatamente a curva monotônica antimétrica $0 \mathrm{Ke}$.

Quando um novo descarregamento ocorrer (trecho KL), é esperado um comportamento da aderência semelhante ao trecho anterior análogo. A tensão de aderência avaliada no ponto $\mathrm{L}$ é admitida igual $\mathrm{a}+\tau_{\mathrm{f} 1}=0,25 \cdot\left(2 / 3 \tau_{\mathrm{G}}\right)$. Durante o recarregamento (deslizamento para a direita), a reação positiva $+\tau_{f 1}$ permanece constante, pelas mesmas razões vistas para $-\tau_{\mathrm{f} 1}$.

Aumentando-se o deslizamento além do valor máximo alcançado no primeiro ciclo $\left(\mathrm{s}>\mathrm{s}_{\mathrm{G}}\right)$, é assumido que a envoltória monotônica seja alcançada novamente. A partir desse ponto, as fissuras de aderência recuperam sua abertura inicial e se opõem a aberturas adicionais. As tensões oriundas do engrenamento mecânico crescem novamente e contribuem para o aumento do fendilhamento e/ou para o esmagamento das bielas de compressão formados entre fissuras de aderência consecutivas.

Entretanto, iniciando-se um novo ciclo a partir do deslizamento $\mathrm{s}_{\mathrm{G}}$, o valor absoluto da tensão de aderência $-\tau_{\mathrm{f} 2}$ será menor do que a tensão $-\tau_{\mathrm{f} 1}$. Na verdade, o autor admite que depois de sucessivas aberturas e fechamentos das fissuras de aderência, o concreto circunvizinho à barra se danificará.

De acordo com o CEB (1996) Bulletin d'Information n.230, o modelo de TASSIOS (1979) é representativo, principalmente como é concebido o ramo descendente da relação $\tau_{\mathrm{b}}-\mathrm{s}$ e a influência dos ciclos de carga na deterioração da aderência, para deslizamentos menores ou iguais ao deslizamento máximo alcançado nos ciclos. Entretanto, não é muito razoável a hipótese de que para deslizamentos maiores que o máximo deslizamento alcançado nos ciclos anteriores, a envoltória cíclica alternada alcance e acompanhe, a partir daí, a envoltória monotônica; enquanto as tensões de aderência na direção reversa são reduzidas em 1/3, comparando-se com a envoltória monotônica. 
A referida publicação ainda acrescenta que o modelo de TASSIOS (1979) é representativo somente para deslizamentos muito menores que o deslizamento correspondente à tensão de aderência última monotônica.

\subsubsection{MODELO DO CÓDIGO MODELO CEB-FIP 1990}

Para parte ascendente e horizontal da curva $\tau_{\mathrm{b}}-\mathrm{s}$, o Código Modelo CEBFIP 1990 assume que o ramo de descarregamento seja linear. A inclinação desse ramo é independente do deslizamento e admitido igual a $200 \mathrm{~N} / \mathrm{mm}^{3}$.

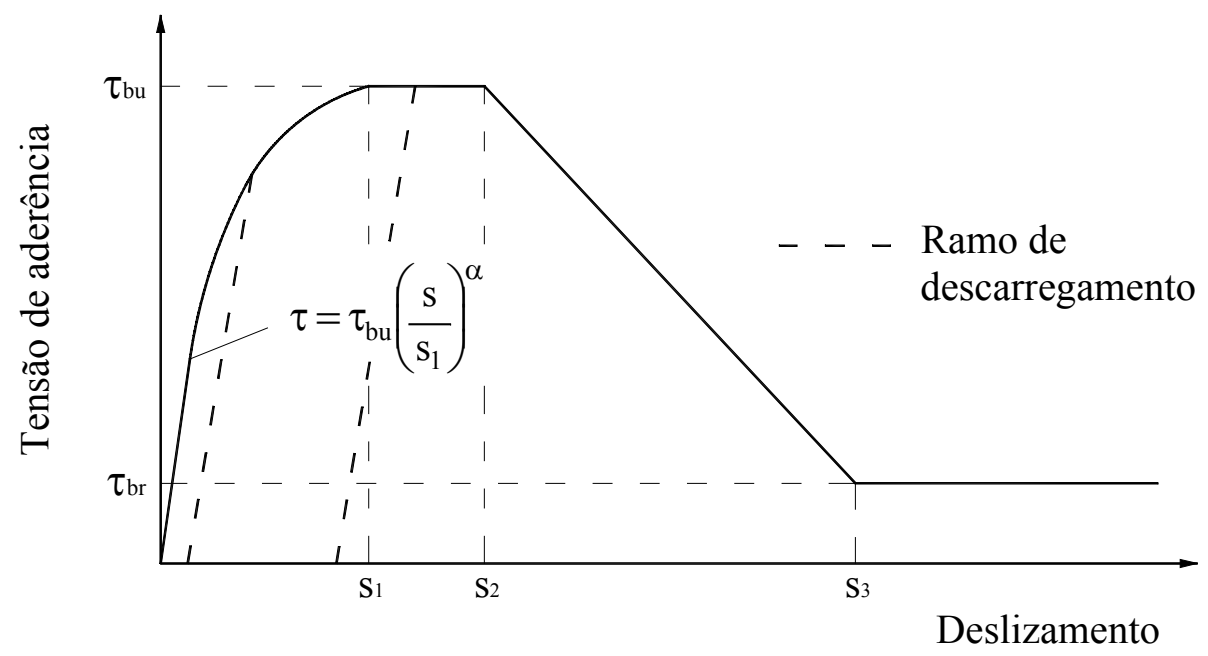

Figura 4.19 - Ramo de descarregamento da curva $\tau_{\mathrm{b}}-\mathrm{s}$ (CÓDIGO MODELO CEB-FIP 1990)

A influência da manutenção e repetição do carregamento no comportamento da aderência é descrita por curvas onde o deslizamento $s_{n, t}$, devido a carregamento permanente ou a carregamento repetido, pode ser calculado de acordo com a seguinte equação:

$\mathrm{s}_{\mathrm{n}, \mathrm{t}}=\mathrm{s} \cdot\left(1+\mathrm{k}_{\mathrm{n}, \mathrm{t}}\right)$

$\mathrm{O}$ fator $\mathrm{k}_{\mathrm{t}}$ para carregamento de longa duração é dado por: 
$\mathrm{k}_{\mathrm{t}}=(1+10 \cdot \mathrm{t})^{0,080}-1$

onde t é a duração do carregamento em horas.

Para carregamento repetido $\mathrm{o}$ fator $\mathrm{k}_{\mathrm{n}}$ pode ser determinado, independentemente do nível de carregamento, pela seguinte equação:

$\mathrm{k}_{\mathrm{n}}=(1+\mathrm{n})^{0,107}-1$

onde $\mathrm{n}$ é o número de ciclos de carga.

$\mathrm{Na}$ Equação 4.1 o deslizamento $\mathrm{s}$ corresponde a situação $\mathrm{t}=0 \mathrm{ou} \mathrm{n}=1$. A Figura 4.20 ilustra o modelo de aderência ora apresentado. A validade desse modelo, conforme acrescenta o Código Modelo CEB-FIP 1990, é restrito ao ramo ascendente da curva $\tau_{\mathrm{b}}-\mathrm{s}$.

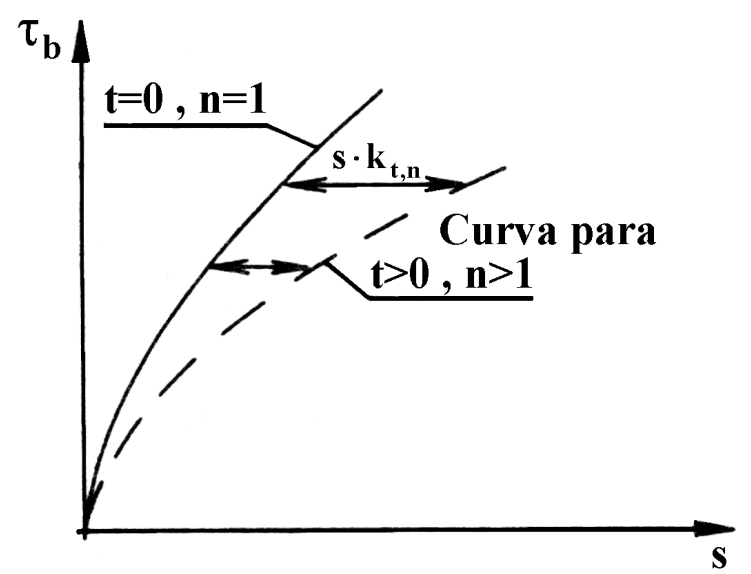

Figura 4.20 - Modelo de aderência sob carregamentos de longa duração e repetido (CÓDIGO MODELO CEB-FIP 1990)

\subsection{FADIGA DO CONCRETO}

O processo de fadiga é um fenômeno associado ao efeito da ação repetida. Neste item é apresentada uma síntese desse efeito sobre o concreto, mostrando a influência do carregamento repetido com grande número de ciclos e baixa intensidade. 
A fadiga do concreto é um processo que produz modificações progressivas e permanentes na estrutura interna do material. O efeito desfavorável da fadiga pode ser observado pelo aumento de deformações, pela formação prematura de fissuras e pelo próprio aumento do número de fissuras com maior abertura individual das mesmas.

A degradação oriunda do efeito da fadiga pode provocar a ruptura do concreto com nível de carregamento menor que sua resistência estática. Para determinado número de ciclos e intensidade do carregamento, a resistência à ruptura por fadiga do concreto pode ser expressa como fração da resistência estática. Entretanto, ao contrário do aço, o concreto não possui limite abaixo do qual a vida seria infinita.

Devida a maiores deformações e microfissuração decorrentes do efeito da fadiga, ao contrário dos metais, a ruptura por fadiga do concreto é de natureza dúctil.

Em elementos estruturais de concreto armado a influência da fadiga é mais significativa no comportamento em serviço. Os efeitos desfavoráveis da fadiga sobre as deformações, fissuração e durabilidade são, freqüentemente, mais importantes que seus efeitos em relação à ruptura.

Segundo REHM \& ELIGEHAUSEN (1979), o efeito do carregamento repetido sobre o deslizamento e a tensão de aderência última é semelhante, respectivamente, ao comportamento da deformação e da resistência do concreto simples sob compressão repetida. 


\section{CAPÍTULO 5}

\section{MATERIAIS E MÉTODOS}

\subsection{GENERALIDADES}

Este trabalho foi basicamente desenvolvido no Departamento de Engenharia de Estruturas da Escola de Engenharia de São Carlos (EESC).

Entretanto, na investigação experimental foi necessário buscar recursos em outros setores da EESC, bem como em empresa privada. Os dispositivos de madeira para montagem das fôrmas dos modelos foram confeccionados pela marcenaria da EESC. Os dispositivos de aço foram usinados pela Oficina Mecânica (Departamento de Engenharia Mecânica). O corte longitudinal para instrumentação interna de barras foi feito pela ICAM Industria e Comércio Ltda, empresa com sede em São Carlos. Os ensaios propriamente dito foram realizados no Laboratório de Engenharia de Estruturas (Departamento de Engenharia de Estruturas).

\subsection{CARACTERIZAÇÃO DO CONCRETO}

Foi empregado cimento do tipo CP-V ARI Plus (Cimento Portland de Alta Resistência Inicial), marca CIMINAS, com massa específica aparente de 3,15 $\mathrm{kg} / \mathrm{dm}^{3}$. 
A areia empregada, de origem quartzosa proveio do rio Mogi-Guaçu, município de Rincão, com módulo de finura igual a 2,14, dimensão máxima característica 2,4 e massa específica aparente $2,58 \mathrm{~kg} / \mathrm{dm}^{3}$.

Utilizou-se agregado graúdo de origem basáltica da Pedreira Morada do Sol do município de Araraquara, com massa específica aparente igual a 2,96 kg/ $\mathrm{dm}^{3}$, módulo de finura igual a 7,54 e dimensão máxima característica igual a $19 \mathrm{~mm}$.

$\mathrm{O}$ aditivo superplastificante empregado foi RX 3000 da REAX Indústria e Comércio Ltda, com densidade de $1,11 \mathrm{~kg} / \mathrm{dm}^{3}$.

Utilizou-se água da rede pública de abastecimento de São Carlos.

\subsubsection{DOSAGEM DOS MATERIAIS}

O programa experimental utiliza concreto com resistência à compressão da ordem de $85 \mathrm{MPa}$. No traço desenvolvido no Departamento de Engenharia de Estruturas não se utilizou sílica ativa.

Consumo dos materiais e traço em massa são apresentados na Tabela 5.1.

Tabela 5.1 - Consumo dos materiais utilizados na confecção do concreto

\begin{tabular}{|c|c|}
\hline Materiais & Consumo por $\mathrm{m}^{3}$ de concreto \\
\hline Cimento CP - V ARI Plus & $534 \mathrm{~kg}$ \\
\hline Areia & $635,46 \mathrm{~kg}$ \\
\hline Brita & $1126,74 \mathrm{~kg}$ \\
\hline Água & $198,65 \mathrm{~kg}$ \\
\hline Superplastificante & $5,34 \mathrm{~kg}$ \\
\hline Traço em massa: $1: 1,19: 2,11: 0,38: 0,010$ \\
\hline
\end{tabular}




\subsubsection{EXECUÇÃO DA MISTURA}

A mistura foi feita em betoneira de eixo vertical, e os materiais colocados na seguinte ordem:

a. Mistura de todo o agregado graúdo com o cimento, 2/3 da água e metade do superplastificante durante 3 minutos;

b. Toda a areia, o restante da água e o superplastificante, misturados por mais 3 minutos.

\subsubsection{RESISTÊNCIAS À COMPRESSÃO E À TRAÇÃO DO CONCRETO}

A resistência à compressão do concreto foi mensurada através de ensaios de três corpos-de-prova cilíndricos de 100 por $200 \mathrm{~mm}$. Nesses ensaios foram utilizados apoios de neoprene e a velocidade de carregamento foi de $2,4 \mathrm{kN} / \mathrm{s}$.

Para mensurar a resistência à tração do concreto utilizou-se o ensaio de tração por compressão diametral, em cilindros de 100 por $200 \mathrm{~mm}$. O carregamento foi aplicado, continuamente, com velocidade constante de $0,94 \mathrm{kN} / \mathrm{s}$. Como o plano de fratura, imposto pelo arranjo do ensaio de compressão diametral, não é necessariamente o plano de menor resistência, os resultados fornecidos por esse ensaio foram multiplicados por um fator de conversão igual a 0,9 , conforme o Código Modelo CEB-FIP 1990. Dessa forma, os resultados médios de ensaios de compressão diametral foram transformados para os de tração direta.

\subsection{BARRAS DE AÇO}

Foram empregadas barras de aço nervuradas CA-50 de fabricação da AÇOMINAS (empresa controlada pela GERDAU PARTICIPAÇÕES LTDA) com 
diâmetro nominal de $16 \mathrm{~mm}$. O aço utilizado foi o de classe A, obtido por laminação a quente, com escoamento definido por patamar no diagrama tensão-deformação.

O padrão de nervuras é caracterizado por nervuras transversais, inclinadas em relação ao eixo da barra, e por duas nervuras longitudinais diametralmente opostas, cujos eixos são paralelos ao eixo da barra.

\subsection{ENSAIOS DE ADERÊNCIA}

\subsubsection{GENERALIDADES}

Neste trabalho foram utilizados dois tipos de ensaios de aderência: ensaio de arrancamento e ensaio das quatro barras. No plano definitivo, onde se estudou o efeito do carregamento repetido, foram utilizados somente ensaios de arrancamento.

\subsubsection{ENSAIO DE ARRANCAMENTO}

\subsubsection{DESCRIÇÃO DAS FÔRMAS E DISPOSITIVOS}

Para moldagem dos corpos-de-prova foram utilizadas fôrmas cilíndricas de tubos de PVC com corte longitudinal, para facilitar a desfôrma. O fundo é constituído por um forro de madeira com furo central, fixado ao tubo de PVC, através de parafusos, na direção radial. Para garantir a verticalidade da barra, a parte superior da fôrma possui um sarrafo fixado a um gabarito que envolve o tubo de PVC. O trecho não aderente é obtido através de mangueira de plástico. $O$ detalhamento da fôrma do modelo PT-PILOTO 1 é apresentado na Figura 5.1. 


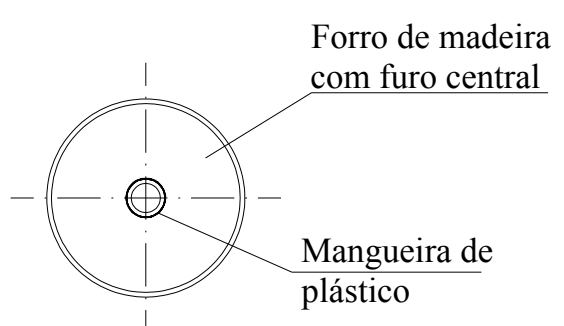

Vista Inferior

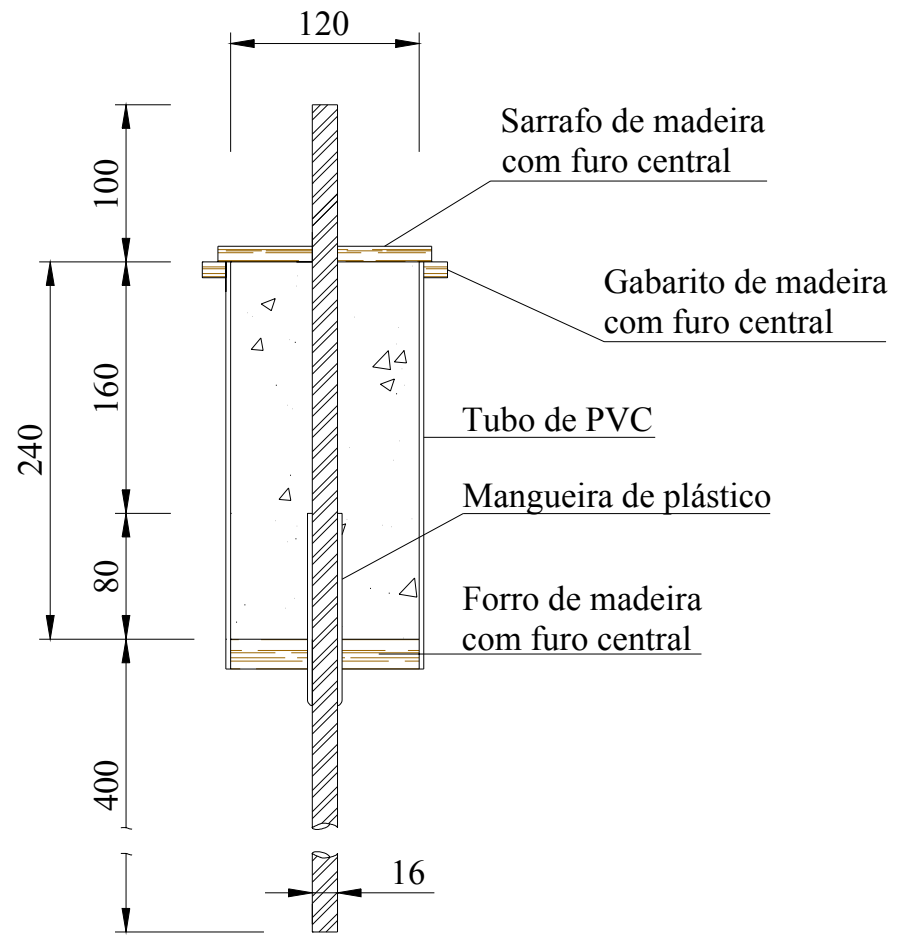

Corte A-A

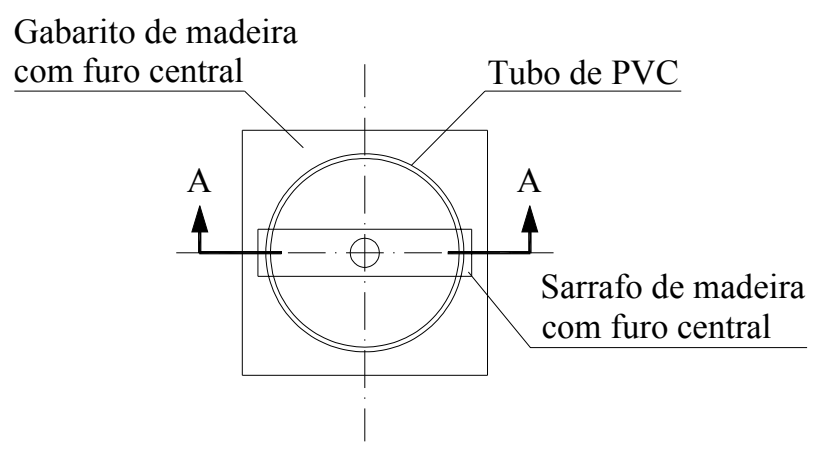

Vista Superior

Cotas [mm]

Figura 5.1 - Fôrma para o corpo-de-prova do modelo PT-PILOTO 1 


\subsubsection{MOLDAGEM E CURA DOS CORPOS-DE-PROVA}

Os corpos-de-prova foram moldados na posição vertical, isto é, com a base da fôrma apoiada horizontalmente, com eixo da barra de aço paralelo à direção do lançamento do concreto.

O concreto foi compactado em três camadas com adensamento realizado em mesa vibratória. Três dias após a moldagem, os corpos-de-prova foram retirados das fôrmas e armazenados em câmara úmida.

\subsubsection{EXECUÇÃO DO ENSAIO}

Os modelos foram retirados da câmara úmida 48 horas antes do ensaio. A idade do concreto quando se executou os ensaios foi de 9 dias para os ensaios do plano piloto, 18 dias para os ensaios da série 7,5 do plano definitivo e 15 dias para os ensaios da série 12,5 .

A barra de aço foi solicitada por força de tração aplicada no mesmo sentido ao da concretagem. O corpo-de-prova é apoiado em uma placa, com furo central, presa por quatro hastes rosqueadas na máquina de ensaio (INSTRON). Essa placa funciona como vínculo de transição, onde a força $F_{t}$ é transmitida para a máquina de ensaio. Na Figura 5.2 é apresentado um esquema com a disposição do corpo-deprova na máquina INSTRON. 


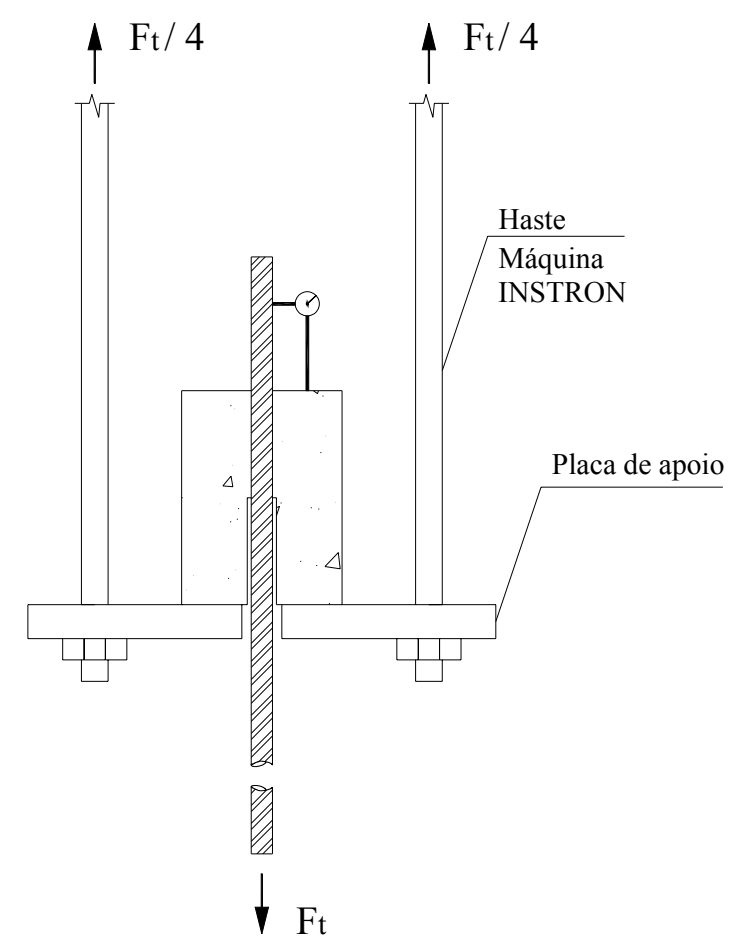

Figura 5.2 - Esquema do ensaio de arrancamento

Após posicionamento do corpo-de-prova na máquina, ajustado às garras com pequena carga inicial e nivelado à chapa, onde estará fixado o corpo-de-prova, os instrumentos foram zerados e verificado seu funcionamento. Dessa forma, é possível dar início à aplicação da carga com velocidade de deslocamento de $0,01 \mathrm{~mm} / \mathrm{s}$ e discretamente fazer registros dos deslizamentos. Nos ensaios monotônicos, essa seqüência é mantida até que seja obtido o arrancamento da barra central ou o fendilhamento do concreto.

Os deslocamentos da barra de aço em relação ao concreto foram medidos na extremidade descarregada. A medida dos deslocamentos foi feita por transdutores indutivos de deslocamentos. 


\subsubsection{ENSAIO DAS QUATRO BARRAS}

\subsubsection{DESCRIÇÃO DAS FÔRMAS E DISPOSITIVOS}

As fôrmas para moldagem dos corpos-de-prova têm formato cilíndrico com $210 \mathrm{~mm}$ de diâmetro formadas por duas peças usinadas com chapa de aço de $2,5 \mathrm{~mm}$ de espessura. Foram utilizados corpos-de-prova com duas alturas diferentes (320 e $395 \mathrm{~mm}$ ). A usinagem dessas fôrmas foi feita por processo de calandragem, conforme detalhamento apresentado na Figura 5.3.
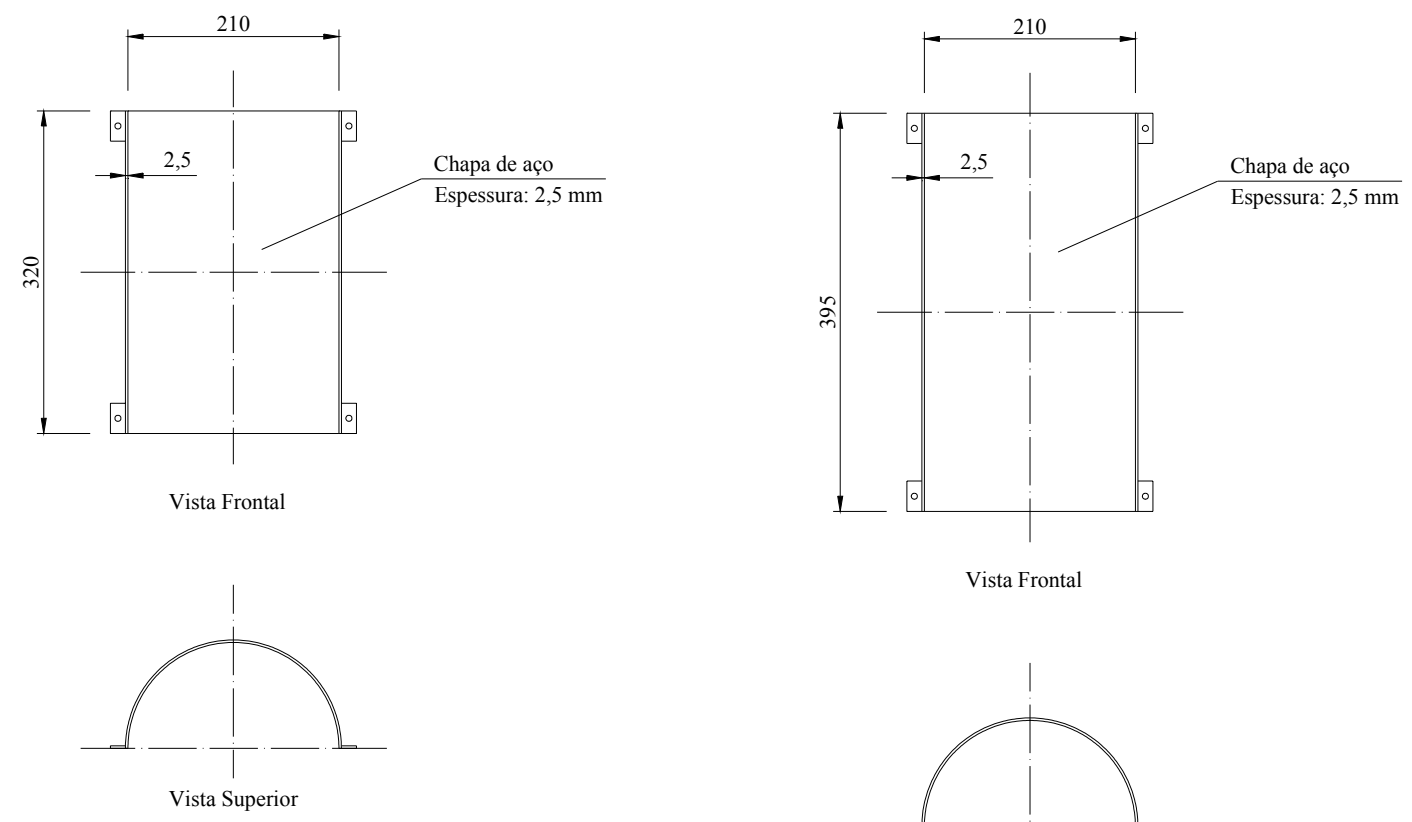

Vista Frontal

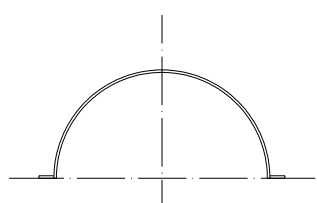

Vista Superior

Figura 5.3 - Fôrmas para o ensaio das quatro barras

O fundo é constituído de chapa de compensado com $14 \mathrm{~mm}$ de espessura, firmemente mantido na posição por tirantes de aço colocados externamente às fôrmas, que mantêm sob pressão as paredes do tubo cilíndrico contra o fundo e contra gabarito de chapa de aço na boca da fôrma. Este gabarito (Figura 5.4) tem 
formato de estrela de três pontas com orifícios, através dos quais posicionam-se verticalmente, as quatro barras.

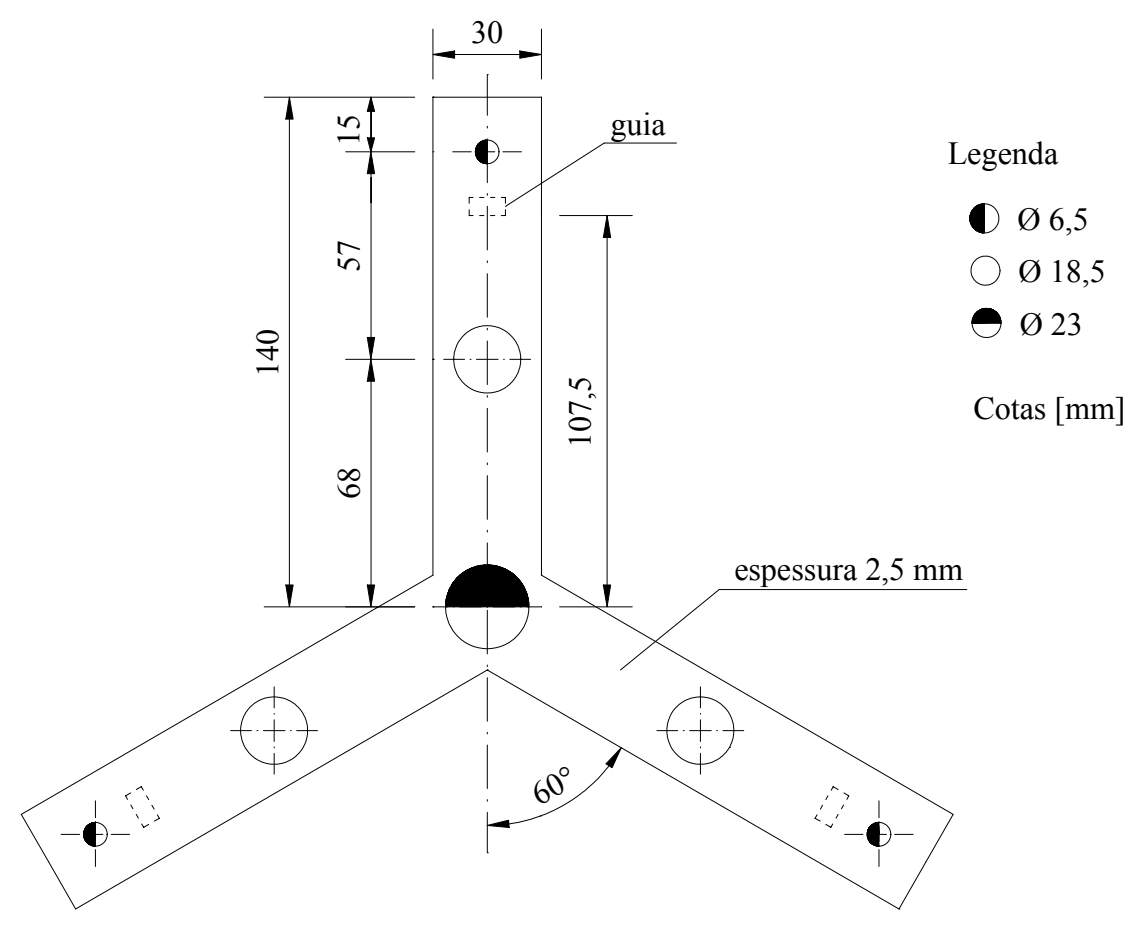

Figura 5.4 - Gabarito da chapa de aço com formato de estrela de três pontas

As três barras perimetrais possuem pontas rocáveis, fixadas por porcas em placa de aço de $350 \times 350 \mathrm{~mm}$, com 1" de espessura. Essa placa presa por quatro hastes rosqueadas na máquina INSTRON, funciona como vínculo de transição, onde os esforços das três barras são transmitidos para a máquina. A Figura 5.5 apresenta o detalhamento dessa placa de transição. 


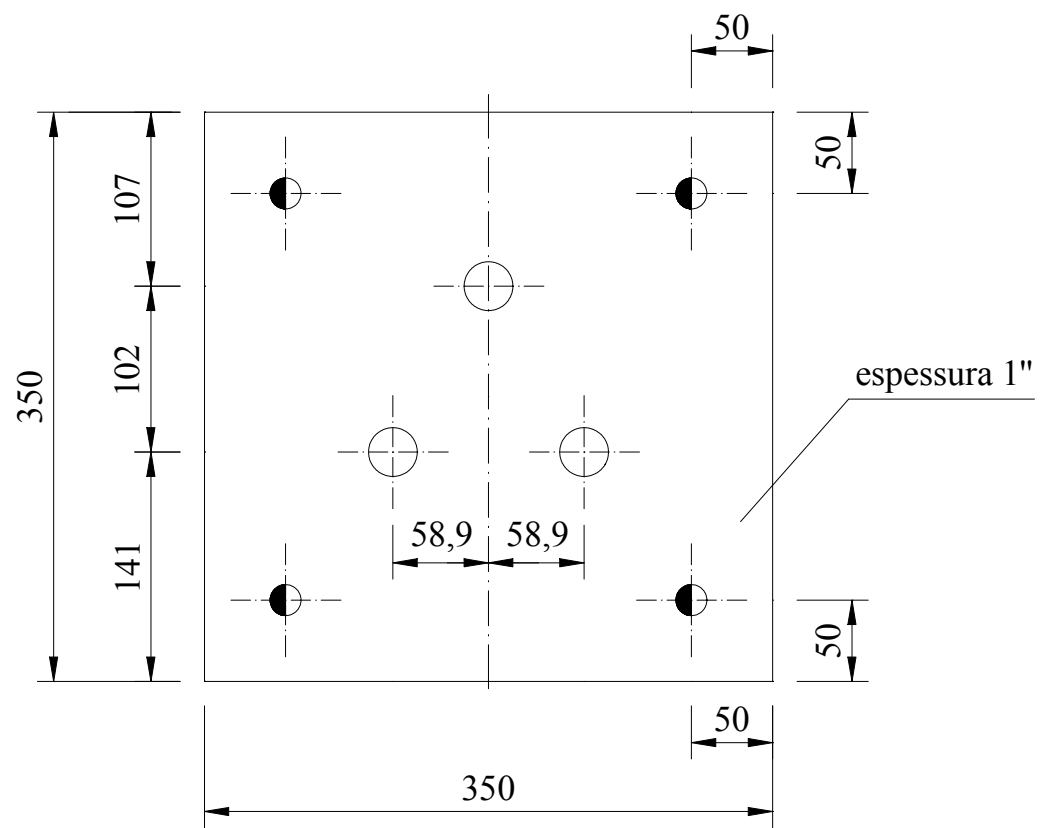

Legenda

(1) 19

Ø 30

Cotas $[\mathrm{mm}]$

Figura 5.5 - Placa de apoio das barras perimetrais

Entre a placa e as porcas são interpostos sistemas de apoio formados por duas peças cilíndricas de aço, uma côncava e outra convexa, perfeitamente ajustáveis e lubrificadas, que funcionam como articulação, de modo a compensar, durante o ensaio, qualquer possível desnivelamento ou excentricidade das forças nas barras tracionadas. Esse sistema está detalhado na Figura 5.6. 


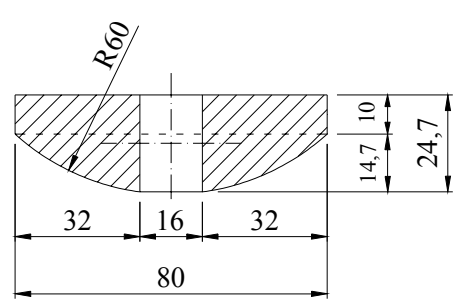

Corte A-A

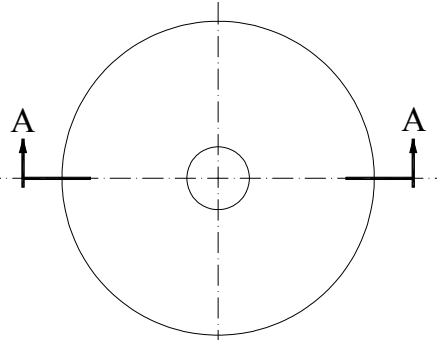

Vista Superior

Peça 1

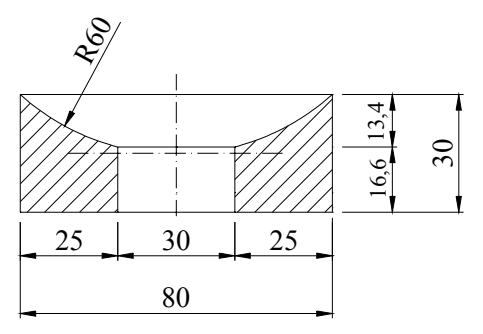

Corte B-B

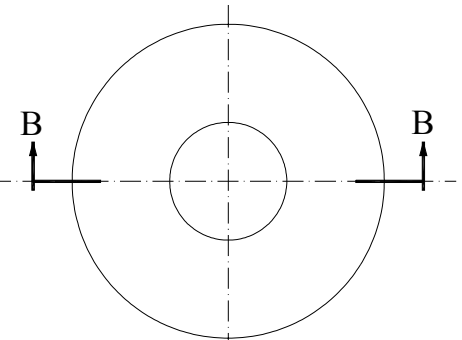

Vista Superior

Peça 2

Cotas $[\mathrm{mm}]$

Figura 5.6 - Sistema de apoio das barras perimetrais

\subsubsection{MOLDAGEM E CURA DOS CORPOS-DE-PROVA}

Os corpos-de-prova foram moldados na posição vertical, ou seja, com a base da fôrma apoiada horizontalmente. Assim, os eixos das barras permaneceram paralelos à direção do lançamento do concreto.

O concreto foi compactado em três camadas com adensamento realizado em uma mesa vibratória. Os corpos-de-prova foram retirados das fôrmas três dias após a moldagem e armazenados em câmara úmida. 


\subsubsection{EXECUÇÃO DO ENSAIO}

Os modelos foram retirados da câmara úmida 48 horas antes do ensaio. Os ensaios foram realizados aos 9 dias de idade do concreto. A barra central foi solicitada por força de tração aplicada no mesmo sentido ao do lançamento do concreto.

Após o posicionamento do corpo-de-prova na máquina, ajustado às garras com pequena carga inicial e nivelado à chapa onde as barras perimetrais estão fixadas com os sistemas de apoio, os instrumentos foram zerados e seu funcionamento verificado. Dessa forma, pode-se iniciar a aplicação da carga com velocidade de deslocamento de $0,01 \mathrm{~mm} / \mathrm{s}$, registrando-se discretamente em pequenos intervalos de tempo os deslizamentos na extremidade descarregada da barra central. A medida dos deslocamentos da barra central em relação ao concreto, foi feita por transdutores indutivos de deslocamentos.

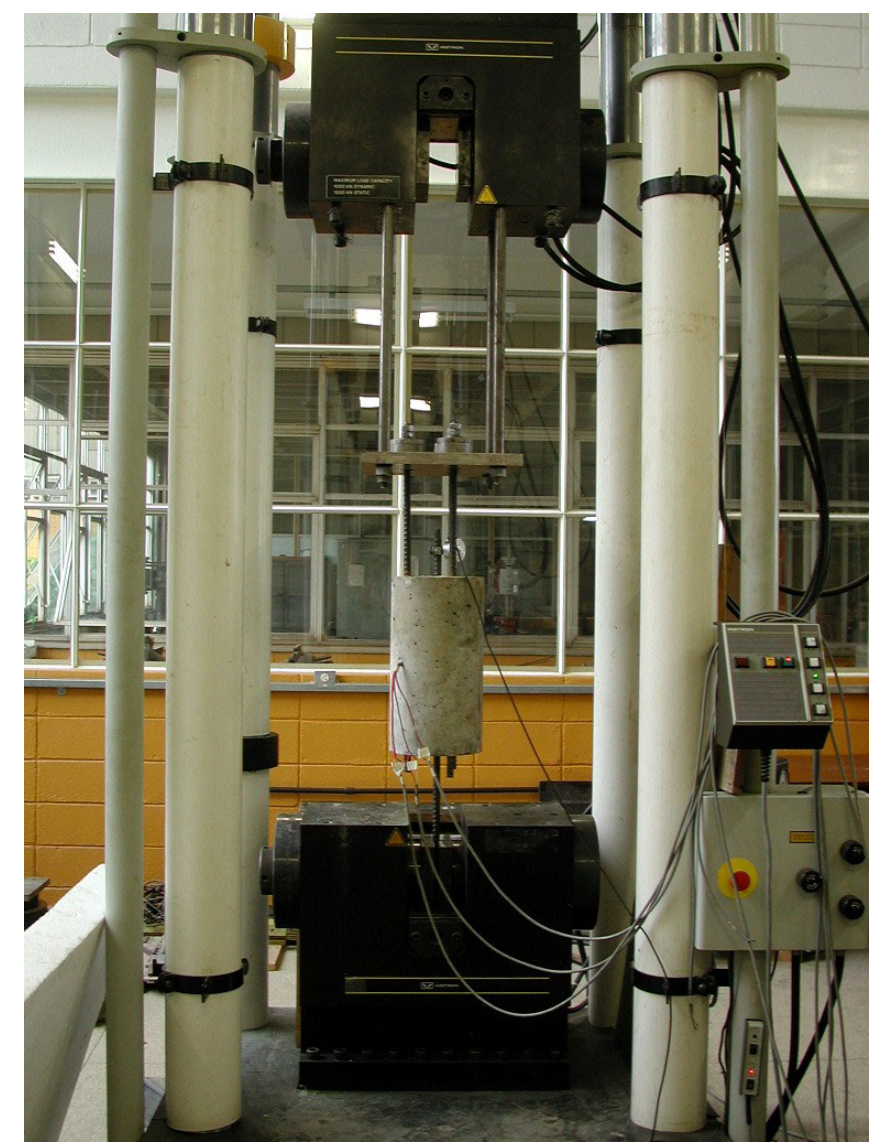

Figura 5.7 - Arranjo de ensaio das quatro barras (modelo 4B-PILOTO 3) 


\subsection{PLANO PILOTO}

A investigação experimental preliminar foi feita com quatro corpos-de-prova, um do ensaio de arrancamento e três do ensaio das quatro barras. Os ensaios foram executados aos 9 dias de idade do concreto, com a solicitação da barra no mesmo sentido ao da concretagem.

\subsubsection{CORPO-DE-PROVA DO ENSAIO DE} ARRANCAMENTO

A Figura 5.8 apresenta esquematicamente o corpo-de-prova do ensaio de arrancamento, o modelo é semelhante aos ensaios de arrancamento utilizados por diversos autores no decorrer dos anos, incluindo os ensaios padronizados pela RILEM-FIP-CEB (1973) e ASTM (1991).

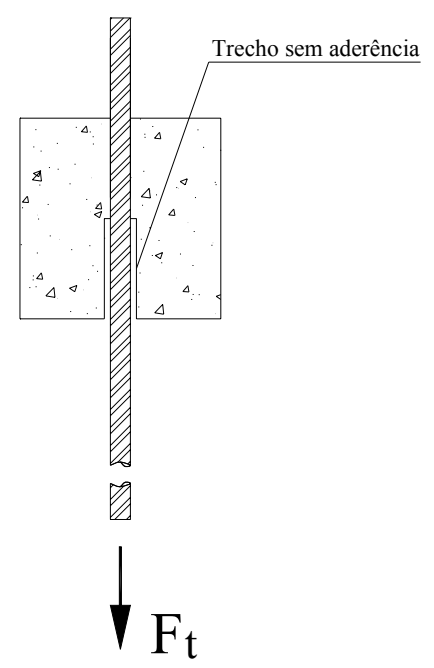

Figura 5.8 - Desenho esquemático do corpo-de-prova do ensaio de arrancamento

O corpo-de-prova é um cilindro de concreto, tendo ao centro uma barra de aço, que contém um trecho aderente ao concreto e outro sem aderência, para evitar a influência do confinamento causado pela placa de apoio. 
Os modelos do ensaio de arrancamento foram denominados de PT, uma alusão ao ensaio Pull-Out Test proposto pela RILEM-FIP-CEB (1973). Para o ensaio piloto essa denominação foi acompanhada pela palavra PILOTO e o número do modelo.

As características principais do corpo-de-prova para o ensaio de arrancamento piloto estão indicadas na Figura 5.9 e ressaltadas a seguir:

a. Trecho sem aderência (na ponta carregada) de $5 \phi$;

b. Comprimento de ancoragem igual a $10 \phi$;

c. Distância da face da barra à extremidade do corpo-de-prova com 3,25 $\phi$; o diâmetro do cilindro, por isso, foi definido em $7,5 \phi$.

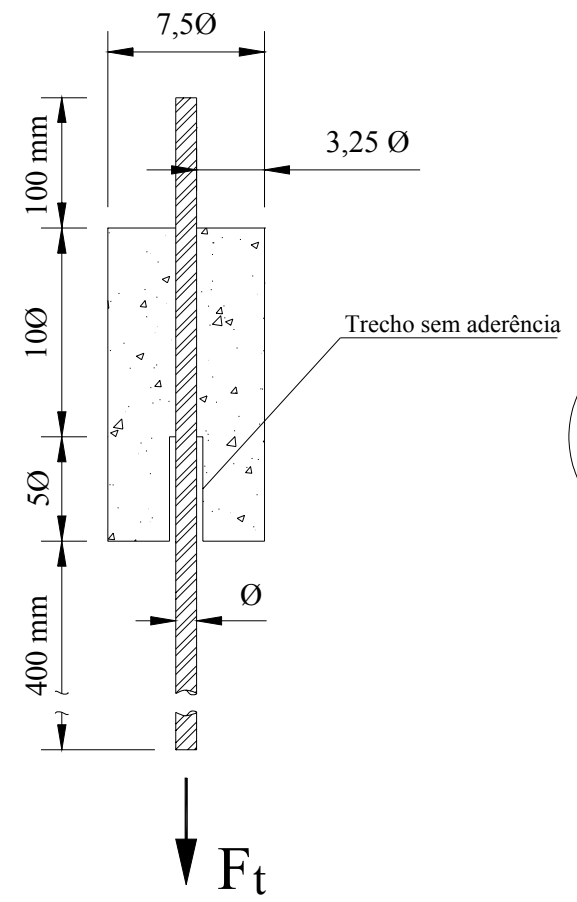

Figura 5.9 - Características do corpo-de-prova para o ensaio de arrancamento piloto

Dessa forma pode-se apresentar o modelo PT-PILOTO 1, conforme a Figura 5.10 . 


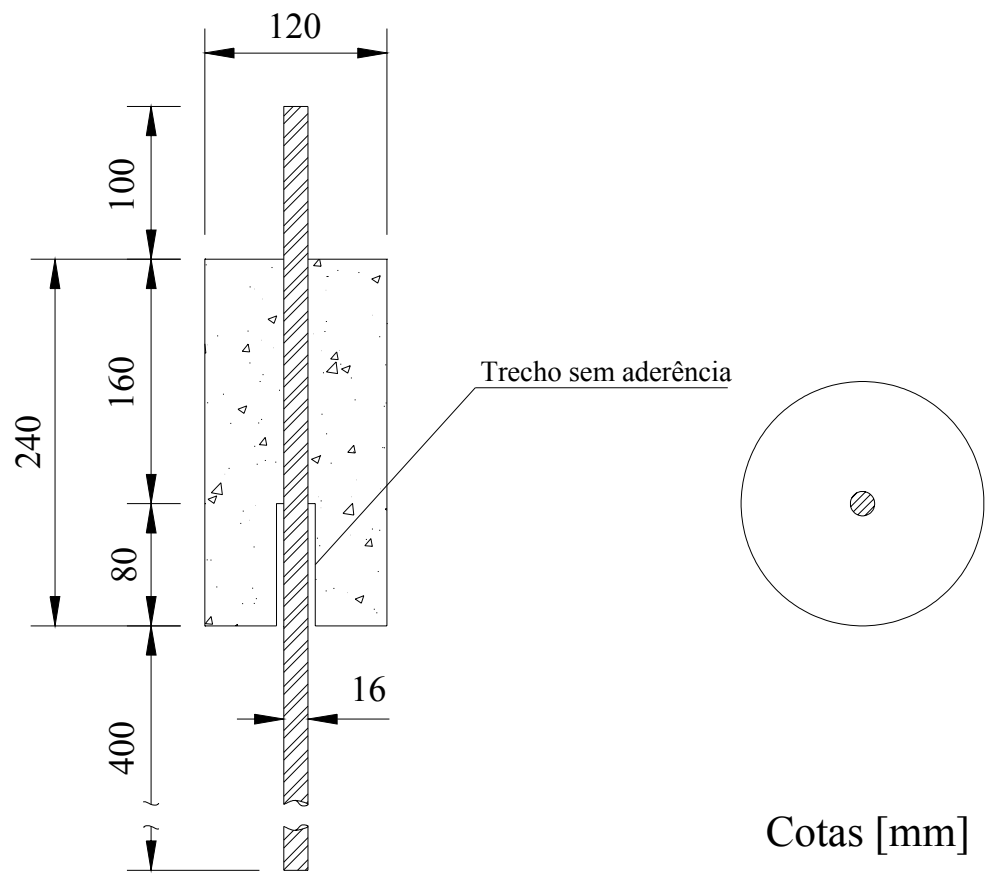

Figura 5.10 - Modelo PT-PILOTO 1

\subsubsection{CORPOS-DE-PROVA DO ENSAIO DAS QUATRO BARRAS}

Foram feitos três modelos do ensaio das quatro barras, com as seguintes características, em função do diâmetro nominal da barra $\phi$ :

a. Trecho sem aderência, nas duas extremidades, igual a $5 \phi$;

b. Comprimento de ancoragem igual a $10 \phi$;

c. Distância $\mathrm{a}_{\mathrm{s}}$ entre as barras perimetrais e a barra central igual a $3,25 \phi$. 


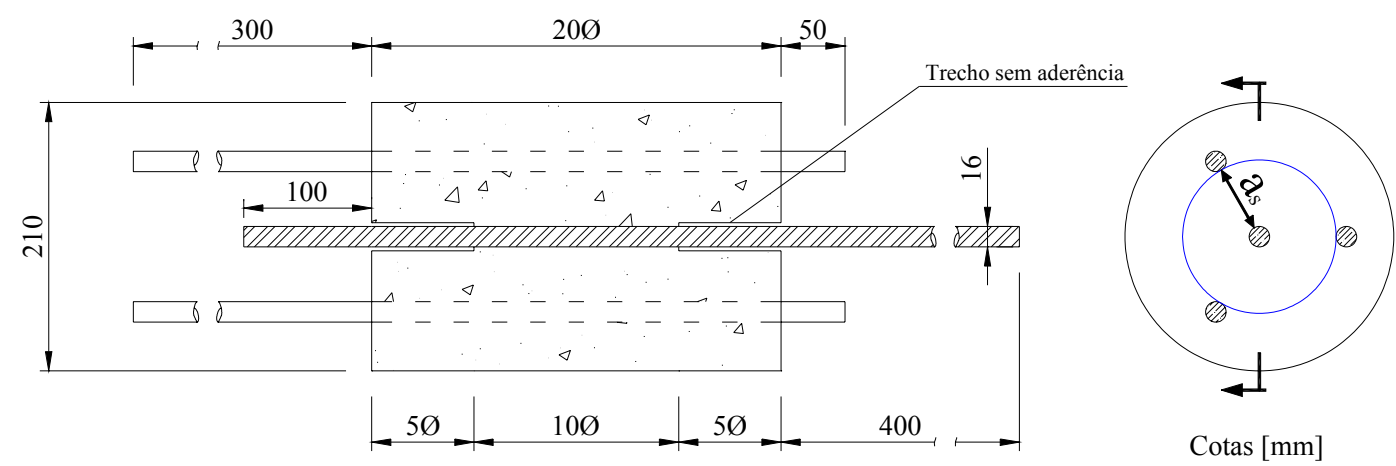

Figura 5.11 - Características dos modelos para o ensaio das quatro barras

O diâmetro dos corpos-de-prova foi definido em $210 \mathrm{~mm}$ e os comprimentos das barras externos aos cilindros de concreto foram definidos segundo as características da máquina de ensaios e de alguns dispositivos utilizados.

Os modelos do ensaio das quatro barras foram denominados 4B, acompanhados da palavra PILOTO e o número do modelo.

Na Figura 5.12 é apresentado o detalhadamente do modelo 4B-PILOTO 2.
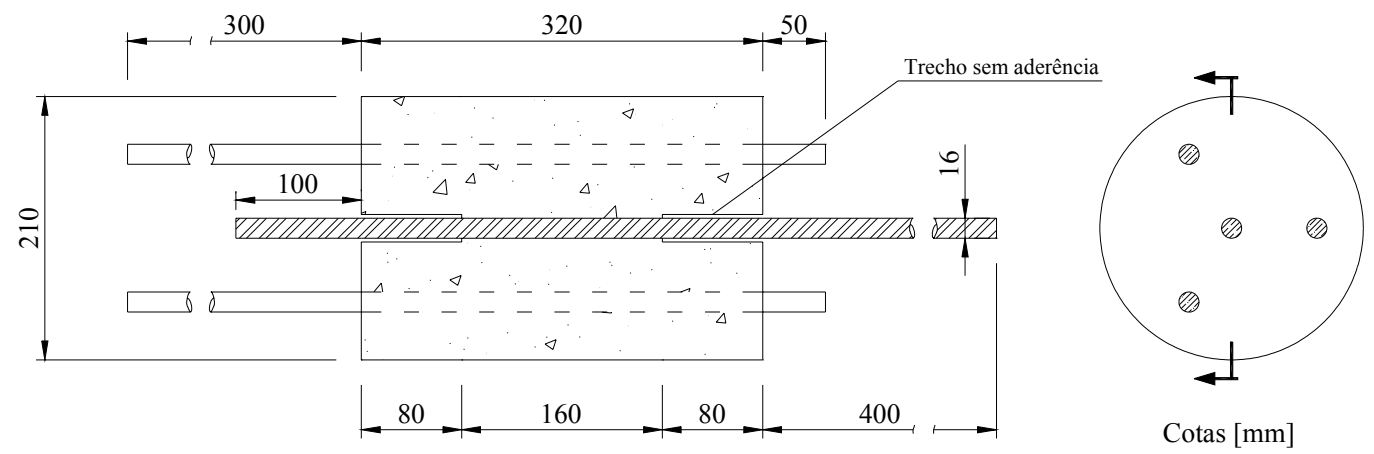

Figura 5.12 - Modelo 4B-PILOTO 2

Nos modelos 4B-PILOTO 3 e 4B-PILOTO 4 a barra central foi instrumentada com extensômetros elétricos de resistência, para avaliar a distribuição das tensões de aderência.

No modelo 4B-PILOTO 3, apresentado na Figura 5.13, os extensômetros foram colocados na superfície externa da barra e protegidos com fita isolante. Assumindo que a proteção de cada extensômetro equivale a $25 \mathrm{~mm}$, o trecho aderente do modelo 4B-PILOTO 3 foi acrescido de $75 \mathrm{~mm}$. Com esse modelo 
também se objetiva verificar o efeito da interrupção da aderência devido à colocação dos extensômetros.

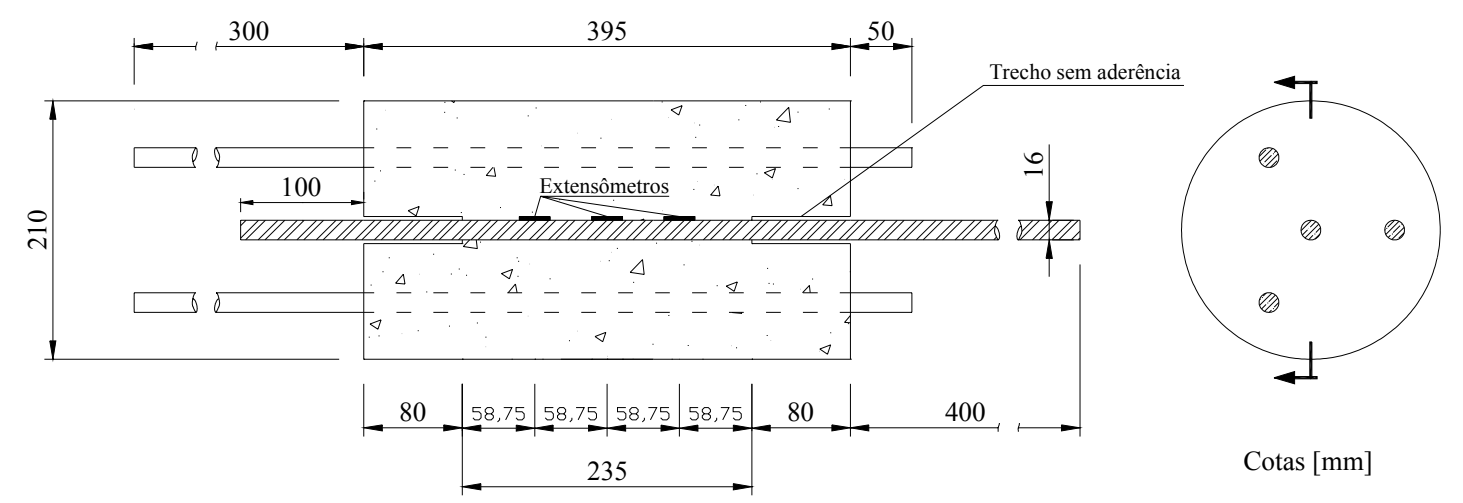

Figura 5.13 - Modelo 4B-PILOTO 3

No modelo 4B-PILOTO 4 os extensômetros foram colocados no interior da barra central conforme processo detalhado no item 5.7 desta dissertação. As posições desses extensômetros estão apresentadas na Figura 5.14 e na Tabela 5.2. Essas posições dos extensômetros são apresentadas como a distância da extremidade descarregada A até o centro do extensômetro.

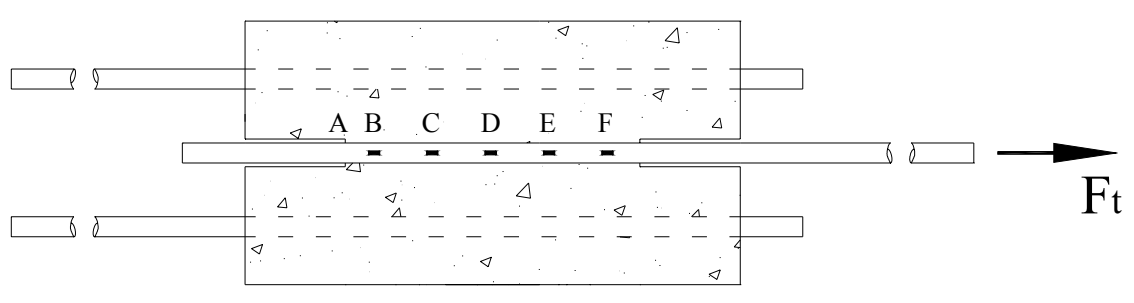

Figura 5.14 - Representação dos extensômetros na barra instrumentada internamente (modelo 4B-PILOTO 4) 
Tabela 5.2 - Posição dos extensômetros na barra instrumentada internamente (modelo 4B-PILOTO 4)

\begin{tabular}{|c|c|}
\hline Pontos & Posição [mm] \\
\hline B & 16 \\
\hline C & 48 \\
\hline D & 80 \\
\hline E & 112 \\
\hline F & 144 \\
\hline
\end{tabular}

Os extensômetros foram alocados alternadamente em cada uma das duas partes da barra. Na posição D foram utilizados dois extensômetros, uma em cada parte, com finalidade de acompanhar o comportamento das duas partes da barra. Dessa forma, em uma parte da barra havia extensômetros nas posições B, D e F e na outra parte os extensômetros estavam alocados nas posições C, D e E.

As dimensões do modelo 4B-PILOTO 4 são iguais ao do modelo 4BPILOTO 2 (Figura 5.12).

\subsection{PLANO DEFINITIVO}

O plano definitivo foi composto apenas por ensaios de arrancamento. Após os ensaios do plano piloto definiram-se os parâmetros que foram o escopo deste trabalho, os quais estão apresentados a seguir:

a. Distribuição de tensão ao longo do comprimento de ancoragem;

b. Grau de confinamento oriundo do cobrimento de concreto. Foram utilizadas duas séries de ensaios com diferentes diâmetros do cilindro de concreto $(7,5 \phi$ ou 12,5 $\phi)$. Essas séries foram denominadas 7,5 e 12,5, conforme o diâmetro do cilindro de concreto em função do diâmetro nominal da barra $(\phi)$;

c. Tipo de carregamento (monotônico e repetido);

d. Nível máximo da amplitude do carregamento repetido $\left(\tau_{\mathrm{b}, \max }\right)$. 
Dessa forma, foram fixados alguns outros parâmetros importantes, que estão enumerados a seguir:

a. Diâmetro nominal da barra $\phi$ igual a $16 \mathrm{~mm}$;

b. Comprimento de ancoragem $\ell$ igual a $5 \phi$;

c. Trecho sem aderência (na extremidade carregada do corpo-de-prova) de $5 \phi$;

d. Resistência à compressão do concreto em torno de $85 \mathrm{MPa}$.

Com a definição de todos os parâmetros são apresentadas a seguir as características geométricas dos modelos das duas séries de ensaio. Nas Figuras 5.15 e 5.16 as características geométricas, referentes às séries 7,5 e 12,5 respectivamente, são apresentadas em função do diâmetro nominal da barra. Nas Figuras 5.17 e 5.18 são apresentadas as dimensões dos modelos propriamente dita, séries 7,5 e 12,5 respectivamente.

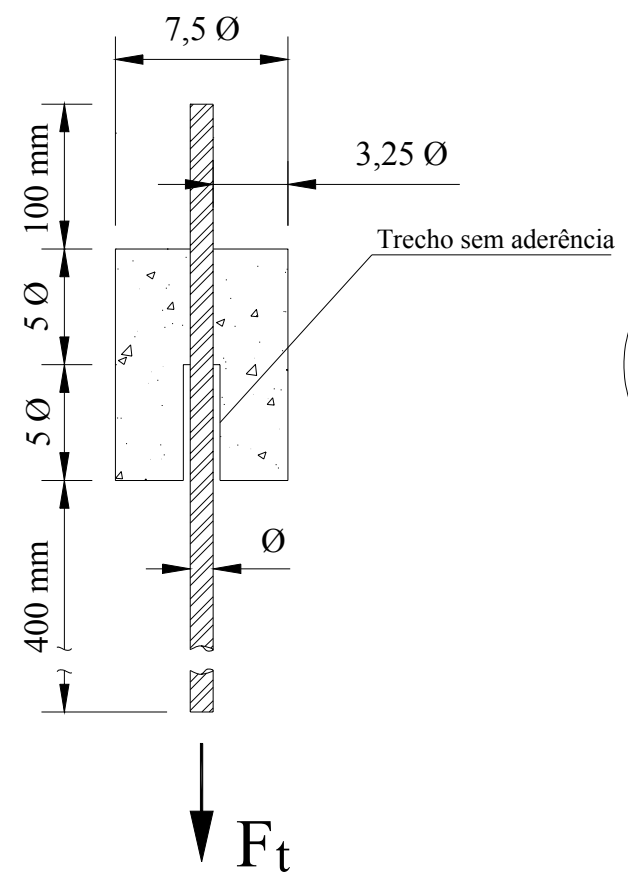

Figura 5.15 - Características geométricas dos modelos da série 7,5 


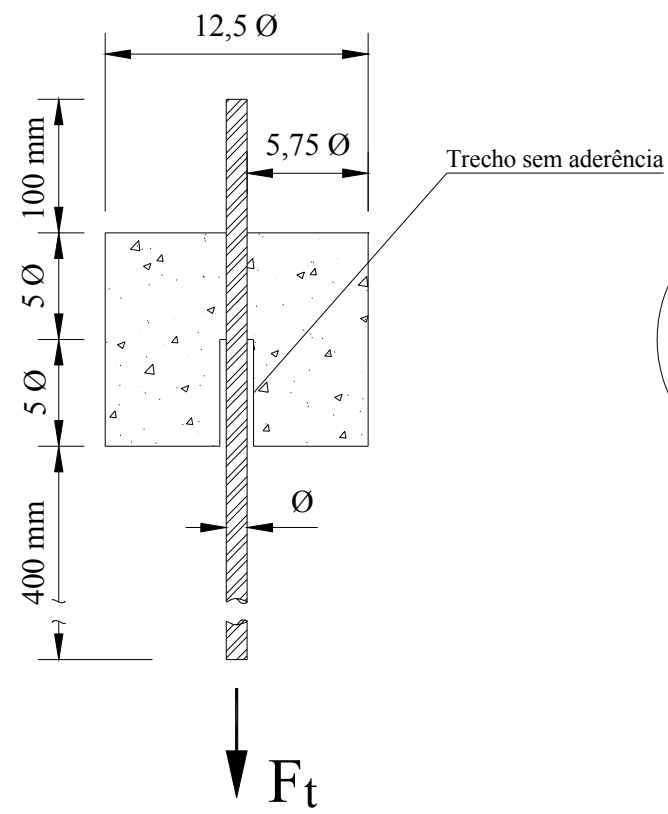

Figura 5.16 - Características geométricas dos modelos da série 12,5

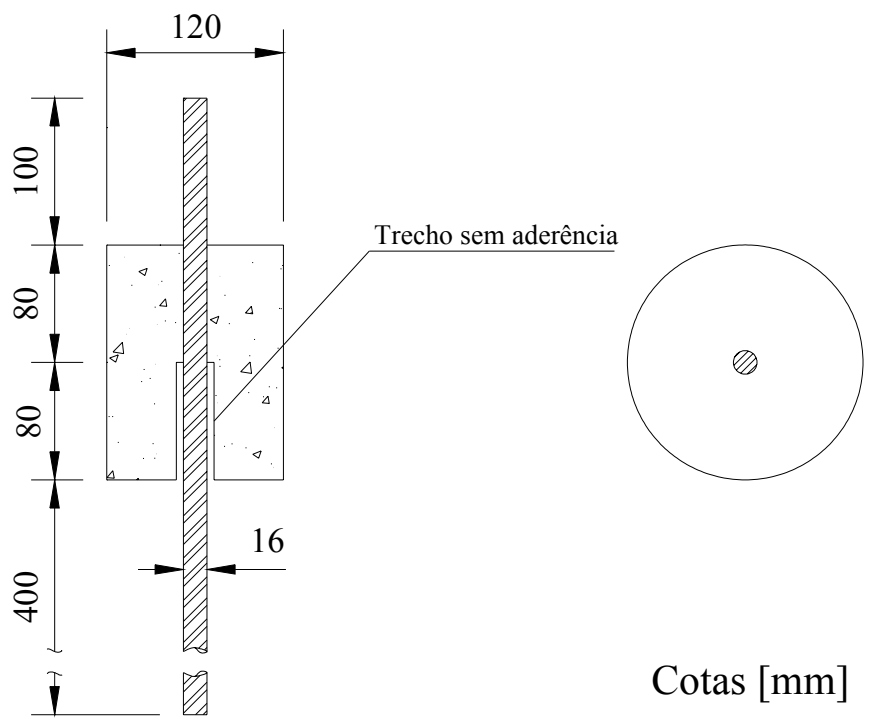

Figura 5.17 - Modelos da série 7,5 


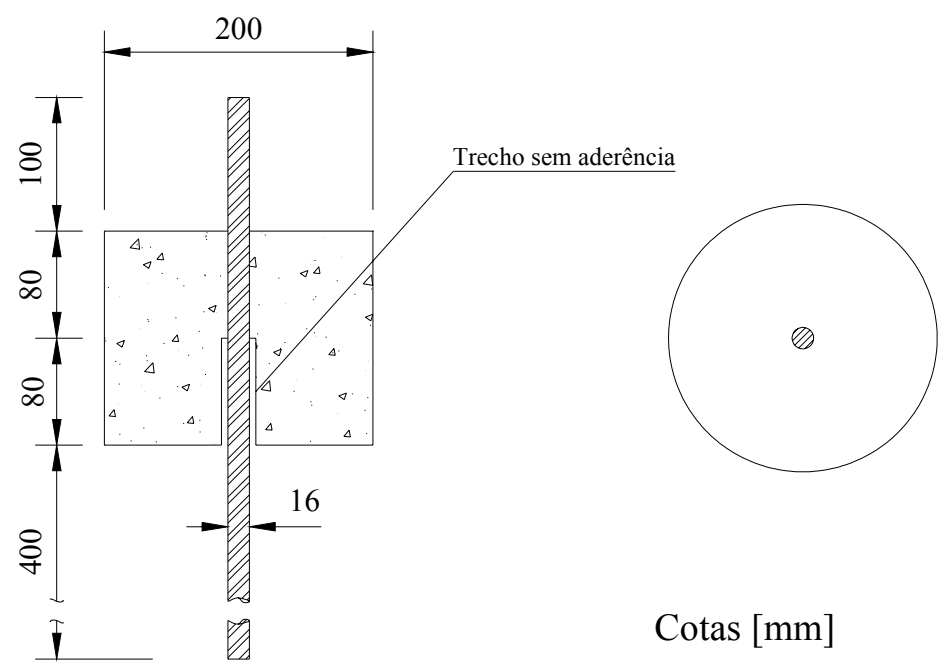

Figura 5.18 - Modelos da série 12,5

A idade do concreto quando se executou os ensaios foi de 18 dias para os ensaios da série 7,5 e 15 dias para os ensaios da série 12,5. A barra foi solicitada no mesmo sentido ao da concretagem.

A influência do carregamento repetido foi verificada com aplicação de determinado número de ciclos, com posterior ruptura do modelo, por carregamento monotônico. Primeiramente, para cada série de ensaio, foram ensaiados três modelos monotônicos. Em seguida, os modelos com carregamento repetido foram submetidos a determinado número de ciclos com amplitudes com níveis mínimos e máximos relacionados ao valor da tensão de aderência última desses ensaios monotônicos. Por fim, os modelos repetidos foram submetidos a carregamento monotônico até a ruptura.

Foram verificadas duas amplitude de carregamento repetido, o nível de tensão mínimo para essas duas amplitudes foi $10 \%$ da tensão de aderência última $\tau_{\mathrm{bu}}$ média de três modelos submetidos a carregamento monotônico e os níveis de tensão máximos das amplitudes foram 60 e $80 \%$ de $\tau_{\mathrm{bu}}$. Foram utilizados dois números de ciclos: 200 e 360 .

O carregamento repetido (com controle de força) foi aplicado com variação linear e freqüência de $0,01 \mathrm{~Hz}$. Em todas a situações, o carregamento monotônico foi aplicado com controle de deslocamento onde a velocidade do pistão foi de 0,01 $\mathrm{mm} / \mathrm{s}$. 
Os modelos do ensaio de arrancamento foram denominados de PT. Essa denominação foi acompanhada por um número que indica a série do modelo (7,5 ou 12,5). Em seguida, são indicados o número do modelo e o tipo de carregamento em estudo: M para monotônico e $\mathrm{R}$ para repetido.

$\mathrm{Na}$ Tabela 5.3 são apresentadas as características gerais de cada modelo utilizado no plano experimental definitivo.

Tabela 5.3 - Características gerais dos modelos do plano definitivo

\begin{tabular}{|c|c|c|c|c|}
\hline & Modelo & $\begin{array}{c}\text { Tipo de } \\
\text { carregamento }\end{array}$ & $\begin{array}{l}\text { Número de } \\
\text { ciclos }\end{array}$ & $\begin{array}{l}\text { Nível máximo da } \\
\text { amplitude do } \\
\text { carregamento }\end{array}$ \\
\hline \multirow{7}{*}{ 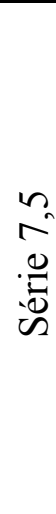 } & PT(7,5)-1M & \multirow{3}{*}{ Monotônico } & \multirow{3}{*}{ - } & \multirow{3}{*}{-} \\
\hline & $\mathrm{PT}(7,5)-2 \mathrm{M}$ & & & \\
\hline & PT(7,5)-3M & & & \\
\hline & $\mathrm{PT}(7,5)-1 \mathrm{R}$ & \multirow{4}{*}{ Repetido } & 200 & \multirow{2}{*}{$\tau_{\mathrm{b}, \max }=0,60 \cdot \tau_{\mathrm{bu}}$} \\
\hline & PT(7,5)-2R & & 360 & \\
\hline & PT(7,5)-3R & & 200 & \multirow{2}{*}{$\tau_{\mathrm{b}, \max }=0,80 \cdot \tau_{\mathrm{bu}}$} \\
\hline & PT $(7,5)-4 \mathrm{R}$ & & 360 & \\
\hline \multirow{7}{*}{ 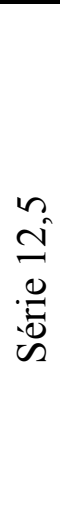 } & PT(12,5)-1M & \multirow{3}{*}{ Monotônico } & \multirow{3}{*}{ - } & \multirow{3}{*}{-} \\
\hline & PT(12,5)-2M & & & \\
\hline & PT(12,5)-3M & & & \\
\hline & $\mathrm{PT}(12,5)-1 \mathrm{R}$ & \multirow{4}{*}{ Repetido } & 200 & \multirow{2}{*}{$\tau_{\mathrm{b}, \max }=0,60 \cdot \tau_{\mathrm{bu}}$} \\
\hline & $\mathrm{PT}(12,5)-2 \mathrm{R}$ & & 360 & \\
\hline & $\mathrm{PT}(12,5)-3 \mathrm{R}$ & & 200 & \multirow{2}{*}{$\tau_{\mathrm{b}, \max }=0,80 \cdot \tau_{\mathrm{bu}}$} \\
\hline & $\mathrm{PT}(12,5)-4 \mathrm{R}$ & & 360 & \\
\hline
\end{tabular}

Para avaliar a distribuição das tensões de aderência, a barra do modelo PT(7,5)-2R foi instrumentada internamente com extensômetros. O processo desenvolvido para instrumentação interna de barras está detalhado no item 5.7 desta dissertação. Na Figura 5.19 e na Tabela 5.4 são apresentadas as posições dos 
extensômetros. Essas posições são apresentadas como a distância da extremidade descarregada A até o centro do extensômetro.

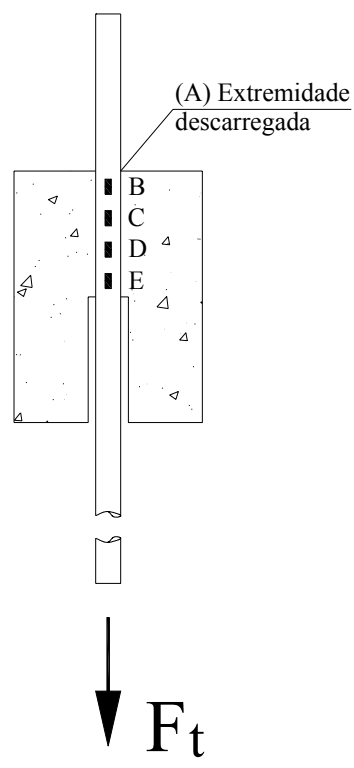

Figura 5.19 - Representação dos extensômetros na barra instrumentada internamente (modelo PT(7,5)-2R)

Tabela 5.4 - Posição dos extensômetros na barra instrumentada internamente modelo PT $(7,5)-2 \mathrm{R}$

\begin{tabular}{|c|c|}
\hline Pontos & Posição $[\mathrm{mm}]$ \\
\hline A & 0 \\
\hline B & 10 \\
\hline C & 30 \\
\hline D & 50 \\
\hline E & 70 \\
\hline
\end{tabular}

Os extensômetros foram dispostos alternadamente em cada uma das duas partes da barra. Assim, em uma das partes havia extensômetros nas posições B e D e na outra parte da barra os extensômetros estavam alocados nas posições $\mathrm{C}$ e $\mathrm{E}$. 


\subsection{INSTRUMENTAÇÃO INTERNA DE BARRAS DE AÇO}

Foi extremamente laborioso o processo de desenvolvimento da técnica de instrumentação interna da barra. Algumas etapas como, por exemplo, o corte da barra e a isolação dos extensômetros no interior da barra requereram atenção especial.

A barra foi cortada, longitudinalmente, em duas partes através de um jato d'água sob alta pressão. Esse tipo de corte, além de preciso, mantém todas as propriedades físicas e mecânicas do material.

O corte feito no plano que contém os eixos de nervuras longitudinais, evita o corte de nervuras transversais e, portanto, mantém as características da barra quanto à aderência. Para evitar perda do diâmetro devido à espessura de corte $(1,5 \mathrm{~mm}) \mathrm{o}$ corte foi feito do plano médio para uma extremidade. Assim, a menos de pequena imprecisão, obteve-se metade da barra intacta e uma parte menor, que foi descartada posteriormente. Para obter o comprimento desejado foi preciso cortar o dobro deste comprimento, pois a barra é composta por duas metades intactas.

Para alocar os extensômetros na superfície das duas metades, foram feitos sulcos longitudinais com 1,0 $\mathrm{mm}$ de profundidade por 3,5 de largura, com o comprimento estendido além da extremidade carregada do cilindro de concreto, para não interferir na distribuição de tensões.

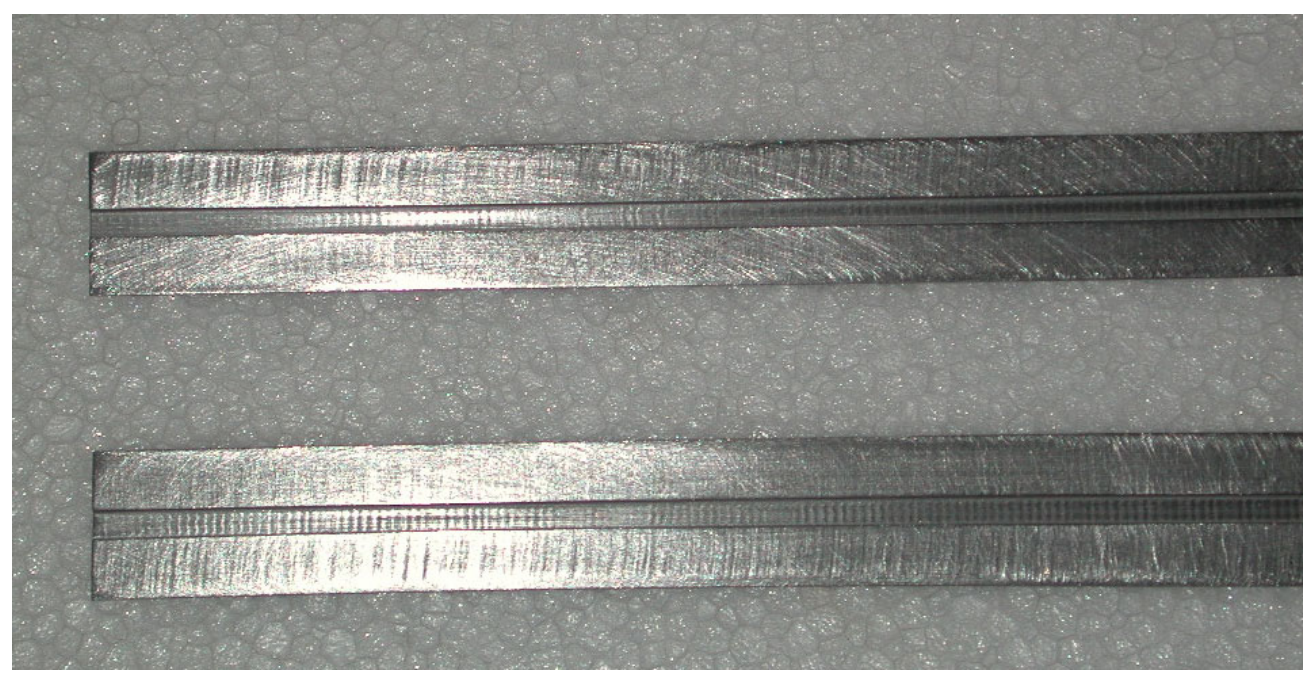

Figura 5.20 - Sulcos na superfície da barra 
A preparação da superfície ("interna") das duas metades que formam a barra foi feita por abrasão com jateamento de areia e acabamento final com lixa para metais $n^{\circ} .80$, aplicada em movimentos circulares. A superfície foi limpa com álcool isopropílico.

A isolação dos extensômetros foi assim executada:

a. Depois de posicionado e colado dentro do sulco da superfície da barra, foi colado pedaço de fita isolante a partir de cada uma das extremidades do extensômetro;

b. Para as leituras, os extensômetros foram conectados a fios esmaltados FICAP com bitola nominal do condutor de $0,203 \mathrm{~mm}$.

c. Pequena quantidade de vernis protetor M-COAT A foi aplicada diretamente sobre o extensômetro;

d. A isolação da ligação extensômetro-fio foi feita com fita isolante líquida;

e. O processo foi finalizado com pequeno pedaço de fita isolante fixado diretamente sobre o extensômetro e a ligação extensômetro-fio.

As Figuras 5.21 e 5.22 ilustram detalhes do processo de isolação dos extensômetros

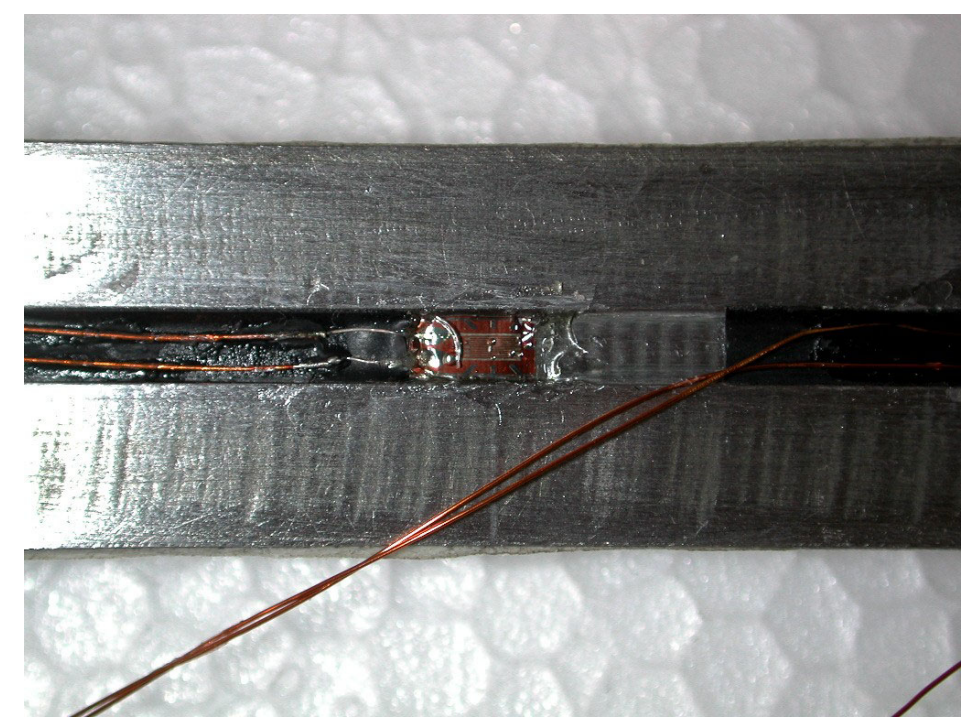

Figura 5.21 - Detalhes do processo de isolação dos extensômetros 


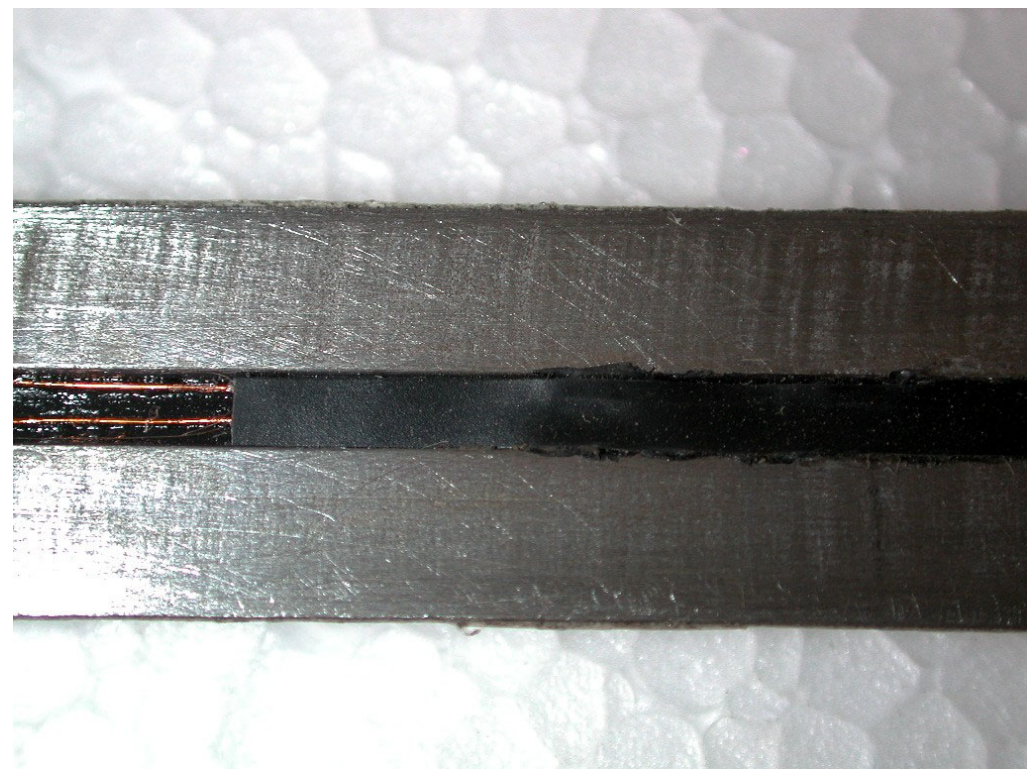

Figura 5.22 - Detalhe final do processo de isolação de um extensômetro

Por fim, a barra foi fechada utilizando-se o adesivo EPÓXI bicomponente ARALDITE (Profissional).

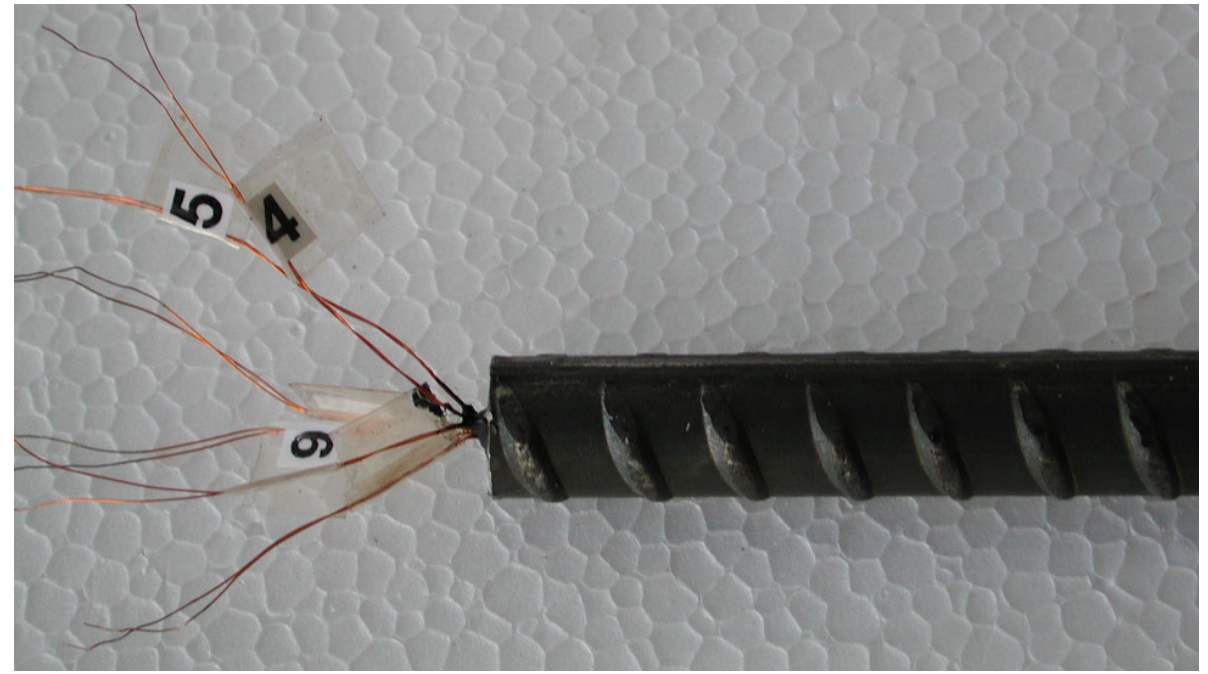

Figura 5.23 - Detalhe da saída dos fios na barra instrumentada internamente

\subsection{INSTRUMENTOS E EQUIPAMENTOS UTILIZADOS}

Os instrumentos e equipamentos de medição utilizados nos ensaios estão indicados na Tabela 5.5. 
Tabela 5.5 - Instrumentos utilizados nos ensaios

\begin{tabular}{|c|c|c|c|c|}
\hline Instrumentos & Tipo & Finalidade & Marca & Características \\
\hline $\begin{array}{c}\text { Sistema de } \\
\text { aquisição de } \\
\text { dados por } \\
\text { extensometria }\end{array}$ & $\begin{array}{c}\text { SYSTEM 5000 } \\
\text { PROGRAM } \\
\text { POWER-UP }\end{array}$ & $\begin{array}{c}\text { Coleta e } \\
\text { gravação } \\
\text { automática de } \\
\text { dados }\end{array}$ & $\begin{array}{c}\text { MEASUREMENTS } \\
\text { GROUP }\end{array}$ & - \\
\hline $\begin{array}{c}\text { Extensômetros } \\
\text { elétricos de } \\
\text { resistência }\end{array}$ & KFG-2-120-C1-11 & $\begin{array}{c}\text { Medição das } \\
\text { deformações } \\
\text { do aço }\end{array}$ & KYOWA & GF $=2,11$ \\
\hline $\begin{array}{c}\text { Extensômetros } \\
\text { elétricos de } \\
\text { resistência }\end{array}$ & KFG-10-120-C1-11 & $\begin{array}{c}\text { Medição das } \\
\text { deformações } \\
\text { do concreto }\end{array}$ & KYOWA & Base $=10 \mathrm{~mm}$ \\
\hline $\begin{array}{c}\text { Transdutor de } \\
\text { deslocamento }\end{array}$ & DTH-A-10 & $\begin{array}{c}\text { Medição de } \\
\text { deslocamentos }\end{array}$ & KYOWA & $0,001 \mathrm{~mm}$ \\
\hline $\begin{array}{c}\text { Máquina } \\
\text { hidráulica } \\
\text { automática }\end{array}$ & Modelo Autotest & $\begin{array}{c}\text { Ensaio dos } \\
\text { corpos-de- } \\
\text { prova de } \\
\text { concreto }\end{array}$ & ELE & Controle de força \\
\hline $\begin{array}{c}\text { Máquina de } \\
\text { ensaio servo- } \\
\text { hidráulica, com } \\
\text { controle digital } \\
\text { por computador }\end{array}$ & Modelo 8506 & $\begin{array}{c}\text { Aplicação da } \\
\text { força do } \\
\text { ensaio de } \\
\text { aderência }\end{array}$ & INSTRON & $\begin{array}{c}\text { Controle de } \\
\text { deslocamento }\end{array}$ \\
\hline
\end{tabular}




\section{CAPÍTULO 6}

\section{RESULTADOS E \\ DISCUSSÃO DOS ENSAIOS}

\subsection{CARACTERIZAÇÃO DO CONCRETO E DO AÇO}

As caracterizações do concreto e do aço estão apresentadas nas Tabelas $6.1 \mathrm{e}$ 6.2, respectivamente. As propriedades mecânicas do concreto foram medidas em corpos-de-prova cilíndricos de 100 por $200 \mathrm{~mm}$. Os valores apresentados são as médias dos resultados de três corpos-de-prova. A idade do concreto quando se executou os ensaios foi de 9 dias para os ensaios do plano piloto, 18 dias para os ensaios da série 7,5 do plano definitivo e 15 dias para os ensaios da série 12,5.

Tabela 6.1 - Caracterização do concreto

\begin{tabular}{|c|c|c|c|c|}
\hline ENSAIO & $\mathbf{E}_{\mathbf{c}}[\mathbf{M P a}]$ & $\mathbf{f}_{\mathrm{cm}}[\mathbf{M P a}]$ & $\mathbf{f}_{\mathrm{tm}}[\mathbf{M P a}]$ & Slump $[\mathbf{m m}]$ \\
\hline PILOTO & - & 64,61 & 4,20 & 170 \\
\hline SÉRIE 7,5 & 36.220 & 83,04 & 4,67 & 130 \\
\hline SÉRIE 12,5 & 37.765 & 86,14 & 4,88 & 100 \\
\hline
\end{tabular}


Tabela 6.2 - Caracterização do aço

\begin{tabular}{|c|c|c|c|c|}
\hline PLANO & $\mathbf{E}_{\mathbf{s}}[\mathbf{M P a}]$ & $\mathbf{f}_{\mathbf{y}}[\mathbf{M P a}]$ & $\mathbf{f}_{\mathbf{u}}[\mathbf{M P a}]$ & $\phi$ efetivo [mm] \\
\hline PILOTO & 211656 & 589 & 711 & 15,92 \\
\hline DEFINITIVO & 198819 & 597 & 715 & 15,74 \\
\hline $\begin{array}{c}\text { MODELOS COM } \\
\text { BARRAS } \\
\text { INSTRUMENTADAS } \\
\begin{array}{c}\text { INTERNAMENTE } \\
\text { 4B-PILOTO 4 e PT(7,5)-2R }\end{array}\end{array}$ & 211656 & 589 & 711 & 16,22 \\
\hline
\end{tabular}

\subsection{PLANO PILOTO}

Na Figura 6.1 são apresentadas as curvas experimentais tensão de aderência por deslizamento dos modelos pilotos. Na Tabela 6.3 são apresentados os resultados obtidos com os ensaios. As siglas da primeira coluna indicam a denominação dos modelos ensaiados. Os resultados expostos são força de tração última $F_{t u}$, tensão de aderência última $\tau_{\mathrm{bu}}$ e seu respectivo deslizamento $\mathrm{s}\left(\tau_{\mathrm{bu}}\right)$ na seção da extremidade descarregada e a tensão de aderência $\tau_{1 \mathrm{R}}$ correspondente ao deslizamento de 0,1 $\mathrm{mm}$, ou seja, o valor convencionado como resistência de aderência de cálculo. Os valores das tensões de aderência expressam valor médio, considerando-se tensões uniformemente distribuídas. 


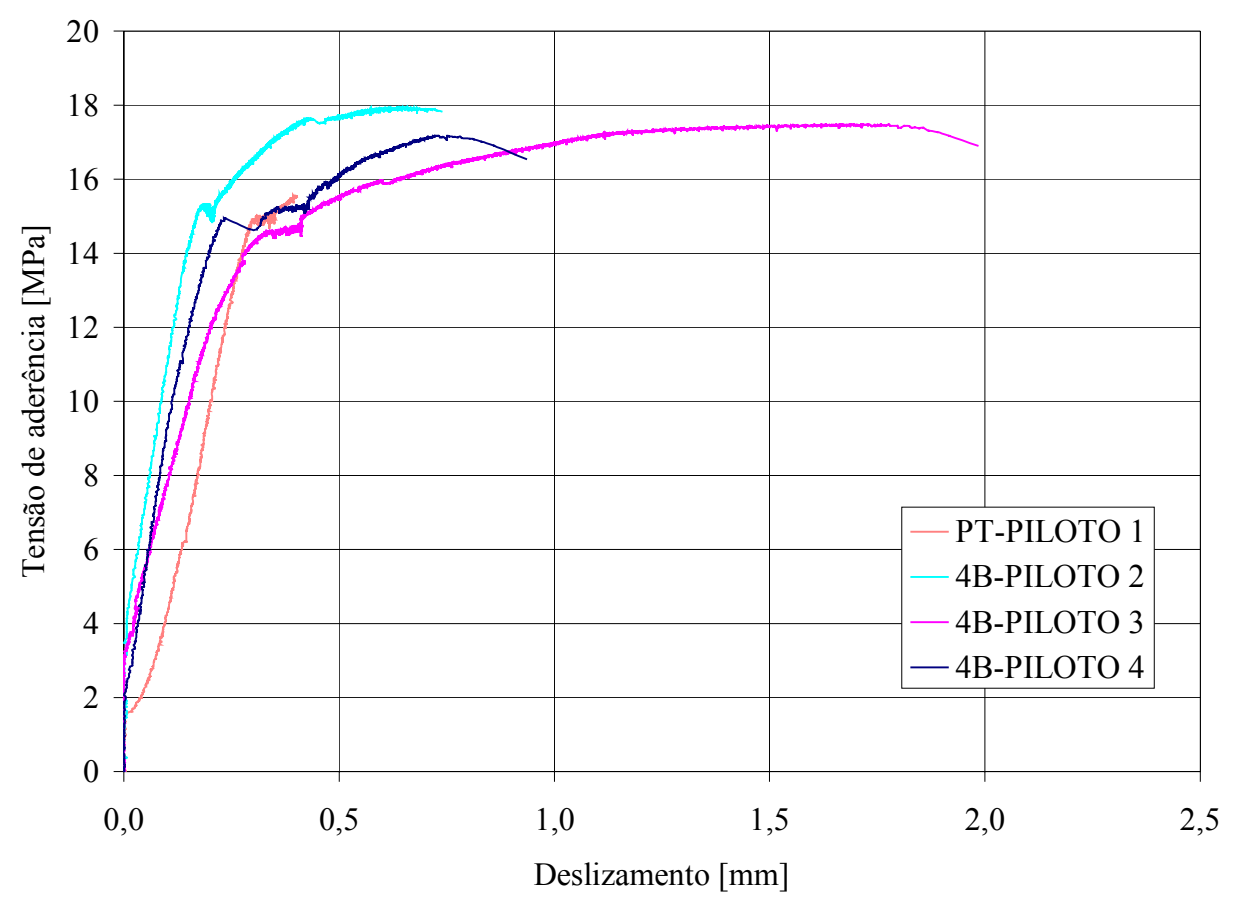

Figura 6.1 - Curvas monotônicas tensão de aderência-deslizamento dos modelos do plano piloto

Tabela 6.3 - Resultados dos ensaios com os modelos do plano piloto

\begin{tabular}{|c|c|c|c|c|}
\hline Modelo & $\mathrm{F}_{\mathrm{tu}}[\mathrm{kN}]$ & $\tau_{\text {bu }}[\mathrm{MPa}]$ & $\mathrm{s}\left(\tau_{\mathrm{bu}}\right)[\mathrm{mm}]$ & $\tau_{1 \mathrm{R}}[\mathrm{MPa}]$ \\
\hline PT-PILOTO 1 & 125,21 & 15,57 & 0,393 & 4,24 \\
\hline 4B-PILOTO 2 & 144,36 & 17,95 & 0,657 & 10,96 \\
\hline 4B-PILOTO 3 & 139,48 & 17,34 & 1,282 & 7,71 \\
\hline 4B-PILOTO 4 & 138,10 & 17,17 & 0,728 & 9,27 \\
\hline
\end{tabular}

Em todos os modelos foi atingido o limite de escoamento do aço. No modelo de ensaio de arrancamento (PT-PILOTO 1) a ruptura se deu por fendilhamento e o cilindro de concreto dividiu-se em três partes. 


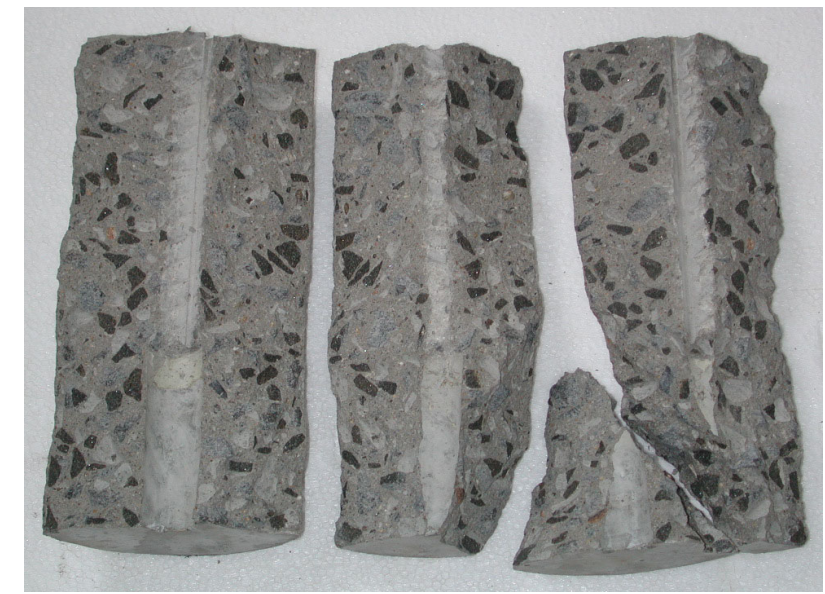

Figura 6.2 - Ruptura por fendilhamento (PT-PILOTO 1)

Os espaços entre as nervuras transversais saíram com certa quantidade de pasta de cimento, resultado do efeito de cisalhamento do concreto.

Os modelo do ensaio das quatro barras romperam-se segundo um dos três planos verticais que contém a barra central e uma das barras perimetrais (Figura 6.3).

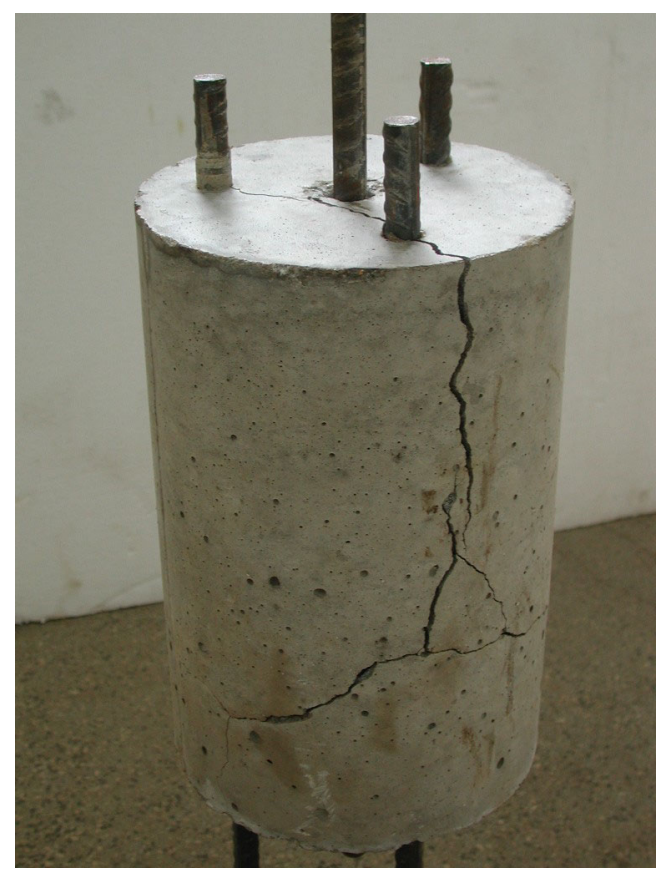

Figura 6.3 - Ruptura por fendilhamento dos modelos do ensaio das quatro barras

Os resultados dos ensaios dos modelos PT-PILOTO 1 e 4B-PILOTO 2 permitem comparar as curvas de aderência obtidas através do ensaio de arrancamento e do ensaio das quatro barras. 
O objetivo foi confrontar os efeitos do confinamento atuantes nos dois ensaios.

a. No ensaio de arrancamento (PT-PILOTO 1) a espessura da camada de concreto que envolve a barra e o atrito da base do corpo-de-prova com a placa de apoio;

b. No ensaio das quatro barras (4B-PILOTO 2) o efeito da espessura de concreto entre as barras perimetrais e a barra central e a presença das três barras perimetrais.

A curva do ensaio das quatro barras é quase paralela à curva do ensaio de arrancamento, porém, apresenta maior tensão de aderência para determinado deslizamento. A tensão de aderência última no ensaio das quatro barras foi $15,3 \%$ maior que no ensaio de arrancamento. Para deslizamentos menores a diferença entre tensões de aderência é ainda maior, no caso da tensão de aderência $\tau_{1 \mathrm{R}}$ (para o deslizamento de $0,1 \mathrm{~mm}$ ) o ensaio das quatro barras forneceu resultado $158,5 \%$ maior que a do ensaio de arrancamento.

$\mathrm{O}$ modelo das quatro barras apresentou maiores deslizamentos. $\mathrm{O}$ deslizamento correspondente à tensão de aderência última foi $66,7 \%$ superior ao do modelo do ensaio de arrancamento.

Quanto ao modelo 4B-PILOTO 4, ou seja, o modelo onde se utilizou a barra instrumentada internamente, verificou-se resultados totalmente compatíveis, tendo como referência o modelo 4B-PILOTO 2. Este modelo de referência apresentou maiores tensões de aderência, a diferença foi de $4,5 \%$ para a tensão de aderência última e 18,2\% para a tensão $\tau_{1 \mathrm{R}}$ convencionada como resistência de aderência. $\mathrm{O}$ modelo 4B-PILOTO 4 apresentou maiores deslizamento, para o deslizamento último a diferença foi de $10,8 \%$.

Tendo como referência o modelo 4B-PILOTO 2, o modelo 4B-PILOTO 3, com extensômetros alocados externamente, apresentou deslizamento 89,2\% maior para situação de ruptura, devido às dimensões do corpo-de-prova (maior comprimento). Entretanto, houve pequena diferença de 3,5\% na tensão de aderência de última. 


\subsubsection{DISTRIBUIÇÃO DE TENSÕES DE ADERÊNCIA}

Com a instrumentação da barra central dos modelos 4B-PILOTO 4 e 4BPILOTO 3, dentre outras grandezas, é possível determinar a distribuição de tensões de aderência. No entanto, para obter a distribuição de tensões, a partir da mensuração em alguns pontos da deformação específica na barra central, é necessário o uso da teoria apresentada no item 2.4 deste trabalho.

Assim, a condição de equilíbrio na ancoragem é representada pela seguinte equação:

$\tau_{\mathrm{b}}(\mathrm{x})=\frac{\phi}{4} \cdot \frac{\mathrm{d} \sigma_{\mathrm{s}}(\mathrm{x})}{\mathrm{dx}}$

Como a tensão normal na armadura, ao longo do comprimento de aderência, está relacionada a suas deformações,

$\sigma_{\mathrm{s}}(\mathrm{x})=\mathrm{E}_{\mathrm{s}} \cdot \varepsilon_{\mathrm{s}}(\mathrm{x})$

a partir das deformações da armadura pode-se determinar as tensões de aderência:

$\tau_{\mathrm{b}}(\mathrm{x})=\frac{\phi}{4} \cdot \mathrm{E}_{\mathrm{s}} \cdot \frac{\mathrm{d} \varepsilon_{\mathrm{s}}(\mathrm{x})}{\mathrm{dx}}$

Através de ensaios, em alguns pontos do comprimento de ancoragem são obtidas as deformações específicas $\varepsilon_{\mathrm{s}}$. A variação de $\varepsilon_{\mathrm{s}}$ é considerada linear ao longo do comprimento de ancoragem e o equacionamento foi feito através da união, por meio de retas $\left(\varepsilon_{\mathrm{s}}(\mathrm{x})=\mathrm{a} \cdot \mathrm{x}+\mathrm{b}\right)$, dos valores de deformação mensurados nos $\mathrm{B}$, C, D, E e F. Estes pontos estão ilustrados na Figura 6.4. 


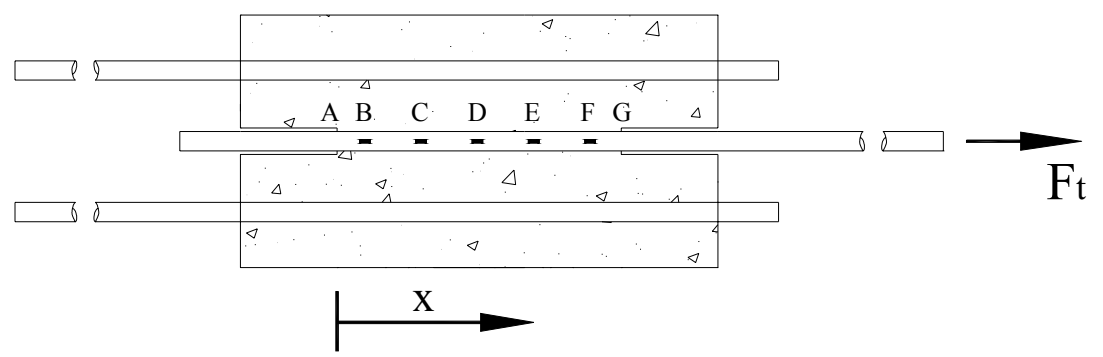

Figura 6.4 - Convenção do eixo x para estabelecimento das equações de deformação

As cotas $\mathrm{x}$ indicam posições da barra central nas quais os extensômetros foram aplicados com origem na extremidade não carregada dessa barra.

Conhecidas as equações de deformação e estabelecido como condição de contorno $\tau_{\mathrm{b}}=0$ na seção $\mathrm{A}$, extremidade descarregada, são determinadas as equações de aderência nos correspondentes trechos, pela Equação 6.3.

Com o intuito de ilustrar esse procedimento será apresentado na Tabela 6.4 o cálculo dessas grandezas para a força de $30,2 \mathrm{kN}$. Esse exemplo refere-se à barra instrumentada internamente do modelo 4B-PILOTO 4.

Tabela 6.4 - Tensões normais e tensões de aderência na barra central do modelo 4B-PILOTO 4

\begin{tabular}{|c|c|c|c|c|}
\hline Pontos & $\begin{array}{c}\text { Posição x } \\
{[\mathrm{mm}]}\end{array}$ & $\begin{array}{c}\text { Deformação } \varepsilon_{\mathrm{s}} \\
{[\%]}\end{array}$ & $\begin{array}{c}\sigma_{\mathrm{s}} \\
{[\mathrm{MPa}]}\end{array}$ & $\begin{array}{c}\tau_{\mathrm{b}} \\
{[\mathrm{MPa}]}\end{array}$ \\
\hline A & 0 & 0 & 0 & 0 \\
\hline B & 16 & 0,0397 & 8,33 & 2,11 \\
\hline C & 48 & 0,0836 & 17,56 & 1,17 \\
\hline D & 80 & 0,1582 & 33,22 & 1,98 \\
\hline E & 112 & 0,2932 & 61,56 & 3,59 \\
\hline F & 144 & 0,5736 & 120,46 & 7,46 \\
\hline G & 160 & 0,6906 & 146,18 & 6,28 \\
\hline
\end{tabular}

Com as deformações nos pontos B, C, D, E, F é possível a determinação das tensões normais à barra central, pela lei de HOOKE. Na seção $G$ a tensão $\sigma_{\mathrm{s}}$ foi 
determinada para a força $F_{t}$ em questão $(30,20 \mathrm{kN})$ e a seção transversal correspondente ao diâmetro efetivo $\phi_{\text {efetivo }}=16,22 \mathrm{~mm}$.

No ponto D foram alocados dois extensômetros, um em cada parte da barra, com finalidade de acompanhar o comportamento dessas duas partes. Entretanto, um dos extensômetros não funcionou.

As Figuras 6.5 e 6.6 apresentam, para o modelo 4B-PILOTO 4, as curvas de tensão normal para a barra central e tensão de aderência para diferentes níveis de carregamento, respectivamente. É importante ressaltar que os diagramas foram obtidos a partir da determinação das tensões $\left(\sigma_{\mathrm{s}}\right.$ ou $\left.\tau_{\mathrm{b}}\right)$ em pontos pré estabelecidos (posições dos extensômetros) e posteriormente, foi feita união desses pontos através de curvas, para se ter, simplificadamente, a distribuição de tensões.

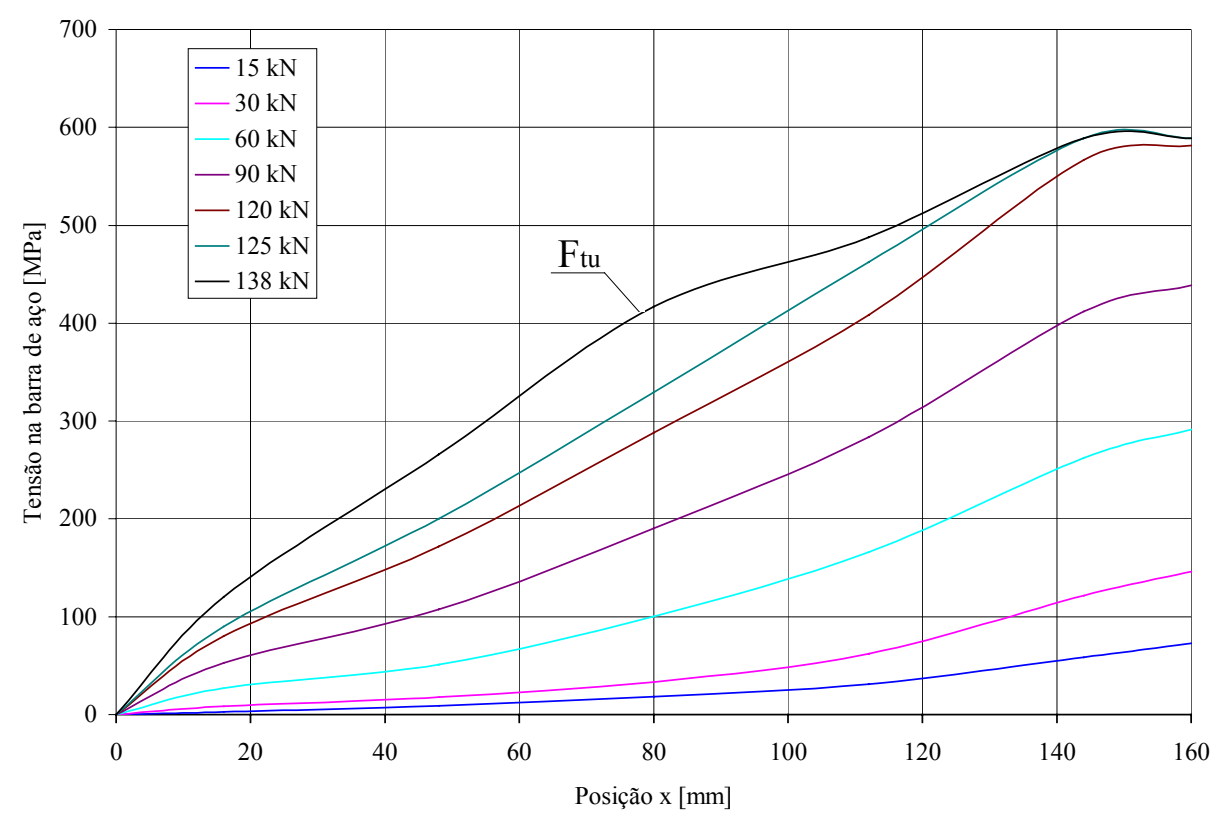

Figura 6.5 - Distribuição de tensões normais na barra central-modelo 4B-PILOTO 4 


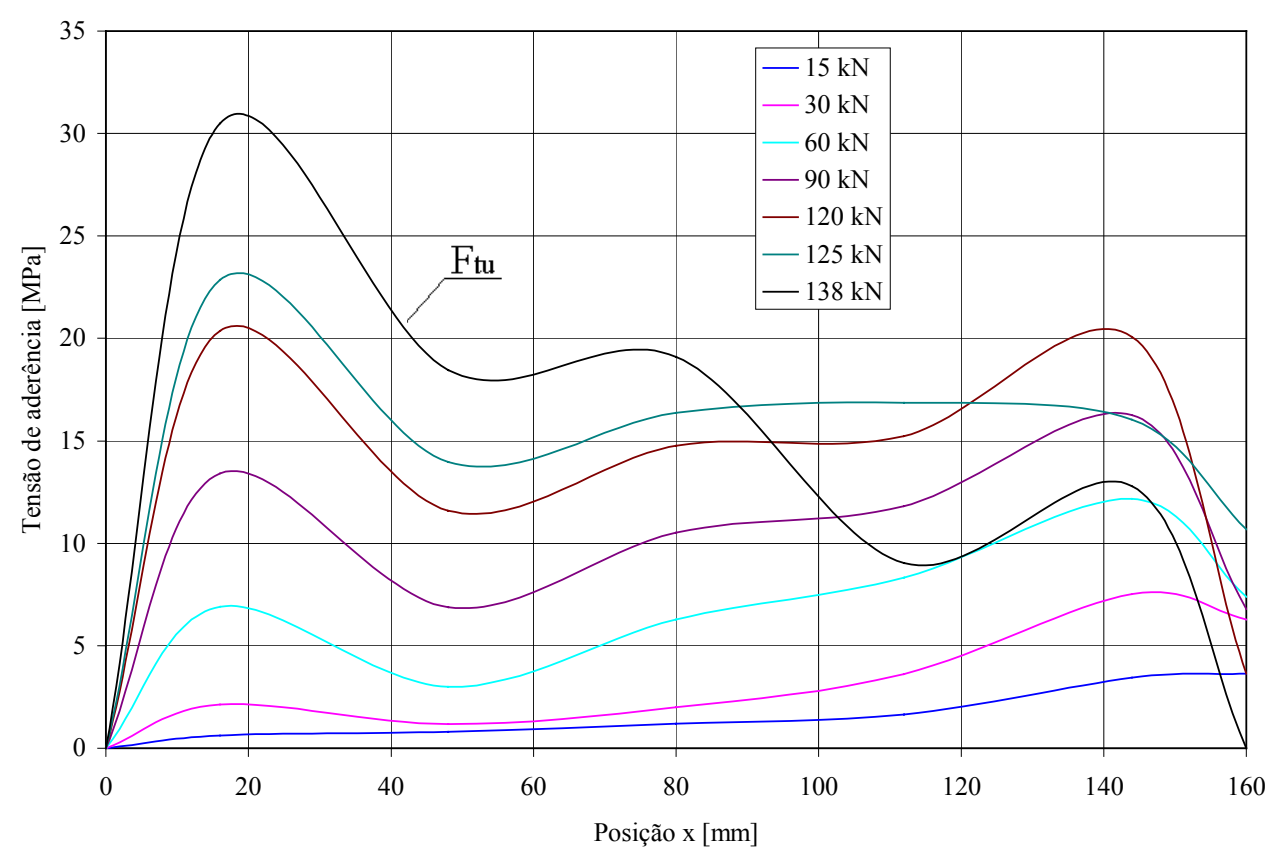

Figura 6.6 - Distribuição de tensões de aderência - modelo 4B-PILOTO 4

No caso do modelo das 4 barras, ou seja, uma emenda por traspasse, observase que as tensões de aderência tendem a se concentrar próximas as extremidades da barra central, com dois picos distantes aproximadamente $1,15 \phi$ das extremidades.

Inicialmente, a tensão de aderência no pico da extremidade carregada é muito superior. Próximo à ruptura ocorreu uma mudança da tensão de aderência máxima da extremidade carregada do modelo para a extremidade descarregada.

A máxima tensão de aderência alcançada durante o ensaio $(\approx 31 \mathrm{MPa})$, obtida através da instrumentação interna da barra, é aproximadamente $80 \%$ maior que a tensão de aderência última, onde assume-se que na ruptura as tensões de aderência são uniformemente distribuídas ao longo do comprimento de ancoragem.

Com a instrumentação (convencional) do modelo 4B-PILOTO 3 não foi possível analisar a distribuição de tensões de aderência porque dois extensômetros não funcionaram. 


\subsection{PLANO DEFINITIVO}

\subsubsection{ADERÊNCIA SOB AÇÃO MONOTÔNICA}

$\mathrm{Na}$ Tabela 6.5 são apresentados os resultados dos ensaios sob ação monotônica das duas séries de ensaio. As curvas $\tau_{\mathrm{b}}-\mathrm{s}$ estão nas Figuras 6.7 e 6.8 .

Tabela 6.5 - Resultados dos ensaios monotônicos com os modelos do plano definitivo

\begin{tabular}{|c|c|c|c|c|c|}
\hline & Modelo & $\mathrm{F}_{\mathrm{tu}}[\mathrm{kN}]$ & $\tau_{\mathrm{bu}}[\mathrm{MPa}]$ & $\mathrm{s}\left(\tau_{\mathrm{bu}}\right)[\mathrm{mm}]$ & $\tau_{1 \mathrm{R}}[\mathrm{MPa}]$ \\
\hline \multirow{4}{*}{$\begin{array}{r}n \\
\stackrel{0}{0} \\
\stackrel{0}{\infty}\end{array}$} & PT(7,5)-1M & 89,66 & 23,04 & 0,482 & 5,78 \\
\hline & PT(7,5)-2M & 87,67 & 22,53 & 0,463 & 6,61 \\
\hline & PT(7,5)-3M & 84,70 & 21,76 & 0,402 & 7,67 \\
\hline & MÉDIA & 87,34 & 22,44 & 0,449 & 6,69 \\
\hline \multirow{4}{*}{ 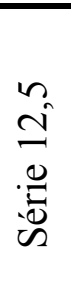 } & $\mathrm{PT}(12,5)-1 \mathrm{M}$ & 119,56 & 30,72 & 1,562 & 18,02 \\
\hline & $\mathrm{PT}(12,5)-2 \mathrm{M}$ & 124,90 & 32,10 & 1,550 & 21,51 \\
\hline & PT(12,5)-3M & 127,04 & 32,65 & 1,255 & 23,39 \\
\hline & MÉDIA & 123,83 & 31,82 & 1,456 & 20,97 \\
\hline
\end{tabular}




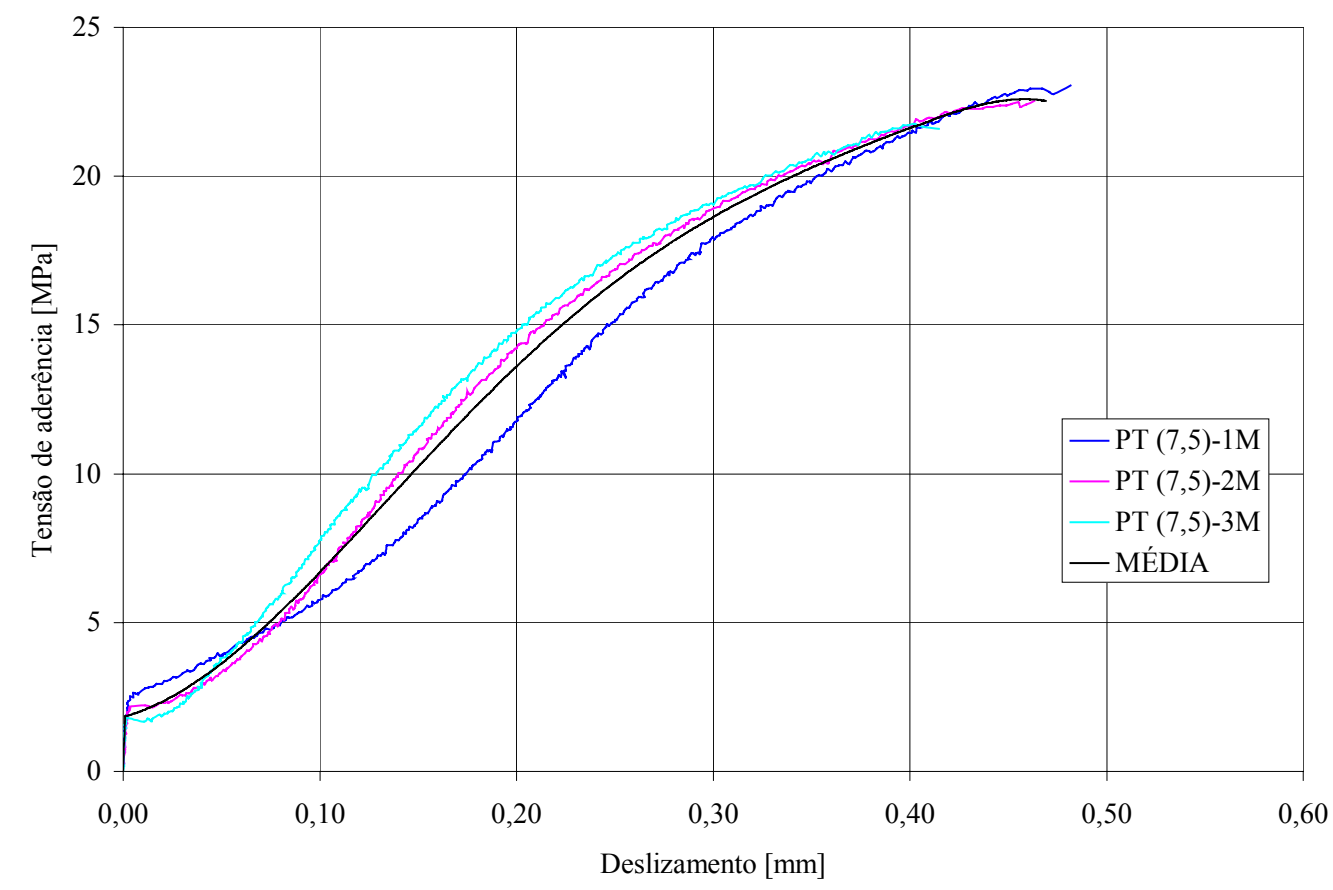

Figura 6.7 - Curvas monotônicas $\tau_{\mathrm{b}}$-s dos modelos da série 7,5 do plano definitivo

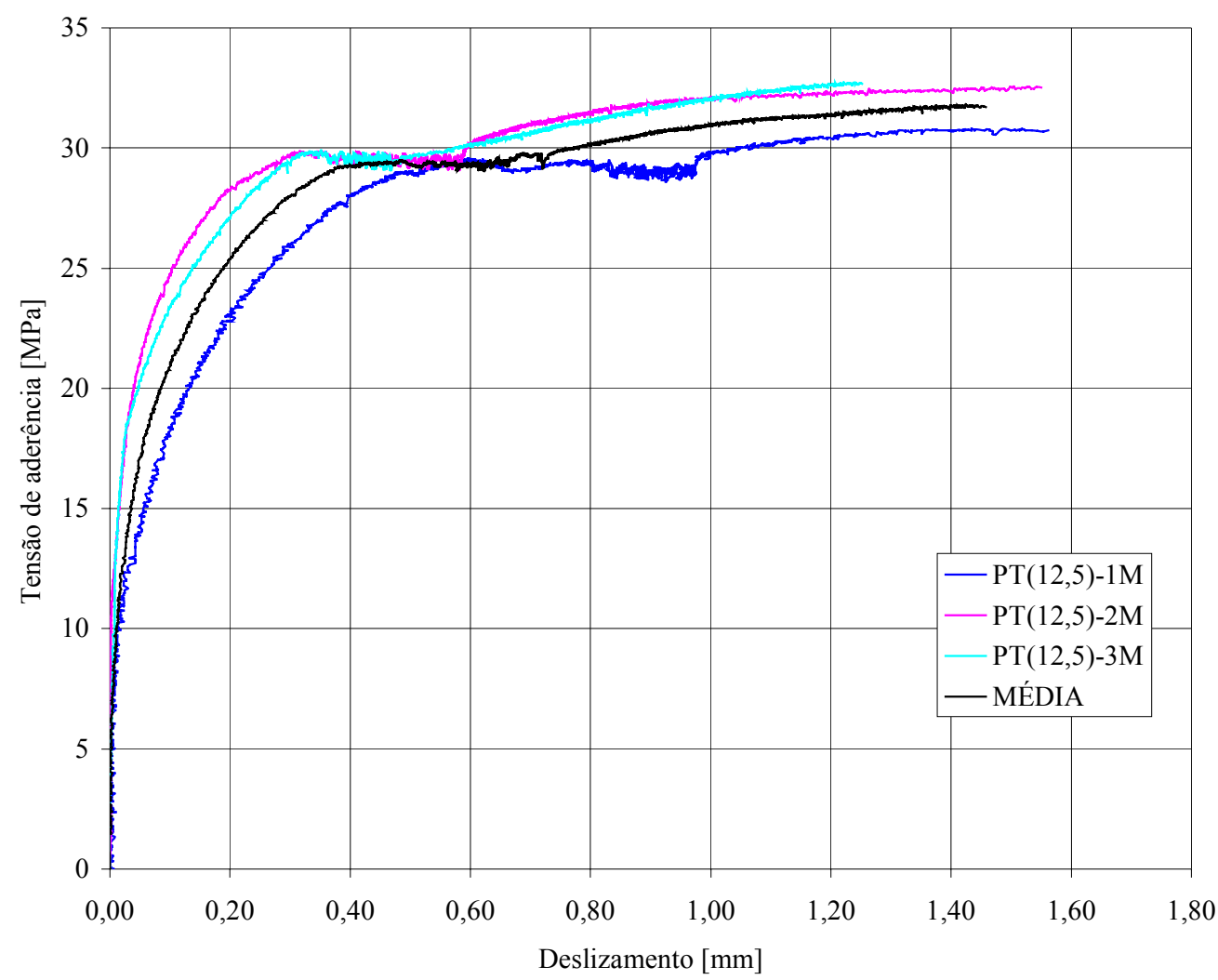

Figura 6.8 - Curvas monotônicas $\tau_{\mathrm{b}}$-s dos modelos da série 12,5 do plano definitivo 
Comparando-se os resultados médios das duas séries, nota-se que a série 12,5 apresenta em relação a série 7,5:

a. Tensão de aderência última 41,8\% maior;

b. Deslizamento $\mathrm{s}\left(\tau_{\mathrm{bu}}\right)$ correspondente a tensão de aderência última $224,3 \%$ superior;

c. Tensão de aderência $\tau_{1 \mathrm{R}}$ correspondente ao deslizamento de $0,1 \mathrm{~mm}$ $213,8 \%$ maior.

A série 12,5 apresenta maior rigidez $\left(\tau_{\mathrm{b}} / \mathrm{s}\right)$ e maior ductilidade. A Figura 6.9 apresenta a comparação das curvas monotônicas das duas séries de ensaio do plano definitivo.

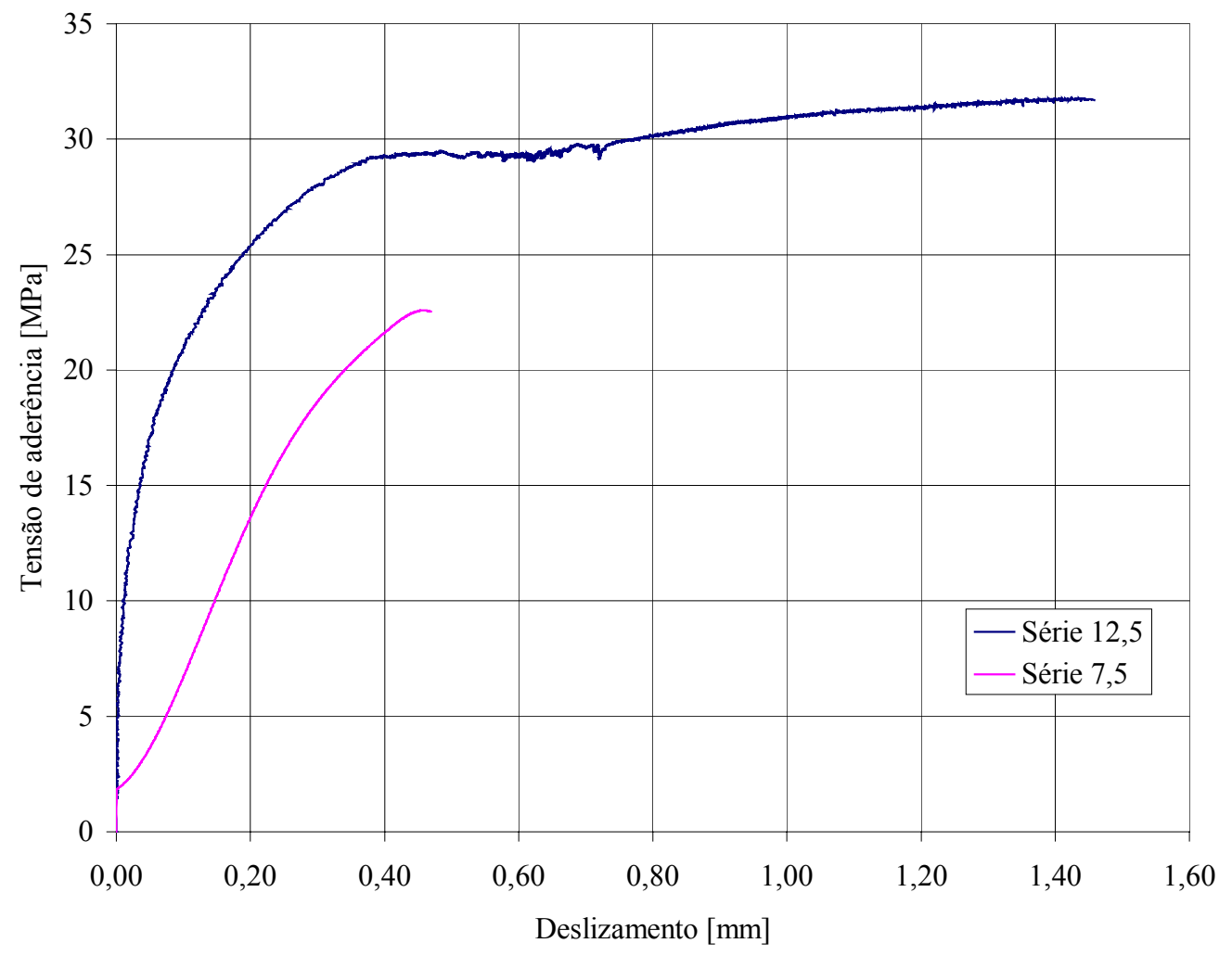

Figura 6.9 - Comparação das curvas monotônicas $\tau_{\mathrm{b}}$-s das duas séries de ensaios do plano definitivo 
Como a diferença entre a resistência à compressão do concreto $\mathrm{f}_{\mathrm{cm}}$ das duas séries de ensaio do plano definitivo foi extremamente pequena (aproximadamente $3,5 \%$ ), optou-se por não fazer nenhuma transformação para comparar os resultados.

A ruptura dos modelos da série 7,5 se deu por fendilhamento com o cilindro de concreto dividindo-se em três partes, conforme mostrado na Figura 6.10.

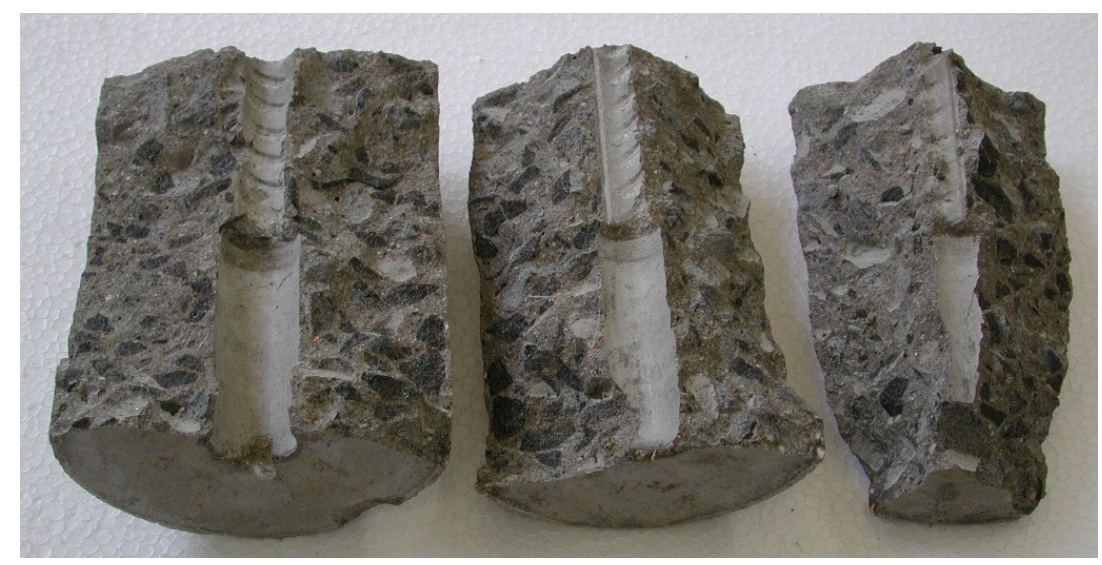

Figura 6.10 - Ruptura por fendilhamento dos modelos da série 7,5

Em todos os modelos da série 12,5 foi atingido o limite de escoamento do aço. A ruptura também foi por fendilhamento, no entanto, devido ao maior grau de confinamento o cilindro de concreto se dividiu em duas partes. Os espaços entre as nervuras transversais saíram com pasta de cimento, em quantidade bem superior a da série 7,5. Isso devido ao maior efeito de cisalhamento do concreto entre as nervuras proporcionado pelo maior grau de confinamento.

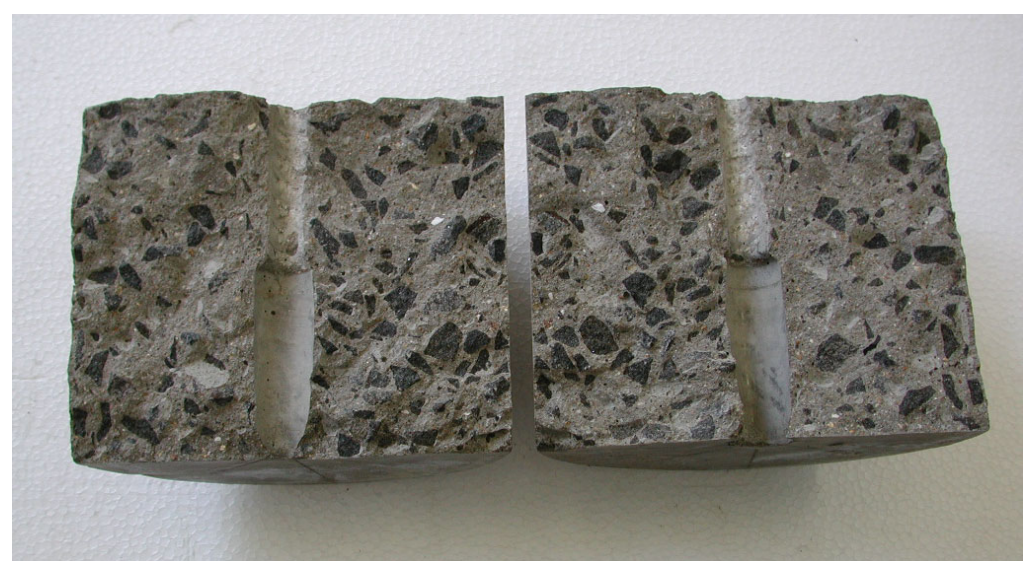

Figura 6.11 - Ruptura por fendilhamento dos modelos da série 12,5 
Apesar de nos modelos da série 12,5 o cobrimento de concreto (igual a $5,75 \phi)$ ser suficiente para se considerar aderência sob confinamento, os modelos romperam por fendilhamento. Indubitavelmente, esse tipo de ruptura ocorreu devido à natureza frágil do $\mathrm{CAD}$.

\subsubsection{COMPARAÇÃO DA ADERÊNCIA MONOTÔNICA COM OS VALORES ESPECIFICADOS POR NORMAS}

Neste item será comparado o valor da resistência de aderência prescrito por normas com o valor da tensão de aderência $\tau_{1 \mathrm{R}}$ correspondente ao deslizamento de 0,1mm. Apesar dos diversos códigos não explicitarem que a tensão $\tau_{1 \mathrm{R}}$ é a resistência de aderência especificada, neste trabalho optou-se por fazer tal comparação devido ao respaldo no meio técnico de que essas duas tensões são correspondentes.

As normas utilizadas nessa comparação foram o Código Modelo CEB-FIP 1990 e a NBR 6118/1978, apesar de essa norma não se aplicar a CAD. Não foram considerados o EUROCODE 2 e o projeto de revisão da NBR 6118/2001 porque esses dois códigos trazem as mesmas especificações do Código Modelo CEB-FIP 1990.

Como a resistência de aderência prescrita pelas normas corresponde a situações confinadas, somente os resultados da série 12,5 podem ser comparados com as especificações das normas. Na Tabela 6.6 são apresentados os valores da resistência de aderência especificados pelas normas, bem como a média da tensão $\tau_{1 \mathrm{R}}$ dos modelos da série 12,5 . 
Tabela 6.6 - Comparação do valor de $\tau_{1 \mathrm{R}}$ experimental (série 12,5) com os valores prescritos pelas normas

\begin{tabular}{|c|c|}
\hline Média experimental da série 12,5 & $\tau_{1 \mathrm{R}}=20,97 \mathrm{MPa}$ \\
\hline Código Modelo CEB-FIP 1990 & $\mathrm{f}_{\mathrm{b}}=10,98 \mathrm{MPa}$ \\
\hline NBR 6118/1978 & $\mathrm{f}_{\mathrm{b}}=8,19 \mathrm{Mpa}$ \\
\hline
\end{tabular}

Os valores referentes às normas foram calculados para situação dos ensaios do plano definitivo, os quais são mencionados a seguir:

a. Barra nervurada $\phi 16 \mathrm{~mm}\left(\mathrm{NBR} 6118 / 1978-\eta_{\mathrm{b}} \geq 1,5\right.$ );

b. Situação de boa aderência (barra concretada verticalmente);

c. Características mecânicas do concreto:

$$
\left\{\begin{array}{l}
\mathrm{f}_{\mathrm{cm}}=86,14 \mathrm{MPa} \text { - Código Modelo CEB/FIP } 1990 \\
\mathrm{f}_{\mathrm{tm}}=4,88 \mathrm{MPa}-\text { NBR } 6118 / 1978
\end{array}\right.
$$

d. Para representar a situação real o coeficiente de ponderação $\gamma_{c}$ foi considerado igual a unidade.

$\mathrm{O}$ valor experimental $\tau_{1 \mathrm{R}}$ médio da série 12,5 foi $91,0 \%$ superior à resistência de aderência prescrita pelo Código Modelo CEB-FIP 1990. Dessa forma, mesmo admitindo-se altíssimo grau de confinamento dos modelos da série 12,5, as especificações do Código Modelo CEB-FIP 1990 mostram-se bastante conservadoras. Quanto a NBR 6118/1978, o valor experimental $\tau_{1 \mathrm{R}}$ médio da série 12,5 foi $156 \%$ superior à resistência prescrita por essa norma, mostrando que a especificação da NBR 6118/1978 é inadequada a CAD.

\subsubsection{ADERÊNCIA SOB AÇÃO REPETIDA}

O comportamento da aderência sob ação repetida dos modelos das duas séries é apresentado nas Figuras 6.12 a 6.19 . Os modelos foram ensaiados conforme descrito no item 5.5 desta dissertação. 


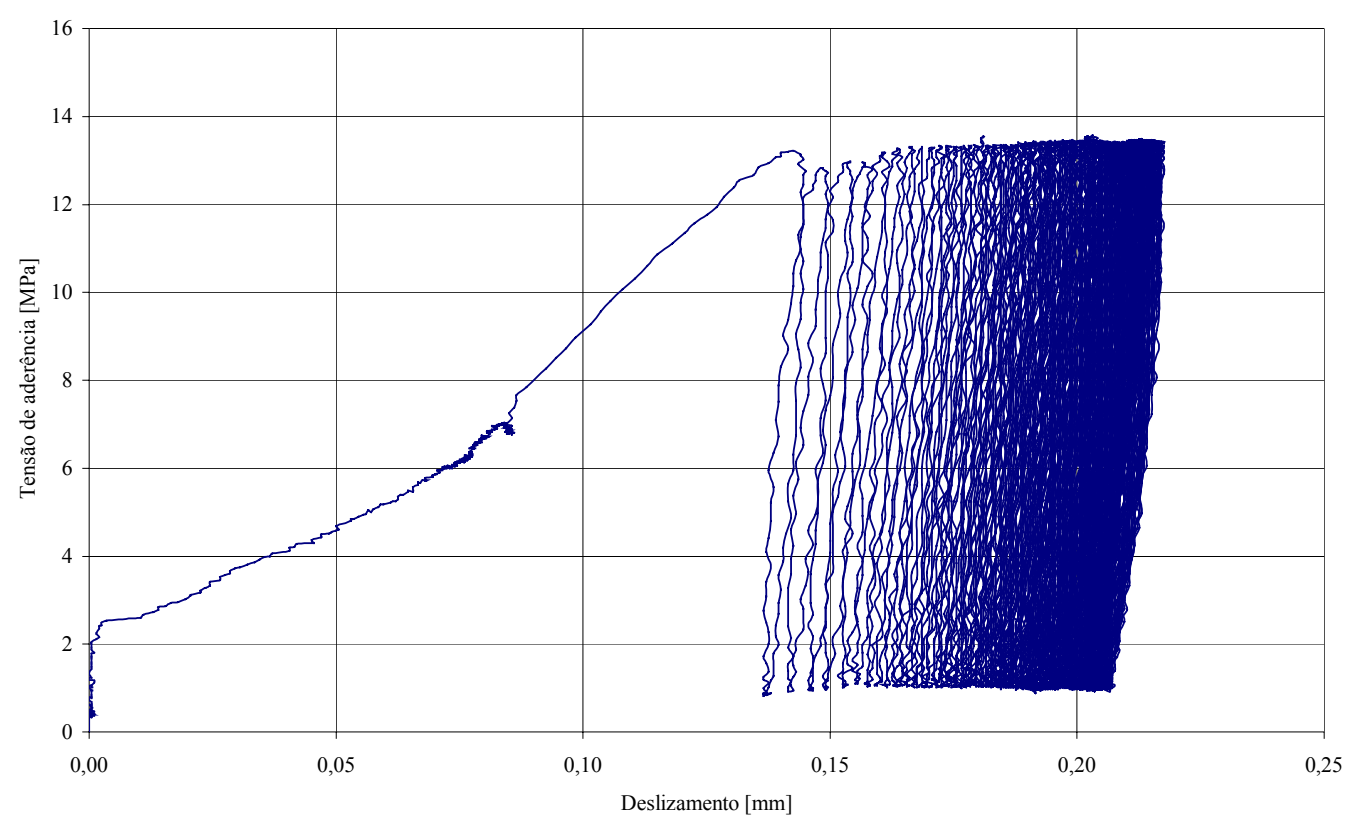

Figura 6.12 - Curva repetida $\tau_{\mathrm{b}}$-s do modelo PT(7,5)-1R

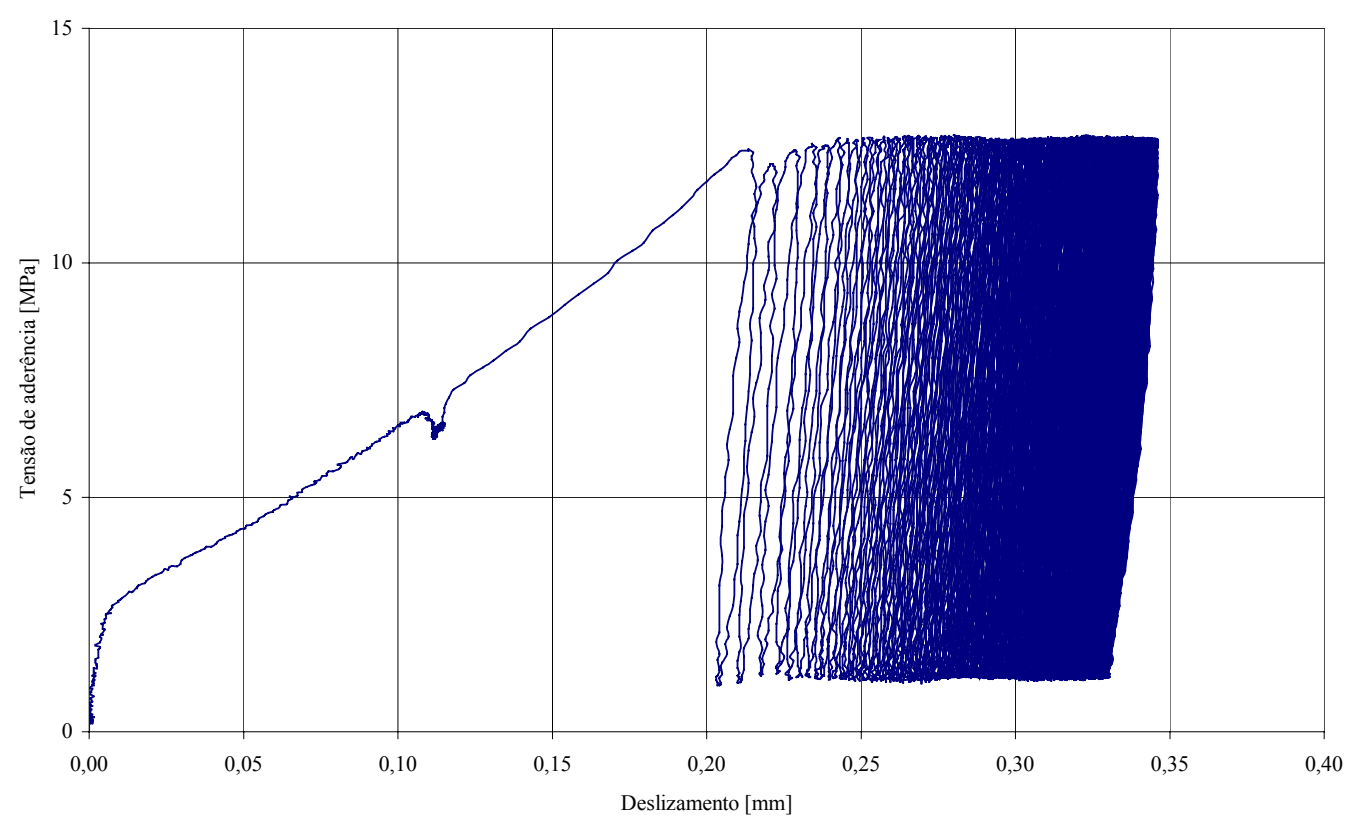

Figura 6.13 - Curva repetida $\tau_{b}$-s do modelo PT(7,5)-2R 


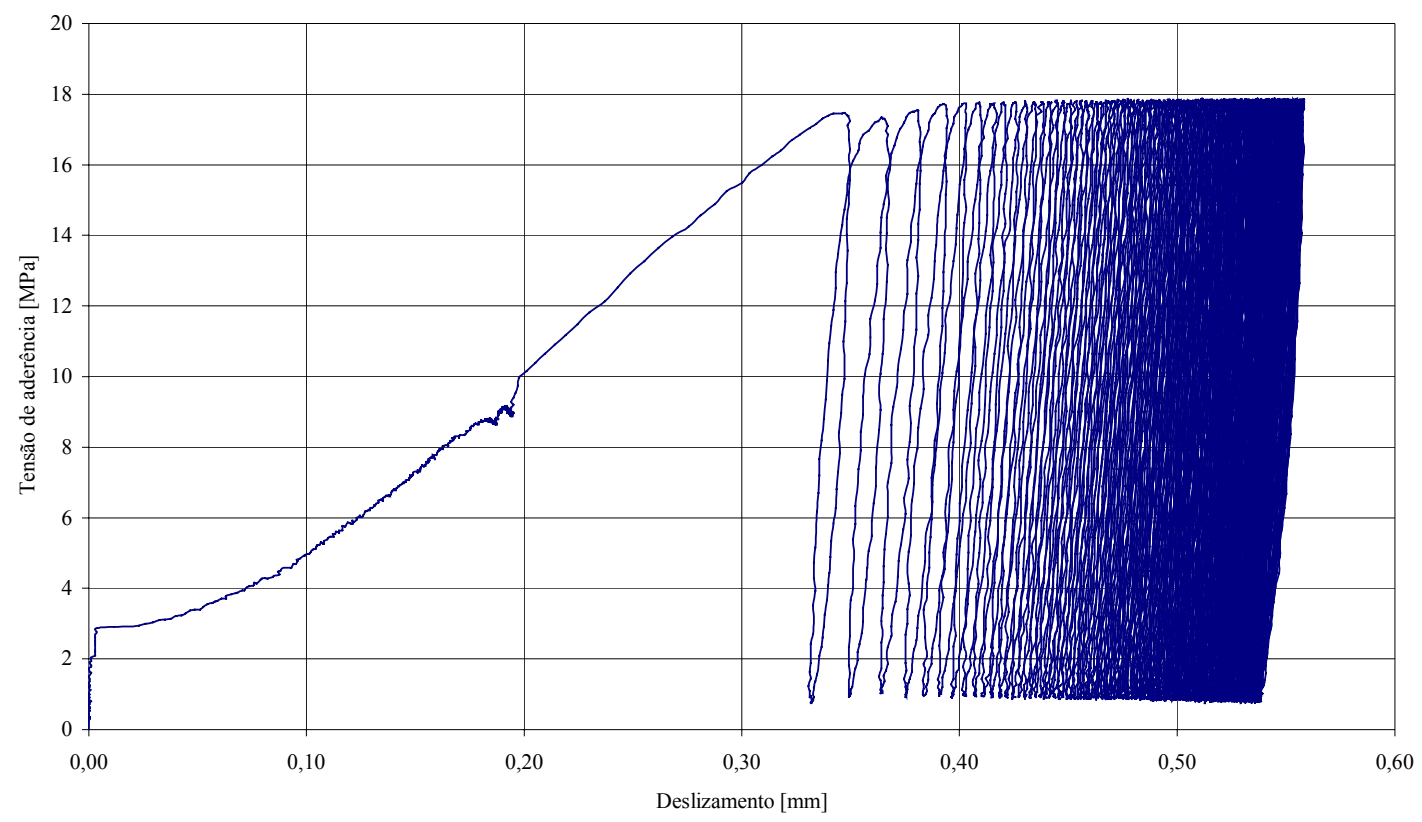

Figura 6.14 - Curva repetida $\tau_{\mathrm{b}}$-s do modelo PT(7,5)-3R

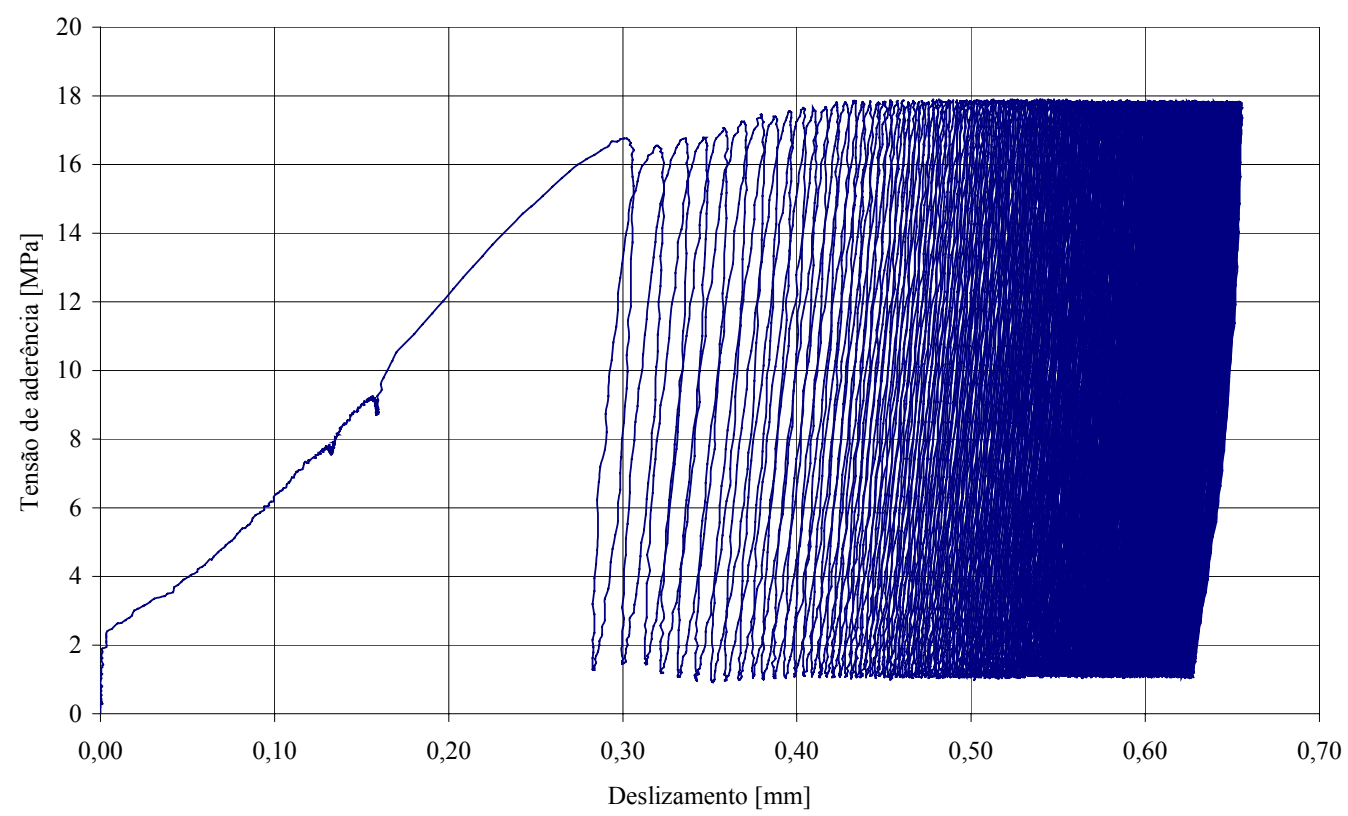

Figura 6.15 - Curva repetida $\tau_{b}$-s do modelo PT(7,5)-4R 


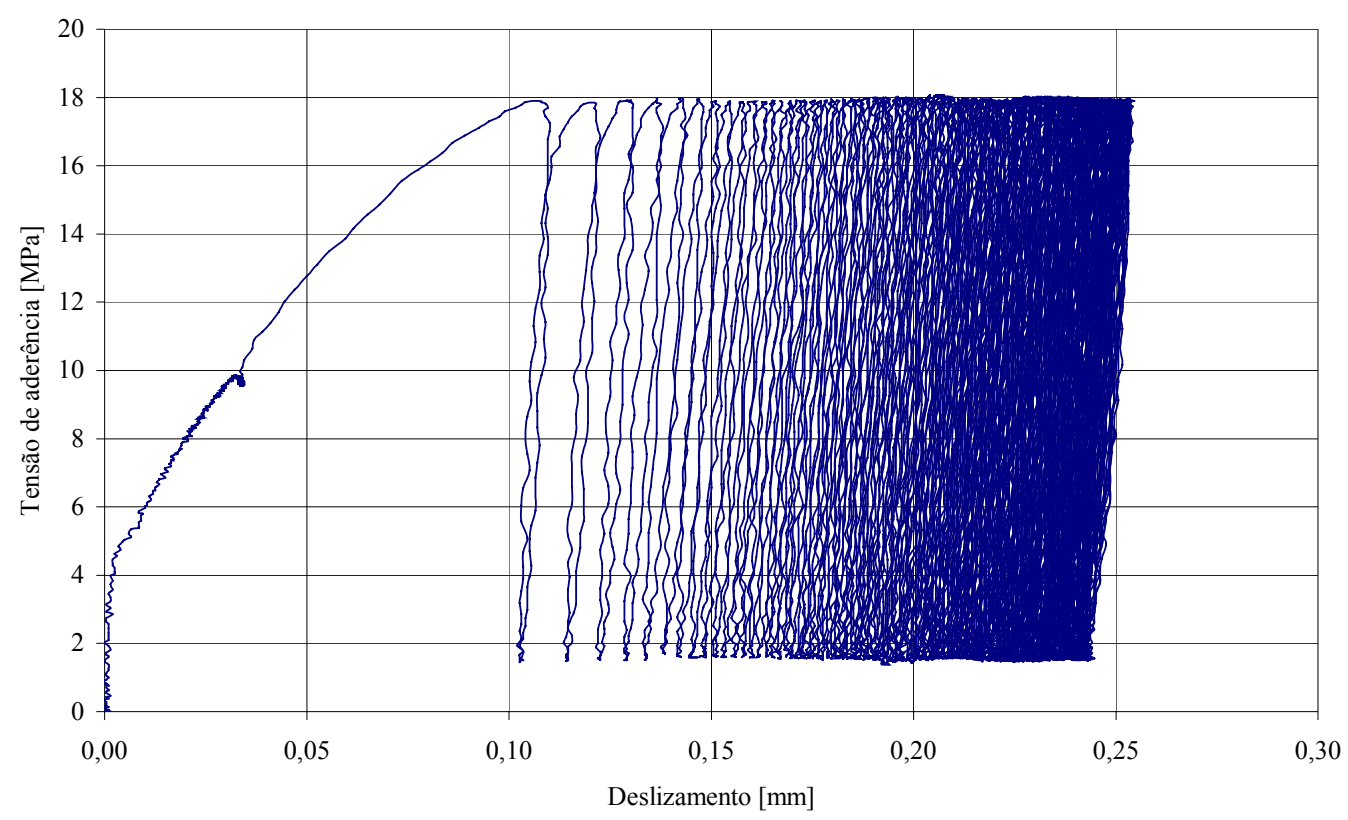

Figura 6.16 - Curva repetida $\tau_{\mathrm{b}}$-s do modelo PT(12,5)-1R

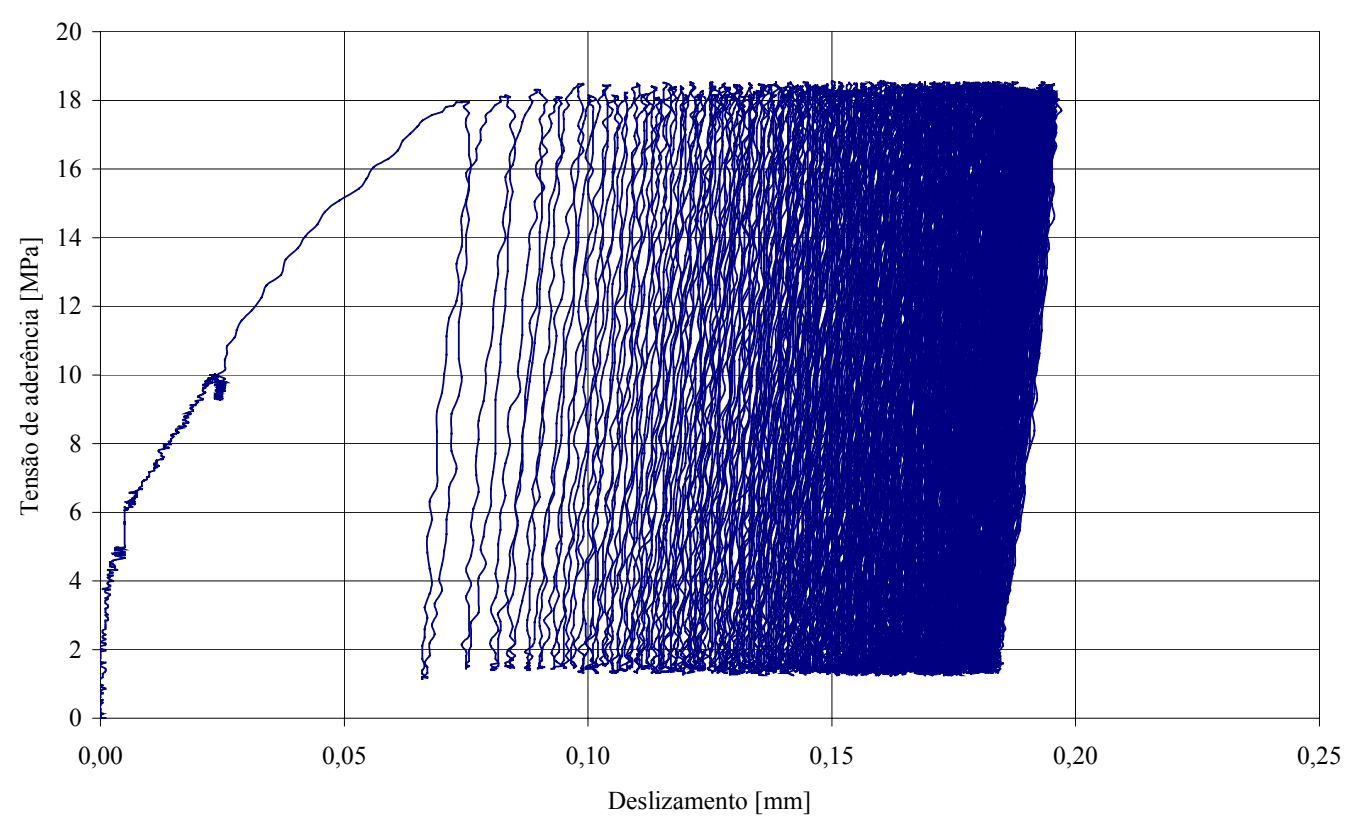

Figura 6.17 - Curva repetida $\tau_{\mathrm{b}}$-s do modelo PT(12,5)-2R 


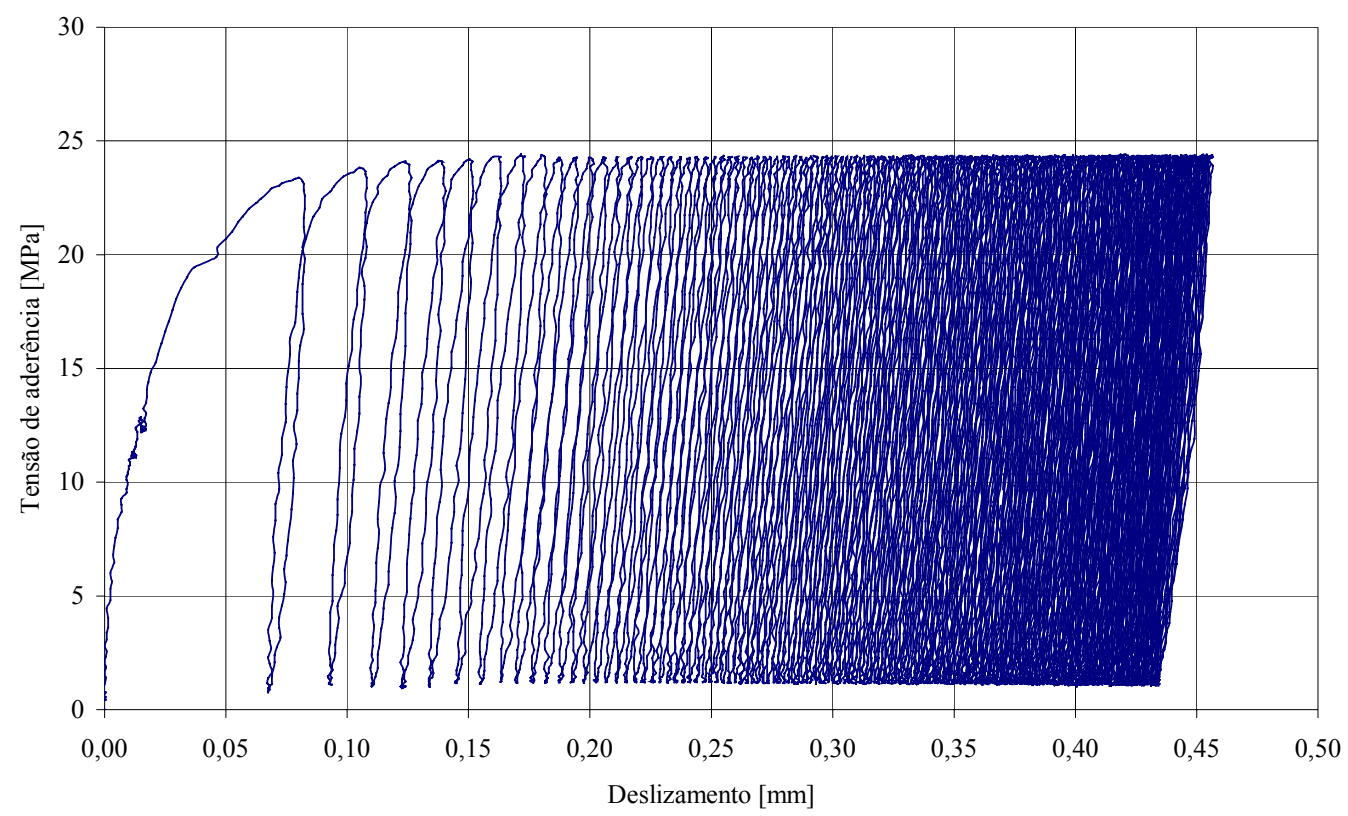

Figura 6.18 - Curva repetida $\tau_{\mathrm{b}}$-s do modelo PT(12,5)-3R

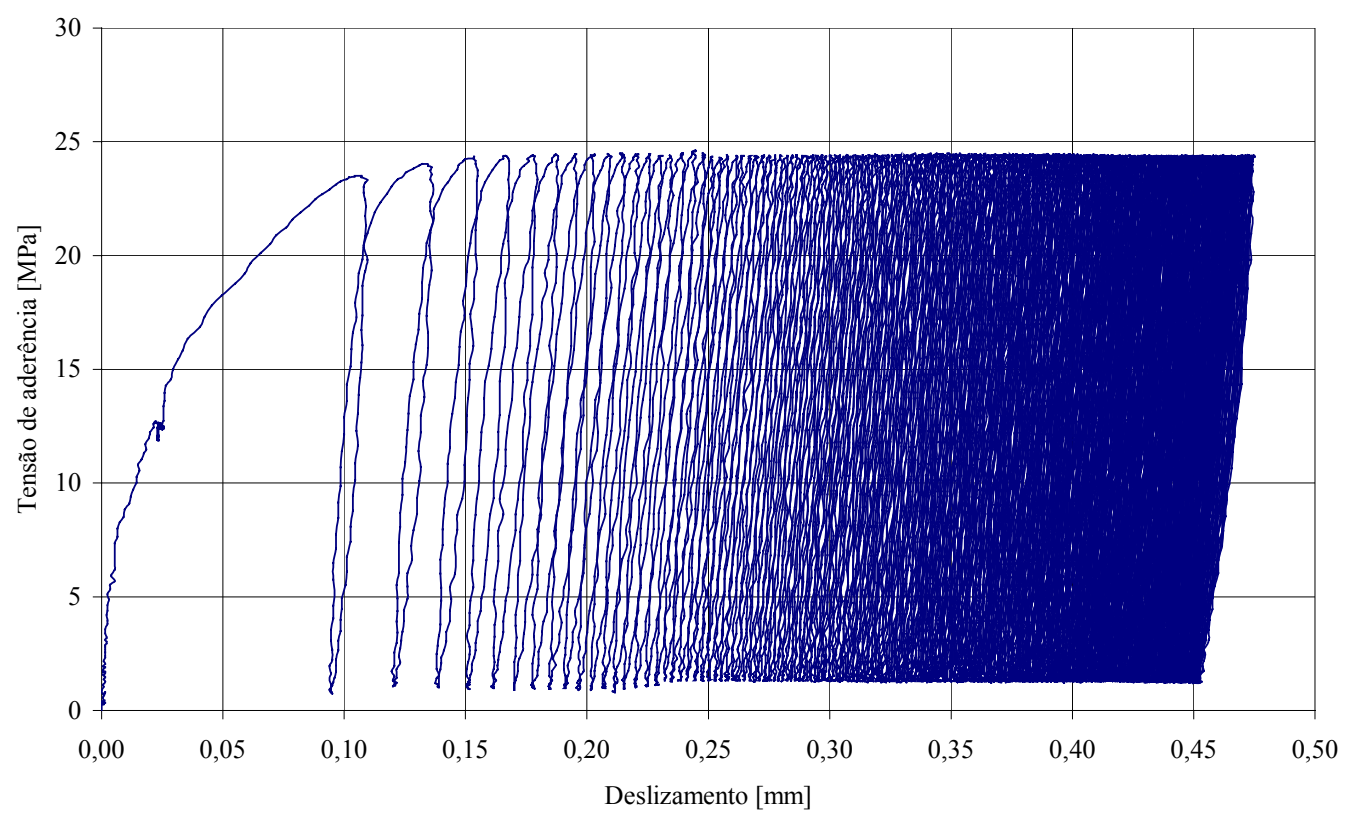

Figura 6.19 - Curva repetida $\tau_{\mathrm{b}}$-s do modelo PT(12,5)-4R

A velocidade de deslizamento é maior nos primeiros ciclos. Depois de alguns ciclos a velocidade de deslizamento torna-se constante. Não pôde ser observados nos ensaios uma terceira fase, comumente observada em modelos com concreto usual, onde o deslizamento cresce rapidamente até produzir a ruptura. Essa terceira fase não foi observada devido ao pequeno número de ciclos utilizados neste trabalho. 
Entretanto, é incerta a presença dessa fase, seja pela natureza frágil do CAD ou pelo menor grau de confinamento da série 7,5.

Sob ação repetida é característico um deslizamento residual. Para amplitudes com nível de carregamento máximo acima de $60 \%$ de $\tau_{\text {bu }}$, como neste trabalho, esse deslizamento residual é praticamente o deslizamento máximo atingido durante o ciclo anterior.

Quando o modelo é recarregado, a aderência assume a mesma rigidez do descarregamento anterior até próximo ao nível de carregamento máximo. A partir desse ponto, a rigidez começa a diminuir, ou seja, o deslizamento aumenta, em comparação ao deslizamento máximo atingido no ciclo anterior.

Nos modelos da série 7,5 com nível de carregamento máximo da amplitude em $80 \%$ de $\tau_{\text {bu }}$, ou seja, nos modelos PT(7,5)-3R e PT(7,5)-4R, o deslizamento $\mathrm{s}\left(\tau_{\mathrm{bu}}\right)$ correspondente à tensão de aderência última monotônica foi ultrapassado. A velocidade de deslizamento ainda permaneceu constante em um número de ciclos considerável, sem atingir a ruptura. Portanto, $\mathrm{s}\left(\tau_{\mathrm{bu}}\right)$ também pode ser utilizado como critério seguro para análise do efeito de fadiga na aderência em CAD.

Nas Figuras 6.20 e 6.21 são apresentadas curvas deslizamento versus número de ciclos em escala dupla logarítmica dos modelos das séries 7,5 e 12,5, respectivamente. Essas curvas são aproximadamente lineares como nos modelos com concreto usual. 


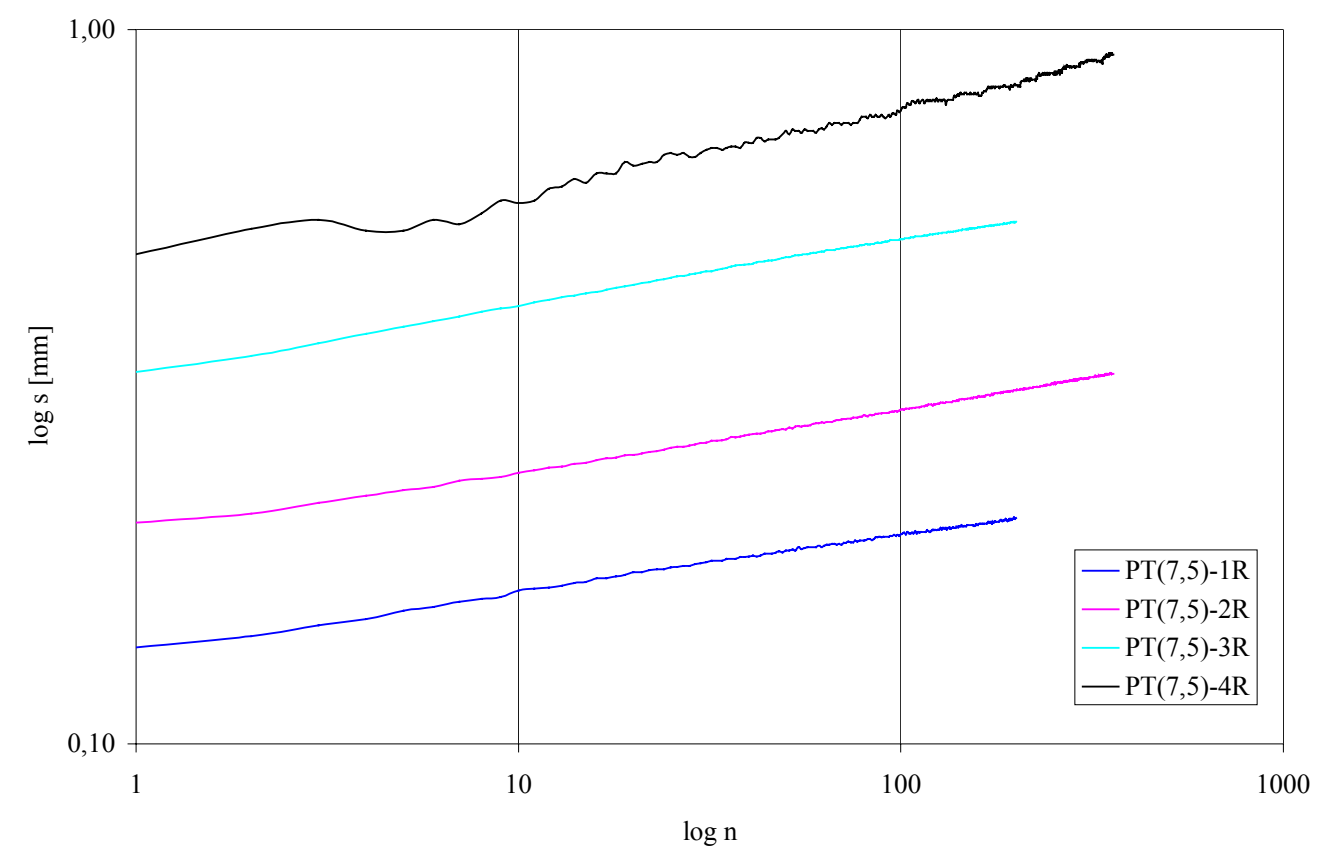

Figura 6.20 - Curvas deslizamento versus número de ciclos em escala dupla logarítmica dos modelos da série 7,5 do plano definitivo

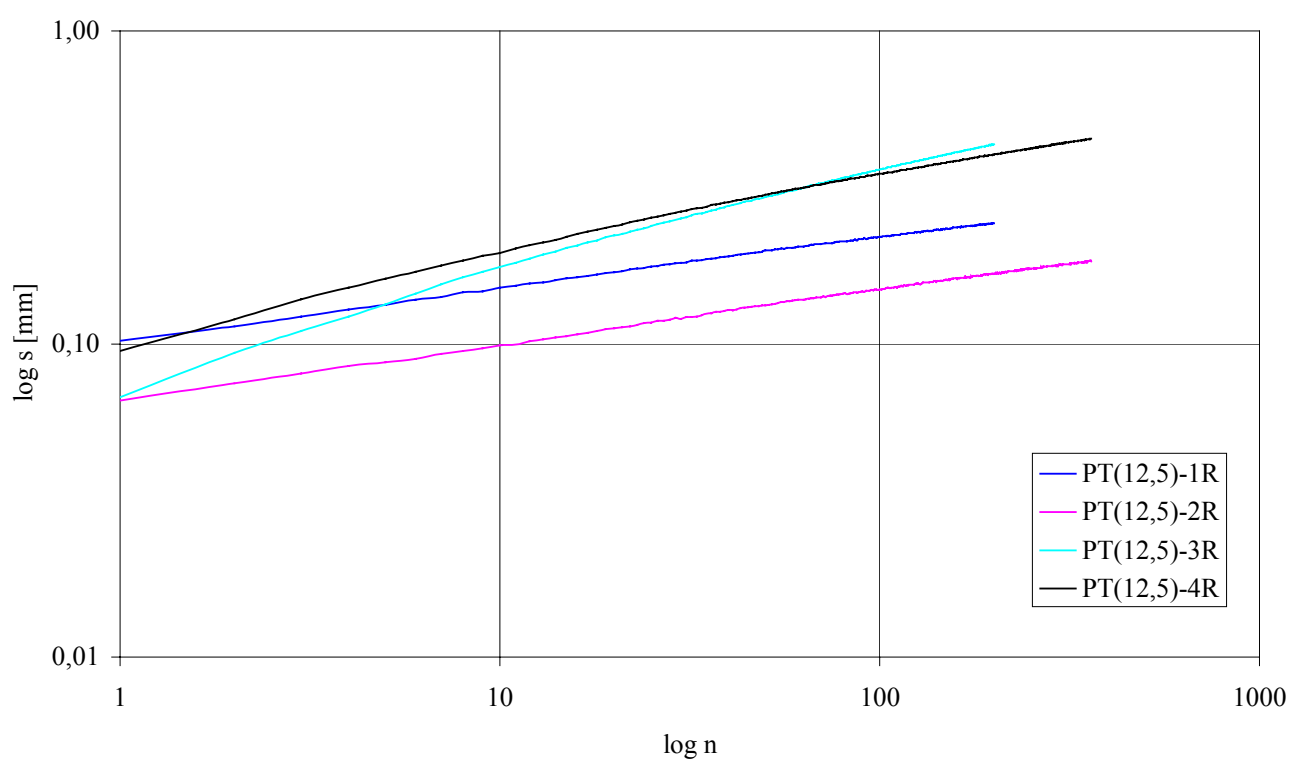

Figura 6.21 - Curvas deslizamento versus número de ciclos em escala dupla logarítmica dos modelos da série 12,5 do plano definitivo

Como se pode observar nas Figuras 6.22 e 6.23, resultados das séries 7,5 e 12,5 respectivamente, as curvas deslizamento versus número de ciclos em escala linear são também semelhantes às curvas de modelos com concreto usual. Essas 
curvas apresentam um trecho côncavo e um linear. Um terceiro trecho (convexo) não foi observado devido ao diminuto número de ciclos utilizado nos ensaios, no entanto, é incerta a presença desse trecho devido a provável ruptura por fendilhamento dos modelos com CAD.

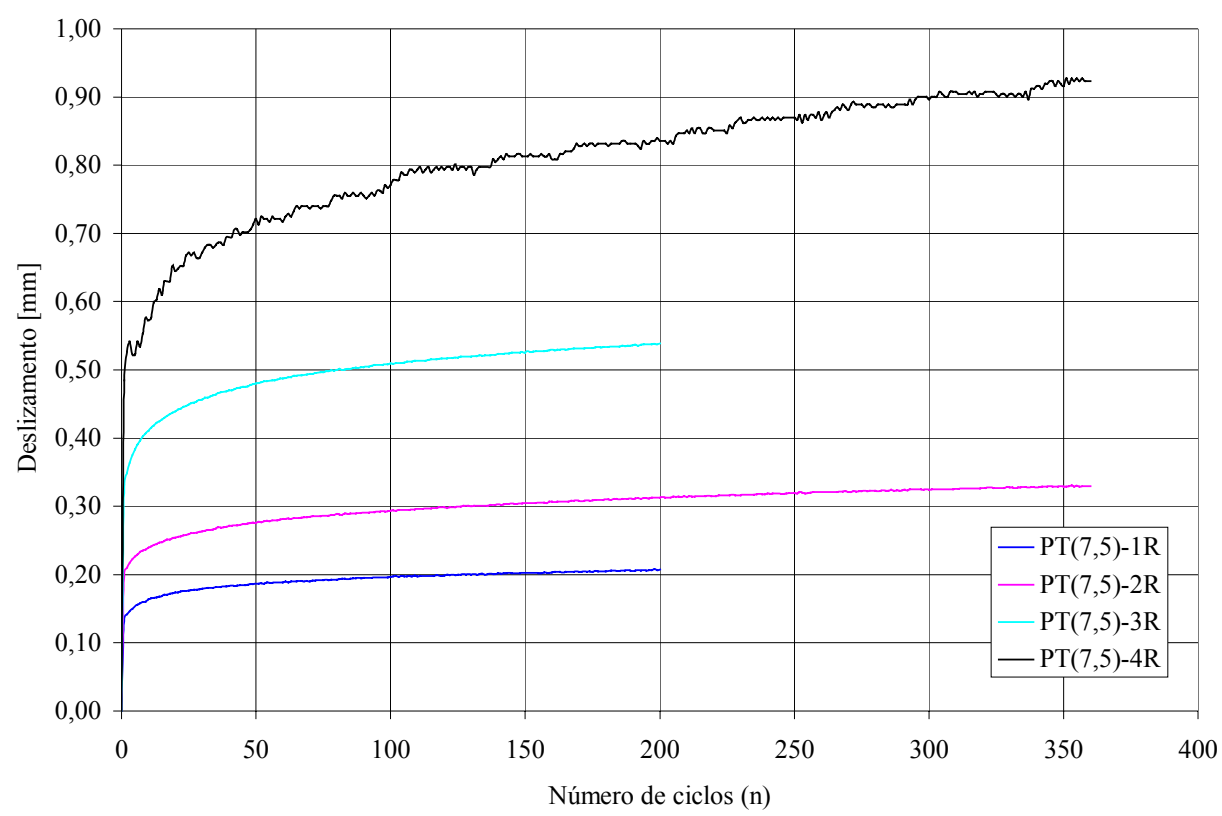

Figura 6.22 - Curvas deslizamento versus número de ciclos em escala linear dos modelos da série 7,5 do plano definitivo 


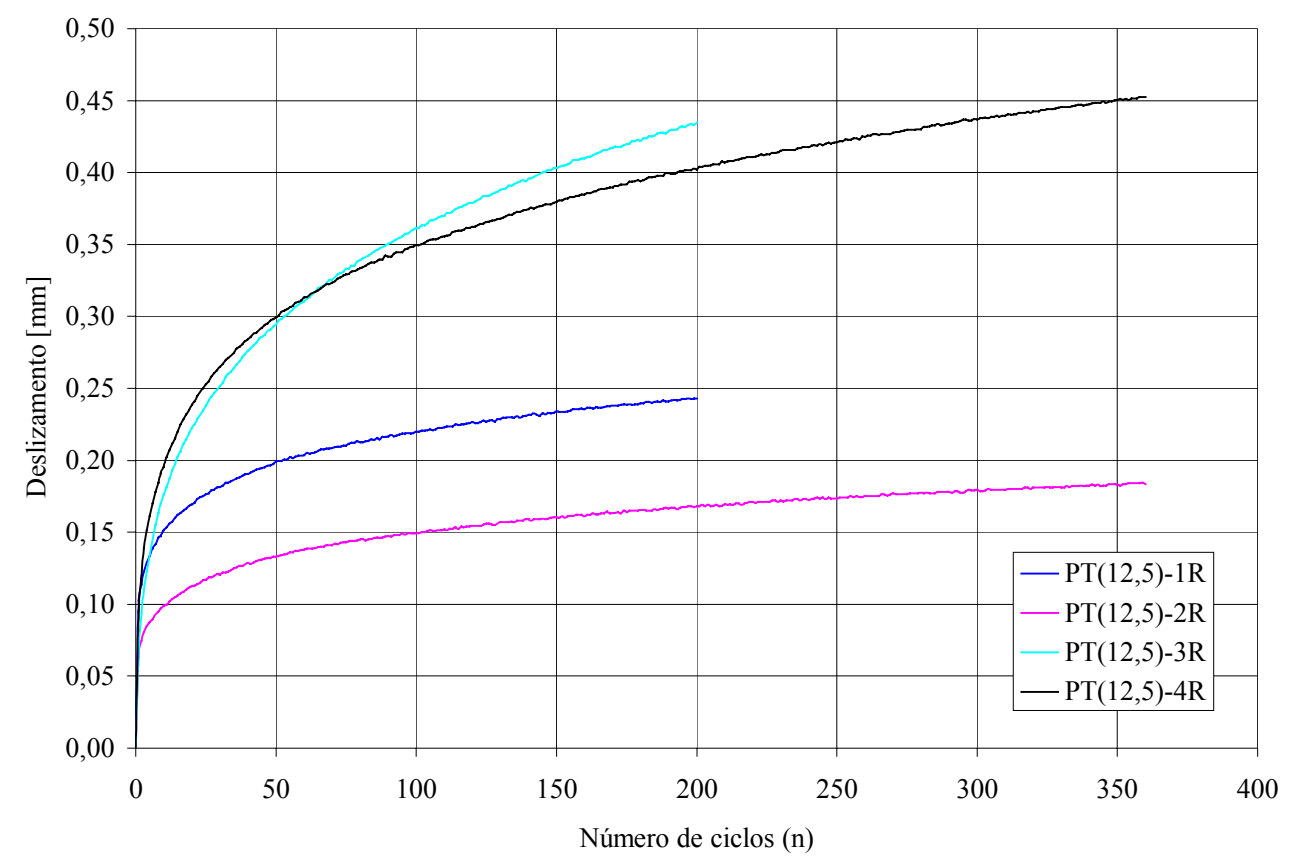

Figura 6.23 - Curvas deslizamento versus número de ciclos em escala linear dos modelos da série 12,5 do plano definitivo

Após a aplicação dos ciclos, conforme anteriormente estipulado, os modelos foram submetidos à ação monotônica até a ruptura. O comportamento dos modelos das séries 7,5 e 12,5 é apresentado nas Figuras 6.24 e 6.25, respectivamente. $\mathrm{Na}$ Tabela 6.7 são apresentados os parâmetros controlados, que foram basicamente os mesmos dos ensaios monotônicos. Para diferenciar os resultados dos modelos com carregamento repetido prévio dos resultados monotônicos, os símbolos utilizados para designar os parâmetros controlados foram acrescidos da letra R. Assim, além do deslizamento residual $\mathrm{s}_{\text {residual }}$ (na extremidade descarregada) após os ciclos previamente aplicados, quando submetidos ao carregamento monotônico, os parâmetros controlados nos modelos repetidos foram a força de tração última $\mathrm{F}_{\mathrm{tuR}}$, a tensão de aderência última $\tau_{\text {buR }}$ e seu respectivo deslizamento $s\left(\tau_{\text {buR }}\right)$ na seção da extremidade descarregada. 
Tabela 6.7 - Resultados dos ensaios monotônicos com os modelos submetidos a carregamento repetido prévio

\begin{tabular}{|c|c|c|c|c|c|}
\hline & Modelo & $\mathrm{F}_{\text {tuR }}[\mathrm{kN}]$ & $\tau_{\mathrm{buR}}[\mathrm{MPa}]$ & $\mathrm{s}\left(\tau_{\mathrm{buR}}\right)[\mathrm{mm}]$ & $\mathrm{s}_{\text {Residual }}[\mathrm{mm}]$ \\
\hline \multirow{4}{*}{ 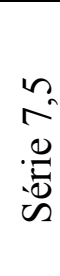 } & $\mathrm{PT}(7,5)-1 \mathrm{R}$ & 92,10 & 23,67 & 0,409 & 0,207 \\
\hline & PT(7,5)-2R & 81,72 & 21,00 & 0,490 & 0,327 \\
\hline & PT(7,5)-3R & 90,34 & 23,22 & 0,625 & 0,536 \\
\hline & PT(7,5)-4R & 77,07 & 19,80 & 0,671 & 0,622 \\
\hline \multirow{4}{*}{ 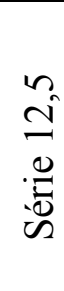 } & PT(12,5)-1R & 121,24 & 31,15 & 2,289 & 0,241 \\
\hline & PT(12,5)-2R & 120,48 & 30,96 & 1,755 & 0,181 \\
\hline & PT(12,5)-3R & 121,85 & 31,31 & 1,642 & 0,431 \\
\hline & PT(12,5)-4R & 125,06 & 32,14 & 1,495 & 0,451 \\
\hline
\end{tabular}

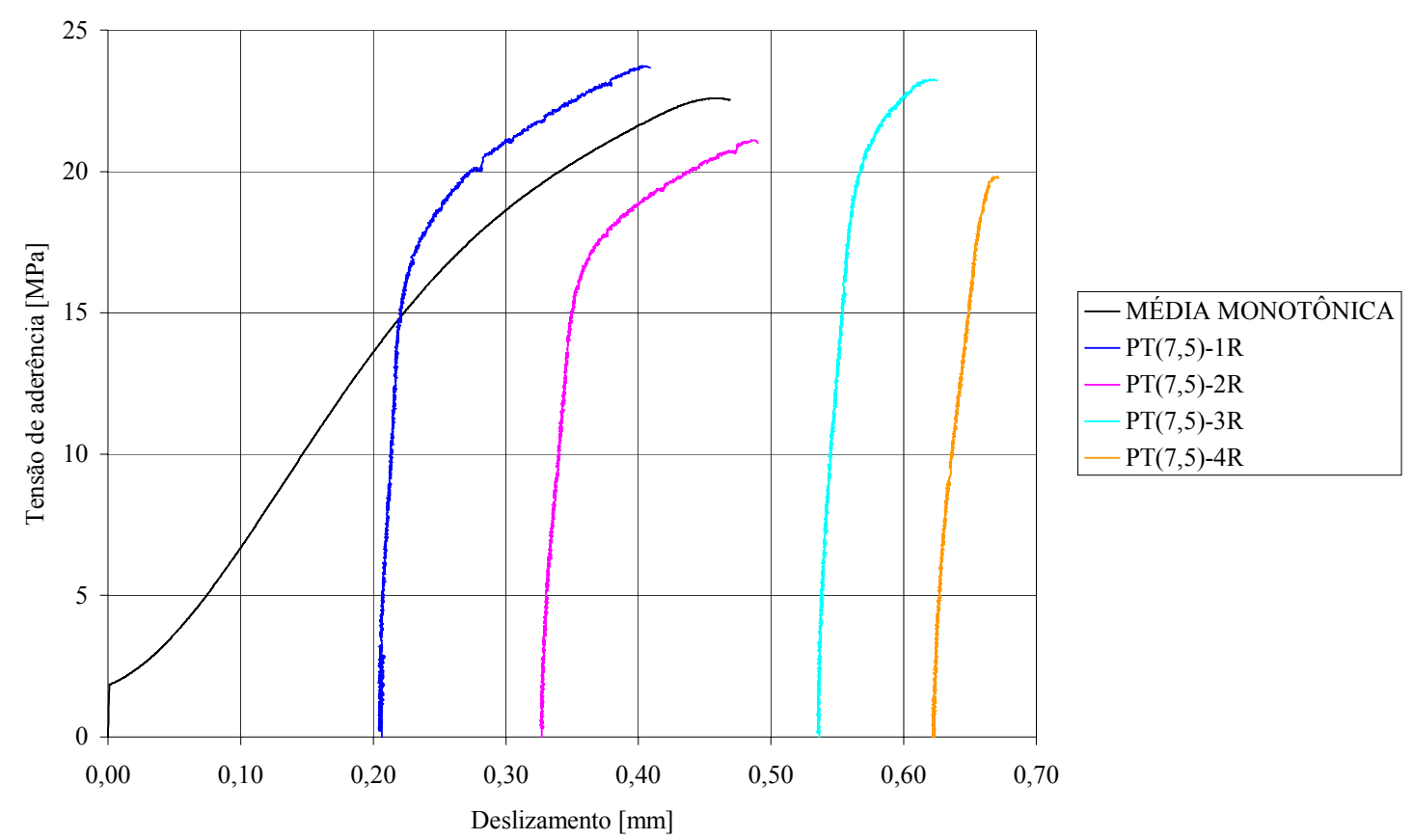

Figura 6.24 - Curvas monotônicas $\tau_{\mathrm{b}}$-s dos modelos da série 7,5 submetidos previamente a carregamento repetido 


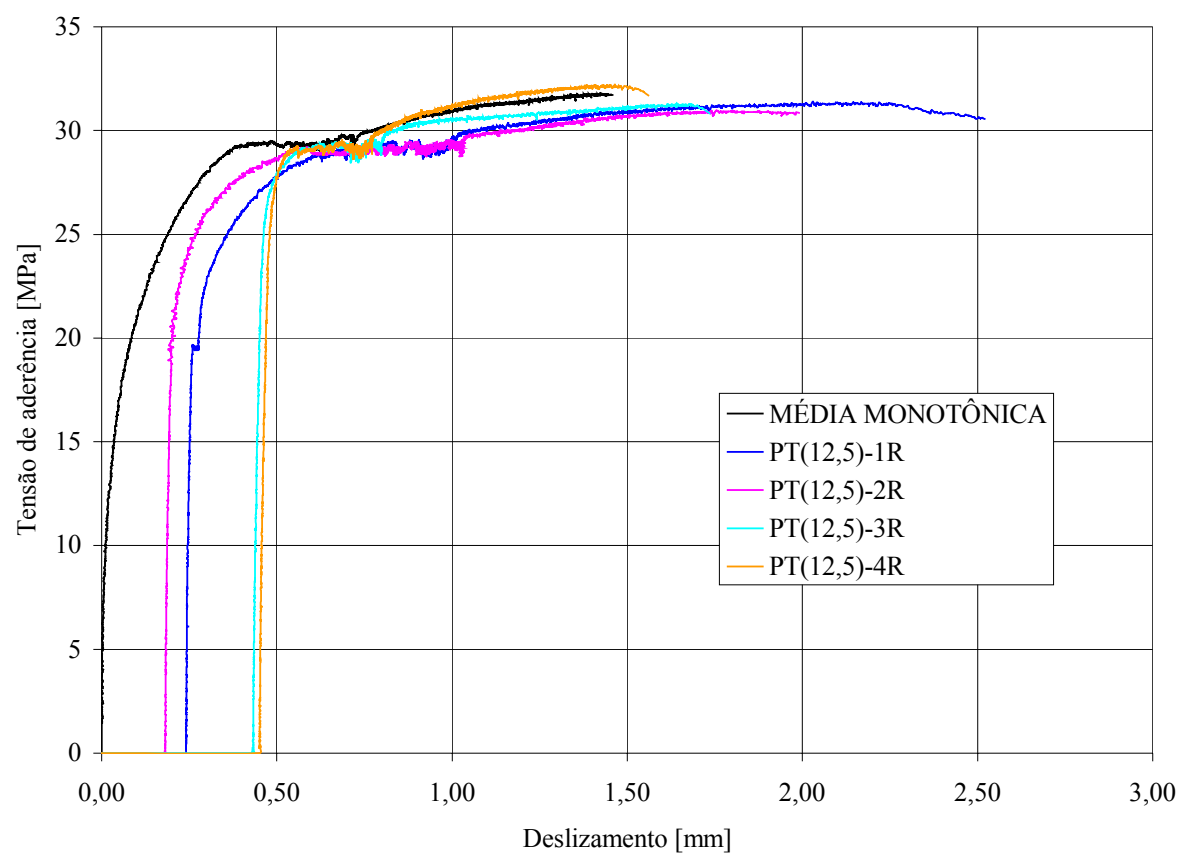

Figura 6.25 - Curvas monotônicas $\tau_{\mathrm{b}}$-s dos modelos da série 12,5 submetidos previamente a carregamento repetido

A ruptura sob ação monotônica dos modelos submetidos previamente a carregamento repetido foi a mesma dos modelos submetidos somente ao carregamento monotônico. A ruptura foi devida ao fendilhamento, com os modelos da série 7,5 se dividindo em três partes e os modelos da série 12,5 dividindo-se em duas partes. As Figuras 6.10 e 6.11 ilustram o modo de ruptura das séries 7,5 e 12,5, respectivamente. Nos modelos da série 12,5 foi atingido o limite de escoamento do aço.

Sob ação monotônica os modelos com ciclos previamente aplicados apresentaram a mesma rigidez do ciclo anterior até próximo a tensão de aderência última. A partir desse ponto, a curva $\tau_{\mathrm{b}}-\mathrm{s}$ dos modelos submetidos a ação repetida prévia foi paralela à curva $\tau_{\mathrm{b}}-\mathrm{s}$ monotônica.

Nos modelos da série 7,5 com 200 ciclos previamente aplicados, modelos PT(7,5)-1R e PT(7,5)-3R, houve aumento da tensão de aderência última $\tau_{\text {buR }}$ em relação ao valor médio da tensão última monotônica, 5,5 e 3,5\% respectivamente. Com 360 ciclos, modelos PT(7,5)-2R e PT(7,5)-4R, houve redução na tensão $\tau_{\text {buR }}$ 
em relação ao valor médio da tensão última monotônica, 6,4 e 11,8\% respectivamente.

Quanto ao nível de tensão máxima da amplitude, nos modelos da série 7,5 com 200 ciclos, o aumento desse nível de tensão de 60 para $80 \%$ da tensão de aderência última monotônica aumentou o deslizamento $\mathrm{s}\left(\tau_{\mathrm{buR}}\right)$ (correspondente à tensão de aderência última sob ação monotônica em modelos com ciclos previamente aplicados) em 52,8\% e o deslizamento residual em 158,9\%. Nos modelos com 360 ciclos o aumento do nível de tensão máxima da amplitude de 60 para $80 \%$ de $\tau_{\text {bu }}$ aumentou o deslizamento $\mathrm{s}\left(\tau_{\text {buR }}\right)$ em $36,9 \%$ e o deslizamento residual em 90,2\%.

A tensão de aderência última nos modelos da série 7,5 submetidos a ação repetida com 200 ciclos diminuiu $1,9 \%$ com o aumento de $\tau_{b \text {,max }}$ de 60 para $80 \%$ de $\tau_{\mathrm{bu}}$. Nos modelos com 360 ciclos, a tensão de aderência última diminuiu 5,7\% com o mesmo aumento de $\tau_{\mathrm{b} \text {,max }}$.

O aumento do número de ciclos de 200 para 360 acarretou aumento no deslizamento residual de 58,0 e 16,0\%, para níveis de carregamento máximo da amplitude $\tau_{\mathrm{b} \text {,max }}$ igual a 60 e $80 \%$ de $\tau_{\mathrm{bu}}$, respectivamente. O aumento do número de ciclos ainda aumentou o deslizamento $\mathrm{s}\left(\tau_{\mathrm{buR}}\right)$ em 19,8 e $7,7 \%$ para $\tau_{\mathrm{b} \text {,max }}$ igual a 60 e $80 \%$ de $\tau_{\text {bu }}$, respectivamente. Quanto à tensão de aderência última dos modelos com ciclos previamente aplicados, o aumento do número de ciclos reduziu essa tensão $\tau_{\text {buR }}$ em 11,3 e $14,7 \%$, para $\tau_{b \text {,max }}$ igual a 60 e $80 \%$ de $\tau_{\text {bu }}$, respectivamente.

Com os resultados da série 7,5 observa-se claramente que o efeito do aumento do número de ciclos e do aumento do nível de carregamento máximo da amplitude é qualitativamente o mesmo. Esse efeito, também verificado em trabalhos com concreto usual, é o aumento do deslizamento e a diminuição da tensão de aderência última quando o modelo é levado à ruptura sob ação monotônica.

Nos modelos da série 12,5 os resultados não mostraram nenhuma tendência quanto ao efeito do número de ciclos e nível de carregamento máximo da amplitude. Provavelmente, devido ao menor efeito desses parâmetros sob o comportamento da aderência em concreto com alto grau de confinamento, a própria individualidade dos modelos gerou a dispersão que ofuscou qualquer tendência. Outro ponto importante 
na análise dos resultados da série 12,5 é o fato de as barras terem atingido o limite de escoamento do aço. Além disso, apesar de não ter sido notada nenhuma anormalidade, podem ter ocorrido problemas desde a concretagem até o ensaio propriamente dito.

\subsubsection{COMPARAÇÃO DO COMPORTAMENTO DA ADERÊNCIA MONOTÔNICA COM MODELOS ANALÍTICOS}

Neste item são apresentadas comparações do resultado monotônico, das duas séries de ensaios do plano definitivo, com modelos analíticos. Nas Figuras 6.26 e 6.27 são mostradas as comparações das séries 7,5 e 12,5, respectivamente.

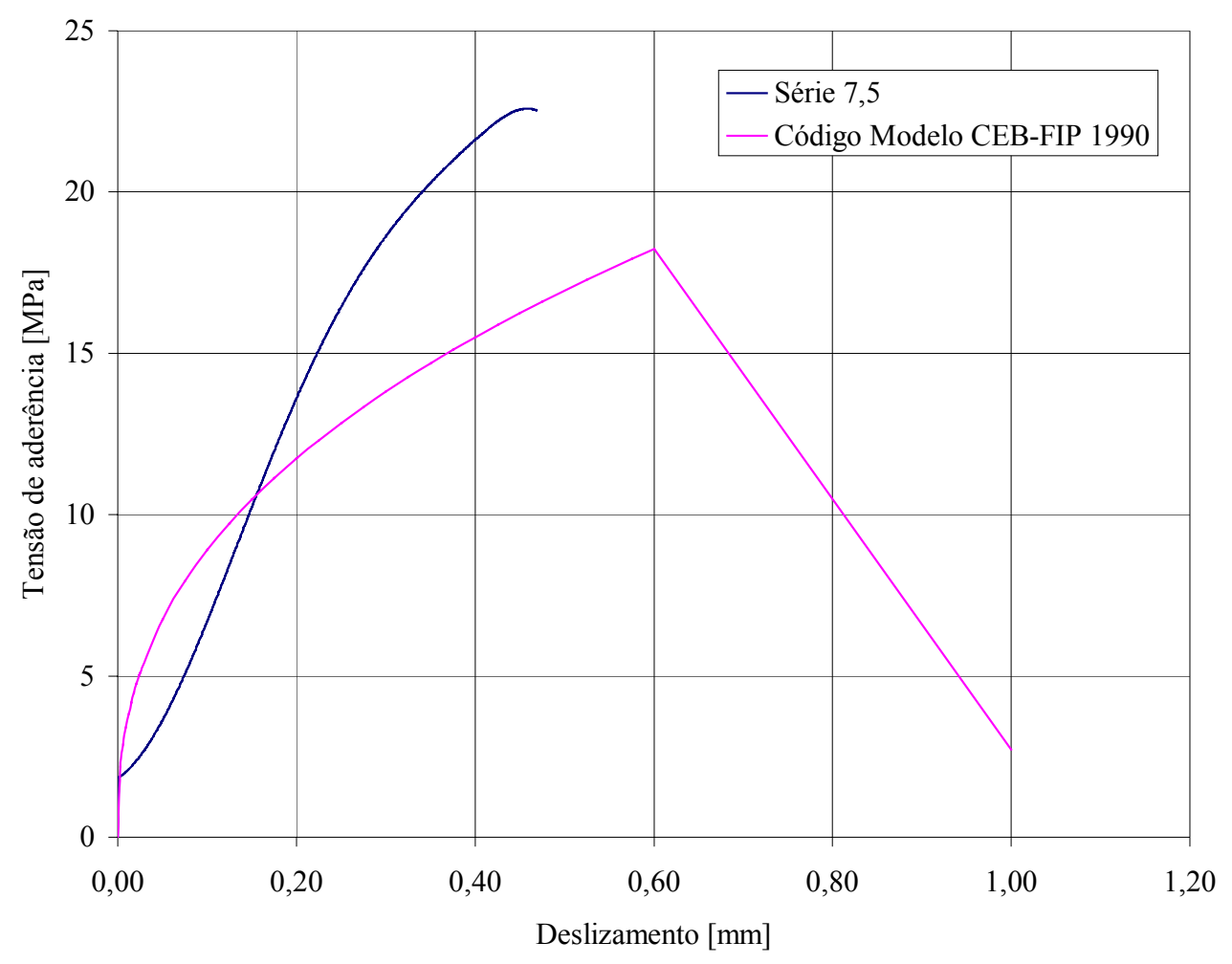

Figura 6.26 - Comparação da média monotônica da série 7,5 com o modelo analítico do Código Modelo CEB-FIP 1990 


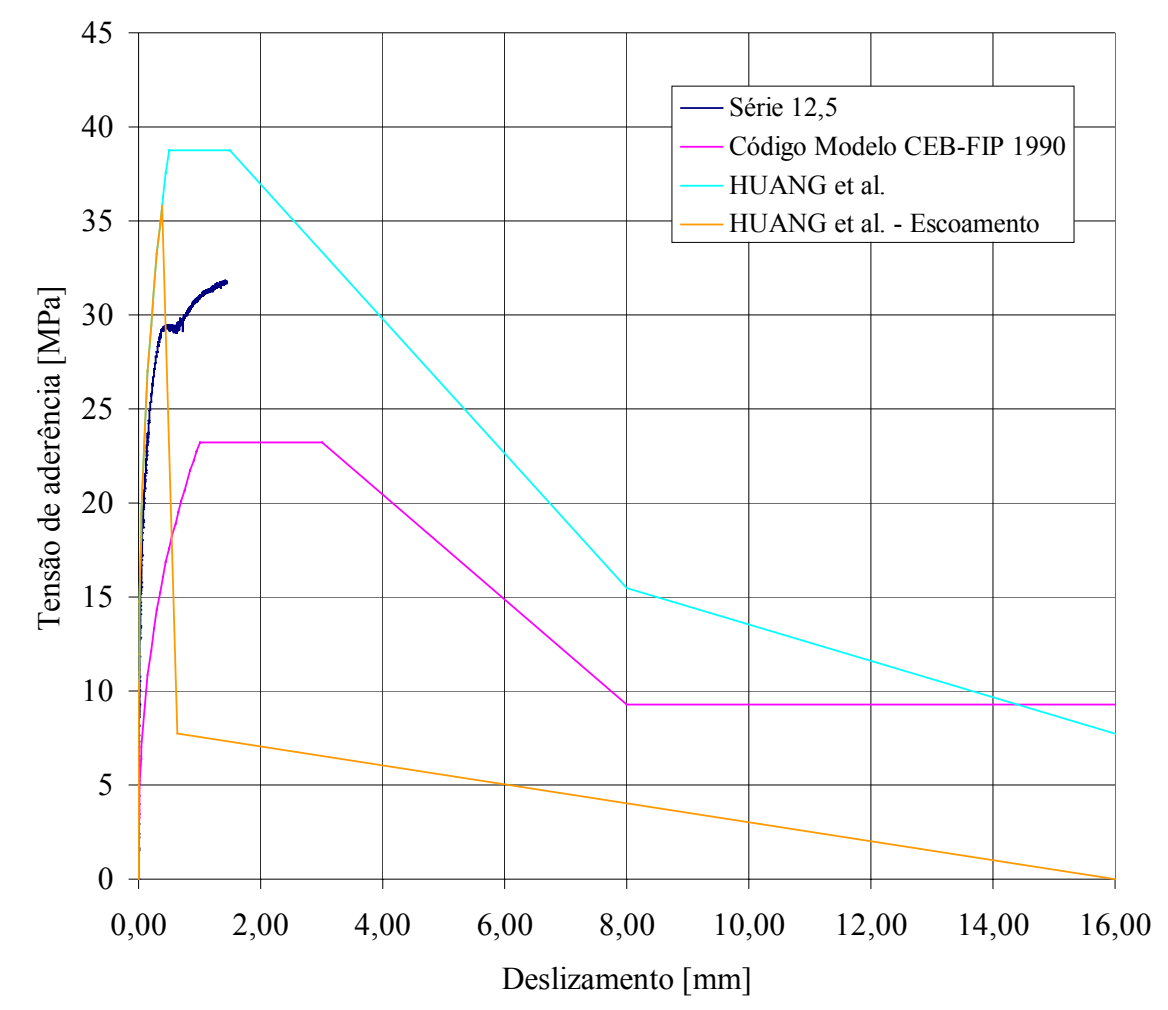

Figura 6.27 - Comparação da média monotônica da série 12,5 com modelos analíticos

O resultado médio da série 7,5 foi comparado com o modelo analítico do Código Modelo CEB-FIP 1990. Pelas especificações do referido código a situação em questão se enquadra em aderência em concreto não confinado (cobrimento de concreto menor que $5 \phi$ ) em boas condições de aderência (barra concretada verticalmente).

O resultado médio da série 12,5 foi comparado com o modelo do Código Modelo CEB-FIP 1990 e com o modelo proposto por HUANG et al. ${ }^{12}$ apud FIB (2000) Bulletin n.10. Os modelos dessa série são considerados confinados

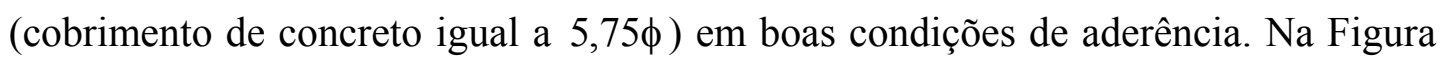
6.27 são mostradas as duas curvas propostas por HUANG et al. ${ }^{12}$ apud FIB (2000) Bulletin n.10, representando situações onde pode ou não ser atingido o limite de escoamento do aço. Contudo, a curva para barras apenas em regime elástico está inclusa na Figura 6.27 somente para exemplificação, já que de fato deve-se comparar o resultado da série 12,5 com o modelo para barras que se plastificam. 
A média da tensão de aderência última da série 7,5 é $23,1 \%$ superior a do Código Modelo CEB-FIP 1990. O deslizamento s $\left(\tau_{\text {bu }}\right)$ médio é 25,2\% menor que o valor especificado pelo Código Modelo CEB-FIP 1990.

Quanto a série 12,5, a média da tensão de aderência última é 37,2\% maior que a especificada pelo Código Modelo CEB-FIP 1990 e 11,0\% menor que a proposta pelo modelo de HUANG et al. para barras que atingem o limite de escoamento do aço. Entretanto, a média do deslizamento $s\left(\tau_{b u}\right)$ dos modelos da série 12,5 foi 281,2\% superior ao deslizamento correspondente do modelo de HUANG et al.

$\mathrm{Na}$ verdade, os modelos analíticos em questão não representam satisfatoriamente o comportamento da aderência.

\subsubsection{DISTRIBUIÇÃO DE TENSÕES DE ADERÊNCIA}

Através da instrumentação interna da barra do modelo PT(7,5)-2R foi possível determinar a distribuição de tensões. Para tanto foi utilizada a teoria apresentada no item 2.4 e exemplificada no item 6.2.1 deste trabalho.

As deformações específicas foram mensurados nos pontos B, C, D e E da Figura 6.28. As cotas $\mathrm{x}$ indicam posições da barra com origem na extremidade descarregada. 


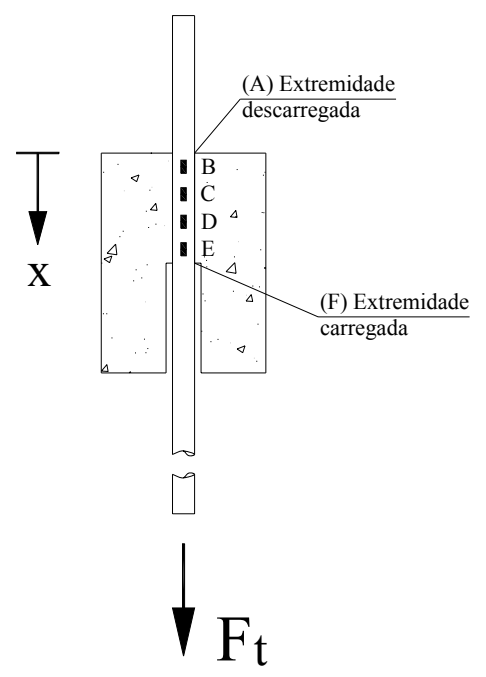

Figura 6.28 - Convenção do eixo x para estabelecimento das equações de deformação do modelo PT(7,5)-2R

Tabela 6.8 - Posição x na barra instrumentada internamente do modelo PT(7,5)-2R

\begin{tabular}{|c|c|}
\hline Pontos & Posição $\mathrm{x}[\mathrm{mm}]$ \\
\hline A & 0 \\
\hline B & 10 \\
\hline C & 30 \\
\hline D & 50 \\
\hline E & 70 \\
\hline F & 80 \\
\hline
\end{tabular}




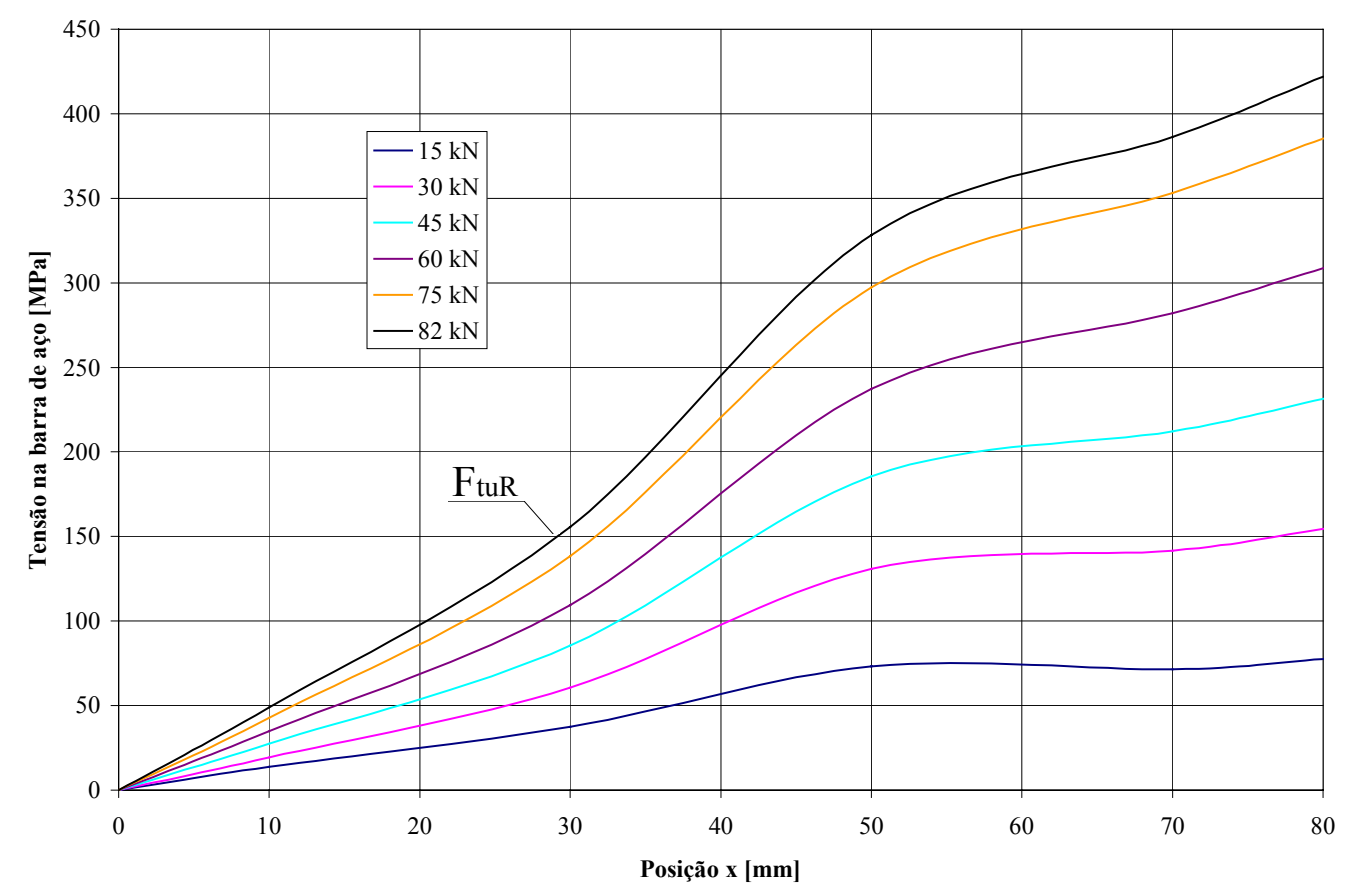

Figura 6.29 - Distribuição de tensões normais na barra sob ação monotônica após repetição de 360 ciclos - modelo PT $(7,5)-2 \mathrm{R}$

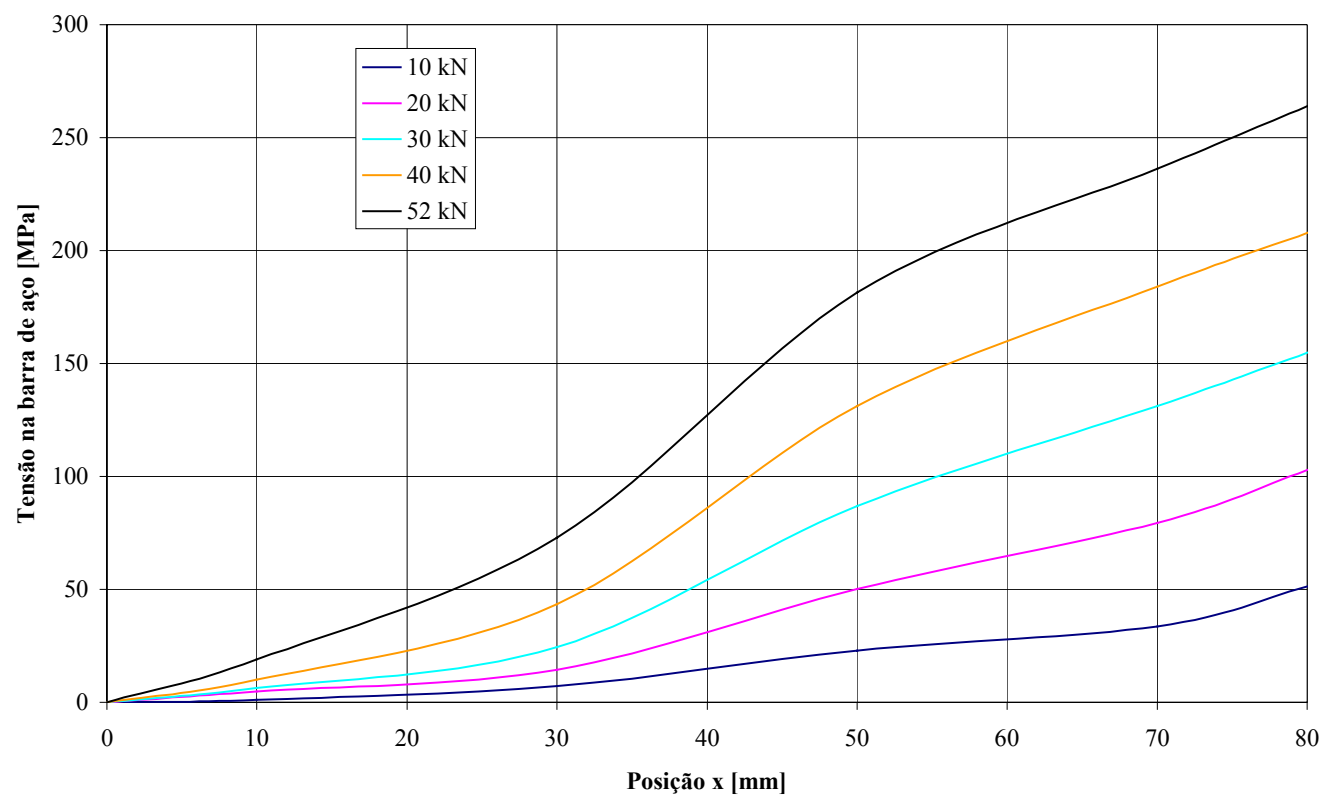

Figura 6.30 - Distribuição de tensões normais na barra no primeiro ciclo de carga $(n=1)$, para diversos valores de $F_{t}$ - modelo PT $(7,5)-2 R$ 


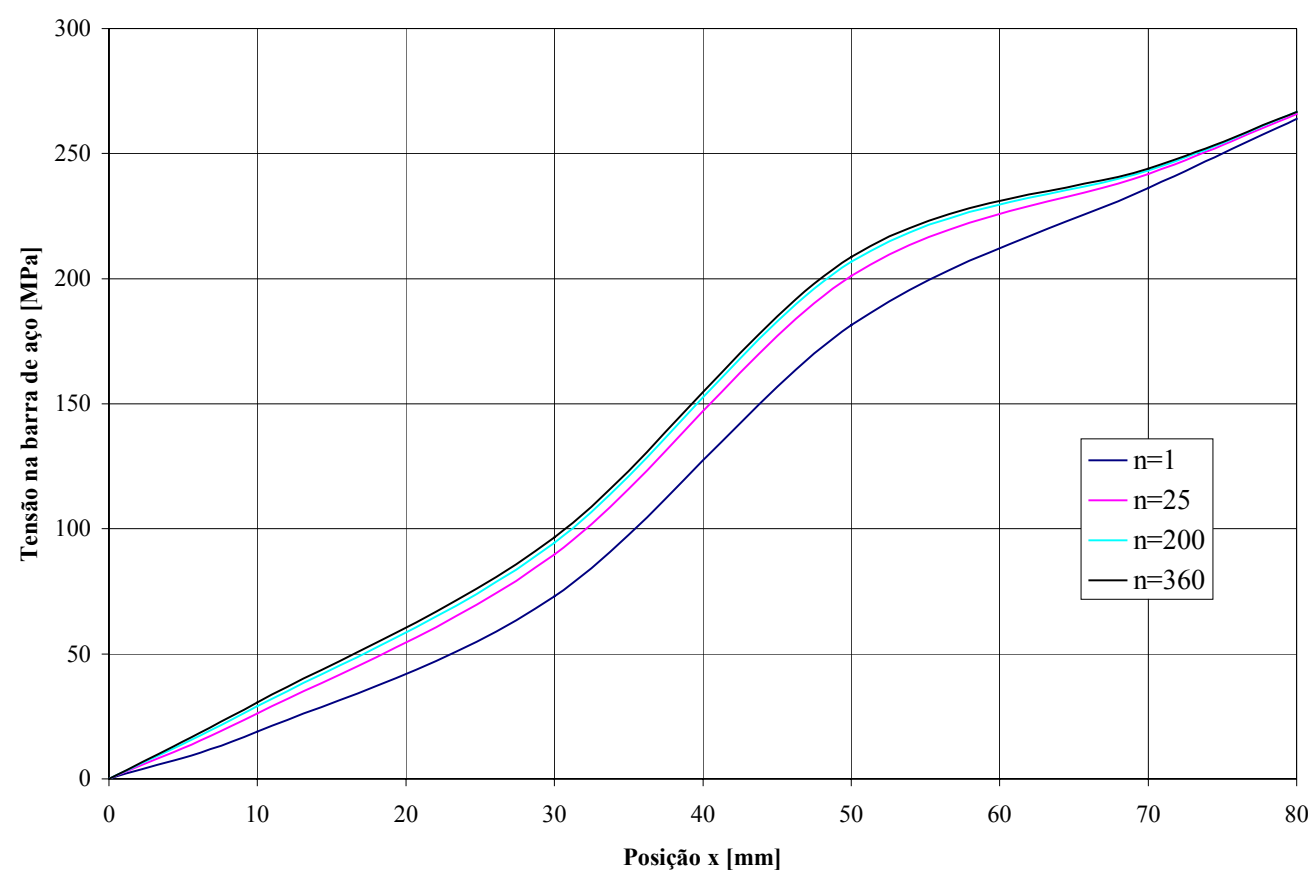

Figura 6.31 - Distribuição de tensões normais na barra para diversos ciclos de carga com $\mathrm{F}_{\mathrm{t}} \approx 52 \mathrm{kN}\left(\approx 0,6 \cdot \tau_{\mathrm{bu}}\right)$ - modelo $\mathrm{PT}(7,5)-2 \mathrm{R}$

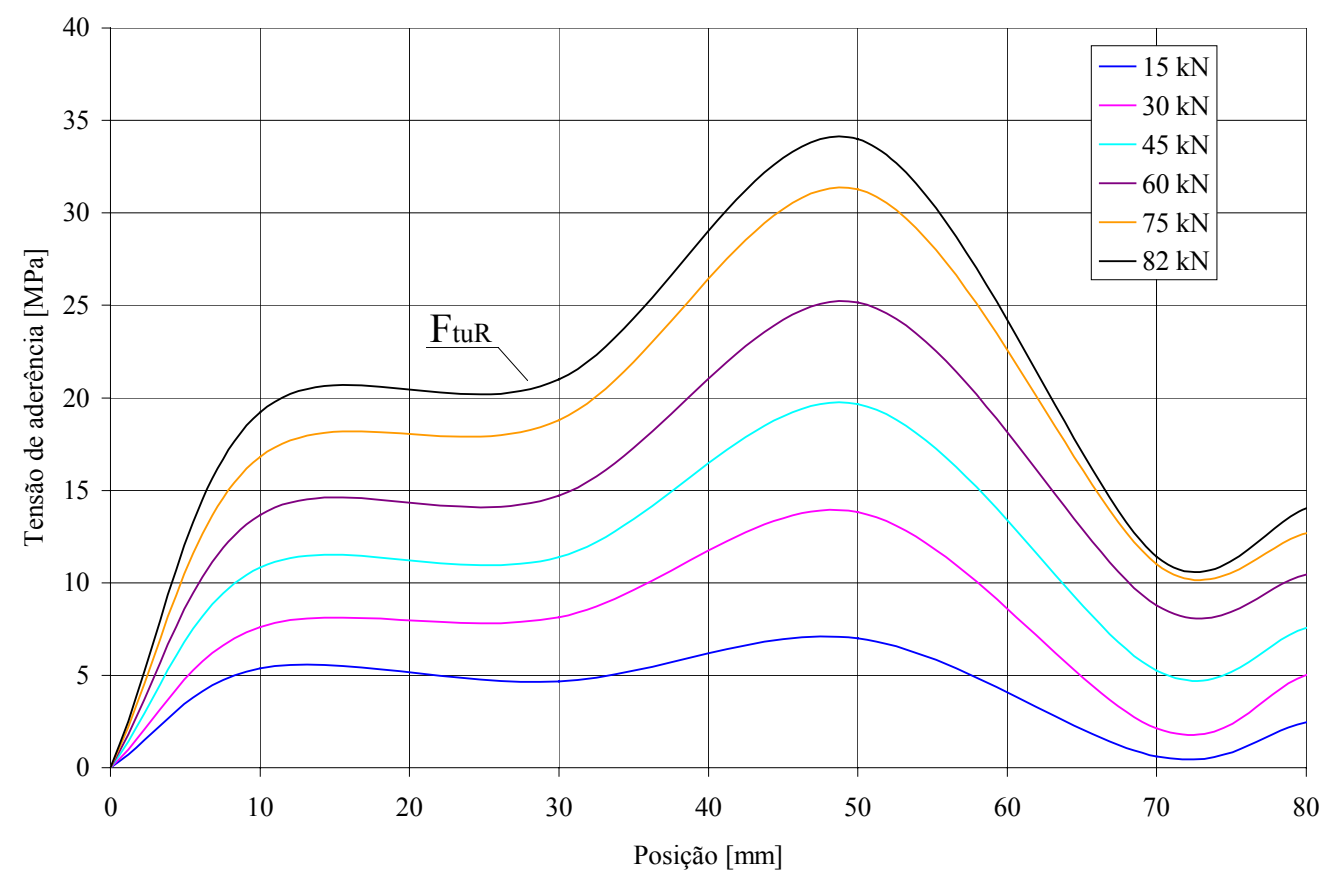

Figura 6.32 - Distribuição de tensões de aderência sob ação monotônica após repetição de 360 ciclos - modelo PT(7,5)-2R 


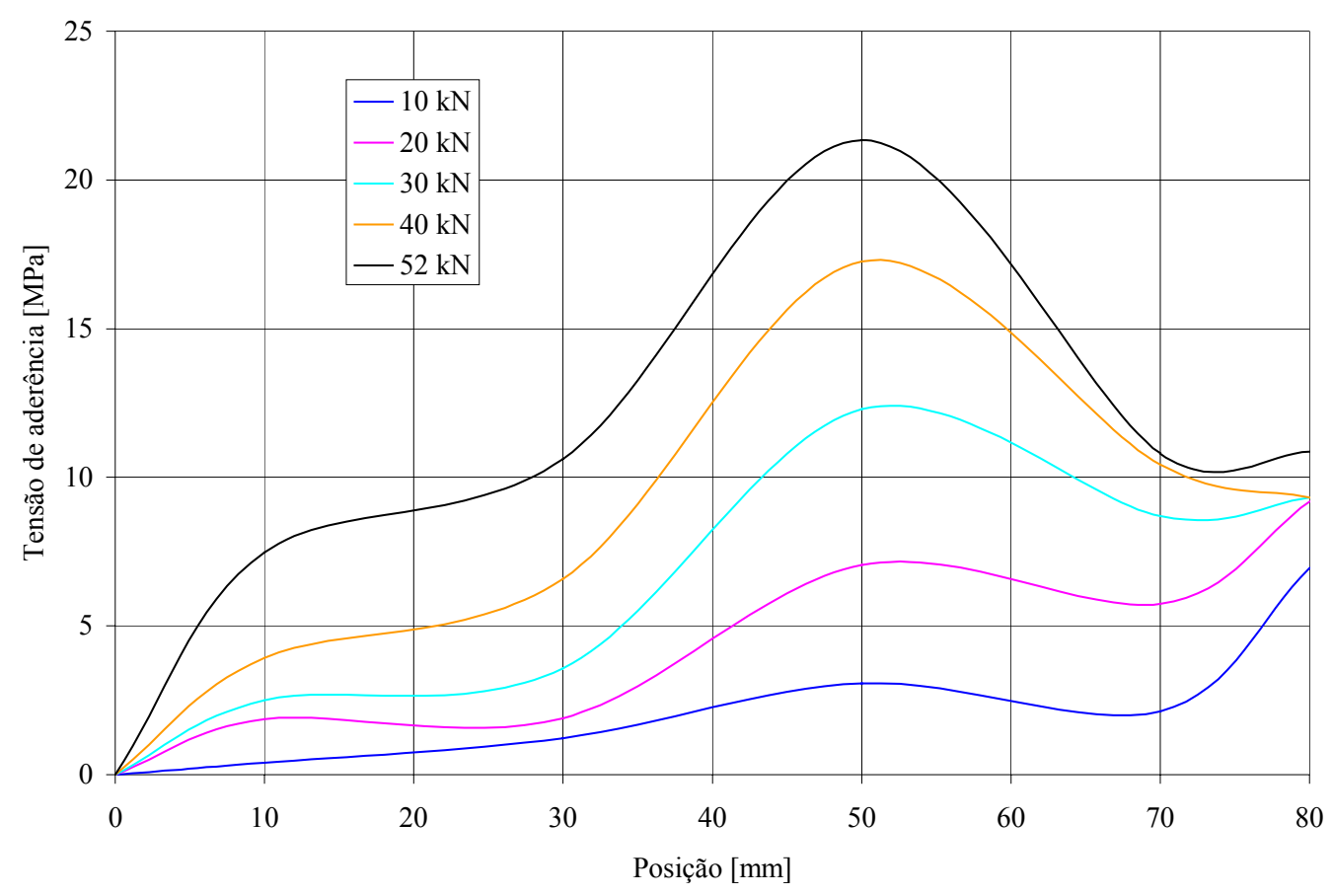

Figura 6.33 - Distribuição de tensões de aderência no primeiro ciclo de carga $(n=1)$, para diversos valores de $F_{t}$ - modelo PT $(7,5)-2 R$

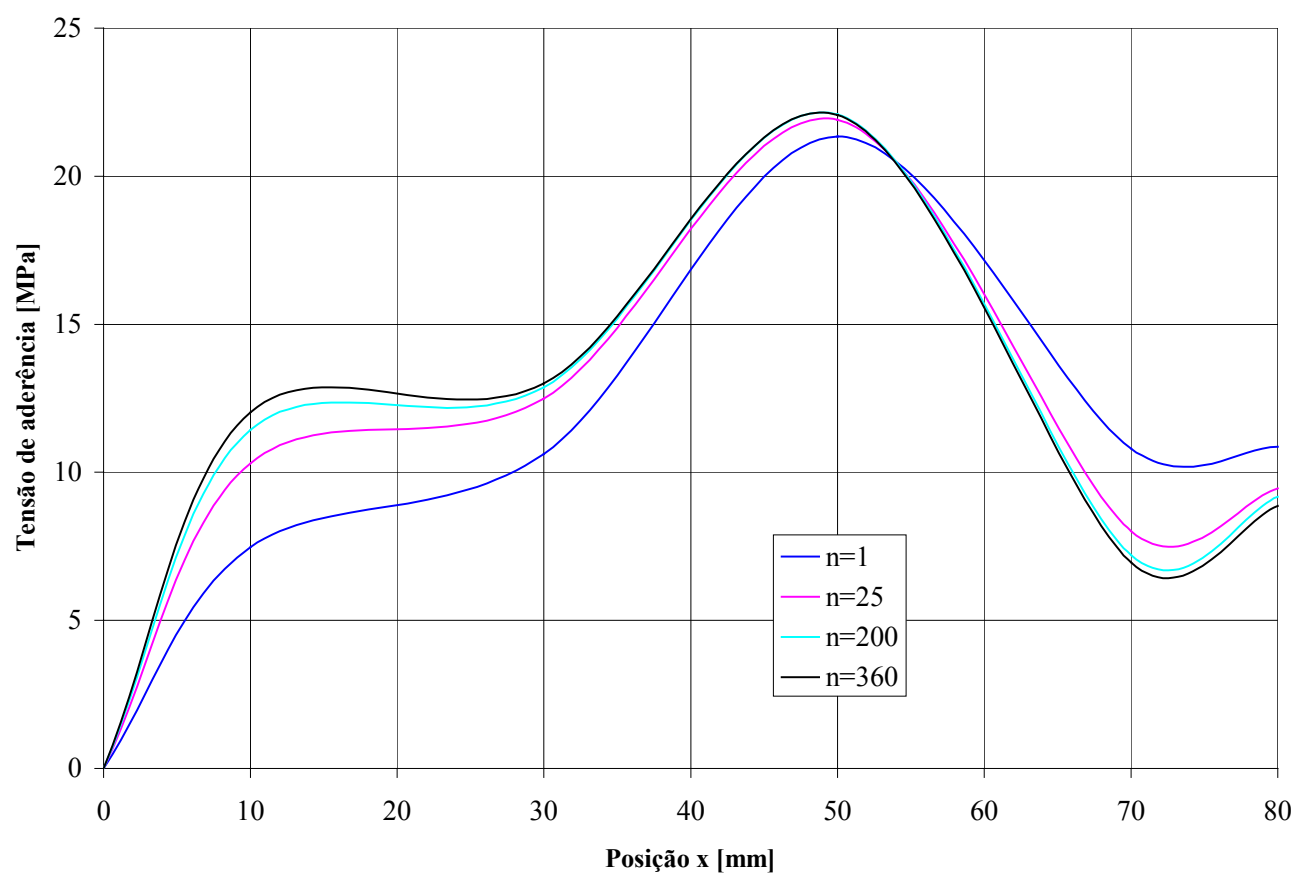

Figura 6.34 - Distribuição de tensões de aderência para diversos ciclos de carga com $\mathrm{F}_{\mathrm{t}} \approx 52 \mathrm{kN}\left(\approx 0,6 \cdot \tau_{\text {bu }}\right)$ - modelo $\mathrm{PT}(7,5)-2 \mathrm{R}$ 
Primeiramente, nota-se diferença entre distribuição de tensões de aderência típica de uma emenda por traspasse (ensaio das quatro barras) e de um comprimento de ancoragem. Enquanto a emenda apresenta dois picos de tensão de aderência o comprimento de ancoragem tem apenas um. Para o comprimento de ancoragem, esse pico dista aproximadamente $1,95 \phi$ da extremidade carregada.

A máxima tensão de aderência alcançada durante o ensaio ( $\approx 34 \mathrm{MPa})$, sob ação monotônica após 360 ciclos, obtida através da instrumentação interna da barra, é aproximadamente $62 \%$ maior que a tensão de aderência última, onde assume-se que na ruptura as tensões de aderência são uniformemente distribuídas ao longo do comprimento de ancoragem.

Mesmo submetido a um número de ciclos razoável com uma intensidade do nível de tensão máxima da amplitude $\tau_{\mathrm{b} \text {,max }}$ da ordem de $60 \%$ de $\tau_{\mathrm{bu}}$, o modelo não redistribuiu tensões. Observando a Figura 6.34, nota-se que a aplicação de um carregamento cíclico prévio não afeta a distribuição de tensões de aderência, alterando somente a ordem de grandeza das tensões alcançadas durante o andamento do ensaio. 


\section{CAPÍTULO 7}

\section{CONSIDERAÇÕES FINAIS}

\subsection{CONCLUSÕES}

Apesar de inúmeros trabalhos desenvolvidos por vários pesquisadores desde o inicio do século passado, o estudo da aderência ainda é um tema atual.

A falta de padronização dos ensaios é um grande entrave para se estabelecer o verdadeiro comportamento da aderência. Esse fenômeno é bastante influenciado pelas condições de contorno, principalmente pela forma e dimensão dos modelos. Além disso, os experimentos diferenciam-se na composição dos materiais empregados, na tecnologia de produção e cura do concreto, etc. Até que estejam claramente identificados e quantificados os fatores que influenciam o comportamento da aderência, os resultados experimentais não serão conclusivos. Dessa forma, questões como a influência da sílica ativa no comportamento da aderência serão ambíguas.

A despeito dos inúmeros trabalhos, ainda é difícil prever o comportamento da aderência. Os modelos teóricos e numéricos existentes não têm resposta satisfatória, seja pela complexidade do fenômeno, pelos erros na conduta de pesquisas ou pelas dificuldades em desenvolver modelos numéricos, como por exemplo, o modo de se considerar o contato aço-concreto e a dificuldade em implementar modelos que considerem deformações residuais sob ações cíclicas. 
A aderência sempre foi tratada de forma determinística. Devido a inúmeros fatores que intervém no comportamento da aderência e a inevitável dispersão dos resultados, é necessário o uso de métodos estatísticos e probabilísticos.

$\mathrm{O}$ estudo da aderência não se restringe à resposta macroscópica. Os mecanismos mobilizados pela aderência em diferentes níveis de carregamento precisam ser estudados. Não basta quantificar a resposta macroscópica, são necessários modelos que expliquem o fenômeno.

Diante do exposto acredita-se que o método de instrumentação interna de barras foi um avanço frente às necessidades inerentes ao estudo da aderência.

Quanto ao plano experimental deste trabalho, constatou que o comportamento da aderência em CAD é qualitativamente o mesmo de concretos usuais. Entretanto, devido à natureza frágil do $\mathrm{CAD}$, mesmo em concreto confinado, a ruptura dos modelos foi por fendilhamento.

Os resultados monotônicos do plano definitivo foram comparados com as prescrições de dois códigos, Código Modelo CEB-FIP 1990 e NBR 6118/1978. Observou-se que as resistências de aderência especificadas pelas normas são muito inferiores ao valor experimental. Assim, deve-se procurar critérios mais reais para se estabelecerem regras para projetos em $\mathrm{CAD}$. $\mathrm{Na}$ verdade, a própria definição do que seja ou o que representa a resistência de aderência precisa ser mais bem especificada.

A comparação dos resultados monotônicos do plano definitivo com modelos analíticos, mostrou que o comportamento da aderência não é descrito facilmente. Não basta exprimir esse comportamento em função da resistência à compressão do concreto. Apesar de essa variável ser importantíssima, neste caso, o paradigma da engenharia de estruturas de descrever todo comportamento em função de resistência à compressão do concreto, não é razoável. O fenômeno da aderência é bastante complexo.

Em relação ao carregamento repetido, observa-se que inicialmente a velocidade de deslizamento é decrescente, em uma segunda fase, essa velocidade se torna constante. Nos ensaios deste trabalho não foi possível verificar uma terceira fase, comumente observada em concreto (usual) confinado, onde a velocidade de deslizamento cresce muito rapidamente até a ruptura. Essa terceira fase não foi observada devido à pequena quantidade de ciclos de carga, contudo, é importante 
salientar que devido à natureza frágil do $\mathrm{CAD}$, mesmo em concreto confinado, essa terceira fase provavelmente não será verificada.

$\mathrm{O}$ deslizamento $\mathrm{s}\left(\tau_{\mathrm{bu}}\right)$ correspondente à tensão de aderência última monotônica pode ser utilizado como critério seguro para análise do efeito da fadiga no comportamento da aderência em CAD. Isso porque depois de ultrapassado o deslizamento $\mathrm{s}\left(\tau_{\mathrm{bu}}\right)$ a velocidade de deslizamento ainda permanece constante em um número de ciclos razoável, sem atingir a ruptura.

$\mathrm{O}$ aumento do número de ciclos e o aumento do nível máximo da amplitude têm qualitativamente o mesmo efeito no comportamento da aderência, aumentando o deslizamento e diminuindo a tensão de aderência última quando o modelo é levado à ruptura sob ação monotônica. $\mathrm{O}$ modo de ruptura dos modelos não foi influenciado pelo carregamento repetido prévio.

Para carregamentos repetidos com níveis de tensão máxima da amplitude utilizadas neste trabalho, 60 e $80 \%$ da tensão de aderência última monotônica, uma vez atingido um determinado deslizamento, este se torna praticamente residual.

Quanto à distribuição de tensões de aderência, a aplicação de um carregamento repetido prévio altera somente a ordem de grandeza das tensões alcançadas durante o andamento do ensaio, não afetando a distribuição de tensões.

Mesmo próxima à ruptura, a distribuição de tensões de aderência em CAD não se modifica, mostrando a dificuldade do $\mathrm{CAD}$ em redistribuir esforços, devido sua natureza frágil.

\subsection{SUGESTÕES PARA NOVAS PESQUISAS}

Neste trabalho constatou-se que a necessidade mais premente no estudo da aderência é o desenvolvimento de modelos analíticos que representem satisfatoriamente o comportamento da aderência.

São necessários também, modelos que representem os mecanismos mobilizados pela aderência, sendo importante estudos que preencham as lacunas da resposta microscópica. 


\section{REFERÊNCIAS BIBLIOGRÁFICAS}

ACI COMMITTEE 408 (1991). Abstract of: State-of-the-art-report: bond under cyclic loads. ACI Materials Journal, v.88, n.6, p.669-73, Nov./Dec.

AMERICAN SOCIETY FOR TESTING AND MATERIALS (1991). ASTM C 234 - 91a - Standart test method for comparing concretes on the basis of the bond developed with reinforced steel. Philadelphia.

ASSOCIAÇÃO BRASILEIRA DE NORMAS TÉCNICAS (1978). NBR 6118 Projeto e execução de obras de concreto armado. Rio de Janeiro.

ASSOCIAÇÃO BRASILEIRA DE NORMAS TÉCNICAS (1982). NBR 7477 Determinação do coeficiente de conformação superficial de barras e fios de aço destinados a armaduras de concreto armado. Rio de Janeiro.

ASSOCIAÇÃO BRASILEIRA DE NORMAS TÉCNICAS (1996). NBR 7480 Barras e fios de aço destinados a armaduras para concreto armado. Rio de Janeiro.

ASSOCIAÇÃO BRASILEIRA DE NORMAS TÉCNICAS (2001). Projeto de Revisão NBR 6118 - Projeto de estruturas de concreto. Rio de Janeiro. 
AZIZINAMINI A.; STARK M.; ROLLER J.J.; GHOSH S.K. (1993). Bond performance of reinforcing bars embedded in High-Strengh concrete. ACI Structural Journal, p.554-61, Sept./Oct.

BALÁZS, G.L. (1991). Fatigue of bond. ACI Materials Journal, v.88, n.6, p.620-29, Nov./Dec.

BALÁZS, G.L. (1993). Cracking analysis based on slip and bond stresses. $A C I$ Materials Journal, v.90, n.4, p.340-8, July/Aug.

BALÁZS, G.L.; KOCH, R. (1994). Bond behaviour under random cyclic loading. Otto Graf Journal, v.5, p.52-67.

BALÁZS, G.L.; KOCH, R. (1995). Bond charactersitics under reversed cyclic loading. Otto Graf Journal, v.6, p.47-62.

BARBOSA, M.P. (1998). Uma contribuição experimental e numérica sobre estruturas de concreto armado de elevado desempenho: estudo da aderênciaancoragem e do comportamento de vigas fletidas. Ilha Solteira. 174p. Tese (Livre-docência) - Faculdade de Engenharia de Ilha Solteira, Universidade Estadual Paulista.

BRESLER, B.; BERTERO, V. (1968). Behavior of reinforced concrete under repeated load. Proceedings of the American Society of Civil Engineers (ASCE). Journal of the Structural Division. v.94, n.ST6, p.1567-90, June.

CARRASQUILLO, P.M. (1988). Pullout tests on straight deformed bars embedded in superplasticized concrete. ACI Materials Journal, v.85, n.2, p.90-4, Mar./Apr.

CHAPMAN, R.A.; SHAH, S.P. (1987). Early-age bond strength in reinforced concrete. ACI Materials Journal, v.84, n.6, p.501-10, Nov./Dec. 
COMITE EURO-INTERNATIONAL DU BETON (1982). Bond action and bond behaviour of reinforcement: state-of-the-art report. Bulletin d'Information, n.151.

COMITE EURO-INTERNATIONAL DU BETON (1991). CEB-FIP Model Code 1990. Bulletin d'Information, n.203-205.

COMITE EURO-INTERNATIONAL DU BETON (1995). High performance concrete. Recommended extensions to the Model Code 90, Research Needs. Bulletin d'Information, n.228.

COMITE EURO-INTERNATIONAL DU BETON (1996). RC elements under cyclic loading: state-of-the-art report. Bulletin d'Information, n.230.

DUCATTI, V.A. (1993). Concreto de elevado desempenho: estudo da aderência com a armadura. São Paulo. 273p. Tese (Doutorado) - Escola Politécnica, Universidade de São Paulo.

ELIGEHAUSEN, R.; POPOV, E.P.; BERTERO, V.V. (1983). Local bond stress-slip relationships of deformed bars under generalized excitations. Report n.UCB/EERC 83-23, Earthquake Engineering Research Center. University of California, Berkeley, Oct.

EUROCODE 2 (1992). Design of concrete structures. Part 1: General rules and rules for buildings. Brussels, CEN.

EZELDIN, A.S.; BALAGURU, P.N. (1989). Bond behavior of normal and highstrength fiber reinforced concrete. ACI Materials Journal, v.86, n.5, p.515-24, Sept./Oct.

FÉDÉRATION INTERNATIONALE DU BÉTON (1999). Structural concrete. Textbook on behaviour, design and performance updated knowledge of the CEB/FIP Model Code 1990. Bulletin n.1. 
FÉDÉRATION INTERNATIONALE DU BÉTON (2000). Bond of reinforcement in concrete. Bulletin n.10.

FERNANDES, R.M. (2000). A influência das ações repetidas na Aderência Açoconcreto. São Carlos. 155p. Dissertação (Mestrado) - Escola de Engenharia de São Carlos, Universidade de São Paulo.

FUSCO, P.B. (1976). Estruturas de concreto - Fundamentos do projeto estrutural. 1.ed. São Paulo, EDUSP/McGraw-Hill do Brasil.

FUSCO, P.B. (1995). Técnica de armar as estruturas de concreto. São Paulo, Pini.

GJORV, O.E.; MONTEIRO, P.J.M.; MEHTA, P.K. (1990). Effect of condensed silica fume on the steel-concrete bond. ACI Materials Journal, v.87, n.6, p.57380, Nov./Dec.

GOTO, Y. (1971). Cracks formed in concrete around deformed tension bars. $A C I$ Journal, v.68, n.4, p.244-51, Apr.

HAMAD B.S.; ITANI M.S. (1998). Bond strength of reinforcement in HighPerformance concrete: The role of silica fume, casting position, and superplasticizer dosage. ACI Materials Journal, Sept./Oct.

HAWKINS, N.M.; LIN, I.J.; JEANG, F.L. (1982). Local bond strength of concrete for cyclic reversed loadings. In: BARTOS, P., ed. Bond in concrete. London, Applied Science, p.151-61.

HOTA, S.; NAAMAN, A.E. (1997). Bond stress-slip response of reinforcing bars embedded in FRC matrices under monotonic and cyclic loading. ACI Structural Journal, v.94, n.5, p.525-37, Sept./Oct. 
HWANG. S.J.; LEE Y.Y.; LEE C.S. (1994). Effect of silica fume on the splice strength of deformed bars of High-Performance concrete. ACI Structural Journal, p.294-302, May/June.

KOCH, R.; BALÁZS, G.L. (1993). Slip increase under cyclic and long term loads. Otto Graf Journal, v.4, p.160-91.

LARANJEIRAS, A.C.R. (1976). Redução da aderência aço-concreto sob a ação de cargas repedidas. In: JORNADAS SUL-AMERICANAS DE ENGENHARIA ESTRUTURAL, 28., Salvador, 1976. Anais. Salvador, IBRACON, 1976, 25p.

LARANJEIRAS, A.C.R. (1990). Fadiga das estruturas de concreto. In: SIMPÓSIO EPUSP SOBRE ESTRUTURAS DE CONCRETO, 2., São Paulo, 1990. Anais. São Paulo, EPUSP. v.1, p.187-232.

LEONHARDT, F.; MÖNNIG, E. (1977). Construções de concreto: Princípios básicos do dimensionamento de estruturas de concreto armado. 1.ed. Rio de Janeiro, Interciência. v.1.

LUTZ, L.A.; GERGELY, P. (1967). Mechanics of bond slip of deformed bars in concrete. ACI Journal, v.64, n.11, p.711-21, Nov.

REHM, G.; ELIGEHAUSEN, R. (1979). Bond of ribbed bars under cycle repeated loads. ACI Materials Journal, v.76, n.2, p.297-309, Feb.

RILEM-FIP-CEB (1973). Bond test for reinforcing steel. 1. Beam test (7-II-28 D). 2. Pull-Out Test (7-II-128). Tentative Recommendations. RILEM Journal Materials and Structures, v.6, n.32, p.96-105. Mar./Apr.

SORETZ, S.; HÖLZENBEIN, H. (1979). Influence of rib dimensions of reinforcing bars on bond and bendability. ACI Journal, v.76, n.1, p.111-28, Jan. 
SOROUSHIAN, P.; CHOI, K. (1989). Local bond of deformed bars with different diameters in confined concrete. ACI Structural Journal, v.86, n.2, p.217-22, Mar./Apr.

SOROUSHIAN, P.; CHOI, K.; PARK, G.; ASLANI, F. (1991). Bond of deformed bars to concrete: effects of confinement and strength of concrete. ACI Materials Journal, v.88, n.3, p.227-32, May/June.

TASSIOS, T.P. (1979). Properties of bond between concrete and steel under load cycles idealizing seismic actions. AICAP-CEB Symposium, Structural Concrete Under Seismic Actions. CEB, Bulletin d'Information, n.131, p.67-122.

UNTRAUER, R.E.; HENRY, R.L. (1965). Influence of normal pressure on bond strength. ACI Journal, v.62, n.5, p.577-85, May.

VALLE, A. (1994). Estudo da aderência entre concreto e armadura sob carregamento cíclico. São Paulo. 171p. Dissertação (Mestrado) - Escola Politécnica, Universidade de São Paulo.

YANNOPOULOS, P.J.; TASSIOS, T.P. (1991). Reinforced concrete axial elements analyzed under monotonic and cyclic actions. ACI Structural Journal, v.88, n.1, p.3-11, Jan./Feb. 


\section{BIBLIOGRAFIA COMPLEMENTAR}

ASSOCIAÇÃO BRASILEIRA DE NORMAS TÉCNICAS (1982). NBR 7223 Determinação da consistência do concreto pelo abatimento do tronco de cone: Ensaio de abatimento. Rio de Janeiro.

ASSOCIAÇÃO BRASILEIRA DE NORMAS TÉCNICAS (1982). NBR 7251 Agregado em estado solto: Determinação da massa unitária. Rio de Janeiro.

ASSOCIAÇÃO BRASILEIRA DE NORMAS TÉCNICAS (1983). NBR 7211 Agregado para concreto. Rio de Janeiro.

ASSOCIAÇÃO BRASILEIRA DE NORMAS TÉCNICAS (1984). NBR 8522 Concreto: Determinação do módulo de deformação estática e diagrama tensãodeformação. Rio de Janeiro.

ASSOCIAÇÃO BRASILEIRA DE NORMAS TÉCNICAS (1987). NBR 7217 Agregados: Determinação da composição granulométrica. Rio de Janeiro.

ASSOCIAÇÃO BRASILEIRA DE NORMAS TÉCNICAS (1987). NBR 9776 Agregados: Determinação da massa específica de agregados miúdos por meio do frasco de Chapman. Rio de Janeiro. 
ASSOCIAÇÃO BRASILEIRA DE NORMAS TÉCNICAS (1992). NBR 6152 Materiais metálicos: Determinação das propriedades mecânicas à tração. Rio de Janeiro.

ASSOCIAÇÃO BRASILEIRA DE NORMAS TÉCNICAS (1994). NBR 5738 Moldagem e cura de corpos-de-prova cilíndricos ou prismáticos de concreto. Rio de Janeiro.

ASSOCIAÇÃO BRASILEIRA DE NORMAS TÉCNICAS (1994). NBR 5739 Concreto: Ensaio de compressão de corpos-de-prova cilíndricos. Rio de Janeiro.

ASSOCIAÇÃO BRASILEIRA DE NORMAS TÉCNICAS (1994). NBR 7222 Argamassa e concreto: Determinação da resistência à tração por compressão diametral de corpos-de-prova cilíndricos. Rio de Janeiro.

BAZANT, Z.P.; SENER, S. (1988). Size effect in pullout tests. ACI Materials Journal, v.85, n.5, p.347-51, Sept./Oct.

CAMPAGNOLO, J.L.; GOBETTI, L.C.W.; RIBEIRO, J.L.; DAL MOLIN, E. (1988). Análise do comportamento quanto à aderência das barras de aço nervuradas fabricadas no Brasil. In: COLLOQUIA, Madri, Espanha, 1988. Anais, Madri, C OLLOQUIA. v.4, p.45-59.

DETWILER, R.L.; MEHTA, P.K. (1989). Chemical and physical effects of silica fume on the mechanical behavior of concrete. ACI Materials Journal, v.86, n.6, p.609-14, Nov./Dec.

DRIEMEIER, L. (1995). Considerações sobre a fadiga em metais e o comportamento do concreto sob solicitação cíclica. São Carlos. 149p. Dissertação (Mestrado) - Escola de Engenharia de São Carlos, Universidade de São Paulo. 
LUTZ, L.A. (1970). Analysis of stresses in concrete near a reinforcing bar due to bond and transverse cracking. ACI Journal, v.67, n.10, p.778-87, Oct.

PERRY, E.S.; JUNDI, N. (1969). Pullout bond stress distribution under static and dynamic repeated loadings. ACI Journal, v.66, n.5, p.377-80, May.

RIBEIRO, J.L.; GOBETTI, L.C.W. (1988). Influência do recobrimento e da armadura transversal na aderência de barras nervuradas. In: COLLOQUIA, Madri, Espanha, 1988. Anais, Madri, COLLOQUIA. v.4, p.61-75.

RÜSCH, H. (1981). Concreto armado e protendido: propriedades dos materiais e dimensionamento. Rio de Janeiro, Campus.

SORETZ, S. (1972). A comparison of beam tests and pull-out tests. RILEM Journal Materials and Structures, v.5, n.28, p.261-64. July/Aug.

UNIVERSIDADE DE SÃO PAULO. Escola de Engenharia de São Carlos. Serviço de Biblioteca. (1996). Diretrizes para elaboração de dissertações e teses na EESC-USP. São Carlos.

WELCH, G.B.; PATTEN B.J.F. (1965). Bond strength of reinforcement affected by concrete sedimentation. ACI Journal, v.62, n.2, p.251-63, Feb. 